\title{
Toxicological stress indicators in human red blood cells : changes in glutathione and glutathione S- transferase as biological markers for electrophilic and oxidative stress
}

Citation for published version (APA):

Evelo, C. T. A. (1994). Toxicological stress indicators in human red blood cells : changes in glutathione and glutathione S-transferase as biological markers for electrophilic and oxidative stress. [Doctoral Thesis, Maastricht University]. Rijksuniversiteit Limburg. https://doi.org/10.26481/dis.19950119ce

Document status and date:

Published: 01/01/1994

DOI:

10.26481/dis.19950119ce

Document Version:

Publisher's PDF, also known as Version of record

Please check the document version of this publication:

- A submitted manuscript is the version of the article upon submission and before peer-review. There can be important differences between the submitted version and the official published version of record. People interested in the research are advised to contact the author for the final version of the publication, or visit the DOI to the publisher's website.

- The final author version and the galley proof are versions of the publication after peer review.

- The final published version features the final layout of the paper including the volume, issue and page numbers.

Link to publication

\footnotetext{
General rights rights.

- You may freely distribute the URL identifying the publication in the public portal. please follow below link for the End User Agreement:

www.umlib.nl/taverne-license

Take down policy

If you believe that this document breaches copyright please contact us at:

repository@maastrichtuniversity.nl

providing details and we will investigate your claim.
}

Copyright and moral rights for the publications made accessible in the public portal are retained by the authors and/or other copyright owners and it is a condition of accessing publications that users recognise and abide by the legal requirements associated with these

- Users may download and print one copy of any publication from the public portal for the purpose of private study or research.

- You may not further distribute the material or use it for any profit-making activity or commercial gain

If the publication is distributed under the terms of Article 25fa of the Dutch Copyright Act, indicated by the "Taverne" license above, 


\section{Toxicological Stress Indicators in Human Red Blood Cells}

Changes in Glutathione and Glutathione S-Transferase as Biological Markers

for Electrophilic and Oxidative Stress 


\section{CIP-DATA Koninklijke Bibliotheek, Den Haag}

Evelo, Christoffel Theodorus Anthonius

Toxicological stress indicators in human red blood cells :

Changes in glutathione and glutathione S-transferase as

biological markers for electrophilic and oxidative stress. /

Christoffel Theodorus Anthonius Evelo. - Maastricht :

Universitaire Pers Maastricht. - Ill.

Thesis Maastricht. - With ref. - With summary in Dutch. ISBN 90-5278-168-0

Subject headings: toxicology / erythrocytes / glutathione.

(C) C.T.A. Evelo, Maastricht 1994.

Financial support by the corporate safety, health, environment and technology division of DSM, the Dr.Ir. J.H.J. van de Laar foundation for the advancement of biochemical research and by Perkin-Elmer Nederland B.V. and Bio-Rad Laborotories B.V. for the publication of this thesis is gratefully acknowledged. 


\section{Toxicological Stress Indicators in Human Red Blood Cells}

Changes in Glutathione and Glutathione S-Transferase as Biological Markers

for Electrophilic and Oxidative Stress

\section{PROEFSCHRIFT}

ter verkrijging van de graad van doctor aan de Rijksuniversiteit Limburg te Maastricht, op gezag van de Rector Magnificus, Prof.Dr. H. Philipsen, volgens het besluit van het College van Dekanen,

in het openbaar te verdedigen

op donderdag 19 januari 1995 om 16.00 uur

door

Christoffel Theodorus Anthonius Evelo 


\section{Promotor:}

Prof.Dr. P.Th. Henderson

\section{Beoordelingscommissie:}

Prof.Dr. H.A.J. Struijker Boudier (voorzitter)

Prof.Dr. A. Bast (Vrije Universiteit Amsterdam)

Dr. B.J. Blaauboer (Universiteit Utrecht)

Prof.Dr. P.J. Brombacher

Prof.Dr. E.F.M. Wouters

The investigations presented in this thesis were carried out at the department of Toxicology of the university of Nijmegen (chapters 3 and 7), at the former department of Occupational \& Environmental Health and Toxicology (chapters 6, 8 and 9) and at the department of Pharmacology (Toxicology section) of the university of Limburg (chapters 4 and 5). 
"It is quite imaginable that scientists abandon a paradigm out of frustration and not because they have arguments against it.

Besides, it is not at all prudent to put too much trust in experimental results. Indeed, it would be a complete surprise and even a cause for suspicion, if all the available evidence should turn out to support a single theory, even if this theory happened to be true"

Paul Feyerabend

in: Criticism and the growth of knowledge

Voor Chantal, Jannemiek en Sjoerd 


$$
\text { . }
$$




\section{Contents}

Abbreviations used/Gebruikte afkortingen $\quad 9$

1 Outline 11

2 General introduction 13

\section{PART 1: IN VITRO STUDIES}

3 Influence of glutathione on the formation of cysteine alkylation products in human hemoglobin

4 Modulation of glutathione and glutathione S-transferase levels by cyclophosphamide and cisplatin

5 Two mechanisms for toxic effects of hydroxylamines in human erythrocytes: involvement of free radicals and risk of potentiation

\section{PART 2: HUMAN MONITORING STUDIES}

6 Biological effect monitoring

7 Biological effect monitoring of occupational exposure to 1,3-dichloropropene: effects on liver and renal function and on glutathione conjugation

8 Changes in blood glutathione concentrations, and in erythrocyte glutathione reductase and glutathione S-transferase activity after running training and after participation in contests

9 Decreased glutathione content and glutathione S-transferase activity in red blood cells of coal miners with early stages of pneumoconiosis 
10 General discussion

11 Samenvatting en discussie

APPENDIC'ES

A Curriculum vitac

B List of publications

167

C Nawoord 


\section{Abbreviations used/Gebruikte afkortingen:}

$\begin{array}{ll}\text { 3-HAA } & \text { 3-hydroxyacetanilide } \\ \text { 4-PDS } & 4 \text {, } \text {-dithiodipyridine } \\ 5 \text {-FU } & \text { 5-fluorouracil } \\ \text { 6PGDH } & \text { 6-phospho-gluconate dehydrogenase } \\ \beta \text {-Gal } & \beta \text {-galactosidase } \\ \beta_{2} \text {-M-S } & \beta_{2} \text {-microglobulin in serum } \\ \beta_{2} \text {-M-U } & \beta_{2} \text {-microglobulin in urine } \\ \text { AAP } & \text { alanine aminopeptidase } \\ \text { ALAT } & \text { alanine aminotransferase } \\ \text { ALB-U } & \text { albumine in urine } \\ \text { ALP } & \text { alkaline phosphatase } \\ \text { AOS } & \text { active oxygen species } \\ \text { Ara-C } & \text { cytosine arabinoside } \\ \text { ASAT } & \text { aspartate aminotransferase } \\ \text { Bil-tot } & \text { total billirubin } \\ \text { BM } & \text { biological monitoring } \\ \text { BEM } & \text { biological effect monitoring } \\ \text { C-DDP } & \text { cisplatin (cis-diamminedichloroplatinum(II)) } \\ \text { CBB } & \text { Coomassie Brilliant Blue } \\ \text { CDNB } & \text { 1-chloro-2,4-dinitrobenzene } \\ \text { CP } & \text { cyclophosphamide } \\ \text { Creat-S } & \text { creatinine in serum } \\ \text { DCP } & \text { 1,3-dichloropropene } \\ \text { DEM } & \text { diethyl maleate } \\ \text { DTT } & \text { dithiothreitol } \\ \text { DTNB } & \text { 5,5'-dithio-bis(2-nitrobenzoic acid) } \\ \text { EDTA } & \text { ethylenediaminetetraacetic acid } \\ \text { ELISA } & \text { enzyme linked immunosorbent assay } \\ \text { EM } & \text { environmental monitoring } \\ \text { F6P } & \text { fructose 6-phosphate } \\ \text { FAD } & \text { flavin adenine dinucleoticle } \\ \text { G6P } & \text { glucose 6-phosphate } \\ \text { G6PDH } & \text { glucose 6-phosphate dehydrogenase } \\ \text { GPX } & \text { glutathione peroxidase } \\ \text { GSH } & \text { glutathione (reduced) } \\ \text { GSSG } & \text { glutathione (oxidized) } \\ \text { GST } & \text { glutathione S-transferase } \\ \text { GR } & \text { glutathione reductase } \\ \text { GR } \text { coeff } & \text { GR riboflavin activity coefficient } \\ \text { GGT } & \gamma \text {-glutamyltranspeptidlase } \\ \text { GT } & \text { glutathione (total) } \\ & \end{array}$




\begin{tabular}{|c|c|}
\hline $\mathrm{Hb}$ & hemoglobin \\
\hline $\mathrm{Hb}^{+}$ & methemoglobin: hemoglobin with iron in the ferric state \\
\hline HbSH & free sulfhydryl groups in hemoglobin \\
\hline HS & health surveillance \\
\hline HYAM & hydroxylamine $\left(\mathrm{HONH}_{2}\right)$ \\
\hline IAcA & iodoacetamide \\
\hline IEF & isoelectric focusing \\
\hline FPLC & fast protein liquid chromatography \\
\hline LP & lipid peruxidation \\
\hline MAS & microsomal activating system \\
\hline MDA & malondialdehyde \\
\hline MTX & methotrexate \\
\hline $\mathrm{NAD}(\mathrm{H})$ & $\beta$-nicotinamide adenine dinucleotide $(\mathrm{H}=$ reduced $)$ \\
\hline NADH-HbR & NADH-methemoglobin reductase \\
\hline $\operatorname{NADP}(\mathrm{H})$ & $\beta$-nicotinamide adenine dinucleotide phosphate ( $\mathrm{H}=$ reduced $)$ \\
\hline NADPH-HbR & NADPH-methemoglobin reductase \\
\hline NEM & N-ethylmaleimide \\
\hline NODMH & $\mathrm{N}, \mathrm{O}$-dimethyl hydroxylamine $\left(\mathrm{CH}_{3} \mathrm{ONHCH}_{3}\right)$ \\
\hline $\mathrm{OEH}$ & O-ethyl hydroxylamine $\left(\mathrm{CH}_{3} \mathrm{CH}_{2} \mathrm{ONH}_{2}\right)$ \\
\hline OEL & occupational exposure limit (Dutch) \\
\hline $\mathrm{OMH}$ & O-methyl hydroxylamine \\
\hline PBS & phosphate-buffered saline \\
\hline $\mathrm{RBC}$ & red blood cells \\
\hline RBP & retinol binding protein \\
\hline RS & NADPH regenerating system \\
\hline SD & standard deviation \\
\hline $\mathrm{SE}$ & standard error \\
\hline SEMD & standard error of the mean difference \\
\hline SLDH & serum lactate dehydrogenase \\
\hline TBA & thiobarbituric-acid \\
\hline TBARS & thiobarbituric-acid reactive substance \\
\hline $\mathrm{TCA}$ & trichloroacetic acid \\
\hline TLV & treshold limit value \\
\hline $\mathrm{TT}$ & thioltransferase \\
\hline
\end{tabular}




\section{Chapter 1}

\section{Outline}

This thesis describes the use of changes in glutathione $(G S H \text { or } G T)^{1}$ levels in human blood and glutathione S-transferase (GST) activity in human red blood cells for the assessment of electrophilic and oxidative stress. For the sturly of biological effects of chemical exposure in man, red blood colls form a rather unique entity. For routine purposes blood cells are the only cell type from within the body that can be made easily available. and red blood colls are by far the most abundant blood cells. Red cells are also very special cells. They do not coutain a nucleus or mitochondria. This. combined with the very high uxygen turnover and special membrane properties, leads to a special biochemistry. As it will be discussed in chapter 2, both GSH and GST play a prominent part in erythroyte biochemistry. This prominence combined with the highly specialized physiology of the erythrocyte may however result in increased vulnerability of both GSH and GST, which may in turn be of use for biological effect monitoring.

In chapter 2 a general introduction to the subject is given. The biochemistry of red blood cells and the physiological functionality of GSH and GSTs are discussed. Chapters 3 to 5 are descriptions of in vitro and in vivo laboratory experiments to study the vulnerability of GSH and GST's during electrophilic and oxidative stress. In chapter 3 depletion of GT after in vitro treatment of human red blood cells with some model electrophilic compounds is compared with another well-known effect parameter, the formation of hemoglobin adducts. In chapter 4 the in vitro effects of a number of cytostatic drugs on GT and GST in erythrocytes are described. Since the efficacy of some of these drugs depends on metabolic activation by membrane bound mixed function oxygenases the in vitro system was extended with a rat derived liver microsomal activating system.

1. Throughout this thesis the abbreviations GSH, GSSG and GT are used to discriminate reduced, oxidized and total glutathione respectively. The abbreviation GSSG is only used to explicitly indicate oxidized glutathione, as is usual in biochemical literature. The abbreviation GT is less usual, but also uncomplicated. GT explicitly indicates the total of reduced and oxidized glutathione, as it is determined with the glutathione reductase dependent cyclic oxidation-reduction assay. The use of GSH in the literature, and in some cases in this thesis, is unfortunately rather ambivalent. It is both used to indicate reduced glutathione (i.e. with a free sulfhydryl (SH) group) and as a general abbreviation for glutathione. 
In chapter 5 an extensive in vitro study towards the hematotoxicity of three industrially used hydroxylamines is described. Next to effects on glutathione and GST, several other biochemical effects were studied.

In the next part - chapter 6-9- several human monitoring studies are described. Chapter 6 is supplied as an introduction to the use of biological effect monitoring methods in occupational toxicology. It also contains some descriptions of pilot studies in smokers and creosote workers, and reviews part of the results described in the following chapters. Chapter 7 describes a biological effect monitoring study in pesticide applicators using the soil fumigant 1,3-dichloropropene. In these workers classical liver and kidney toxicity tests were also performed. This allows for an interesting comparison of the sensitivity of the methods used. In chapter 8 a study towards the effects of long distance running is described. Physical activity leads to increased oxygen turnover rates and to increases in the formation of active oxygen species. This chapter describes that the GT and GST parameters can be used to assess the increased oxidative stress resulting from contest participation. The changes in basal values of these and some related parameters during endurance training were also studied. Finally, chapter 9 describes the effects found in ex-miners with coal workers pneumociosis. Here oxidative stress probably results from the continuous inflammatory activity in the lung.

The findings from chapter 3 to 9 are summarized and discussed in chapter 10. A summary in Dutch is included in chapter 11 (Een samenvatting in het Nederlands is te vinden in hoofdstuk 11).

Chapters $3,6,7,8$ and 9 were published previously (see the respective title pages for details). In some cases minor modifications such as the completion of references in press at the time of publication, correction of typing errors and addition of newer relevant references were made. 


\section{Chapter 2}

\section{General Introduction}

As occupational toxicologists we face an intriguing dilemma. When healthy persons are exposed to low quantities of noxious chemicals small changes in some biological parameters may occur. To know the nature and magnitude of such changes could be very helpful in estimations of the exposure that has occurred and in evaluations of a possible resulting risk $[65,168]$. The problem is that interesting changes often occur in tissues that are not accessible for routine analyses. Pesticide applicators, nurses handling cytostatic drugs, process operators in chemical industry and many others exposed to chemicals in their daily work may all welcome our interest in their personal welfare, and show a positive interest in our work. Their enthusiasm would definitely transform into a more defensive attitude when we would ask them for tissue samples. The use of for instance liver tissue may be useful in animal studies and even in some in vitro experimental studies using human tissue; it is not a practical option in occupational toxicology. What remains for us is mainly the determination of chemicals or their metabolites in excreta and in some cases in clippings like nails and hair. The problem is that such so called "biological monitoring" studies [17] do give us an indication of the exposure that has occurred, but not of any possible effect that resulted of it. As a matter of fact this problem is not limited to toxicology. Clinicians have always had an interest in possible changes in the functionality of organs buried deep in the human body. And, more often than not, they too encounter situations where cutting is not the most appropriate way of doing. Fortunately, alternatives were found. In many cases disturbances of internal physiological functions are visible from the outside or can be monitored using readily available samples of excreta and blood. Well-known examples of the use of urine and blood samples are the determination of liver and kidney function, of genetic variations, of hematological disorders, of factors of immunological importance and of aberrations of hormonal regulation including diabetes. In fact the possibilities to monitor health state using biological samples are so extensive that they are covered by a separate discipline: clinical chemistry. Books describing the multitude of tools available to the clinical chemist (e.g. $[71,136,154])$ are also a most valuable source of information for the occupational toxicologist $[55,84,168]$. 
An important difference of interest between clinicians and occupational toxicologists should however be noted. The clinician is primarily interested in parameters that may indicate changes in health state. Monitoring of health effects (or health surveillance [168]) is of course also of interest to the toxicologist, although it belongs more to the domain of the occupational physician. As stated, the toxicologist is primarily interested in biomarkers ${ }^{1}$ that might indicate the occurrence of exposure to hazardous compounds or that might be useful for evaluation of the risks resulting thereof. For both purposes it is not necessary that the parameters evaluated are in itself a consequence of impaired health. For this reason we may use clinical parameters at a level where they are not of clinical significance, or choose to use entirely different parameters.

Next to conceptual difficulties $[134,168]$, the use of clinical parameters for the study of early effects introduces some problems of methodological nature. The actual changes in the parameters determined are often very small, and the values affected may still lay within the normal range. This means that often sensible studies can only be done at a group level, which is in contrast with the more individual centered approach of the physician. Another useful approach is not to study just the momentary value of a parameter but to look at its change in time. Most often this is done by comparison of pre- and post-exposure values. In this way much more sensitive methods can be developed, assisted at large by the ability to use paired comparison statistics. On the other hand, the use of comparisons of multiple analyses performed at different times, asks for rigid control of between assay variations and seasonal changes [55]. In general such controls can be done by the inclusion of control samples with known values in each analyzed batch of samples. Again the final analyses can be performed on a group basis (i.e. statistical analyses to verify whether changes in values are significant), or on an individual basis. In the latter case differences between toxicological and clinical analyses will tend to disappear again, as many clinicians will argue that significant individual changes within the normal range might still be of clinical value.

Since biomarkers used in toxicology need not always be indicative of individual health changes, parameters that are not useful to the clinician may prove to be of use for the toxicologist. Especially when monitoring is performed to evaluate the risk of quantal effects like the development of cancer, the use of such early markers is indicated. Good examples of this approach can be seen in the determination of nucleic acid $[117,161]$ or protein adducts $[46,105]$ for the monitoring of exposure to electrophilic genotoxic compounds $[2,38,163]$ and in the monitoring of lipid peroxidation products $[52,77,97,111,116]$ as a measure for oxidative stress $[12,13,35,49,76,144,156]$

1. The term biomarkers - a contraction of biological markcrs-- is used here to indicate both substance related parameters - as used in biological monitoring - and effect related parameters -as used in biological effect monitoring and health surveillance-. See chapter 6 for definitions of these three monitoring concepts. 


\section{Erythrocytes}

Blood cells are of special interest for the assessment of in vivo changes in biological parameters. In general, blood cells are the easiest available cells from within the body. They can be obtained with hardly invasive techniques, and therefore volunteers can easily be found. Like it is generally the case for use of human material in biomedical experiments, it should be noted that microbiological contaminations can be present, and special care should be taken with regard to possible viral infections (especially HIV and hepatitis). Human erythrocytes have a longevity of about 120 days [30], and new cells are continuously being formed in the hematopoietic tissues located mainly in the bone marrow. Erythrocytes are extremely specialized cells. Their main function is the transport of oxygen from the lungs to periferal tissues. To enable them for this task a very large fraction (about $80 \%$ of the soluble protein) of the erythrocyte consists of hemoglobin. Other adaptations result from the necessity to be able to squeeze through tiny spaces between cells. For this reason erythrocyte membranes are very flexible. This is attained by a high abundance of poly-unsaturated fatty acids, and by specialized membrane proteins. Also, many organelles normally present in human cells are removed from the erythrocyte after the process of erythropoesis, and mature erythrocytes do no longer contain a nucleus, mitochondria or ribosomes. As a consequence erythrocytes do not contain any DNA and are not able to divide or to synthesize new proteins. In effect erythrocytes are slowly dying cells [30]. Because of the absence of mitochondria the erythrocyte is fully dependent on glycolysis for phosphorylation of ATP and reduction of $\mathrm{NAD}^{+}$to $\mathrm{NADH}$ and on the so called hexose monophosphate shunt for reduction of NADP to NADPH. The key enzyme in this hexose monophosphate shunt is glucose 6-phosphate dehydrogenase.

The absence of de novo protein synthesis in mature erythrocytes has important consequences for the usability of erythrocytes for monitoring purposes. In most other cell types damaged proteins will be removed and resynthesized. While erythrocytes do contain proteolytic enzymes which are able to remove oxidized proteins [36], hemoglobin adducts are not normally removed [46]. For the monitoring of hemoglobin adducts this is a great advantage, especially when compared with the monitoring of DNA adducts. While DNA adducts are rapidly repaired, the hemoglobin adducts remain present in the erythrocyte until sequestration of this cell. Therefore, it is possible to use hemoglobin adduct measurements some time after incidental exposure has occurred -in principle up to 3 months - or to determine a cumulative dose as a result of chronic exposure. Sequestration of erythrocytes is not a simple age related phenomenon. A fraction of the erythrocytes is removed independent of age. In rats this random destruction appears to be of more importance than in man [105], and amounts to about 3\% of the erythrocytes per day. In such cases the removal of erythrocytes can best be described by a function that combines exponential removal of old cells with random 
removal [72]. When changes in activities of enzymes present in erythrocytes are used as an effect parameter, the stability of the affected enzymes is not even a prerequisite. Since irreversible inactivation of erythrocyte enzymes will lead to decreased activities, older erythrocytes are expected to have lower activities of vulnerable enzymes. In accordance with this expectation, an age related decline in activities of aspartate amino transferase [114], glutathione reductase [73,114, 148], glutathione peroxidase [73], glucose 6-phosphate dehydrogenase [73], and superoxide dismutase [30] has been found in human erythrocytes, while the activity of the erythrocyte glutathione S-transferase (GST) studied in this thesis is also known to be affected [50]. It is important not to confuse this decreased activity changes in older cells with the changes occurring in older individuals. Lowered activities of copper-zinc superoxide dismutase, glutathione reductase and GST were found in erythrocytes in elderly [26], the same study showed that glutathione peroxidase activity is increased in older persons.

\section{Glutathione}

The tripeptide glutathione ( $G S H$, L- $\gamma$-glutamyl-L-cysteinyl-glycine, see figure 2.1 on the facing page) plays a central role in the protection of cells against oxidative $^{2}[75,129,135]$ and electrophilic stress ${ }^{3}[37,67,135]$ and radiation [24]. GSH is the most abundant non-protein sulfhydryl present in cells, with intracellular concentrations ranging from 0.5 to $10 \mathrm{mM}$ [129].

The synthesis of GSH by aerobic cells can be considered as a way to hold high levels of usable cysteine in a non-toxic form. Cysteine itself will rapidly autoxidize in the presence of metal ions like $\mathrm{Fe}^{3+}$ and $\mathrm{Cu}^{2+}$ [157]. As a result of the hydrogen peroxide liberated during this autoxidation, simple thiols like cysteamine $[147,160]$ and cysteine [160] can be toxic to cells. Blocking of the cysteine amino group by forming $\gamma$-glutamyl-cysteine slows its autoxidation considerably [145]. This may have been the selective factor that led to the evolution of $\gamma$-glutamylcysteine synthetase [48]. The special $\gamma$-binding makes this dipeptide, and glutathione, resistant to normal peptidase activity [44], and $\gamma$-glutamyl transpeptidase ( $\gamma G T$; see figure 2.2) is therefore needed for cleavage of glutathione or glutathione conjugates. Coupling of glycine to the $\gamma$-glutamylcysteine dipeptide by glutathione synthetase, leading to GSH synthesis, makes it even more resistant to autoxidation [145]. Furthermore, it provides a more extended

2. Oxidative stress refers to the unusually high presence of molecules with a high potency to abstract electrons from biomolecules. In practice free radicals are the most importance class of biological oxidators.

3. Electrophilic stress is defined as the effect of compounds with a high reactivity towards nucleophilic centers like --with increasing reactivity - oxygen, nitrogen and sulphur present in biomolecules. Reaction of electrophiles with nucleophilic centers in biomolecules leads to the formation of new chemicals bonds between the two (adduct formation). 


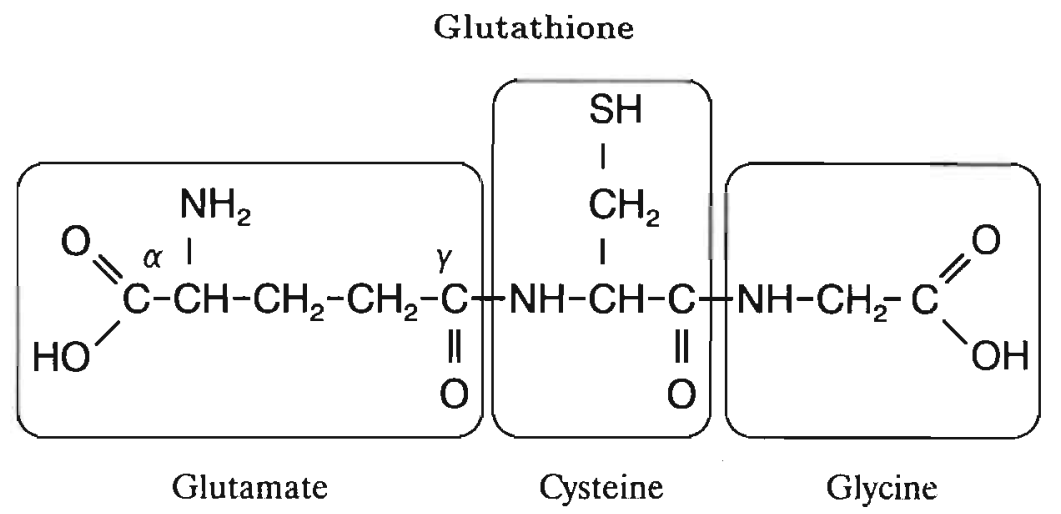

Figure 2.1: The structure of the tripeptide glutathione (GSH: L- $\gamma$-glutamyl-Lcysteinyl-glycine). Note the $\gamma$ linkage between glutamate and cysteine which makes glutathione resistant to normal peptidase activity.

carboxylic site that is used by many glutathione-dependent enzymes for substrate recognition and active site handling $[44,45]$.

The abundancy of glutathione in biological systems has led to enormous amounts of research to find "the role of glutathione". The crusade for this Holy Grail -as Kenneth Douglas called it in one of his excellent reviews [44] - led to the recognition of many functions. So many, that the said review was introduced with the quotation:

There was an old woman who lived in a shoe,

Who had so many children she didn't know what to do.

Whether the original function of glutathione was to create a save storage form of cysteine or not, currently a myriad of functions is known, and many of them are vital. Some of the more important functions include the detoxification of xenobiotics [91], removal of hydrogen peroxide and other peroxides and free radicals [129], maintenance of free protein sulfhydryl groups [74] and the synthesis of leukotriene $\mathrm{LTC}_{4}$ and derivatives [70]. These activities may lead to variations in the cellular availability of GSH [159]. This thesis will focus on glutathione loss in erythrocytes as a result of electrophilic or oxidative stress, and on concomitant changes in GST activity.

Due to the high nucleophilic potency of the glutathione sulfhydryl, GSH can function as an excellent nucleophilic scavenger for many reactive electrophiles $[37,45]$. In many cases this reactivity is increased further by glutathione $S$-transferases [91]. Since electrophilic chemicals can also react with biological macromolecules like DNA, and therehy present a genotoxic risk [101], this glutathione conjugation furnishes an important detoxification mechanism. In some 
instances however, the glutathione conjugates themselves may be toxic to the cells $[5,39,103]$. Glutathione S-conjugates can be metabolised to the corresponding cysteine conjugates by $\gamma \mathrm{GT}$ and cysteinylglycine dipeptidase and aminopeptidase $\mathrm{M}$ [39], which can subsequently be $\mathrm{N}$-acetylated by $\mathrm{N}$-acetyl transferase to yield the mercapturic acid $[22,163]$ (Figure 2.2). Formation of glutathione conjugates will therefore lead to loss of available glutathione. The thioethers formed are often excreted in urine, and can themselves be used for biological monitoring of exposure to electrophilic compounds $[64,163]$.

The mercapturic acid pathway.

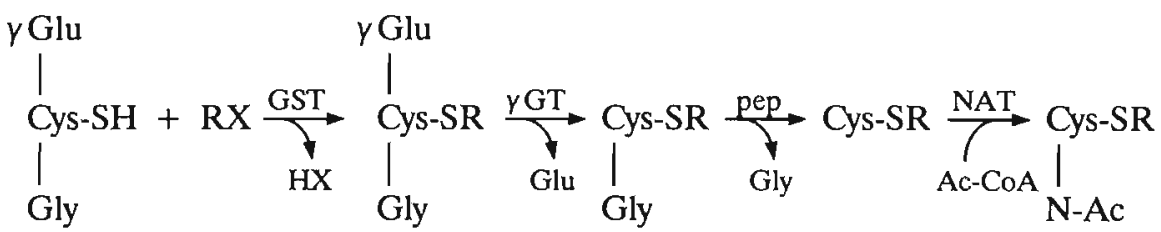

Figure 2.2: Glutathione conjugation by glutathione S-transferase (GST) and subsequent steps of the mercapturic acid pathway. The $\gamma$-glutamyl moiety is removed by $\gamma$-glutamyl transferase $(\gamma \mathrm{GT})$. The remaining dipeptide can subsequently be cleaved by cysteinyl glycine dipeptidase or aminopeptidase $M$ to yield a cysteine conjugate. This cysteine conjugate can be $\mathrm{N}$-acetylated by $\mathrm{N}$-acetyl transferase (NAT), which leads to mercapturic acid formation. Note that erythrocy tes do not contain $\gamma \mathrm{GT}$ and therefore have to excrete the complete glutathione conjugate.

Upon oxidative stress conditions a variety of processes can occur which may lead to the oxidation of GSH to its oxidized form, the disulfide GSSG. Among those are the activity of glutathione peroxidase [eq. 2.1] and some of the reactions catalysed by thioltransferase [164] [see eq. 2.2 for an example]. A more extensive

$$
\begin{aligned}
\mathrm{ROOH}+2 \mathrm{GSH} & \stackrel{\mathrm{GPX}}{\rightleftarrows} \mathrm{ROH}+\mathrm{H}_{2} \mathrm{O}+\mathrm{GSSG} \\
\text { Protein-SSG }+\mathrm{GSH} & \stackrel{\mathrm{TT}}{\rightleftarrows} \text { Protein-SH + GSSG }
\end{aligned}
$$

The glutathione peroxidase (GPX) reaction [eq. 2.1] and an example of a thioltransferase (TT) [164] catalysed reaction [eq. 2.2]. Both reactions lead to the oxidation of GSH to GSSG.

description of the role of glutathione in the protection against oxidative stress will be given below. For the moment it suffices to note that such conditions may lead to oxidation of glutathione. In the next section it will be shown that when such an oxidation occurs in erythrocytes the result may be excretion of GSSG. 


\section{Glutathione Turnover in Erythrocytes}

Oxidized glutathione is exported from erythrocytes by two separate ATP dependent transport systems $[19,81]$ with apparent $K_{\mathrm{m}}$ values for GSSG of $0.1 \mathrm{mM}$ and $7.1 \mathrm{mM}$ respectively. The two systems are probably related but not identical ATPases with unidirectional transport activity $[3,83]$. The high affinity (low $K_{\mathrm{m}}$ ) system has a $V_{\max }$ of $0.33 \mathrm{nmol} / \mathrm{min} / \mathrm{ml}$ cells and seems to be devoted to GSSG export. The low affinity system has a ten times higher $V_{\max }$ and is also involved in the transport of thioethers formed by conjugation of xenobiotic compounds like 1-chloro-2,4-dinitrobenzene. Awasthi and coworkers [11] demonstrated that thioether export is likely to be the main function of this system, since its GSSG exporting activity is inhibited by thioethers while thioether export is not inhibited by GSSG concentrations up to $11.8 \mathrm{mM}$. Even under normal conditions glutathione removal from mature erythrocytes is considerable, leading to a turnover half-time of 2-4 days [68]. This export rate confronts erythrocytes with a problem. They are not able to import glutathione directly over the plasma membrane. Moreover, mature erythrocytes lack $\gamma$-glutamyltranspeptidase activity $[137,138]$. As a result of this, erythrocytes are not able to recover the glutamic acid or glycine moiety of GSH from the S-conjugates, but have to excrete the complete GSH conjugate. $\gamma \mathrm{GT}$ is also an important enzyme in the $\gamma$-glutamyl cycle $[40,96]$. The absence of $\gamma \mathrm{GT}$ from erythrocytes therefore also means that they cannot utilize $\gamma$-glutamyl cycle activity for efficient amino acid uptake.

Synthesis of glutathione in erythrocytes is catalysed by $\gamma$-glutamylcysteine synthetase [eq. 2.3] and glutathione synthetase [eq. 2.4] [90]. The activity of $\gamma$ -

$$
\begin{gathered}
\text { glutamic acid }+ \text { cysteine }+ \text { ATP } \longrightarrow \gamma \text {-glutamylcysteine }+ \text { ADP }+P_{i} \\
\gamma \text {-glutamylcysteine }+ \text { glycine }+ \text { ATP } \longrightarrow \text { GSH }+ \text { ADP }+P_{i}
\end{gathered}
$$

Enzymatic synthesis of glutathione is catalysed by $\gamma$-glutamylcysteine synthetase [eq. 2.3] and glutathione synthetase [eq. 2.4].

glutamylcysteine synthetase in human erythrocytes is quite low (about $0.25 \mathrm{U} \cdot g$ $\mathrm{Hb}^{-1}[19]$ ), but would still be sufficient for a glutathione turnover half-time of less than $20 \mathrm{~min}$. $\gamma$-Glutamylcysteine synthetase is feedback inhibited by glutathione, and this is probably a crucial factor in regulation of erythrocyte glutathione levels [119]. Under normal conditions the two enzymes are nearly saturated with ATP [19], since the $K_{\mathrm{m}}$ values of approximately $0.4 \mathrm{mM}$ for both enzymes; [110] are well below the ATP concentration of $1.4 \mathrm{mM}$ found in normal erythrocytes. Substrate availability, mainly of glutamate, is considered to be a serious limiting factor in erythrocyte glutathione synthesis [19]. The permeability of the erythrocyte membrane for glutamic acid is very low [47], and increased plasma glutamate levels do not lead to increases in erythrocytes [139]. Several other 
sources for glutamate in erythrocytes have been suggested. Direct conversion of glutamine to glutamate, as suggested by Ellory and coworkers [47], is not possible since erythrocytes do not contain glutaminase activity $[79,122]$. The amino group of glutamine can also be transferred to nicotinic acid [115] as part of the NAD synthesis. It is unlikely however that NAD synthesis in erythrocytes is sufficiently high to provide the amounts of glutamate needed for glutathione synthesis. King and Kuchel [79] suggested that uptake of $(\alpha)$-glutamate containing di- and tripeptides and subsequent cleavage could supply the glutamate. Again this is unlikely because of the expected low concentrations of these peptide fragments in plasma [85]. Glutamate can also be produced from oxaloacetate and aspartate by glutamic oxaloacetic acid transaminase activity. The practical importance of this route remains unclear [19]. It can be concluded from the above that limitation of glutamate availability is likely to restrict the erythrocyte capacity to svnthesize glutathione under conditions where more than normal amounts of glutathione are lost. It is also possible that cysteine availability becomes limiting under some conditions. Both cysteine and glycine are imported by sodium dependent uptake systems $[47,120]$. In sheep a hereditary disorder has been described where erythrocyte glutathione deficiency may be caused by inadequate cysteine transport [166].

\section{Oxidative Stress in Erythrocytes}

The human erythrocyte is a cell that one might expect to be at risk for free radical damage $[27,34,63]$. It is exposed to high oxygen tension, especially during passage through the lungs. Erythrocytes are rich in polyunsaturated lipids [42] and iron [66]. Methyl groups between two cis double bonds in polyunsaturated lipids - as they exist in for instance arachidonic acid- are especially sensitive to lipid peroxidation $[27,58,128]$. The radical formed after hydrogen abstraction from such a methyl group is resonance stabilized by, energetically favorable, conjugated dienes. After reaction with oxygen and abstraction of a hydrogen atom from somewhere else - most often from another polyunsaturated lipid, resulting in a chain reaction of lipid radicals - a lipid peroxide molecule is formed (See eqs 2.5 to 2.7). Free iron and free cupric ions can catalyse reaction 2.8 (the Fenton reaction), in which the potent hydroxyl radical $(\mathrm{OH} \cdot)$ is formed from hydrogen peroxide $\left(\mathrm{H}_{2} \mathrm{O}_{2}\right)$. To complete the Haber-Weiss cycle the $\mathrm{Fe}^{3+}$ has to be reduced by either hydrogen peroxide [eq. 2.9] or superoxide [eq. 2.10]. Apart from this, free iron can also stimulate hemoglobin autoxidation and stimulate the decomposition of hydroperoxides (see below for those two aspects). During erythrocyte life there is a constant conversion of oxyhemoglobin to methemoglobin. Normally about $3 \%$ of the total hemoglobin is converted to methemoglobin each day [25]. This methemoglobin is reduced by NADH methemoglobin reductase, which depends on the glycolytic pathway for NADH reduction [155]. An NADPH depen- 


$$
\begin{aligned}
& \text { Initiation } \\
& \mathrm{RH}+\text { initiator } \longrightarrow \mathrm{R} . \\
& \text { Propagation } \\
& \mathrm{R} \cdot+\mathrm{O}_{2} \longrightarrow \mathrm{ROO} \cdot \\
& \mathrm{ROO}+\mathrm{RH} \longrightarrow \mathrm{ROOH}+\mathrm{R} . \\
& \text { Termination } \\
& \mathrm{ROO}+\mathrm{R} \cdot \stackrel{\longrightarrow}{\mathrm{ROOR}} \\
& \mathrm{ROO}+\mathrm{ROO} \cdot \longrightarrow \mathrm{ROOR}+\mathrm{O}_{2}
\end{aligned}
$$

Classical description of the three phases in free radical reactions. In the initiation phase [eq. 2.5] a free radical is formed. During the repetitive propagation phase [eqs. 2.6] an existing radical will, in most cases, first react with oxygen. Next, the peroxyl radical formed abstracts a hydrogen atom from another molecule (most often a polyunsaturated fatty acid), yielding a new radical. Finally, it is conceivable -although not likely - that two free radicals meet each other. This would than lead to termination [eqs. 2.7].

$$
\begin{aligned}
& \mathrm{Fe}^{2+}+\mathrm{H}_{2} \mathrm{O}_{2} \longrightarrow \mathrm{Fe}^{3+}+\mathrm{OH}^{-}+\mathrm{OH} \\
& \mathrm{Fe}^{3+}+\mathrm{H}_{2} \mathrm{O}_{2} \longrightarrow \mathrm{Fe}^{2+}+\mathrm{H}^{+}+\mathrm{HO}_{2} \\
& \mathrm{Fe}^{3+}+\mathrm{O}_{2}^{-} \longrightarrow \mathrm{Fe}^{2+}+\mathrm{O}_{2}
\end{aligned}
$$

The Fenton reaction [eq. 2.8] leading to formation of hydroxyl radicals from hydrogen peroxide. The $\mathrm{Fe}^{3+}$ formed can be reduced by either another hydrogen peroxide molecule or by a superoxide radical. In this way superoxide radicals could stimulate the formation of more potent hydroxyl radicals $[13,121]$.

dent methemoglobin reductase - depending on the hexose monophosphate shunt for NADPH reduction - is also present in human erythrocytes. Under normal conditions the activity of this enzyme accounts for only about $20 \%$ of total methemoglobin reduction [167], but it may be of much more importance during stress conditions [127]. The autoxidation of oxyhemoglobin involves the formation of a superoxide radical $[25,102,165]$. Normally the heme iron electron binding $\mathrm{O}_{2}$ returns to the iron when oxygen is released, and the iron remains in its ferrous $\mathrm{Fe}^{2+}$ state. When water or other small anions enter the heme pocket - which is normally prevented due to the hydrophobic nature of this pocket- oxygen can be displaced with an extra electron, i.e. as superoxide [eq. 2.11]. The autoxidation of oxyhemoglobin can be further increased by $\mathrm{Cu}^{2+}$ and $\mathrm{Fe}^{3+}$ ions present 


$$
\mathrm{HbFe}^{2+}-\mathrm{O}_{2}+\mathrm{H}_{2} \mathrm{O} \longrightarrow \mathrm{HbFe}^{3+}-\mathrm{OH}_{2}+\mathrm{O}_{2}^{-} \text {. }
$$

Superoxide radical $\left(\mathrm{O}_{2}^{-}\right)$formation during autoxidation of oxyhemoglobin. See [25] for a schematic representation of the mechanism involved.

in the red cell $[25,121]$, and this also leads to superoxide radical generation [25]. As a result of this phenomenon there is a continual spontaneous source of activated oxygen within the erythrocyte. Methemoglobin forming substances that stimulate this mechanism, for instance because they form relatively hydrophobic anions that can more easily enter the heme pocket, will also stimulate superoxide radical formation. The results presented in chapter 5 indicate that this may be the case for hydroxylamines (see also [140]).

Apart from this internal source for active oxygen species, erythrocytes circulate in an environment in which they are exposed to extracellular sources of free radicals. Granulocytes and macrophages can generate hydrogen peroxide and superoxide anions that can damage the erythrocytes $[28,29,162]$. This formation of active oxygen species by granulocytes and macrophages is part of the normal inflammatory activity of these cells. Mature polymorphonuclear leukocytes are capable to ingest, kill and digest microorganisms. They can be stimulated by microorganisms and a variety of chemicals to a respiratory burst. This process is characterized by increased oxygen uptake, a shift in glucose metabolism towards the hexose monophosphate shunt (yielding NADPH), activation of an NADPH oxidase and generation of a variety of toxic oxygen species including $\mathrm{O}_{2}^{-}, \mathrm{H}_{2} \mathrm{O}_{2}$ and $\mathrm{OH} \cdot[27,109]$. One could argue that for this reason oxidative stress in erythrocytes might be increased during inflammatory diseases [34]. Indeed, Machiedo and coworkers describe decreased red blood cell deformability in sepsis patients [89]. Decreases in red blood cell deformability are a known effect of erythrocyte membrane peroxidation, probably resulting from protein crosslinking and lipid structure disturbances [36]. In the study by Machiedo et al. the red blood cell deformability was found to correlate not only to sepsis state but also to malon dialdehyde levels in plasma, supporting the theory that the deformability decreases are induced by lipid peroxidation. Supportive evidence came from a rat study where the radical scavenger $\alpha$-tocopherol was found to prevent red blood cell deformability decreases after induced sepsis [113]. Interestingly, red blood cell deformability decreases in patients did not only correlate to sepsis - which could actually be predicted two days before normal diagnosis - but also to multiplesystem organ failure. This is an often fatal condition which has previously been related to oxidative stress $[13,34]$.

The oxidative stress resulting from ischemia-reperfusion episodes $[13,33$, $34,52,95]$ forms another possible external source for exposure of erythrocytes to oxidative stress. In erythrocytes from patients with various kinds of circula- 
tory shock (mostly hypovolemic and cardiogenic) increased lipid peroxidation was detected by determination of aldehydes [112]. This indicates that serious hypoxiareperfusion situations may indeed induce lipid peroxidation in erythrocytes.

From the above, it can be concluded that several factors may increase oxidative stress in human erythrocytes. Among these are increased oxygen turnover, for instance as a result of increased physical activity (studied in chapter 8 of this thesis), inflammatory diseases for instance in coal workers pneumoconiosis (studied in chapter 9) and exposure to oxidative chemicals or chemicals leading to increased methemoglobin formation (studied in vitro in chapter 5).

\section{Glutathione Protection against Oxidative Stress}

In order to understand the role of glutathione in protection against oxidative stress and more specifically lipid peroxidation we have to focus on some aspects of the oxidative processes described, and to look at the protective mechanisms that are present within the erythrocyte. The primary initiation of the radical chain-reaction is normally the formation of an active oxygen species, for instance during hemoglobin autoxidation, neutrophil activation or in the Fenton reaction (see above). When such active oxygen species reach the lipid membrane they can abstract a hydrogen atom from a polyunsaturated fatty acid. The exact nature of the actual active oxygen species involved remains unknown, but the hydroxyl radical is considered to be a likely candidate $[121,128]$. Due to its high reactivity $\left(\sim 10^{9} \mathrm{~mol}^{-1} \mathrm{sec}^{-1}\right)$ it will react with the nearest target available. The predominant reaction of poly unsaturated lipids observed can however also occur during the subsequent propagative chain reactions. The hydrogen abstraction by an active oxygen species is often called the initiation step in lipid peroxidation, strictly speaking it should be denominated a propagation reaction [58]. Once a lipid radical is formed a chain reaction of lipid peroxidation can commence, until either two radicals meet in a termination reaction or a stable (e.g. $\alpha$-tocopheryl) radical is formed.

The erythrocyte contains protective systems that can detoxify the active oxygen species formed - thereby preventing lipid peroxidation- and that can terminate the peroxidation process. Three enzymes are present that detoxify active oxygen species: superoxide dismutase, catalase and glutathione peroxidase. The superoxide dismutase reaction [eq. 2.12] results in the formation of $\mathrm{H}_{2} \Omega_{2}$. The longevity of $\mathrm{H}_{2} \mathrm{O}_{2}$, its ability to pass through lipid bilayers and its reactivity towards iron that will produce the highly reactive hydroxyl radical [eqs. 2.8 to 2.10] make $\mathrm{H}_{2} \mathrm{O}_{2}$ an extremely dangerous molecule $[9,126]$. Its formation by superoxide dismutase is therefore in itself not necessarily a detoxification. $\mathrm{H}_{2} \mathrm{O}_{2}$ itself can be detoxified by either catalase [eq. 2.13] or the selenium dependent glutathione peroxidase [eq. 2.14]. From studies with resealed, normal and acatalasemic, erythrocytes overloaded with either catalase or glutathione [126], it can 


$$
\begin{array}{rll}
2 \mathrm{O}_{2}^{-}+2 \mathrm{H}^{+} & \stackrel{\text { sOD }}{\longrightarrow} & \mathrm{H}_{2} \mathrm{O}_{2}+\mathrm{O}_{2} \\
\mathrm{H}_{2} \mathrm{O}_{2} & \stackrel{\text { Catalase }}{\longrightarrow} & 2 \mathrm{H}_{2} \mathrm{O}+\mathrm{O}_{2} \\
\mathrm{H}_{2} \mathrm{O}_{2}+2 \mathrm{GSH} & \stackrel{\text { Gr'X-Se }}{\longrightarrow} & 2 \mathrm{H}_{2} \mathrm{O}+\text { GSSG }
\end{array}
$$

Reaction equations for the three main antioxidant enzymes present in erythrocytes. Superoxide radicals can be converted to hydrogen peroxide by superoxide dismutase (SOD: eq. 2.12). The hydrogen peroxide itself has to be detoxified by either catalase [eq. 2.13] or selenium dependent glutathione peroxidase [eq. 2.14].

be concluded that catalase is likely to be the most important of the two. The opposite view has been presented in older literature though [31]. The glutathione peroxidase reaction with $\mathrm{H}_{2} \mathrm{O}_{2}$ [eq. 2.14] results in the oxidation of GSH. When sufficient NADPH is available this will be reduced by glutathione reductase [87], a reaction in which NADPH is oxidized to $\mathrm{NADP}^{+}$[eq. 2.15]. The NADPH can

$$
\mathrm{GSSG}+\mathrm{NADPH}+\mathrm{H}^{+} \stackrel{\mathrm{GR}}{\longrightarrow} 2 \mathrm{GSH}+\mathrm{NADP}^{+}
$$

By means of the glutathione reductase (GR) reaction the erythrocyte is able to reduce glutathione. The reaction consumes NADPH that has to be provided by the hexose monophosphate pathway.

normally be regenerated by the hexose monophosphate shunt, which has a high reserve capacity. Under oxidative stress conditions up to $92 \%$ of the phosphorylated glucose can pass through this pathway - normally about $11 \%-[4]$. Under such conditions the turnover is no longer limited by glucose 6-phosphate dehydrogenase but by phosphorylation of glucose itself, catalysed by hexokinase [153]. It was proved by Llobell et al. [86] that, at least in yeast, the activation of glucose 6-phosphate dehydrogenase by GSSG is actually a result of NADP+ formation by glutathione reductase. Using this knowledge it is possible to discriminate hemolytic drugs that directly consume NADPH (like methylene blue) from those that primarily oxidize GSH (like doxorubicine) [69]. Under high oxidative stress conditions glutathione reductase activity may become insufficient and toxic amounts of GSSG have to be removed in another way. As we shall see in the next few paragraphs, oxidation of GSH by glutathione peroxidase activity towards $\mathrm{H}_{2} \mathrm{O}_{2}$ will most likely be only a small fraction of the total glutathione oxidation under oxidative stress conditions. NADPH is also of importance for catalase activity - albeit as a cofactor and not as a substrate- and it was suggested by Scott and coworkers that this might be one of the reasons why NADPH, and not GSH, modulates the oxidant sensitivity in normal and glucose 6-phosphate deficient erythrocytes [127]. 
Apart from the antioxidant enzymes, the red cell contains some soluble antioxidant like ascorbate (vitamin $\mathrm{C}$ ) and uric acid that can stabilize the active oxygen before it reaches the lipid structure [106]. Whether GSH can function as such a direct radical scavenger is debatable [106]. Such an activity would result in the formation of thiyl (GS-) radicals, that can be stabilized by ascorbate [58, 106]. Alternatively a thiyl radical might react sequentially with another GSH and oxygen and yield GSSG and $\mathrm{O}_{2}^{-} \cdot[106]$.

Once lipid peroxidation has been initiated the most important protective factor is tocopherol $[106,107,151]$. When a lipid peroxyl radical reacts with vi-

$$
\mathrm{ROO}+\mathrm{Vit} \mathrm{E} \longrightarrow \mathrm{ROOH}+\mathrm{Vit} \mathrm{E}
$$

Termination of lipid peroxidation by formation of a stable chromanoxyl radical from vitamin $\mathrm{E}$.

tamin $\mathrm{E}$ [eq. 2.16] a fairly stable vitamin $\mathrm{E}$ radical is formed, as a result of flectron delocalisation in the chromanoxyl head. The concentration of vitamin $\mathrm{E}$ in membranes is relatively low [32], and it has to be recycled in order to obtain the protection seen in erythrocytes. Already in the original studies by Tappel [151.] it was shown that vitamin $\mathrm{E}$ radicals can be restored by vitamin $C$. Recently clegant studies confirmed a direct interaction between the two [16,32]. The ascorbyl radical thus formed can be enzymatically reduced back to vitamin

$$
\text { Vit } \mathrm{E} \cdot \mathrm{Vit} \mathrm{C} \longrightarrow \text { Vit } \mathrm{E}+\text { Vit } \mathrm{C} \text {. }
$$

Restoration of vitamin $\mathrm{E}$ from vitamin $\mathrm{E}$ radicals by vitamin $\mathrm{C}$.

$\mathrm{C}$ by NADH-dependent enzymes [27]. It can also react further with a second tocopheryl radical yielding dehydroascorbate [16], or two vitamin $\mathrm{C}$ radicals can disproportionate yielding an ascorbate and a dehydroascorbate molecule [20]. The formation of dehydroascorbate by either of those two mechanisms is of special interest to us, since dehydroascorbate can be reduced by glutathione, a reaction that may be catalysed by thioltransferases [164]. In this way glutathione could assist the vitamin $E$ radical scavenging. The existence of a free radical reductase [94], whereby GSH could directly reduce vitamin E radicals, was suggested by the work of Reddy et al. [118], and further evidence for its existence was pres'nted by Haenen et al. $[56,57,58]$. Fuji and coworkers also described a heat-labile glutathione dependent protection system in erythrocytes that was not identical to glutathione peroxidase or glutathione S-transferase [54]. It can be speculated that they were also looking at free radical reductase activity. Both the direct. free radical reductase activity and the dehydroascorbate reduction would result 
in increased glutathione oxidation. Thereby adding to the glutathione oxidation rate resulting from hydrogen peroxide peroxidase activity as described above.

So far the role of glutathione in the protection against reactive oxygen species in the aqueous phase and in the termination of lipid peroxidation were discussed. Two other important protective functions of glutathione remain to be described: the removal of lipid hydroperoxides and the protection of protein thiols.

Lipid peroxidation can not only be initiated by reactive oxygen species (the so called lipid hydroperoxide independent lipid peroxidation). It is also possible that a lipid hydroperoxide, formed as the result of another reaction chain, decomposes [eqs 2.18 and 2.19]. As a result of this new lipid radicals are formed, which will result in a whole new propagating lipid peroxidation chain reaction (i.e. lipid hydroperoxide dependent lipid peroxidation). Two separate mechanisms for this

$$
\begin{aligned}
\mathrm{ROOH}+\mathrm{Fe}^{2+} & \longrightarrow \mathrm{RO} \cdot+\mathrm{OH}^{-}+\mathrm{Fe}^{3+} \\
\mathrm{ROOH}+\mathrm{Fe}^{3+} & \longrightarrow \mathrm{ROO} \cdot+\mathrm{H}^{+}+\mathrm{Fe}^{2+} \\
\mathrm{ROOH} & \stackrel{\mathrm{Hb}}{\longrightarrow} \mathrm{RO} \cdot+\mathrm{OH} .
\end{aligned}
$$

Amplification of lipid peroxidation by iron catalysed [eq. 2.18] bimolecular and hemoglobin induced unimolecular [eq. 2.19] decomposition of lipid hydroperoxides.

phenomenon are described in the literature. Metal-catalysed decomposition depends on free metal ions (e.g. iron ions in eqs. 2.18 [128]). The bond dissociation energy for a simple alkyl hydroperoxide is so high $\left(\sim 47 \mathrm{kCal} \mathrm{mol}^{-1}\right)$ that spontaneous unimolecular decomposition [eq. 2.19] can be excluded [27]. Hemoglobin will however catalyse this activity, a close look at the mechanism might however lead to something very close to equation 2.18. One of the main protective functions of glutathione is probably that it can prevent this amplification of lipid peroxidation by detoxification of the lipid hydroperoxides themselves [see eq. 2.1 on page 18]. Erythrocytes contain both a hydrophilic and a hydrophobic form of the selenium dependent glutathione peroxidase [51]. The hydrophobic form can directly interact with phospholipid hydroperoxides. Before the hydrophilic form can become active the lipid hydroperoxide must be removed from the glycerol moiety by phospholipase activity $[82,150]$. The same is true for the glutathione peroxidase activity of glutathione S-transferase. The activity of all three enzymes -i.e. selenium dependent hydrophobic, selenium dependent hydrophilic and glutathione S-transferase - activity will lead to the glutathione oxidation.

Finally, glutathione can be used to reduce protein mixed disulfide [74], or to reduce cystine bridges. An example of the first type of reactions is given in equation 2.2 on page 18 . The reduction of a cystine bridge would be a two 
step process [164], in which the disulfide bridge is reduced at the expense of

$$
\begin{aligned}
& \mathrm{RSSR}+\mathrm{GSH} \stackrel{\mathrm{TT}}{\rightleftarrows} \mathrm{RSSG}+\mathrm{RSH} \\
& \mathrm{RSSG}+\mathrm{GSH} \stackrel{\mathrm{TT}}{\rightleftarrows} \mathrm{GSSG}+\mathrm{RSH}
\end{aligned}
$$

Thioltransferase (TT) catalysed reduction of a disulfide bridge, e.g. an intramolecular cystine bridge.

glutathione oxidation. In human erythrocytes this type of reactions are catalysed by thioltransferase $[99,100]$.

It can be concluded that all four protective mechanisms described -i.e. hydrogen peroxide peroxidase activity, reduction of vitamins $\mathrm{C}$ and $\mathrm{E}$, lipid hydroperoxide peroxidase activity and thioltransferase activity - will lead to glutathione oxidation. Under serious stress conditions glutathione reductase activity may become insufficient to hold the high GSH/GSSG ratio needed for optimum protection. The GSSG export system described on page 19 will than remove part of the GSSG and even under less severe stress conditions this export system may compete with glutathione reductase. Under severe stress conditions the GSSG level may still become high enough to allow formation of mixed proteinglutathione disulfides by the reversal of the thioltransferase catalysed reaction shown in eq. 2.2. Since GSSG export is ATP dependent, insufficient supply of ATP might also stimulate this pathway. Apart from the studies present in this thesis some other reports have become available that show that human erythrocyte GSH may be a valuable marker for oxidative stress. Sugawara and coworkers found increased lipoperoxide concentrations, lowered superoxide dismutase and catalase activities and lowered glutathione concentrations in workers exposed to lead [143]. On the other hand, Saralakumari and Rao showed that in chronic fluoride poisoning - leading to oxidative stress and increased lipid peroxidationerythrocyte GSH was increased two-fold [123]. They also reported increases in $\gamma$-glutamylcysteine synthetase, glutathione $\mathrm{S}$-transferase, glutathione peroxidase and -hard to believe - $\gamma$-glutamyl transpeptidase, and concluded that an adaptation to the permanent stress must have occurred.

\section{Glutathione S-Transferase}

The main glutathione S-transferase present in human erythrocytes - often denoted GST $\rho$ [93] - belongs to the $\pi$ class [21,158]. This isoenzyme accounts for $90-95 \%$ of the total erythrocyte GST activity (using the common substrate CDNB (1-chloro-2,4-dinitrobenzene) [19,50]. The first 20 amino acids of the amino terminal sequence are the same as for GST3 (or GSTP1-1 as it should be called according to new nomenclature [92]), the $\pi$ class isoenzyme from human 
placenta. While the two were not discriminated immunologically, the erythrocyte isoenzyme has a higher isoelectric point [146]. Whether this difference is the result of differences in genetic origin or of post-translational modifications is difficult to evaluate. It may not even be unique for the erythrocyte since structural analysis of human placenta GST also demonstrated coexpression of at least two GST $\pi$ genes [1]

Apart from GST $\rho$, erythrocytes contain another GST with a much higher isoelectric point ( $\mathrm{pI}>10$ as opposed to $\mathrm{pI} \approx 4.5[93]$ for GST $\rho$ ), which has been designated GST $\sigma$ [10]. It can be separated from the major $\rho$ form by affinity chromatography on bromosulfophtalein-S-glutathione columns. This minor isoenzyme has an amino acid content different from the $\rho$ form and shows no immunological cross reactivity. Contrary to GST $\rho$ it will catalyse GSH conjugation of bromosulfophtalein and 1,2-epoxy-3-(p-nitrophenoxy) propane [133]. GST $\sigma$ represents approximately $5 \%$ of the total erythrocyte activity towards CDNB. Its importance might be underestimated however, since it has a comparatively low affinity to this common substrate [133].

More recently another erythrocyte GST, without activity to CDNB, has been described $[60,124]$. This GST is important for the conjugation of methylene chloride. It was separated from GST $\rho$ and GST $\sigma$ by affinity chromatography on GSH sepharose. Based on inhibition studies with deoxycholate and $\mathrm{N}$-ethyl maleate it was further discriminated from $\mu$ class GSTs. The absence of affinity to GSH sepharose and the lack of activity towards CDNB explain why this GST was not described earlier. Schröder et al. [124] concluded that the newly discovered erythrocyte GST shows some resemblance to GST $\theta$. The Theta class is the most recently described class of cytosolic GST isoenzymes - after Alpha, Mu and $\mathrm{Pi}-$ apart from human liver GST $\theta$ it contains the rat liver isoenzymes GST 5-5 and 1212 [98], and the rat liver mitochondrial GST 13-13 [61]. The GST activity towards methylene chloride and some other $\mathrm{C} 1 / \mathrm{C} 2$ compounds (methyl bromide, methyl iodide [59], dichloromethane [152] and ethylene oxide [53]) in human erythrocytes shows polymorphism [60]. This might explain the findings by van Doorn et al. [43], who described that four workers exposed to methyl chloride excreted high levels of a thioether metabolite, while two others exposed under the same conditions excreted almost nothing of this metabolite. This polymorphisms is not only of importance for biological monitoring, but also for risk evaluations. This was confirmed in the study by Hallier et al., who found that the induction of sister chromatid exchanges by methyl bromide, ethylene oxide and dichloromethane was much lower in blood of so called "conjugators" (i.e. individuals with high activity of the described GST) than in that of "non-conjugators" [60]. Risk evaluations are hampered further by the finding that the polymorphic presence of a $\mathrm{C} 1 / \mathrm{C} 2$ conjugating GST seems to be limited to human erythrocytes [41]. In the studies described in this thesis GST activities were determined using CDNB, while protein levels were sometimes determined using antibodies to hGSTP1-1. Both assays do not pick up the polymorphic GST. A small fraction of the total 
detected GST activity (about 5\%) will originate from GST $\sigma$. Western blots of isoelectric focusing gels proved that it is not detected by the antibody used in chapter 6 .

Normal erythrocyte GST activities towards CDNB vary considerably between individuals (6-10 fold) $[125,141]$ (also confirmed in this thesis), and it was suggested early that the cause might be undetected (genetic) variation [142]. Fazi and coworkers showed that GST $\rho$ actually exists in two forms [50] that can be separated using ion-exchange chromatography. Only one isozymic form is present in young erythrocytes (separated from older cells by using density gradients), while older erythrocytes contain two forms, with up to $26 \%$ in the "secondary" form. The "secondary" GST $\rho$ (i.e. the form that is only present in older cells) is more heat stable than the "primary" form. The kinetic properties of the two isozymic forms $\left(K_{\mathrm{m}}\right.$ for CDNB and GSH, $\mathrm{pH}$ optimum and inhibition by 1,2-dichloro-4nitrobenzene, 1,2-epoxy-3-(p-nitrophenoxy) propane and bromosulfophtalein) do not differ. In the same study a decrease in GST activity with erythrocyte age was also demonstrated. Combination of the two results indicates that the activity $\left(V_{\max }\right)$ is likely to be lower for the "secondary" form, but this was not actually measured.

Another interesting study towards interindividual differences in human erythrocyte GST activities was reported by Anosike and coworkers from Nigeria [7]. They compared GST activities in erythrocytes from $20 \mathrm{HbSS}$ individuals - homozygotes for $\mathrm{HbS}$, the sickle cell form of $\mathrm{Hb}$-, with those for $13 \mathrm{HbAS}$ $\mathrm{HbA}, \mathrm{HbS}$ heterozygotes - and $20 \mathrm{HbAA}$ - normal - individuals. GST activities were found to be increased in $\mathrm{HbS}$ individuals. Mean values were $14.61 \mathrm{U} \cdot \mathrm{g} \mathrm{Hb}^{-1}$ for $\mathrm{HbSS}, 4.65 \mathrm{U} \cdot \mathrm{g} \mathrm{Hb}^{-1}$ for $\mathrm{HbAS}$ and $2.75 \mathrm{U} \cdot \mathrm{g} \mathrm{Hb}^{-1}$ for HbAA. The sickle cell disease is characterized by hemolytic crisis which cause anemia and other subsequent complications. The nature of those hemolytic crisis is not fully understood, but they are associated with methemoglobin formation, superoxide release and liberation of hemin. Van den Berg et al. [15] have shown that the lipid peroxidation promoting capabilities of HbS (and hemin) are higher than that of normal $\mathrm{Hb}$. When hemin is liberated it will further increase the damage to the erythrocyte, as hemin itself has been shown to cause hemolysis in vitro [80]. Erythrocyte GST has a high affinity towards heme, and it was suggested by Harvey and Beutler that one of the purposes of the enzyme is to transport newly synthesized heme from mitochondria to be incorporated into globin [62]. It is tempting to speculate - as was done by Anosike et al.- that the extra GST present in HbS subjects is synthesized during hematopoesis to protect the cell against the oxidant species formed or to scavenge hemin or both.

Beutler et al. [18] found GST deficiencies in two sibs with glutathione synthetase deficiency and GSH levels of less than $5 \%$ of normal. Since the parents had half-normal glutathione synthetase activities and normal GST, the authors concluded that deficiency in glutathione synthetase was the primary lesion and that GST appeared to be labile at the very low glutathione concentrations that re- 
sulted thereof. Two different explanations can be given for this phenomenon. The explanation given by Beutler et al. is that binding of GSH may directly stabilize GST. The $K_{\mathrm{m}}$ for GSH binding is about $0.1 \mathrm{mM}$ for most soluble GSTs [91] and for the human erythrocyte form values of $0.14 \mathrm{mM}[7]$ up to $0.58 \mathrm{mM}$ [50] have been reported. Since physiological erythrocyte GSH concentrations are about $2 \mathrm{mM}$ this means that GST will normally be saturated with GSH. This leads to conformational changes that may stabilize the enzyme, as it is known to do in vitro. Decrease of the erythrocyte GSH concentration to $5 \%$ or less of the normal $2 \mathrm{mM}$ means that its value comes below the GST $K_{\mathrm{m}}$ for GSH, and that a large fraction of the GST will be in its more labile non-GSH form. The other possibility is that GSH protects GST in its soluble form. The protective mechanisms of GSH described above might also function to protect GST $\rho$. More specifically, GSH might assist in the prevention of lipid peroxidation - thereby also protecting GST for reactive peroxidation products - and, as a substrate of thioltransferase, GSH might help to restore GST activity when lost as a result of disulfide formation.

That the latter mechanism might actually work was shown as a side effect of the work done by Shen et al. [130]. Rat GST-P and human GST $\pi$ (currently named rGSTP1-1 and hGSTP1-1. [92]) are known to contain 4 cysteine residues at corresponding positions (i.e. at the $14^{\text {th }}, 47^{\text {th }}, 101^{\text {th }}$ and $169^{\text {th }}$ position) [91]. The activity of these $\pi$ class enzymes were found to be vulnerable to $N$-ethylmaleimide, a well-known SH modifier [149]. Tryptic digestion was used to identify the cysteine at position 47 as the critical target. When hydrogen peroxide treatment was used these GSTs were also inactivated, but they could be reactivated with purified rat liver thioltransferase [130]. The positions of the cysteinyl residues were identified using recombinant mutant GST-P forms with alanine instead of one of the four cysteine residues [131]. Again the cysteine 47 residue was found to be critical, but cysteine 101 was also important. Disulfide formation between these residues, resulting in steric hindrance, was considered the most probable cause for the inactivation. It may be noteworthy that, while the elegant work of this Japanese group shows that cysteine residues 47 and 101 are probably located at or near the active center of GST-P, it also shows that the cysteinyl nature of these residues is not critical. After all the two mutant forms with alanine instead of the cysteines at these locations as well as the mouse GST II, which contains glycine instead of the cysteine at location 101, all do show GST activity [131].

The possibility should be considered that the "secondary" GST $\rho$ form described by Fazi et al. [50] is actually a form in which one or more of the sulfhydryl groups is masked, like the S-modified forms reported by Tamai et al. [149], or the S-oxidized forms reported by Shen et al. [130].

The inactivation by oxidative stress seems to be more or less specific for class $\pi$ GSTs. Nishinaka et al. [108] showed that class $\pi$ porcine lens GST could be inactivated by biological disulfides, by a xanthine-xanthine oxidase system, by $\mathrm{H}_{2} \mathrm{O}_{2}$ and by the cataract inducing oxidant 1,2-naphtoquinone. On the other 
hand, bovine lens GST --..which belongs to class $\mu-$ was not sensitive to these factors. In fact, class $\mu$ GST as well as microsomal GST, can even be activated by active oxygen species $[6,88,104]$. GSTs from the $\alpha$ class can be inactivated by AOS [104], but they are less sensitive than $\pi$ class GST.

Apart from model sulfhydryl reagents, like the $\mathrm{N}$-ethyl maleimide used by Tamai et al. [149], several other substances are known to inhibit erythrocyte GST in vitro. Singh and Awasthi showed for instance that $1.3 \mathrm{mM}$ of the herbicide 2,4-D (2,4-dichlorophenoxyacetate) suffices to inhibit $50 \%$ of purified GST $\rho$ and GST $\sigma$ activity towards CDNB [132]. For 2,4,5-T (2,4,5-trichlorophenoxyacetate) these I50 values are $0.5 \mathrm{mM}$ and $1.2 \mathrm{mM}$ for GSTs $\rho$ and $\sigma$ respectively. Ansari and coworkers showed that the industrially important chemicals acrolein, propylene oxide, styrene oxide, ethylene dibromide and ethylene dichloride also inhibited GST from erythrocytes both in situ and in purified GST $\rho$ [8]. They were the first to suggest the use of human erythrocyte GST activity as a biological marker for chemical exposure. Before that, Kíilpikari and Savolainen [78] had measured GST activity in erythrocytes of workers exposed to hot rubber fumes. The rationale for these measurements was the expectation that the high production of thioethers found in such workers might lead to an induction of GST activity. Their finding of a decrease in GST activity was therefore opposite to their expectation and not further investigated. It can be concluded that various indications do exist some of which were only published while the work in this thesis was in progressto make a further study towards changes in human erythrocyte GST during electrophilic and oxidative stress conditions worthwhile. 


\section{References}

[1] Ahmad H., Wilson D.E., Fritz R.R., Singh S., Medh R.D., Nagle G.T., Kurovsky A. (1990). Primary and secondary structural analyses of glutathione S-transferase $\pi$ from human placenta. Arch Biochem Biophys 278: 398-408.

[2] Aitio A., Becking G., Berlin A., Bernard A., Foa V., Kello D., Krug E., Léonard A. and Nordberg G. (Eds). Indicators for assessing exposure and biological effects of genotoxic chemicals. CEC, Brussels, 1988.

[3] Akerboom T. and Sies H. Glutathione transport and its significance in oxidative stress. In: Glutathione: metabolism and physiological functions. Viña J. (Ed.). CRC Press, Boca Raton (1990), pp. 45-55.

[4] Albrecht V., Roigas H., Schultze M., Jacobasch G., Rapoport S. (1971). The influence of $\mathrm{pH}$ and methylene blue on the pathways of glucose utilization and lactate formation in erythrocytes of man. Eur J Biochem 20: 44-50.

[5] Anders M.W., Lash L., Dekant W., Elfarra A.A. and Dohn D.R. (1988). Biosynthesis and biotransformation of glutathione S-conjugates to toxic metabolites. Crit Rev Toxicol 18: 311-342.

[6] Aniya Y. and Naito A. (1993). Oxidative stress-induced activation of microsomal glutathione S-transferase in isolated rat liver. Biochem Pharmacol 45: 37-42.

[7] Anosike E.O., Uwakwe A.A., Monanu M.O. and Ekeke G.I. (1991). Studies on human erythrocyte glutathione-S-transferase from $\mathrm{HbAA}, \mathrm{HbAS}$ and $\mathrm{HbSS}$ subjects. Biomed Biochim Acta 9: 1051-1056.

[8] Ansari G.A.S., S.V. Singh, J.C. Gan and Y.C. Awasthi (1987). Human erythrocyte glutathione S-transferase: a possible marker of chemical exposure. Toxicol Lett 37: 57-62.

[9] Aust S.D., Morehouse L.E. and Thomas C.E. (1985). Role of metals in oxygen radical reactions. J Free Radicals in Biol Med 1: 3-25.

[10] Awasthi Y.C. and Singh S.V. (1984). Purification and characterization of a new form of glutathione S-transferase from human erythrocytes. Biochem Biophys Res Commun 125: 1053-1060.

[11] Awasthi Y.C., Singh S.V., Ahmad H., Wronski L.W., Srivastava S.K. and LaBelle E.F. (1989). ATP dependent primary active transport of xenobiotic-glutathione conjugates by human erythrocyte membrane. Mol Cell Biochem 91: 131-136.

[12] Bandy B. and Davison A.J. (1990). Mitochondrial mutations may increase oxidative stress: implications for carcinogenesis and aging? Free Rad Biol Med 8: $523-539$.

[13] Bast A. and Gorris R.J.A. (1989). Oxidative Stress. Biochemistry and human disease. Pharm Weekbl Sci Ed 11: 199-206.

[14] Bast A. and Haenen G.R.R.M. (1990) Regulation of lipid peroxidation by glutathione and lipoic acid: involvement of liver microsomal vitamin $E$ free radical reductase. Adv Exp Med Biol 264: 111-116.

[15] Berg J.J.M. van den, Kuypers F.A., Qju J.H., Chiu D., Lubin B., Roelofsen B. and Op den Kamp J.A.F. (1988). The use of cis-parinaric acid to determine lipid peroxidation in human erythrocy te membranes. Comparison of normal and sickle erythrocyte membranes. Biochim Biophys Acta 944: 29-39. 
[16] Berg J.J.M. van den, Kuypers F.A., Roelofsen B. and Op den Kamp J.A.F. (1990). The cooperative action of vitamins $E$ and $C$ in the protection against peroxidation in human erythrocyte membranes. Chem Phys Lipids 53: 309-320.

[17] Berlin A., Riihimäki V. and Vainio H. (Eds) (1984). Assessment of toxic agents at the work place. Roles of ambient and biological monitoring. Nijhof, The Hague (etc.).

[18] Beutler E., Gelbart T. and Pegelow C. (1986). Erythrocyte glutathione synthetase deficiency leads not only to glutathione but also to glutathione Stransferase deficiency. $J$ Clin Invest 77: 38-41.

[19] Beutler E. and Dale G.L. Erythrocyte glutathione: function and metabolism. In: Glutathione chemical biochemical and medical aspects. Part B. Dolphin D., Avramović O. and Poulson R. (Eds.). J. Wiley \& Sons, New York (etc.) (1989), pp. 291-317.

[20] Bielski B.H.J. and Richter H.W. (1975). Some properties of the ascorbate free radical. Ann N Y Acad Sci 258: 231-237.

[21] Board P., Coggan M., Johnston P., Ross V., Suzuki T. and Webb G. (1990). Genetic heterogeneity of the human glutathione transferases: a complex of gene families. Pharmac Ther 48: 357-369.

[22] Boyland E. and Chasseaud L.F. (1969). The role of glutathione and glutathione S-transferases in mercapturic acid biosynthesis. Adv Enzymol Rel Areas Mol Biol 32: $173-219$.

[23] Brouwer E.J., Evelo C.T.A., Verplanke A.J.W., van Welie R.T.H. and de Wolff F.A. (1991). Biological effect monitoring of exposure to 1,3-dichloropropene: effects on liver and renal function and on glutathione conjugation. Br J Ind Med 48: $167-172$.

[24] Bump E.A. and Brown J.M. (1990). Role of glutathione in the radiation response of mammalian cells in vitro and in vivo. Pharmac Ther 47: 117-136.

[25] Carrell R.W., Winterbourn C.C., Rachmilewitz E.A. (1975). Activated oxygen and haemolysis. Br J Haematol 30: 259-264.

[26] Ceballos-Picot I., Trivier J., Nicole A., Sinet P. and Thevenin M. (1992). Agecorrelated modifications of copper-zinc superoxide dismutase and glutathionerelated enzyme activities in human erythrocytes. Clin Chem 38: 66-70.

[27] Chiu D., Kuypers F. and B. Lubin (1989). Lipid peroxidation in human red blood cells. Semin Hematol 26: 257-276.

[28] Claster S., Chiu D.T., Quintanilda A. and Lubin D. (1987). Neutrophils mediate lipid peroxidation in human red cells. Blood 64: 1079-1084.

[29] Claster S., Quintanilda A., Schott M.A., Chiu D. and Lubin D. (1987). Neutrophil induced $\mathrm{K}^{+}$leak in human red cells: a potential mechanism for infection mediated hemolysis. J Lab Clin Med 109: 201-210.

[30] Clark M.R. (1988). Senescence of red blood cells: progress and problems. Physiol Rev 68: 503-554.

[31] Cohen G. and Hochstein P. (1963). Glutathione peroxidase: the primary agent for the elimination of hydrogen peroxide in erythrocytes. Biochemistry 6: 14201428 . 
[32] Constantinescu A., Han D. and L. Packer (1993). Vitamin E recycling in human erythrocyte membranes. J Biol Chem 268: 10906-10913.

[33] Coudray C., Pucheu S., Boucher F., de Leiris J. and A. Favier (1992). Ischemia and reperfusion injury in isolated rat heart: Effect of reperfusion duration on xanthine-oxidase, and enzyme antioxidant systems in myocardium. Basic Res Cardiol 87: 478-488.

[34] Cross C.E., Halliwell B., Borish E.T., Pryor W.A., Ames B.N., Saul R.L. and McCord J.M. (1987). Oxygen radicals and human disease. Ann Intern Med 107: 526-545.

[35] Cutler R.G. (1991). Antioxidants in aging. Am J Clin Nutr 53: 373S-379.

[36] Davies K.J.A. and Goldberg A.L. (1987). Oxygen radicals stimulate intracellular proteolysis and lipid peroxidation by independent mechanisms in erythrocytes. $J$ Biol Chem 262: 8220-8226.

[37] DeLeve L.D. and Kaplowitz N. (1991). Glutathione metabolism and its role in hepatotoxicity. Pharmac Ther 52: 287-305.

[38] Dell'Omo M. and Lauwerys R.R. (1993). Adducts of macromolecules in the biological monitoring of workers exposed to polycyclic aromatic hydrocarbons. Crit Rev Toxicol 23: 111-126.

[39] Dekant W., Lash L.H. and Anders M.W. Fate of glutathione conjugates and bioactivation of cysteine S-conjugates by cysteine conjugate 3 -lyase. In: Glutathione conjugation. Mechanism and biological significance. Sies $\mathrm{H}$. and Ketterer B. (Eds.). Academic Press, London (1988), pp. 415-447.

[40] Deneke S.M. and Fanburg B.L. (1989). Regulation of cellular glutathione. Am J Physiol 257: L163-173.

[41] Deutschman S., Peter H., Reichel C., Bolt M., Hallier E. (1989). Kinetik der Metabolisierung von Methylbromid und Methyliodid in Erythrocyten des Menschen und verschiedene Tierspezies. Verb Dtsch Ges Arbeitsmed (Gentner, Stuttgart) 29: 517-519.

[42] Dodge J.T. and Philips G.B. (1967). Composition of phospholipids and of phospholipid fatty acids and aldehydes in red cells. J Lipid Res 8: 667-675.

[43] Doorn R. van, Borm P.J.A., Leijdekkers C.M., Henderson P.Th., Reuvers J. and van Bergen T.J. (1980). Detection and identification of S-methylcysteine in urine of workers exposed to methyl chloride. Int Arch Occup Environ Health 46: 99109.

[44] Douglas K.T. (1987). Mechanism of action of glutathione-dependent enzymes. Adv Enzymol Rel Areas Mol Biol 59: 103-167.

[45] Douglas K.T., Reactivity of glutathione in model systems for glutathione Stransferases and related enzymes. In: Glutathione conjugation. Mechanism and biological significance. Sies H. and Ketterer B. (Eds.). Academic Press, London (1988), pp. 1-41.

[46] Ehrenberg L., and Tornqvist M. (1991). Human health risk assessment and biological reactive intermediates: hemoglobin binding. Adv Exp Med Biol 283: 641-647 
[47] Ellory J.C., Preston R.L., Osotimehin B. and Young J.D. (1983). Transport of amino acids for glutathione biosynthesis in human and dog red cells. Biomed Biochim Acta 42: S48-S52.

[48] Fahey R.C. and Sundquist A.R. 1991. Evolution of glutathione metabolism. $A d v$ Enzymol Rel Areas Mol Biol 64: 1-53.

[49] Farber J.L., Kyle M.E. and Coleman J.B. (1990). Biology of disease. Mechanisms of cell injury by activated oxygen species. Lab Invest 62: 670-679.

[50] Fazi A., Accorsi A., Piatti E. and Magnani M. (1991). Cell age dependent decay of human erytbrocytes glutathione S-transferase. Mech Ageing Dev 58: 255-266.

[51] Flohé L. The selenoprotein glutathione peroxidase. In: Glutathione chemical biochemical and medical aspects. Part A. Dolphin D., Avramović O. and Poulson R. (Eds.). J. Wiley \& Sons, New York (etc.) (1989), pp. 643-731.

[52] Floyd R.A. (1990). Role of oxygen free radicals in carcinogenesis and brain is-

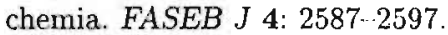

[53] Föst U., Hallier E., Ottenwälder H., Bolt H.M. and Peter H. (1991). Distribution of ethylene oxide in human blood and its implication for biomonitoring. Hum Exp Toxicol 10: 25-31.

[54] Fuji S., Dale G.L. and Beutler E. (1984). Glutathione dependent protection against oxidative damage of the human red cell membrane. Blood 63: 1096 1101 .

[55] Gidlow D.A., Church J.F. and Clayton B.E. (1983). Haematological and biochemical parameters in an industrial workforce. Ann Clin Biochem 20: 341-348.

[56] Haenen G.R.R.M. and Bast A. (1983). Protection against lipid peroxidation by a microsomal glutathione-dependent heat labile factor. FEBS lett 159: 24-28.

[57] Haenen G.R.R.M., Tai Tin Tsoi J.N.L., Vermeulen N.P.E., Timmerman H. and Bast A. (1987). 4-Hydroxy-2,3-trans-nonenal stimulates microsomal lipid peroxidation by reducing the glutathione dependent protection. Arch Biochem Biophys 259: 449-456.

[58] Haenen G.R.R.M. Thiols in oxidative stress. Some implications for catecholamine toxicity. PhD Thesis, Free University of Amsterdam, 1989.

[59] Hallier E., Deutschman S., Reichel C., Bolt H.M., Peter H. (1990). A comparative investigation of the metabolism of methyl bromide and methyl iodide in human erythrocytes. Int Arch Occup Environ Health 62: 221-225.

[60] Hallier E., Langhof T., Dannapel D., Leutbecher M., Schröder K., Goergens H.W., Müller A. and Bolt H.M. (1993). Polymorphism of glutathione conjugation in methyl bromide, ethylene oxide and dichloromethane in human blood: influence on the induction of sister chromatid exchange (SCE) in lymphocytes. Arch Toxicol 67: 173-178.

[61] Harris J.M., Meyer D.J., Coles B. and Ketterer B. (1991). A novel glutathione transferase (13-13) isolated from the matrix of rat liver mitochondria having structural similarity to class Theta enzymes. Biochem $J$ 178: 137-141.

[62] Harvey J.W. and Beutler E. (1982). Binding of heme by glutathione Stransferase: a possible role of the erythrocyte enzyme. Blood 60: 1227-1230.

[63] Hatherill R., Till G.O. and Ward P.A. (1991). Mechanisms of oxidant-induced changes in erythrocytes. Agents Actions 32 351-358. 
[64] Henderson P.Th., van Doorn R., Leijdekkers Ch.-M and Bos R.P. (1984). Excretion of thioethers in urine after exposure to electrophilic chemicals. In: Berlin A. et al. (Eds.) Monitoring human exposure to carcinogenic and mutagenic agents. IARC scientific publ. 59, Lyon, pp. 173-188.

[65] Henderson R.F., Bechtold W.E., Bond J.A. and Sun J.D. (1989). The use of biological markers in toxicology. Crit Rev Toxicology 20: 65-82.

[66] Herschko C. (1989). Mechanism of iron toxicity and its possible role in red cell membrane damage. Semin Hematol 26: 277-285.

[67] Hinson J.A. and Kadlubar F.F. Glutathione and glutathione transferases in the detoxification of drug and carcinogen metabolites. In: Glutathione conjugation. Mechanisms and biological significance Sies H. and Ketterer B. (Eds.), Academic Press, London (1988), 235-280.

[68] Hochberg A., Rigbi M. and Dimant E. (1964). The incorporation in vitro of glycine and L-glutamic acid into glutathione of human erythrocytes. Biochim Biophys Acta 90: 464-471.

[69] Hohl R.J., Kennedy E.J. and Fischer H. (1991). Defenses against oxidation in human erythrocytes: role of glutathione reductase in the activation of glucose decarboxylation by hemolytic drugs. J Lab Clin Med 117: $325-331$.

[70] Huber H. and Keppler D. (1988). Leukotrienes and the mercapturate pathway. In: Glutathione conjugation. Mechanisms and biological significance Sies $\mathrm{H}$. and Ketterer B. (Eds.), Academic Press, London (1988), 449-470.

[71] Hak Hyun B., Gulati G.L. and Ashton J.K. (1986). Color atlas of clinical chemistry. Igaku-Shoin, New York-Tokyo.

[72] International committee for standardization in haematology (1980). Recommended method for radioisotope red-cell survival studies. Br J Haematol 45: 659-666.

[73] Imanishi H., Nakai T., Abe T. and Takino T. (1986). Glutathione-linked enzyme activities in red cell aging. Clin Chim Acta 159: 73-76.

[74] Inoue M. Glutathione: dynamic aspects of protein mixed disulfide formation. In: Glutathione chemical biochemical and medical aspects. Part B. Dolphin D., Avramović O. and Poulson R. (Eds.). J. Wiley \& Sons, New York (etc.) (1989) pp. 613-644.

[75] Ishikawa $\mathrm{T}$. and Sies H. Glutathione as an antioxidant: toxicological aspects. In: Glutathione chemical biochemical and medical aspects. Part B. Dolphin D., Avramović O. and Poulson R. (Eds.). J. Wiley \& Sons, New York (ctc.) (1989), pp. 85-109.

[76] Janssen Y.M.W., Van Houten B., Borm P.J.A. and Mossman B.T. (1993). Biology of disease. Cell and tissue responses to oxidative damage. Lab Invest 69: 261-274.

[77] Jeejeebhoy K.N. (1991). In vivo breath alkane as an index of lipid peroxidation. Free Rad Biol Med 10: 191 193.

[78] Kilpikari I. and H. Savolainen (1984). Decreased erythrocyte glutathione S-transferase activity in rubber workers. Int Arch Occup Environ Health 53: 299-302. 
[79] King G.F. and Kuchel P.W. (1985). Assimilation of $\alpha$-glutamyl peptides by human erythrocytes. A possible means of glutamate supply for glutathione synthesis. Biochem $J 227$ 833-842.

[80] Kirschner-Zilber T., Rabizadeh E. and Shaklai N. (1982). The interaction of hemin and bilirubin with human red cell membrane. Biochim Biophys Acta 690: 20-30.

[81] Kondo T., Kawakami Y. and Taniguchi N. Glutathione disulfide-stimulated $\mathrm{Mg}^{2+}$-ATPase of human erythrocytes. In: Glutathione centennial: molecular perspectives and clinical implications. Taniguchi N, Higashi T, Sakamoto Y. and Meister A. (Eds.). Academic Press, San Diego (1989), pp. 369-380.

[82] Kuijk F.J., Sevaman A., Handelman G.J. and Dratz E.A. (1987). A new role for phospholipase $A_{2}$ : protection from membranes from lipid peroxidation damage. Trends in Biological Sciences 12: 31-34.

[83] LaBelle E.F., Singh S.V., Ahmad H., Wronski I., Srivastava S.K. and Awasthi Y.C. (1988). A novel dinitrophenylglutathione-stimulated ATPase is present in human erythrocyte membranes. FEBS Lett 228: 53-56.

[84] Lauwerys R.R. and Bernard A. (1987). Early detection of nephrotoxic effects of industrial chemicals: state of the art and future prospects. Am J Ind Med 11: 275-285.

[85] Lindblad B.S., Baum A., Burston D., Chao L., Furst P., Lindqvist B., Matthews D.M., Tarchini R. and Taylor E. (1979). Absorption of di- and tripeptides by the intestine of the guinea-pig. Ciba Found Symp 1618: 189-200.

[86] Llobell A., López-Ruiz, Peinado J. and López-Barea J. (1988). Glutathione reductase directly mediates the stimulation of yeast glucose-6-phosphate dehydrogenase, Biochem J 249: 293-296.

[87] López-Barea J., Bárcena J.A., Bocanegra J.A., Florido J., Garcia-Alfonso C., López-Ruiz A., Martínez-Galisteo E. and Peinado J. Structure, mechanism, functions, and regulatory properties of glutathione reductase. In: Glutathione: metabolisı and physiological functions. Viña J. (Ed.), CRC Press, Boca Raton (1990) pp. 105-116.

[88] Lundqvist G. and Morgenstern R. (1992). Mechanism of activation of rat liver microsomal glutathione transferase by noradrenaline and xanthine oxidase. Biochem Pharmacol 43: 1725-1728.

[89] Machiedo G.W., Powell R.J., Rush B.F., Swislocki N.I., Dikdan G. (1989). The incidence of decreased red blood cell deformability in sepsis and the association with oxygen free radical damage and multiple-system organ failure. Arch Surg 124: $1386-1389$.

[90] Majerus P.W., Brauner M.J., Smith M.B. and Minnich V. (1971). Glutathione synthesis in human erythrocytes. II Purification and properties of the enzymes of glutathione biosynthesis. $J$ Clin Invest 50: 1637-1643.

[91] Mannervik B. and Danielson U.H. (1988). Glutathione Transferases - structure and catalytic activity. Crit Rev Biochem 23: 283-337.

[92] Mannervik B., Awasthi Y.C., Board P.G., Hayes J.D., Di llio C., Ketterer B., Listowsky I., Morgenstern R., Muramatsu M., Pearson W.R., Picket C.B., Sato 
K., Widersten M. and Wolf C.R. (1992). Nomenclature for human glutathione transferases. Biochem $J$ 282: 305-306.

[93] Marcus C.J., Habig W.H. and Jakoby W.B. (1978). Glutathione transferase from human erythrocytes. Nonidentity with the enzymes from human erythrocytes. Arch Biochem Biophys 188: 287-293.

[94] McCay P.B. and Powell S.R. Relationship between glutathione and chemically induced lipid peroxidation. In: Glutathione chemical biochemical and medical aspects. Part B. Dolphin D., Avramović O. and Poulson R. (Eds.). J. Wiley \& Sons, New York (ctc.) (1989), pp. 111-151.

[95] McCord J.M. (1985). Oxygen-derived free radicals in post-ischemic tissue injury. $N$ Engl J Med 312: 159-163.

[96] Meister A. On the biochemistry of glutathione. In: Glutathione centennial: molecular perspectives and clinical implications. Taniguchi N, Higashi T, Sakamoto Y. and Meister A. (Eds.). Academic Press, San Diego (1989), pp. 3-21.

[97] Messina M.J. (1991). Oxidative stress status and cancer: methodology applicable for human studies. Free Rad Biol Med 10: 175-176.

[98] Meyer D.J., Coles B., Pemble S.E., Gilmore K.S., Fraser G.M. and Ketterer B. (1991). Theta, a new class of glutathione transferases purified from rat and man. Biochem $J$ 274: 409-414.

[99] Mieyal J.J., Starke D.W., Gravina S.A., Dothey C. and Chung J.S. (1991). Thioltransferase in human red blood cells: purification and properties. Biochemistry 30: 6088-6097.

[100] Mieyal J.J., Starke D.W., Gravina S.A. and Hocevar B.A. (1991). Thioltransferase in human red blood cells: kinetics and equilibrium. Biochemistry 30: 88838891.

[101] Miller E. and J.A. Miller (1966). Mechanisms of chemical carcinogenesis: nature of proximate carcinogens and interactions with macromolecules. Pharmacol Rev 18: 805-838.

[102] Misra H.P. and Fridovich L. (1972). The generation of superoxide radical during the autoxidation of hemoglobin. J Biol Chem 247: 6960-6962.

[103] Monks T.J. and Lau S.S. (1992). Toxicology of quinone-thioethers. Crit Rev Toxicol 22: 243-270.

[104] Murata T., Hatayama I., Satoh K., Tsuchida S. and Sato K. (1990). Activation of rat glutathione transferases in class mu by active oxygen species. Biochem Biophys Res Comm 171: 845-851.

[105] Neumann H.G., Birner G., Kowallik P., Schutze D. and Zwirner-Baier I. (1993). Hernoglobin adducts of N-substituted aryl compounds in exposure control and risk assessment. Environ Health Perspect 99: 65-69.

[106] Lipid antioxidants: how they may act in biological systems. Br J Cancer 55: 153-57.

[107] Niki E., Yamamoto Y., Takahashi M., Komuro E. and Miyama Y. (1990). Inhibition of oxidation of biomembranes by tocopherol. Ann N Y Acad Sci 570: 23-31. 
[108] Nishinaka T., Terada T., Nanjo H., Mizoguchi T. and Nishihara T. (1993). Difference in glutathione S-transferase response to oxidative stress between porcine and bovine lens. Exp Eye Res 56: 299-303.

[109] Oliver C.N. (1987). Inactivation of enzymes and oxidative modification of proteins by stimulated neutrophils. Arch Biochem Biophys 253: 62-72.

[110] Paniker N.V. and Beutler E. (1972). The effect of methylene blue and diaminosulfone on red cell reduced glutathione synthesis. $J$ Lab Clin Invest 80: 481-487.

[111] Pitkänen O.M. (1992). Are ethane and pentane evolution and thiobarbituric acid reactivity specific for lipid peroxidation in erythrocyte membranes? Scand J Clin Lab Invest 52: 379-385.

[112] Poli G., Biasi F., Chiarpotto E., Dianzani M.U., De Luca A. and Esterbauer H. (1989). Lipid peroxidation in human diseases: evidence of red cell oxidative stress after circulatory shock. Free Rad Biol Med 6: 167-170.

[113] Powell R.J., Machiedo G.W., Rush B.F. and Dikdan G. (1989). The effect of alpha-tocopherol on red cell deformability and survival sepsis. Curr Surg 46: 381-383.

[114] Powers H.J., Thurnam D.I. and Dugdale A.E. (1981). Is red blood cell survival limited by the activity of a critical enzyme. $J$ Theor Biol 88: 685-691.

[115] Preiss J. and Handler P. (1958). Biosynthesis of diphosphopyridine nucleotide. II Enzymatic aspects. J Biol Chem 233: 493-500.

[116] Pryor W.A. and Godber S.S. (1991). Oxidative stress status: an introduction. Free Rad Biol Med 10: 173.

[117] Randerath K., Reddy M.V. and Gupta R.C. (1981). ${ }^{32}$ P-Labeling test for DNA damage. Proc Natl Acad Sci USA 78: 6126-6129.

[118] Reddy C.C., Scholz R.W., Thomas C.E., and Massaro E.J. (1982). Vitamin E dependent reduced glutathione inhibition of rat microsomal lipid peroxidation. Life Sci 31: 571-576.

[119] Richman P.G. and Meister A. (1975). Regulation of $\gamma$-glutamyl-cysteine synthetase by nonallosteric feedback inhibition by glutathione. J Biol Chem 250 : 1422-1426.

[120] Rosenberg R. (1988). Amino acid transport in human red blood cells. Acta Psychiatr Scand Suppl 345 78: 25-28.

[121] Saltman P. (1989). Oxidative stress: a radical view. Semin Hematol 26: 249-256.

[122] Sandring K.-H., Rohde A., and Rost J. (1968). Glutaminase in roten Blutzellen. Folia Haematol Int Mag Klin Morphol Blutforsch 89: 201 -211.

[123] Saralakumari D. and Rao P.R. (1991). Erythrocyte glutathione metabolism in human chronic fluoride toxicity. Biochem Int 23: 349-357.

[124] Schröder K.R., Hallier E., Peter H. and Bolt H.M. (1992). Dissociation of a new glutathione S-transferase activity in human erythrocytes. Biochem Pharmacol 43: 1671-1674.

[125] Scott E.M. and Wright R.C. (1980). Variability of glutathione S-transferase of human erythrocytes. Am J Hum Genet 32: 115-117.

[126] Scott M.D., Lubin B.H., Zuo L. and Kuypers F.A. (1991). Erythrocyte defense against hydrogen peroxide: preeminent importance of catalase. J Lab Clin Med 118: $7-16$. 
[127] Scott M.D., Zuo L., Lubin B.H. and Chiu D.T.-Y. (1991). NADPH, Not glutathione, status modulates oxidant sensitivity in normal and glucose-6-phosphate dehydrogenase deficient erythrocytes. Blood 77: 2059-2064.

[128] Sevanian A. and Hochstein P. (1985). Mechnisms and consequences of lipid peroxidation in biological systems. Am Rev Nutr 5: 365-390.

[129] Shan X., Aw T.Y. and Jones D.P. (1990). Glutathione-dependent protection against oxidative injury. Pharmacol Ther 47: 61-71.

[130] Shen H., Tamai K, Satoh K.. Hatayama I., Tsuchida S., and Sato K. (1991). Modulation of class $\mathrm{Pi}$ glutathione transferase activity by sulfhydryl group modification. Arch Biochem Biophys 286: 178-182.

[131] Shen H., Tsuchida S., Tamai K, and Sato K. (1993). Identification of cysteine residues involved in disulfide formation in the inactivation glutathione transferase P-form by hydrogen peroxide. Arch Biochem Biophys 300: 137 -141.

[132] Singh S.V. and A wasthi Y.C. (1985). Inhibition of human glutathione S-transferases by 2,4-dichlorophenoxyacet ate $(2,4-D)$ and 2,4,5-trichlorophenoxyacetate. Toxicol Appl Pharmacol 81: 328-336.

[133] Singh S.V. and Awasthi Y.C. (1986). Cationic glutathione S-transferase of human erythrocytes has unique kinetic characteristics among buman glutathione S-transferases. Biochem Biophys Res Commun 137: 1174-1180.

[134] Sittert van N.J., Veenstra G.E., Dumas E.P. and Tordoir W.F. (1991), Letter to the editor and authors reply regarding [23]. Br J Ind Med 48, 1991, 646-648.

[135] Smith C.V. and Mitchell J.R. Pharmacological aspects of glutathione in drug metabolism. In: Glutathione chemical biochemical and medical aspects. Part $B$. Dolphin D., Avramović O. and Poulson R. (Eds.). J. Wiley \& Sons, New York (etc.) (1989) pp. 1-43.

[136] Sonnenwirth A.C. and Jarett L. (Eds.) (1980). Gradwohl's clinical laboratory methods and diagnosis. Volume 1 (8th ed), C.V. Mosby Company, St. Louis, pp. 809-902.

[137] Srivastava S.K., Awasthi Y.C., Miller S.P.. Yoshida A., And Beutler E. (1976). Studies on $\gamma$-glutamyl transpeptidase in human and rat erythrocytes. Blood 47: 645-650.

[138] Srivastava S.K. (1977). Absence of $\gamma$-glutamyl transpeptidase and the role of GSSG transport in the turnover of GSH in erythrocytes. Blood 49: 668-669.

[139] Stacher A. and Stöckl W. Das Verhalten der freien Aminosaeuren in Plasma und Erythrozyten nach Infusion verschiedener Aminosäurenlösungen. In: Metabolism and merabrane permeability of erythrocytes and thrombocytes. Deutsch E., Gerlach E. and Moser K. (Eds.). Georg Thieme, Stuttgart (1968), pp. 177-182.

[140] Stolze K. and Nohl H. (1989). Detection of free radicals as intermediates in the methemoglobin formation from oxyhemoglobin induced by hydroxylamine. Biochem Pharmacol 38: 3055-3059.

[141] Strange R.C., Johnson P.H., Lawton A., Moult J.A., Tector M.J., Tyminski R.J. and Cotton W. (1982). Studies on the variability of glutathione S-transferase from human erythrocytes. Clin Chim Acta 120: 251-260. 
[142] Strange R.C., Hirrell P.H., Kitley G.A., Hopkinson D.A. and Cotton W. (1983). Erythrocyte glutathione S-transferase. Electrophoretic identification of two enzyme forms. Biochem $J$ 215: 213-216.

[143] Sugawara E., Nakamura K., Miyake T., Fukumura A. and Seki Y. (1991). Lipid peroxidation and concentration of glutathione from workers exposed to lead. $\mathrm{Br}$ $J$ Ind Med 48: 239-242.

144] Sun Y. (1990). Free radicals, antioxidant enzymes, and carcinogenesis. Free Rad Biol Med 8: 583-599.

[145] Sundquist A.R. and Fahey R.C. (1989). Evolution of antioxidant mechsnisms: thiol dependent peroxisidases and thioltransferases among procaryotes. $J \mathrm{Mol}$ Evol 29: 429-435.

[146] Suzuki T., Coggan M., Shaw D.C. and Board P.G. (1987). Electrophoretic and immunological analysis of human glutathione S-transferase isoenzymes. Ann Hum Genet 51: 95-106.

[147] Takagi Y., Shikita M., Terasimo T. and Akoboshi S. (1974). Specificity of radioprotective and cytotoxic effects of cysteamine in HeLa $S_{3}$ cells: generation of peroxide as the mechanism of paradoxical toxicity. Radiat Res 60: 292-299.

[148] Takeuchỉ N., Shishino K., Bando S., Murase M., Go S. and Uchida K. (1985). Aging changes of riboflavin concentration and glutathione reductase activity in erythrocytes. Arch Gerontol Geriatr 4: 205-210.

[149] Tamai K., Satoh K., Tsuchida S., Hatayama I., Maki T. and Sato K. (1990). Specific inactivation of glutathione S-transferases in class pi by SH-modifiers. Biochem Biophys Res Comm 167: 331-338.

[150] Tan K.H., Meyer D.J., Belin J., and Ketterer B. (1984). Inhibition of microsomal lipid peroxidation by glutathione and glutathione transferases $\mathrm{B}$ and $\mathrm{AA}$ : role of endogeneous phospholipase $A_{2}$. Biochem J 220: 243-252.

[151] Tappel A.L. (1962). Vitamin E as the biological lipid antioxidant. Vitam Horm 20: 493-501.

[152] Thier R., Föst U., Deutschman S., Schröder K.R., Westphal G., Hallier E. and Peter H. (1991). Distribution of methylene chloride in human blood. Arch Toxicol Suppl 14: 254-258.

[153] Thorburn D.R. and Kuchel P.W. (1985). Regulation of the human-erythrocyte hexose-monophosphate shunt under conditions of oxidativ stress. A study using NMR spectroscopy, a kinetic isotope effect, a reconstituted system and computer simulation. Eur $J$ Biochem 150: 371-386.

[154] Tietz N.W. (Ed.) (1986). Textbook of clinical chemistry. W.B Saunders, Philadelphia.

[155] Tomoda A., Imoto M., Hirano M., Yoneyama Y. (1979). Analysis of met-form haemoglobins in human erythrocytes of normal adults and of a patient with hereditary methemoglobinaenemia due to deficiency of NADH-cytochrome $b_{5}$ reductase. Biochem $J$ 181: 505-507.

[156] Trush M.A. and Kensler T.W. (1991). An overview of the relationship between oxidative stress and chemical carcinogenesis. Free Rad Biol Med 10: 201-209.

[157] Tsen C.C. and Tappel A.L. (1958). Catalytic oxidation of glutathione and other sulfhydryl compounds by selenite. J Biol Chem 233: 1230-1232. 
[158] Tsuchida S. and Sato K. (1992). Glutathione transferases and cancer. Crit Rev Biochem Mol Biol 27: 337-384.

[159] Uhlig S. and Wendel A. (1992). The physiological consequences of glutathione variations. Life Sciences 51: 1083-1094.

[160] Vos O., Budke L. and Vergroessen A.J. (1962). Protection of tissue-culture cells against ininizing radiation $I$. The effect of biological amines, disulfide compounds and thiols. Int $J$ Rad Biol 5: 543-557.

[161] Watson W.P. (1987). Post-radiolabeling for detecting DNA damage. Mutagenesis 2: $319-331$.

[162] Weiss S.J. (1980). The role of superoxide in the destruction of erythrocyte targets by human neutrophils. $J$ Biol Chem 255: 9912-9917.

[163] Welie R.T.H. van, van Dijck R.G.J.M., Vermeulen N.P.E. and van Sittert N.J. (1992). Mercapturic acids and protein and DNA adducts as biomarkers of electrophilic chemicals. Crit Rev Toxicol 22: 271-306.

[164] Wells W.W., Yang Y. and Deits T.L. (1993). Thioltransferases. Adv Enzymol Rel Areas Mol Biol 60; 149-201.

[165] Wever R., Oudega B. and van Gelder B.F. (1973). Generation of superoxide radicals during the autoxidation of mammalian oxyhaemoglobin. Biochim Biophys Acta 302: 475-478.

[166] Young J.D., Ellory J.C. and Tucker E.M. (1976). Amino Acid transport in normal and glutathione-deficient sheep erythrocytes. Biochem $J$ 154: 43-48.

[167] Yubisui T., Takeshita M. and Yoneyama Y. (1980). Reduction of methemoglobin through flavin at the physiological concentrations by NADPH-flavin reductase of human erythrocytes. J Biochem 87: 1715-1720.

[168] Zielhuis R.L. and Henderson P.Th. (1986). Definitions of monitoring activities and their relevance for the practice of occupational health. Int Arch Occup Environ Health 57: 249-257. 
Chapter 3

\section{Influence of Glutathione on the Formation of Cysteine Alkylation Products in Human Hemoglobin}

C.T.A. Evelo ${ }^{1}$ and P.Th. Henderson ${ }^{2}$

Department of Toxicology,

University of Nijmegen, Nijmegen, The Netherlands.

1: Present address:

Department of Pharmacology (Tosicology section)

University of Limburg, P.O. Box 616, 6200 MD Maastricht, The Netherlands.

2: Present address:

$M B L-T N O$

P.O. Box 5815, 2280 AA Rijswijk, The Netherlands.

Published in: Toxicology 52, 1988, 177-186. 
Summary. Human blood samples were treated in vitro with iodoacetamide. At low concentrations - less than $1 \mathrm{mM}$ - only a low fraction of the $\beta-93$ cysteine in hemoglobin was alkylated, whereas the alkylating reaction with glutathione was extensive. At higher iodoacetamide concentrations the glutathione pool became exhausted leading to more than proportional increases in the alkylation of the sulfhydryl group in hemoglobin. When diethyl maleate was used as a glutathione depletor prior to incubation with iodoacetamide, low concentrations of iodoacetamide were sufficient to obtain high degrees of hemoglobin sulfhydryl alkylation. $\mathrm{N}$-Ethylmaleimide could not be used as glutathione depletor because the reaction with glutathione appeared to be reversible. The lower reactivity of the thiol group in hemoglobin in comparison with that of glutathione was also found for the isolated biomolecules. The protection of hemoglobin by glutathione present in the human erythrocyte renders the measurement of hemoglobin alkylation less attractive for biological effect monitoring. The sensitivity of such methods is lowered, while the important relation between the alkylation of hemoglobin and that of DNA in the target tissues is affected by interindividual differences in the ratios of the effectiveness of glutathione protection between erythrocytes and target cells.

\section{Introduction}

Many genotoxic chemicals are alkylating agents able to react with biological macromolecules. Their reaction with certain nucleophilic centers in DNA is the most probable cause of their genotoxic activity (Miller and Miller, 1966). Human exposure to these chemicals or to their inactive precursors may give rise to unwanted effects, like an increased risk of cancer. Determination of protein or nucleic acid alkylation products is currently considered as one of the most promising methods for monitoring human exposure to genotoxic chemicals (Leonard et al. 1987; Farmer et al. 1987). Because DNA (rather than protein) is believed to be the primary target of genotoxicity, the determination of protein alkylation products provides only an indirect estimation of the biological effective dose. Nevertheless, the blood proteins hemoglobin and albumin are often chosen for molecular dosimetry because they can be easily obtained while especially hemoglobin has a long lifetime (about 120 days; compared to 20-24 for albumin). A relatively low turnover rate has the advantage that it may provide an integrated index of exposure. Studies on hemoglobin alkylation may be complicated by the fact that hemoglobin is protected against chemically reactive agents by the erythrocyte membrane and by the presence of detoxifying enzyme systems in the erythrocyte. In a previous study (Evelo et al. 1987) we showed that hemoglobin is more effectively alkylated at the same dose of alkylating reagent after purification than in whole blood. In the work reported here we studied the role of glutathione in the protection of hemoglobin. 


\section{Materials and Methods}

\section{Chemicals}

Diethyl maleate (DEM), 5,5'-dithio-bis(2-nitrobenzoic acid) (DTNB), 4,4'-dithiodipyridine (4-PDS), iodoacetamide (IAcA) and N-ethylmaleimide (NEM), were from Janssen Chimica (Beerse. Belgium), glutathione (GSH) was from Boehringer (Mannheim, F.R.G.), Sephadex ${ }^{T M}$ G-25 (medium) was from Pharmacia (Uppsala, Sweden). All other chemicals were of analytical purity. Only freshly deionized distilled water was used.

\section{In Vitro Incubations}

Before each experiment fresh blood samples from a single healthy volunteer were collected in vacutainers, containing ethylenediamine-tetraacetic acid (EDTA) to prevent coagulation. In a shaking waterbath $(210 \mathrm{rev} . / \mathrm{min}$ ) closed sterile vials (I.D. $24 \mathrm{~mm}$, height $55 \mathrm{~mm}$ ) each containing $1.5 \mathrm{ml}$ whole blood or $1.5 \mathrm{ml}$ of a $1 \mathrm{mM}$ solution of purified hemoglobin in PBS (phosphate-buffered saline; $10 \mathrm{mM}$ sodium phosphate $+150 \mathrm{mM}$ sodium chloride $+1 \mathrm{mM}$ EDTA) or $1.5 \mathrm{ml} \mathrm{I} \mathrm{mM}$ GSH in PBS were incubated at $37^{\circ} \mathrm{C}$. Sterile solutions of IACA, DEM or NEM were added in $50 \mu \mathrm{l}$ volumes. NEM and IAcA were dissolved in PBS, DEM in ethanol.

\section{Isolation of Hemoglobin ( $\mathrm{Hb})$}

All purification steps were carried out at $4^{\circ} \mathrm{C}$. To $1.5 \mathrm{ml}$ blood $7.5 \mathrm{ml}$ PBS of $\mathrm{pH} 8.0$ was added. The samples were centrifuged at $1000 \mathrm{~g}$ for $5 \mathrm{~min}$. Serum and buffy coat were removed by careful suction, and the erythrocytes were resuspended with $8 \mathrm{ml}$ PBS. After mixing, the samples were centrifuged again at $1000 \mathrm{~g}$ for $5 \mathrm{~min}$. The supernatant was removed by careful suction, and a few erythrocytes were sacrificed to remove any remaining buffy coat. This washing procedure was repeated twice. The erythrocytes were then layered upon a solution of $30 \%$ sucrose, containing $0.5 \%$ Triton X-100 and $10 \mathrm{mM}$ Tris (pH 9.0), and lysed by centrifugation at $900 \mathrm{~g}$ for $10 \mathrm{~min}$ as described by Scott (1970). To the lower part of the sucrose layer, containing the hemoglobin, 1/10 volume of $1 \mathrm{M}$ sodium chloride was added, to optimize the ionic strength towards the removal of cellular debris (Riggs, 1981), and it was centrifuged once more at $10.000 \mathrm{~g}$ for $15 \mathrm{~min}$. Finally, compounds of low molecular weight were removed from the hemoglobin solution with Sephadex G-25. The hemoglobin obtained in this way was approx. $85 \%$ pure when expressed on a hemoglobin/protein basis. Protein concentrations were determined by the Lowry method (Lowry et al. 1951).

\section{Determination of Free Sulfhydryl Groups in Hemoglobin}

Free sulfhydryl groups in hemoglobin ( $\mathrm{HbSH}$ ) were determined by the procedure of Grassetti and Murray (1967) as modified by Neis et al. (1984). The assay is 
based on spectrophotometrical determination of the formation of 4-thiopyridine in the reaction of 4-PDS with $\mathrm{HbSH}$. Purified $\mathrm{Hb}$ samples were diluted 1:150 with a $100 \mathrm{mM}$ sodium phosphate buffer of $\mathrm{pH} 7.15$ containing $1 \mathrm{mM}$ EDTA. To $3 \mathrm{ml}$ of the diluted $\mathrm{Hb}$ sample $200 \mu \mathrm{l}$ of a $1 \mathrm{mM}$ 4-PDS solution was added. The absurbance at $324 \mathrm{~nm}$ was determined after 40 min incubation in the dark at room temperature. Corrections were made for the background absorptions of $\mathrm{Hb}$ and 1-PDS.

The concentration of $\mathrm{Hb}$ was calculated from the absorption of the Hb blank in the Hb sulfhydryl assay. Alternatively the hemoglobin cyanide procedure of van Kampen and Zijlstra (1961) was used. As reported previously, both methods gave identical results provided $\mathrm{Hb}$ was initially in its reduced state (Evelo et al. 1987).

\section{Determination of Reduced Glutathione}

Immediately after incubation $100 \mu \mathrm{l}$ blood samples were prepared for the determination of GSH, essentially as described by Anderson (1985). The samples were acidified with $500 \mu \mathrm{l}$ of $10 \mathrm{mM}$ hydrochloric acid to reduce GSH oxidation and to inactivate $\gamma$-glutamyl transpeptidase. The erythrocytes were lysed by freezing in a dry-ice acetone bath and subsequent thawing. This procedure was repeated three times. After centrifugation at $10.000 \mathrm{~g}$ for $20 \mathrm{~min}, 500 \mu \mathrm{l}$ of the supernatant were deproteinised with $10 \%(\mathrm{w} / \mathrm{v})$ 5-sulfosalicylic acid and centrifugated again at $10.000 \mathrm{~g}$ for $20 \mathrm{~min}$.

For the GSH assay $200 \mu \mathrm{l}$ of the deproteinised sample and $100 \mu \mathrm{l} 6 \mathrm{mM}$ DTNB in $1 \%$ sodium citrate $(w / v)$ were added to $700 \mu \mathrm{l}$ of a $143 \mathrm{mM}$ sodium phosphate buffer of $\mathrm{pH} 7.5$ containing $6.3 \mathrm{mM}$ EDTA. The amount of 5-thio2-nitrobenzoic acid formed was determined spectrophotometrically at $412 \mathrm{~nm}$. Corrections were made for background absorptions of DTNB and of the blood sample.

\section{Results}

In the figures the amounts of thiol groups present are expressed relative to the initial values. Normal $\mathrm{HbSH}$ values were slightly over 2 (mean: $2.20 \pm 0.06$ ) free sulfhydryl groups per tetrameric $\mathrm{Hb}$ molecule. The Hb concentration in the blood samples used was about $2.5 \mathrm{mM}$. The initial GSH concentrations in blood varied slightly between experiments (mean: $0.7 \pm 0.1$ ). For each incubation the $\mathrm{HbSH}$ and GSH values are the mean of duplicate determinations.

When solutions of $1 \mathrm{mM}$ purified $\mathrm{Hb}$ in PBS were incubated with IAcA for $1 \mathrm{~h}$ alkylation was found to be substantially $\mathrm{pH}$ dependent (Figure 3.1 on the next page). At higher $\mathrm{pH}$ values the extend of alkylation was higher. Analogous results were obtained with solutions of $1 \mathrm{mM}$ GSH in PBS. The reaction with GSH was more effective than with $\mathrm{Hb}$. When a solution of $1 \mathrm{mM}$ purified $\mathrm{Hb}$ in PBS of pH 7.3 was supplied with GSH before $1 \mathrm{~h}$ incubation with IAcA the 


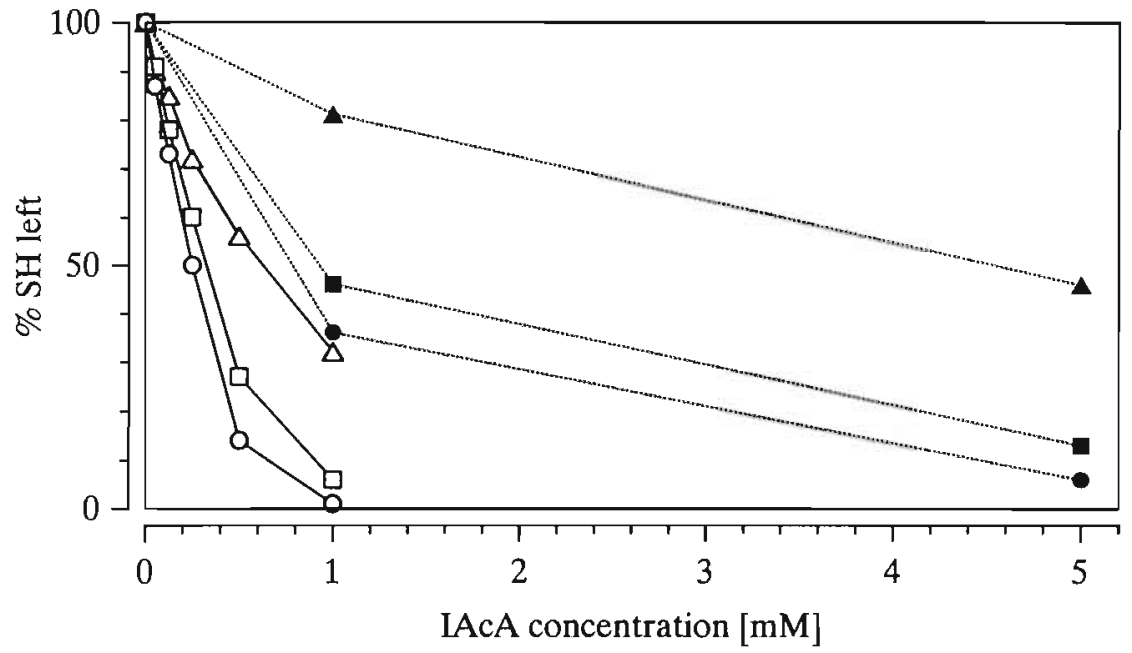

Figure 3.1: Effect of $\mathrm{pH}$ on the disappearance of free sulfhydryl groups from $1 \mathrm{mM}$ purified $\mathrm{Hb}(\cdots \cdots$; closed symbols) and $1.0 \mathrm{mM}$ GSH (-; open symbols) after incubation with IAcA at $37^{\circ} \mathrm{C}$ in PBS for $1 \mathrm{~h} . \Delta=\mathrm{pH} 6.5 ; \square=\mathrm{pH} 7.3 ; \mathrm{O}=$ $\mathrm{pH}$ 8.0. Data are the mean of duplicate determinations. $100 \% \mathrm{HbSH}$ values were $2.12,2.27$ and 2.23 respectively.

extent of SH alkylation was lowered proportional to the amount of GSH added (Table 3.1 on page 49 ). Whereas $33 \%$ of the HbSH was alkylated without GSH addition this percentage was lowered to $12 \%$ when $1 \mathrm{mM}$ GSH was supplied, i.e. under conditions where there is one GSH thiol group present for each IAcA.

Figure 3.2 on the next page shows that in whole blood the reaction of IACA with GSH prevailed over the reaction with $\mathrm{HbSH}$. At IAcA concentrations below $1 \mathrm{mM}$ hardly any reaction occurred with the $\mathrm{Hb}$ thiol, whereas the reaction with GSH was extensive. At higher IAcA concentrations the GSH pool was exhausted and only then the reaction with $\mathrm{HbSH}$ became more important.

In order to verify whether GSH really has the protective action indicated by the above results we looked for an effective GSH depletor which did not react with the SH group of $\mathrm{Hb}$. Figure 3.3 on the following page shows that 15 min incubation with $2.5 \mathrm{mM}$ NEM sufficed to mask nearly all GSH in whole blood. At higher NEM concentrations extensive reaction with $\mathrm{HbSH}$ occurs.

For DEM about $10 \mathrm{mM}$ was needed to obtain the same result. For both substances the specificity was satisfactorily high. Almost $90 \%$ of the $\mathrm{HbSH}$ was still free under conditions where more than $90 \%$ of the GSH had been masked. In subsequent experiments the interaction hetween GSH and the depletors was studied in more detail. The influence of the incubation time on the disappearance of free thiol groups is shown in figure 3.4 on page 50 .

In the presence of $1 \mathrm{mM}$ NEM over $60 \%$ of the initial GSH concentration 


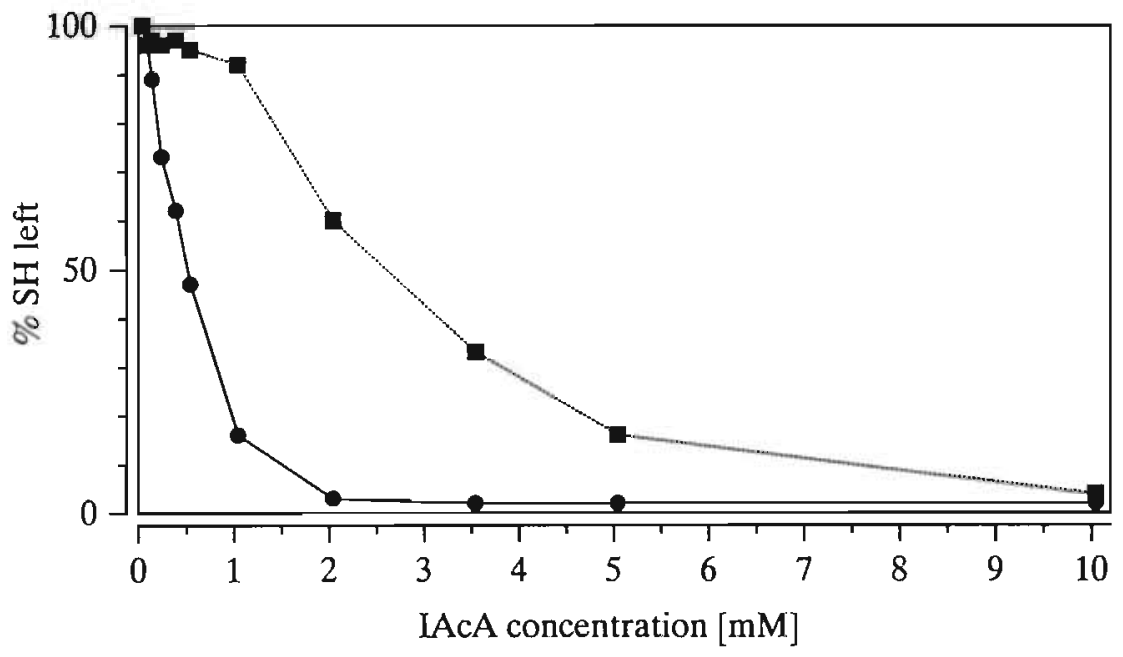

Figure 3.2: Disappearance of free sulfhydryl groups from $\mathrm{Hb}(\cdots \mathbf{\cdots})$ and GSH (- - ) in blood incubated at $37^{\circ} \mathrm{C}$ with LAcA for $1 \mathrm{~h}$. Data are the mean of duplicate determinations. The $100 \% \mathrm{HbSH}$ value was $2.15 ; 100 \% \mathrm{GSH}$ corresponds to $0.86 \mathrm{mM}$.

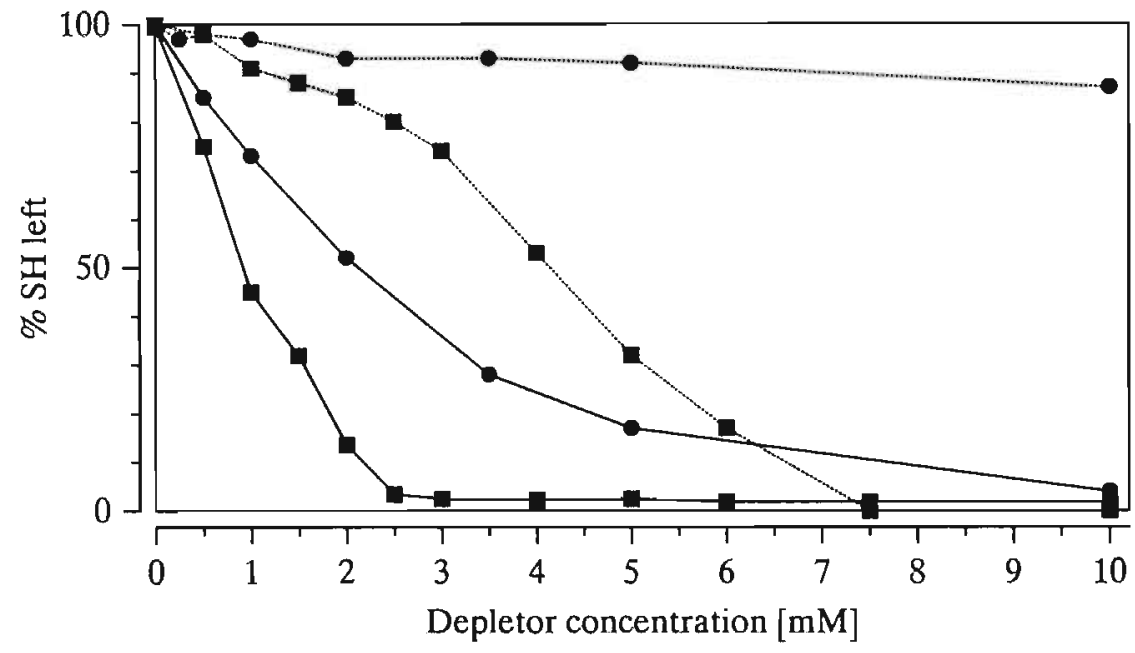

Figure 3.3: Free sulfhydryl groups of Hb $(\cdots \cdots)$ and GSH $(-)$ left after

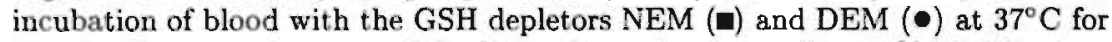
$15 \mathrm{~min}$. Data are the mean of duplicate determinations. The $100 \% \mathrm{HbSH}$ values were 2.18 and 2.29 respectively; $100 \%$ GSH corresponds to 0.72 and $0.82 \mathrm{mM}$ respectively. 


\begin{tabular}{ll}
\hline $\begin{array}{l}\text { GSH added } \\
\mathrm{mM}\end{array}$ & $\begin{array}{l}\text { HbSH left } \\
{[\mathrm{SH} / \mathrm{Hb}]}\end{array}$ \\
\hline- & $2.22^{\mathrm{l}}$ \\
0.00 & 1.41 \\
0.33 & 1.58 \\
0.67 & 1.74 \\
1.00 & 1.84 \\
1.33 & 2.00 \\
\hline
\end{tabular}

1: Initial value without IAcA.

Table 3.1: Disappearance of free sulfhydryl groups from $1 \mathrm{mM}$ purified $\mathrm{Hb}$ incubated with $1 \mathrm{mM}$ IAcA at $37^{\circ} \mathrm{C}$ in PBS of $\mathrm{pH} 7.3$ for $1 \mathrm{~h}$ in the presence of GSH.

was masked after 15 min incubation. Thereupon, increasing amounts of free thiols were found after longer incubation times. After $5 \mathrm{~h}$ incubation the concentration of free thiols had reached again $85 \%$ of the initial value. Similar incubations with $2 \mathrm{mM}$ DEM were also followed for $5 \mathrm{~h}$. The reaction between DEM and GSH was found to be rather slow. Under the conditions used some GSH could still be detected after more than $1 \mathrm{~h}$ incubation time. It was interesting to find that GSH once reacted with DEM did not become available again within the $5 \mathrm{~h}$ period the reaction was followed.

The reaction of IAcA with GSH and $\mathrm{HbSH}$ was also followed during incubation of $0.5 \mathrm{mM}$ IAcA with whole blood over a five hour period (data not shown). The reaction of IAcA with both thiols was found to be fast; maximum thiol depletion was reached within $15 \mathrm{~min}$. No change occurred in the amount of thiol groups detectable after this first $15 \mathrm{~min}$.

Finally, blood samples were incubated with $1 \mathrm{mM}$ IAcA for $1 \mathrm{~h}$ after preincubation with $2 \mathrm{mM} \mathrm{DEM}$ for $2 \mathrm{~h}$ (Figure 3.5 on the following page). In accordance with the results shown in figure 3.4 on the next page, the DEM treatment alone sufficed to mask all GSH while the majority of HbSH groups remained unreacted. As expected, the reaction of $\mathrm{HbSH}$ with IAcA was more pronounced after DEM treatment than without it.

\section{Discussion}

The action of the well-known GSH depletors diethyl maleate (DEM) and Nethylmaleimide (NEM) was found to be different. DEM has been used in vivo (e.g. Yang et al. 1987) and with isolated hepatocytes (Högberg and Kristoferson 


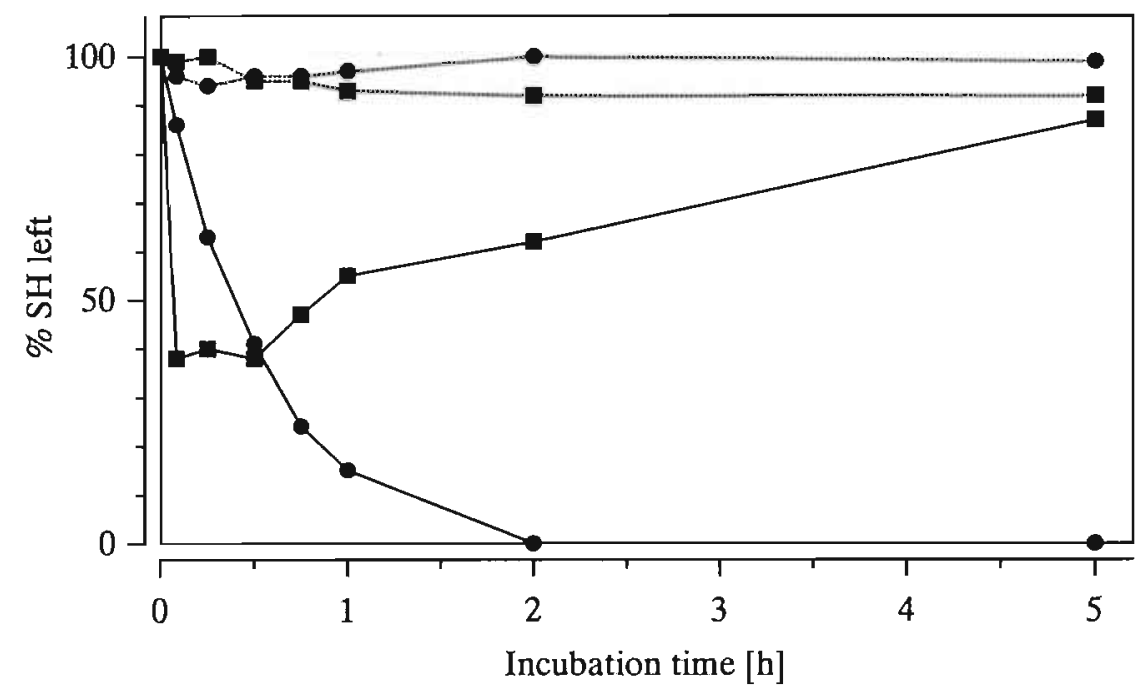

Figure 3.4: Effect of incubation time on the disappearance of free sulfhydryl groups from $\mathrm{Hb}(\cdots)$ ) and $\mathrm{GSH}\left({ }_{-}\right)$after incubation of blood with $1 \mathrm{mM}$ NEM ( $\bullet$ ) and 2 mM DEM ( $\bullet$ ). Data are the mean of duplicate determinations. The initial $\mathrm{HbSH}$ values are 2.23 and 2.30; while the initial GSH values are 0.57 and $0.61 \mathrm{mM}$ respectively.

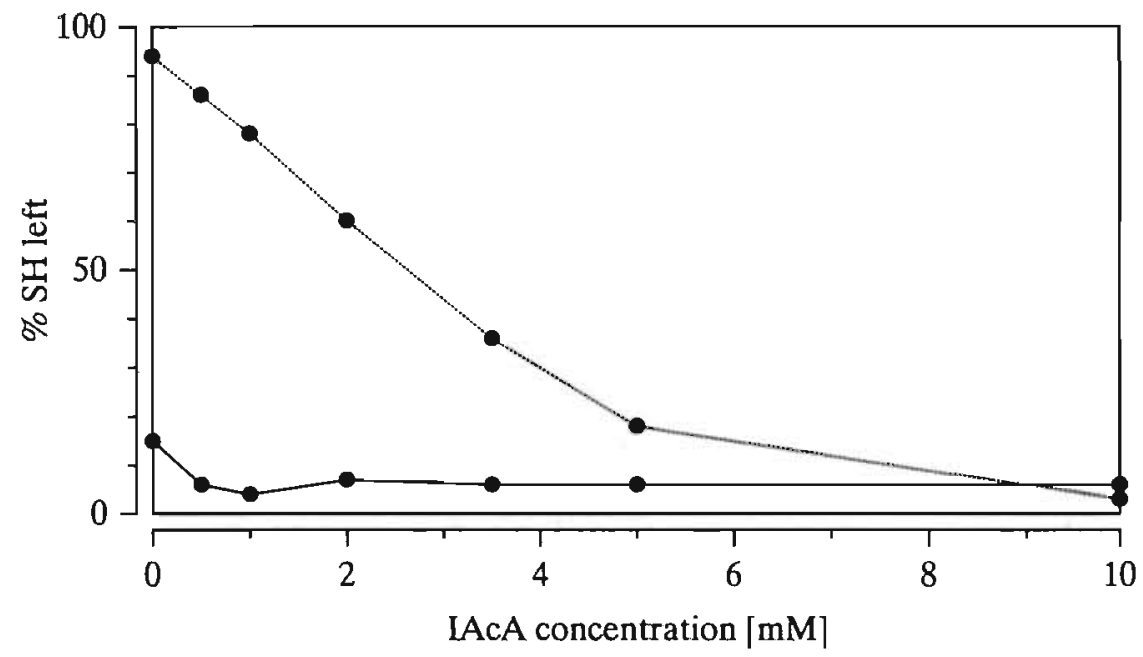

Figure 3.5: Disappearance of free sulfhydryl groups from $\mathrm{Hb}(\cdots)$ and GSH $(\longrightarrow)$ in blood incubated at $37^{\circ} \mathrm{C}$ with IAcA for $1 \mathrm{~h}$ after preincubation with $2 \mathrm{mM}$ DEM for $2 \mathrm{~h}$. Data are the mean of duplicate determinations. The $100 \%$ $\mathrm{HbSH}$ value was 2.19 and the original GSH value (i.e. before preincubation with DEM) was $0.72 \mathrm{mM}$. 
1977). NEM is used to mask reduced GSH before the determination of oxidized glutathione (GSSG) (Tietze 1969). At the low doses needed to obtain specific masking of GSH without affecting the hemoglobin thiol the action of DEM was found to be slow but irreversible. We also found the same slow reaction in in vivo experiments with rats (unpublished). The reaction of NEM was much faster, but the reappearance of free thiol groups during prolonged incubation times indicated that the reaction between NEM and GSH is reversible. We concluded that for the purpose of depleting GSH from whole blood DEM is more useful than NEM. The reversibility of the reaction of NEM with GSH may have some consequences for the application of NEM in the assay of oxidized glutathione as was described by Tietze (1969). Release of GSH during that assay would lead to an overestimation of GSSG, while liberated NEM would disturb the assay because of its ability to inhibit glutathione reductase activity.

The reactivity of the model alkylating agent iodoacetamide towards the thiol group of glutathione was found to be much higher than it's reartivity towards the hemoglobin thiol group. An effective protection of $\mathrm{HbSH}$ by GSH was also found for NEM. The difference in reactivity was not only found in whole blood but also for (the combination of) the isolated components. Therefore, it has to be attributed to differences in direct alkylating activity rather than to glutathione transferase activity. This is in agreement with the very high reactivity towards thiol groups of iodoacetamide. In the case of other, less reactive compounds activity of glutathione transferase is expected to be rate-limiting.

The conformation of the hemoglobin molecule probably lowers the reactivity of the $\beta-93$ thiol group, as it does in extreme for the other two thiol groups, which are only reactive after denaturation of the hemoglobin.

It has been suggested that the alkylation of target nucleophilic centers in DNA may be calculated from the degree of alkylation of other nucleophilic centers in proteins, using the Swain-Scott relationship (e.g. Ehrenberg 1980). The present results show that the nucleophilic strength of centers in biomolecules cannot be derived from the known values for the isolated centers but have to be carefully determined. When conformational effects are the main cause of the lowered activity the apparent nucleophilic strength of the protein centers may even be influencrid by the chemical nature (e.g. their lipophilicity) of the alkylating agents.

In animal studies with various types of radioactively labeled genotoxic compounds the ratio of DNA alkylation product formation in blood cells and binding to hemoglobin was found to be constant over a large dose range (Neumann 1980). The constancy of the ratio of hemoglobin alkylation product formation and the formation of DNA alkylation products in the target tissues, not only at different doses but also between individuals, is an important prerequisite for the estimation of DNA binding on the basis of protein binding measurements. Our results suggest that interindividual differences in the ratio between erythrocyte and target cell glutathione levels (and possibly in glutathione transferase activity) will influence the ratios between erythrocyte and target dose. For individuals with a 
relatively high detoxification activity in their erythrocytes, the erythrocyte dose will be relatively lower at equal target doses. As a consequence equal degrees of hemoglobin alkylation found for individuals with differing ratios of intracellular glutathione levels between erythrocytes and target cells will not correspond with equal degrees of DNA alkylation in those target cells.

The high protection of hemoglobin against alkylation found, renders this protein less promising for the purpose of biological effect monitoring. Since the plasma concentration of GSH is much lower than the erythrocyte concentration measurement of albumin alkylation is expected to be a more sensitive method.

Acknowledgment. The authors are grateful to Dr. Olthuis of the "Bloedbank Nijmegen" for the supply of the blood samples. We thank Lianne de Wijs for her technical assistance. Financial support was given by the General Directorate of Labour, Dutch Ministry of Social Affairs. 


\section{References}

[1] Anderson M.E. (1985). Determination of glutathione and glutathione disulfide in biological samples. Meth Enzymol 113: 548-555.

[2] Bernard A. and R. Lauwerys. Determination of protein nucleic acid adducts. In: A. Aitio, G. Becking, A. Berlin, A. Bernard, V. Foa, D. Kello, E. Krug, A. Léonard and G. Nordberg (Eds). Indicators for assessing exposure and biological effects of genotoxic chemicals. CEC, Brussels, 1988, pp. 61-81.

[3] Ehrenberg L. (1980). Methods of comparing risks of radiation and chemicals. The rad equivalence of stochastic effects of chemicals. In: Radiobiological equivalents of chemical pollutants, International Atomic Energy Agency, Vienna, 1980, p. 11.

[4] Evelo C.T.A., H.J.J.M. Niessen, H.M.J. Roelofs and P.Th. Henderson (1987). Cysteine adducts of human hemoglobin measured by isoelectric focusing in polyacrylamide gels with a non-linear $\mathrm{pH}$ gradient. $J$ Chromatogr 420: 35-42.

[5] Farmer P.B., H-G. Neumann and D. Henschler (1987). Estimation of exposure of man to substances reacting covalently with macromolecules. Arch Toxicol 60: $251-260$.

[6] Grassetti D.R. and J.F. Murray Jr. (1967). Determination of sulfhydryl groups with 2,2'- or 4,4'-dithiopyridine. Arch Biochem Biophys 119: 41-49.

[7] Högberg J. and A. Kristoferson (1977). A correlation between glutathione levels and cellular damage in isolated hepatocytes. Eur J Biochem 74: 77-82.

[8] Kampen van E.J. and W.G. Zijlstra (1961). Standardization of hemoglobinometry. II. The hemiglobincyanide method. Clin Chim Acta 6: 538-544.

[9] Lowry O.H., N.J. Rosebrough, A.L. Farr and R.J. Randall (1951). Protein measurement with the folin phenol reagent. J Biol Chem 193: 265-275.

[10] Miller E. and J.A. Miller (1966). Mechanisms of chemical carcinogenesis: nature of proximate carcinogens and interactions with macromolecules. Pharmacol Rev 18: $805-838$.

[11] Neis J.M., P.J.L. van Gemert, H.M.J. Roelofs and P.Th. Henderson (1984). Disappearance of free SH-groups in hemoglobin of man, rat and rabbit after exposure to alkylating agents. Toxicology 31: 319-327.

[12] Neumann H.G. (1980). Dose-response relationship in the primary lesion of strong electrophilic carcinogens. Arch Toxicol Suppl. 3: 69-77.

[13] Riggs A. (1981). Preparation of blood hemoglobins of vertebrates. Meth Enzymol 76: 5-29.

[14] Scott R.B. (1970). Rapid technique for preparation of hemoglobin solutions for electrophoresis. Am J Clin Path 54: 78-81.

[15] Tietze F. (1969). Enzymic method for quantitative determination of nanogram amounts of total and oxidized glutathione. Anal Biochem 27: 502-522.

[16] Yang D.J., V.J. Teets, B. Bolton, P.I. Brown and G.O. Rankin (1987). Role of glutathione in acute $\mathrm{N}$-(3,5-dichlorophenyl)succinimide-induced nephrotoxicity in Sprague-Dawley and Fischer 344 rats. Toxicology 45: 25-44. 

Chapter 4

Modulation of Glutathione and Glutathione S-Transferase Levels by Cyclophosphamide and Cisplatin

Anita A.M.G. Spooren and Chris T.A. Evelo.

Department of Pharmacology (Toxicology section), University of Limburg, P.O. Box 616, 6200 MD Maastricht, Netherlands.

Submitted for publication. 


\begin{abstract}
In vitro modulation of glutathione (GSH) and glutathione Stransferase (GST) levels by cyclophosphamide (CP) and cisplatin was investigated in rat liver fractions and in human erythrocytes. Some antimetabolites were used for comparison. Incubations with and without a microsomal activating system (MAS) were performed. In microsomal GST studies the microsomes present were completed with a NADPH regenerating system (RS) to attain a complete MAS. Addition of RS alone (i.e. without drug addition) led to an increase in microsomal GST activity. In contrast, addition of MAS alone led to a decrease in liver cytosolic and in erythrocyte GST activity and in GSH concentrations. These effects are probably due to formation of active oxygen species by microsomes in the presence of RS. Supportive evidence for increased active oxygen species availability in erythrocytes was given by methemoglobin formation and lipid peroxidation in erythrocyte incubations with MAS.

The antimetabolites 5-fluorouracil and cytosine arabinoside did not affect the GST activity and GSH concentrations in the different incubations. Methotrexate, another antimetabolite, only inhibited the microsomal GST activity. Cisplatin, an alkylating agent, caused a GST activity decrease in incubations of microsomal and cytosolic liver fractions despite the presence of MAS. In liver cytosolic incubations GSH was depleted by cisplatin. In erythrocyte incubations with cisplatin no significant effects were seen on GST and GSH levels. This suggests that cisplatin is not able to enter the erythrocyte. In the presence of MAS, CP - another alkylating agentgave an almost complete depletion of GSH in rat liver cytosol and in human erythrocytes. Rat liver microsomal GST, diluted rat liver cytosolic GST and GST in human erythrocytes were activated by CP in the presence of MAS. Without dilution cytosolic GST was protected by the high GSH concentration present. Without a complete MAS no significant effects for CP were found.

The modulation of GST activity and GSH concentrations by CP and cisplatin occurred during in vitro incubations where protein synthesis was not possible. This modulation, particularly seen here for GST class $\pi$, could be of importance in relative sensitivity of tumor tissue. Since GSH/GST will detoxify many alkylating antineoplastic agents and organic hydroperoxides formed as a result of chemotherapeutic or radiotherapeutic treatment, changes in GSH and GST levels may influence cytotoxicity and therapeutic efficacy. Therefore, selective GSH depletion in tumor cells by CP and cisplatin in combination with radiation therapy appears to be a promising approach for tumor sensitization.
\end{abstract}

Glutathione S-transferase (GST; EC 2.5.1.18) isoenzymes are found in nearly all tissues and are involved in the detoxification of a variety of noxious xenobiotics, including certain antineoplastic agents and their metabolites [1]. The best known reaction catalyzed by GSTs is the conjugation of electrophiles with the endogenous tripeptide glutathione (GSH), which results in the formation of thio- 
ethers. In general, GSTs are high capacity intracellular binding proteins that, independently of their enzymatic activities, may serve in the storage, transport, or removal of many hydrophobic compounds [2,3]. Additionally, some GST isoenzymes may participate in the repair of oxidative damage to membrane lipids and DNA $[3,4]$. These properties indicate that GSTs function as part of an important cellular defense system against the cytotoxic effects of carcinogenic and antineoplastic agents [5].

Strong evidence exists that elevation of cellular GST and GSH levels, may occur in tumor cells in response to antineoplastic agents. This overexpression of individual GST enzymes and increases in GSH levels are associated with increased cellular resistance to antineoplastic agents $[5,6,7,8,9]$. Recently, much research has focussed on $\pi$ class GSTs. Rat GST P (7-7) was identified as a marker for rat hepatic preneoplastic and neoplastic lesions [10]. In humans GST $\pi$ may be a useful marker not only for various cancers, but also for some high-risk precancerous lesions [8]. Furthermore, absence of GST $\mu$, another soluble GST isoenzyme, has been suggested as a possible marker for greater susceptibility to lung cancer among smokers. Hereditary differences in the expression of this form are due to deletion of the gene [11]. Apparently GSTs and GSH levels do not completely account for the resistance patterns observed in human tumors and cell lines selected for resistance to cytotoxic agents [6]. Nevertheless, further study of changes in GST and GSH levels after exposure to antineoplastic agents may lead to a better insight in the process of drug resistance in tumor cells.

GSH can protect cells against electrophiles and free radicals $[12,13]$. Since formation of radicals is characteristic of ionizing radiation, GSH may play an important role in radiosensitivity. Potential mechanisms of radioprotection by GSH include radical scavenging, and hydrogen donation to molecules (DNA), and reduction of peroxides and maintenance of protein thiols [13,14]. Radioprotection by GSH is not effective under aerobic conditions because the intracellular GSH concentration is not able to compete successfully with oxygen for radiationinduced radicals. Under hypoxic conditions GSH becomes more competitive and GSH depletion will have an effect on radiosensitivity. Since hypoxic cells are a characteristic feature of tumors, depletion of GSH in combination with radiation therapy can be a promising strategy for selective tumor sensitization. However, it may not always be possible to achieve selective depletion of GSH in tumors because of toxicity occurring in normal tissues [14].

In principle, changes in GSH concentrations and in GST abundance, isoenzyme expression and enzyme activity can all be used for human exposure monitoring, as long as the chosen parameter is accessible to experimental determination [15]. For practical monitoring purposes, blood is the most easily available biomatrix containing GST and GSH. Ansari et al. [16] have shown that GST activity in human erythrocytes is inhibited by the industrial chemicals acrolein, propylene oxide, styrene oxide, ethylene dibromide and ethylene dichloride. Kilpikari and Savolainen [17] found a decrease in GST activity in the erythrocytes of workers 
exposed to hot rubber fumes. We previously described [18] a decrease in GST activity in erythrocytes, as well as a depletion of GSH in whole blood after occupational exposure to 1,3-dichloropropene. Furthermore, GST activity in human erythrocytes and GSH concentrations in whole blood were decreased shortly after long distance running and are increased after several months of endurance training [19] and GST activities are decreased in erythrocytes of miners with an early stage of coal miners pneumoconiosis [20].

Modulation of the GSH/GST system by different antineoplastic agents was tested in vitro in rat liver fractions and in human erythrocytes. Erythrocytes were chosen because they contain the same class of GST isoenzyme ( $\pi$ class) as many tumors have in overexpression and because they are easily available. Liver fractions were chosen because this organ is susceptible to reactive metabolites due to a very high phase I metabolic activity [21] and because it has a completely different GST isoenzyme pattern (mainly $\alpha$ class) from that of erythrocytes (only $\pi$ class) [2]. In this study five antineoplastic agents were tested which are widely used in the treatment of various cancers. Cyclophosphamide (CP) and cisplatin (c-DDP, cis-diamminedichloroplatinum(II)) are alkylating agents and therefore effects on the GSH/GST system by these two agents were expected in advance. CP is a biologically inactive nitrogen mustard analogue that requires hydroxylation by hepatic microsomal enzymes to attain its alkylating activity [22]. The rate of CP metabolism is increased in rats pretreated with phenobarbital [23]. Three antineoplastic agents belonging to the group of antimetabolites were used as controls. Cytosine arabinoside (Ara-C, cytosine $\beta$-D-arabinofuranoside), and 5Huorouracil (5-FU) are pyrimidine antagonists and methotrexate (MTX) is a folic acid antagonist.

\section{Materials and Methods}

\section{Analytical methods}

Chemicals. 1-Chloro-2,4-dinitrobenzene (CDNB), cyclophosphamide (CP, CAS: 6055-19-2), cytosine $\beta$-D-arabinofuranoside (Ara-C, CAS: 147-94-4), 5,5'dithiobis-(2-nitrobenzoic acid) (DTNB), dithiothreitol (DTT), 5-fluorouracil (5-FU, CAS: 51-21-8), glucose 6-phosphate (G6P), glucose 6-phosphate dehydrogenase (G6PDH, EC 1.1.1.49), reduced glutathione (GSH), glutathione reductase (EC 1.6.4.2.), 3-hydroxyacetanilide (3-HAA, CAS: 621-42-1), NADP and the reduced form NADPH were obtained from Sigma Chemical Co. (St. Louis, MO, USA). Phenobarbital was from OPG Farma (Utrecht, NL) and 2-thiobarbituricacid (TBA) was from Merck (Darmstadt, FRG). cis-Diamminedichloroplatinum (II) (c-DDP, CAS: 15663-27-1) and methotrexate (MTX, CAS: 59-05-2) were gifts from Multipharma B.V. (Weesp, NL). All other chemicals and solvents were of analytical quality. Only microfiltrated deionized water was used. 
Animals. Male Brown Norway rats (BN/M) weighing 250-280 g were used. Housing was as previously described [24]. A non-albino strain was chosen as there are some indications that biotransformation of xenobiotics is lower in albino strains [25]. Prior to the preparation of microsomes and cytosol, phenobarbital $\left(1 \mathrm{~g} \cdot \mathrm{l}^{-1}\right)$ was added to their drinking water for one week.

Preparation of rat liver microsomes and cytosol. The basic procedure for preparation of rat liver microsomes and cytosol was described previously [26]. To make sure that the microsomal fraction was free of any cytosolic GST and GSH, the pellet was washed with four volumes of ice-cold sodium/potassium phosphate buffer (50 mM, pH 7.4). Microsomal activating system (MAS) was composed of microsomes (final protein concentration $1 \mathrm{mg} \cdot \mathrm{ml}^{-1}$ ) and a NADPH regenerating system (RS; $0.5 \mathrm{mM}$ NADP, $5.0 \mathrm{mM} \mathrm{MgCl}_{2}, 5.0 \mathrm{mM} \mathrm{G6P}$ and $1.0 \mathrm{U} / \mathrm{ml} \mathrm{G6PDH}$ ). In microsomal GST experiments the microsomes present were completed with RS to attain a complete MAS. The protein content in both fractions was determined according to Lowry et al. [27].

Preparation of erythrocytes. Human blood was obtained from the Red Cross Blood Bank "Zuid Limburg" (NL), collected in $10 \mathrm{ml}$ sterile vacuum tubes containing $\mathrm{K}_{3}$ EDTA as an anticoagulant and stored at $4^{\circ} \mathrm{C}$ until the next day. Samples were controlled for viral infections before use. Samples of 3 to 5 persons were pooled. Erythrocytes were separated from plasma and washed three times with phosphate buffered saline (PBS; $15 \mathrm{mM}$ sodium/potassium phosphate $+130 \mathrm{mM}$ sodium chloride, $\mathrm{pH}$ 7.4) and diluted in PBS to a final hemoglobin concentration of about $100 \mathrm{~g} \cdot \mathrm{l}^{-1}$. The hemoglobin concentrations were determined with the hemoglobin cyanide procedure described by Van Kampen and Zijlstra [28].

Procedure. Three different GST sources were used: human erythrocytes (final hemoglobin concentration $23 \mathrm{~g} \cdot \mathrm{I}^{-1}$ ), rat liver cytosol (final protein concentration $1.7 \mathrm{mg} \cdot \mathrm{ml}^{-1}$ in normal and $0.2 \mathrm{mg} \cdot \mathrm{ml}^{-1}$ in diluted samples) and rat liver microsomes (final protein concentration $1.0 \mathrm{mg} \cdot \mathrm{ml}^{-1}$ ). These sources were suspended in $100 \mathrm{mM}$ sodium/potassium phosphate buffer ( $\mathrm{pH} 7.4$ ) except the erythrocyte incubations with c-DDP, which were suspended in PBS to prevent dissociation of the two chloride ligands in the extracellular matrix [29]. Incubations were performed both with and without MAS. The five drugs were used with a final concentration between 0.25 and $2 \mathrm{mM}$. The complete test system without the addition of a drug was preincubated for 5 min at $37^{\circ} \mathrm{C}$ in a shaking water bath $(80 \mathrm{rpm})$. After that, $1 \mathrm{ml}$ drug in the appropriate buffer was added and incubated for $1 \mathrm{~h}$ (final volume test system $3 \mathrm{ml}$ ). After incubation with erythrocytes, red cells were washed three times with PBS and packed by centrifugation $(5 \mathrm{~min}, 2000$ $x \mathrm{~g}$ ). When applicable GSH concentrations and GST activities were determined in the same incubations. All experiments were performed three times on different days and each day all incubations were performed in triplicate.

Determination of GST. For the determination of GST activity in erythrocytes af- 
ter $1 \mathrm{~h}$ incubation, the packed red cells were lysed by addition of three volumes of ice-cold water containing $1.4 \mathrm{mM}$ neutral DTT as previously described [18]. Determination of rat liver microsomal and cytosolic GST activity was performed after appropriate dilution in $100 \mathrm{mM}$ potassium phosphate buffer ( $\mathrm{pH} 6.5)$. Since in the normal incubations with a final cytosolic protein concentration of $1.7 \mathrm{mg} \cdot \mathrm{ml}^{-1}$, the cytosolic GST activity strongly exceeds the microsomal GST activity (approximately $95 \%$ ), it was not necessary to remove the microsomes from these samples. When diluted cytosol with a final protein concentration of $0.2 \mathrm{mg} \cdot \mathrm{ml}^{-1}$ was used the microsomes were sedimented from the cytosolic fraction by centrifugation at $4^{\circ} \mathrm{C}$ for $40 \mathrm{~min}$ at $110,000 \mathrm{x} \mathrm{g}$. The clear supernatant was used for the determinations. The activity towards CDNB was determined as described by Habig and Jakoby [30]. The activities were measured at $25^{\circ} \mathrm{C}$ unless stated otherwise. Units of GST activity are defined as $1 \mu \mathrm{mol}$ product produced per min.

Determination of GSH. For the determination of GSH in packed red cells and in rat liver cytosol after $1 \mathrm{~h}$ incubation, protein was precipitated by the addition of an equal volume of $8 \%(\mathrm{w} / \mathrm{v})$ trichloroacetic acid (TCA). To determine the GSH concentration in the erythrocyte incubations, hemoglobin was measured in the complete test system and in the packed red cells to evaluate the degree of concentration. Total GSH was determined in the TCA supernatants after dilution (9 fold) with $100 \mathrm{mM}$ sodium/potassium phosphate buffer ( $\mathrm{pH} 7.4$ ) with the cyclic oxidation-reduction method essentially as described by Anderson [31].

Determination of methemoglobin formation. The percentage methemoglobin present in hemolysates was calculated from the absorbance change after addition of $\mathrm{KCN}$ compared to the same change in a sample fully converted to the methemoglobin form by the addition of $\mathrm{K}_{3} \mathrm{Fe}(\mathrm{CN})_{6}$ [32]

Determination of lipid peroxidation products. The formation of lipid peroxidation products was assessed by determination of the amount of thiobarbituric-acid reactive substance present in the supernatant and was expressed as malondialdehyde (MDA) equivalents [33]. After incubation and centrifugation $(2000 \times \mathrm{g}$ ), the supernatant was collected and protein was precipitated by the addition of an equal volume of $10 \%$ (w/v) TCA. $1.5 \mathrm{ml}$ of the supernatant was added to $1 \mathrm{ml} 1 \%(\mathrm{w} / \mathrm{v})$ TBA solution in $5 \mathrm{mM} \mathrm{NaOH}$ and heated in a boiling water bath for $15 \mathrm{~min}$. After forced cooling $1.25 \mathrm{ml}$ butanol was added, and the two phases were thoroughly mixed. The absorbance of the butanol phase at $535 \mathrm{~nm}$ was determined and corrected for the background absorbance at $590 \mathrm{~nm}$.

\section{Statistical analyses}

Significance of concentration dependent changes were analyzed separately for both metabolizing systems by linear regression using a model including day of experiment and drug concentration as explanatory variables. Using this model, we 
tested whether slopes of parameter changes versus concentration were significant for each of the metabolizing systems, correcting for the day of the experiment. Effects were considered significant when the $p$ value was smaller than 0.05 and when the effects were greater than $2.5 \%$ per $\mathrm{mM}$. In microsomal incubations with CP and RS and in erythrocyte incubations with 3-HAA and MAS a clear saturation effect was found, in these cases no statistical analyses were performed. The regression model used, will correct for interexperiment variations in control values. Therefore, the standard errors (SE) shown in the figures are given as the standard error of the mean difference (SEMD) between sample value and its control (i.e. the corresponding value at concentration 0 ).

Difference between control values (i.e. without drug addition) of the two different metabolizing systems were analyzed using Wilcoxon's matched pair analysis with matches for control values from the same day.

The coefficients for day to day variation were calculated as (SD/mean) $100 \%$ for control GST activities and GSH concentrations. For the liver microsomal GST activity this was $4 \%$ of the control value $\left(0.125 \mathrm{U} \cdot \mathrm{mg}\right.$ protein $\left.{ }^{-1}\right)$, for liver cytosolic GST activity $10 \%$ (of $4.11 \mathrm{U} \cdot \mathrm{mg}$ protein ${ }^{-1}$ ) and for erythrocyte' GST ar:tivity $16.7 \%$ (of $5.20 \mathrm{U} \cdot \mathrm{g} \mathrm{Hb}^{-1}$ ). For the liver cytosolic GSH concentration this was $11.8 \%$ of the control value $(160.5 \mu \mathrm{M})$ and for erythrocyte GSH concentration $15.7 \%$ (of $145.7 \mu \mathrm{M}$ ).

\section{Results}

\section{Microsomal incubations}

Changes in rat liver microsomal GST activities in incubations with CP or c-DDP, with and without RS, are shown in figure 4.1. GST activities in equivalent incubations with MTX, 5-FU or Ara-C are given in table 4.1. Addition of RS alone (i.e. without drug addition) led to an increase of about $7 \%$ in microsomal GST activity ( $p=0.0002, n=15)$. For CP there was no significant change in GST activity in the absence of RS. In the presence of such a system the GST activity increased from $0.134 \mathrm{U} \cdot \mathrm{mg}$ protein $^{-1}$ (SE 0.001 ) without CP to 0.155 $\mathrm{U} \cdot \mathrm{mg}$ protein $^{-1}$ (SE 0.004) at a CP concentration of $0.5 \mathrm{mM}$. Above this concentration no further increase in liver microsomal (GST activity was seen for CP concentrations up to $2 \mathrm{mM}$. In c-DDP incubations a concentration dependent decrease in liver microsomal GST activity was found both with and without RS. The decreases amounted to $0.030 \mathrm{U} \cdot \mathrm{mg} \mathrm{protein}^{-1}$ (SEMD 0.002) and $0.018 \mathrm{U} \cdot \mathrm{mg}$ protein $^{-1}$ (SEMD 0.006) at $2.0 \mathrm{mM}$ c-DDP with RS and without RS respectively. Significant GST decrease also occurred for MTX where the decreases amounted to $0.008 \mathrm{U} \cdot \mathrm{mg}$ protein ${ }^{-1}$ per $\mathrm{mM} \mathrm{MTX}$ and $0.011 \mathrm{U} \cdot \mathrm{mg}_{\text {protein }}{ }^{-1}$ per $\mathrm{mM} \mathrm{MTX}$ with RS and without RS respectively. Addition of 5-FU and Ara-C did not affect the liver microsomal GST activity, despite the presence of RS. 


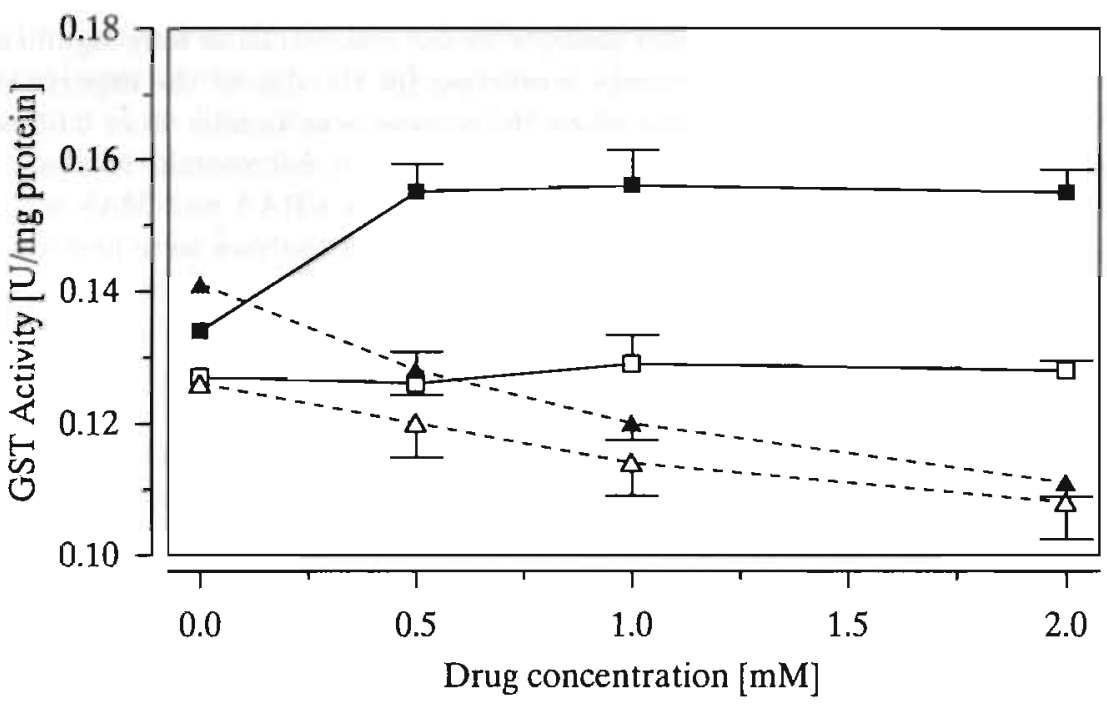

Figure 4.1: Effects of CP $(\square)$ and c-DDP $(\triangle)$ on the GST activity in rat liver microsomes after incubation $\left(1 \mathrm{~h}, 37^{\circ} \mathrm{C}\right.$ ) with (closed symbols) and without (open symbols) a NADPH regenerating system (RS). The error bars represent the standard error of the mean difference (SEMD) between sample value and its control. GST inhibition was significantly related to the c-DDP concentration, both with $\operatorname{RS}(p<0.0001)$ and without RS $(p=0.0004)$.

\section{GST Activity (U.mg protein ${ }^{-1}$ ) in Rat Liver Microsomes}

\begin{tabular}{lccc}
\hline & \multicolumn{3}{c}{ Drug concentration (mM) } \\
\cline { 2 - 4 } Drug type & 0.0 & 1.0 & 2.0 \\
\hline MTX (RS) $^{a}$ & 0.123 & $0.119(0.004)$ & $0.108(0.006)$ \\
MTX $^{a}$ & 0.112 & $0.095(0.004)$ & $0.090(0.004)$ \\
5-FU (RS) & 0.125 & $0.133(0.004)$ & $0.127(0.004)$ \\
5-FU & 0.120 & $0.125(0.002)$ & $0.121(0.004)$ \\
Ara-C (RS) & 0.131 & $0.124(0.003)$ & $0.130(0.002)$ \\
Ara-C & 0.124 & $0.127(0.003)$ & $0.121(0.001)$
\end{tabular}

a. GST inhibition was significantly related to the MTX concentration, both with RS $(p=0.014)$ and without RS $(p=0.004)$.

Table 4.1: Effects of MTX, 5-FU and Ara-C on the GST activity in rat liver microsomes after incubation $\left(1 \mathrm{~h}, 37^{\circ} \mathrm{C}\right)$ with and without a NADPH regenerating system (RS). Values represent the mean followed by the standard error of the mean difference (SEMD) between sample value and its control in brackets. 


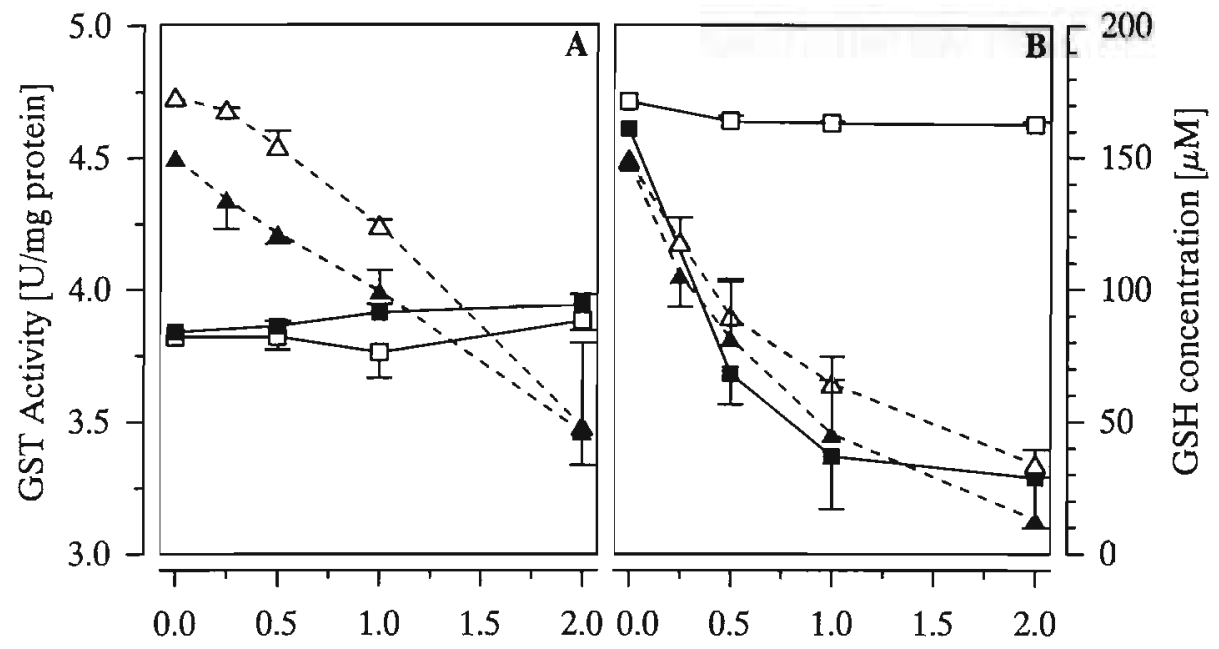

Figure 4.2: Effects of CP $(\square)$ and c-DDP $(\triangle)$ on the GST activity (A) and GSH concentration (B) in rat liver cytosol after incubation $\left(1 \mathrm{~h}, 37^{\circ} \mathrm{C}\right)$ with (closed symbols) and without (open symbols) microsomal activating system (MAS). The error bars represent the standard error of the mean difference (SEMD) between sample value and its control. GST inhibition and GSH depletion were significantly related to the c-DDP concentration; $p<0.0001$ for all the c-DDP effects. For CP only the GSH depletion in incubations with MAS was significantly related to the CP concentration; $(p=0.004)$

\section{Cytosolic incubations}

Rat liver cytosolic GST (figure 4.2A) and GSH (figure 4.2B) values were determined in incubations with CP or c-DDP, with and without MAS. GST activities and GSH concentrations in equivalent incubations with MTX, 5-FU or Ara-C are given in table 4.2. In contrast to the increase seen in microsomal incubations after RS addition alone, here, addition of MAS alone (i.e. without drug addition) led to a decrease of about $9 \%$ in liver cytosolic GST activity $(p=0.0004, n=18)$. Addition of MAS alone also led to a decrease of about $6 \%$ in GSH concentration $(\mathrm{p}=0.005, \mathrm{n}=12)$. In $\mathrm{c}-\mathrm{DDP}$ incubations a concentration dependent GST activity decrease was found of about $0.5 \mathrm{U} \cdot \mathrm{mg}$ protein $^{-1}$ per mM c-DDP both with and without MAS. Ara-C incubations with MAS resulted in a slight increase of GST activity (0.12 U.mg protein ${ }^{-1}$ per mM Ara-C). In incubations without MAS Ara$\mathrm{C}$ did not affect the GST activity. CP, MTX and 5-FU had no effect on the liver cytosolic GST activity despite the presence of MAS.

As CP and MTX were found to have an effect on the microsomal GST activity, we wondered whether a possible effect of CP and MTX on cytosolic GST might be prevented by the high GSH concentrations present. Therefore, incuba- 


\begin{tabular}{|c|c|c|c|}
\hline \multicolumn{4}{|c|}{ GST Activity (U.mg protein ${ }^{-1}$ ) in Rat Liver Cytosol } \\
\hline & \multicolumn{3}{|c|}{ Drug concentration (mM) } \\
\hline Drug type & 0.0 & 1.0 & 2.0 \\
\hline MTX (MAS) & 3.95 & $4.03(0.14)$ & $4.01(0.06)$ \\
\hline MTX & 4.26 & $4.35(0.01)$ & $4.24(0.06)$ \\
\hline $5-\mathrm{FU}(\mathrm{MAS})$ & 3.57 & $3.42(0.10)$ & $3.58(0.15)$ \\
\hline $5-\mathrm{FU}$ & 3.68 & $3.85(0.01)$ & $3.75(0.09)$ \\
\hline Ara-C $(\mathrm{MAS})^{a}$ & 3.95 & $4.07(0.01)$ & $4.19(0.04)$ \\
\hline Ara-C & 4.26 & $4.32(0.11)$ & $4.42(0.08)$ \\
\hline \multicolumn{4}{|c|}{ GSH Concentration $(\mu \mathrm{M})$ in Rat Liver Cytosol } \\
\hline & \multicolumn{3}{|c|}{ Drug concentration (mM) } \\
\hline Drug type & 0.0 & 1.0 & 2.0 \\
\hline MTX (MAS) & 132.3 & $133.9(4.5)$ & $135.6(2.9)$ \\
\hline MTX & 146.8 & $142.9(3.0)$ & $146.1(2.7)$ \\
\hline 5-FU (MAS) & 163.3 & $151.9(3.2)$ & $162.7(2.2)$ \\
\hline 5-FU & 175.4 & $177.7(15.2)$ & $162.6(12.2)$ \\
\hline Ara-C (MAS) & 132.3 & $126.9(4.9)$ & $130.2(3.8)$ \\
\hline Ara-C & 146.8 & $143.9(3.5)$ & $141.2(3.2)$ \\
\hline
\end{tabular}

a. GST inhibition in incubations with Ara-C and MAS was significantly related to the Ara-C concentration $(p=0.0002)$.

Table 4.2: Effects of MTX, 5-FU and Ara-C on the GST activity and GSH concentration in rat liver cytosol after incubation $\left(1 \mathrm{~h}, 37^{\circ} \mathrm{C}\right)$ with and without microsomal activating system (MAS) Values represent the mean followed by the standard error of the mean difference (SEMD) between sample value and its control in brackets.

tions with diluted liver cytosol (final protein concentration $0.2 \mathrm{mg} \cdot \mathrm{ml}^{-1}$ ) were performed. In these incubations the remaining GSH concentration did not exceed the $15 \mu \mathrm{M}$ level. The results of these incubations are given in table 4.3. Like what was found for the undiluted cytosol incubations, addition of MAS alone (i.e. without drug addition) had an inhibitory effect on the GST activity. This effect was stronger in the diluted cytosol incubations. A GST activity decrease of about $17 \%(p=0.03, n=6)$ was seen in the diluted cytosol incubations compared to a GST decrease of about $4 \%(p=0.03, n=12)$ in the concentrated cytosol incubations. The GST activity in incubations with CP and MAS actually increased from 
GST Activity (U.mg protein ${ }^{-1}$ ) in Diluted Rat Liver Cytosol

\begin{tabular}{|c|c|c|c|c|}
\hline \multirow[b]{2}{*}{ Drug type } & \multicolumn{4}{|c|}{ Drug concentration (mM) } \\
\hline & 0.0 & 0.5 & 1.0 & 2.0 \\
\hline $\mathrm{CP}(\mathrm{MAS})^{a}$ & 4.56 & $5.56(0.06)$ & $5.63(0.13)$ & $5.72(0.05)$ \\
\hline $\mathrm{CP}$ & 5.68 & $5.66(0.04)$ & $5.67(0.13)$ & $5.77(0.14)$ \\
\hline MTX (MAS) & 3.59 & $-b$ & $3.70(0.08)$ & $3.46(0.02)$ \\
\hline MTX & 4.22 & - & $4.06(0.04)$ & $4.34(0.14)$ \\
\hline
\end{tabular}

a. Increase of GST activity in incubations with CP and MAS was significantly related to the CP concentration $(p=0.0007)$.

b. Not determined

Table 4.3: Effects of CP and MTX on the GST activity in diluted rat liver cytosol (final protein concentration $\left.0.20 \mathrm{mg} \cdot \mathrm{ml}^{-1}\right)$ after incubation $\left(1 \mathrm{~h}, 37^{\circ} \mathrm{C}\right.$ ) with and without microsomal activating system (MAS). GST activity in the CP incubates was measured at $37^{\circ} \mathrm{C}$. Values represent the mean followed by the standard error of the mean difference (SEMD) between sample value and its control in brackets.

$4.56 \mathrm{U} \cdot \mathrm{mg} \mathrm{protein}^{-1}$ (SE 0.14) without CP to $5.72 \mathrm{U} \cdot \mathrm{mg} \mathrm{protein}^{-1}$ (SE 0.12) at $2.0 \mathrm{mM} \mathrm{CP}$ and was linear over the whole range of concentrations tested. However, the activity value at $2.0 \mathrm{mM} \mathrm{CP}$ with MAS did not exceed the control value without MAS (5.68 U.mg protein ${ }^{-1}$ (SE 0.14)). Without MAS there was no significant change in GST activity for CP. MTX had still no effect on the liver cytosolic GST activity despite the presence of MAS.

GSH was concentration dependently depleted in the non-diluted incubations by CP after metabolic activation and by c-DDP, both with and without MAS. In al these incubations, a GSH depletion of about $80 \%$ was found. CP incubations without MAS resulted in a minor GSH depletion $(3.7 \mu \mathrm{M}$ per $\mathrm{mM}$ $\mathrm{CP} ; \mathrm{p}=0.02$ ). Addition of 5-FU, MTX or Ara-C had no significant effect on the GSH concentration, despite the presence of MAS.

\section{Erythrocytes incubations}

Human erythrocyte GST (figure 4.3A) and GSH (figure 4.3B) values were determined in incubations with CP or c-DDP, with and without MAS. GST activities and GSH concentrations in equivalent incubations with $\mathrm{MTX}, 5 \mathrm{FU}$ or Ara-C are given in table 4.4. Similar to the liver cytosolic incubations, addition of MAS alone (i.e. without drug addition) led to a decrease of about $30 \%$ in erythrocyte GST activity and of about $19 \%$ in GSH concentration ( $p=0.0001$ and $p=0.0002$ respectively, $n=15$ ). No significant change in GST activity was found in CP incubations without MAS. In the presence of MAS the GST activity actually increased from $4.31 \mathrm{U} \cdot \mathrm{g} \mathrm{Hb}^{-1}$ (SE 0.58) without $\mathrm{CP}$ to $5.59 \mathrm{U} \cdot \mathrm{g} \mathrm{Hb}^{-1}$ (SE 0.76) at $2.0 \mathrm{mM}$ 


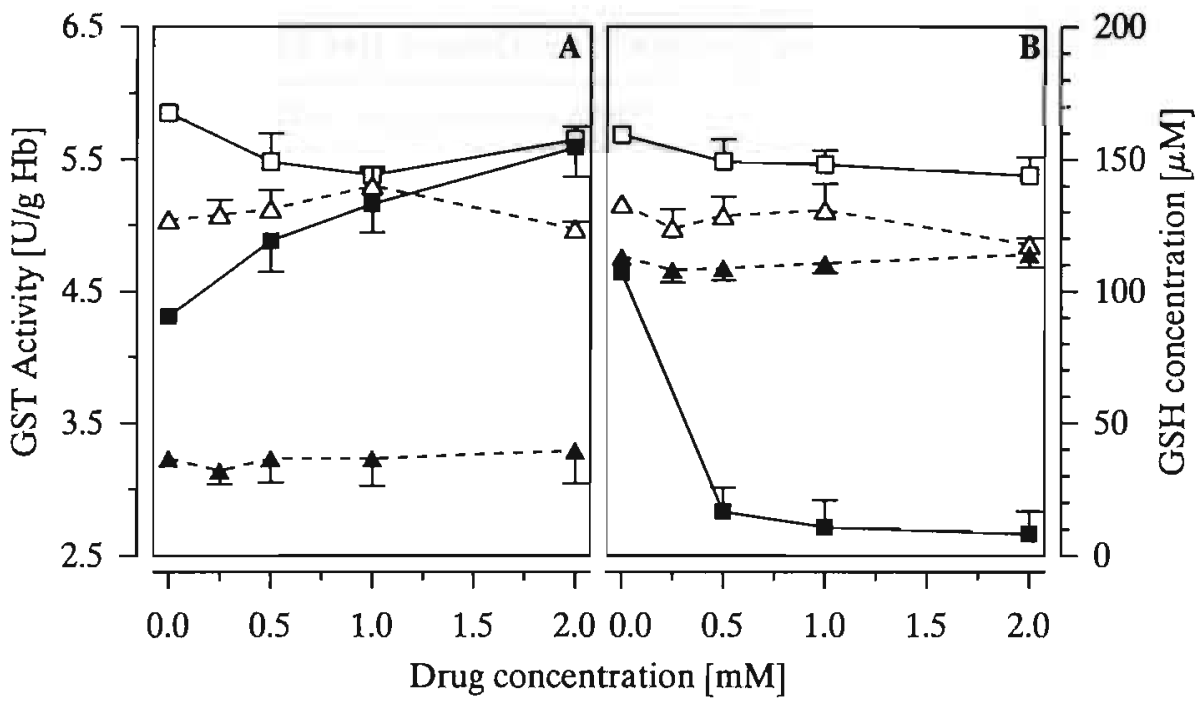

Figure 4.3: Effects of CP ( $\square$ ) and c-DDP $(\triangle)$ on the GST activity (A) and GSH concentration $(B)$ in human erythrocytes after incubation $\left(1 \mathrm{~h}, 37^{\circ} \mathrm{C}\right)$ with (closed symbols) and without (open symbols) microsomal activating system (MAS). The error bars represent the standard error of the mean difference (SEMD) between sample value and its control. Increase of GST activity and GSH depletion in incubations with CP and MAS were significantly related to the CP concentration $(p=0.0004$ and $p=0.02$ respectively).

$\mathrm{CP}$ and was linear over the whole range of concentrations tested. Here again, the activity value at $2.0 \mathrm{mMCP}$ with MAS did not exceed the control value without MAS (5.85 U.g $\mathrm{Hb}^{-1}$ (SE 0.59)). CP after metabolic activation depleted the GSH almost completely at a CP concentration of $0.5 \mathrm{mM}$ (from $107.1 \mu \mathrm{M}$ (SE 8.2) without $\mathrm{CP}$ to $16.6 \mu \mathrm{M}$ (SE 2.8) at $0.5 \mathrm{mM} \mathrm{CP}$ ). Although the decrease was clearly not linear, linear regression still showed a significant GSH depletion at increasing CP concentrations (40.8 $\mu \mathrm{M}$ per mM CP). In CP incubations without MAS a small depletion in GSH was found $(6.8 \mu \mathrm{M}$ per $\mathrm{mM} \mathrm{CP} ; \mathrm{p}=0.04)$. In both types of incubations with c-DDP no effects were found on the GST activity and GSH concentrations. However, under the same conditions, GST inhibition values of $29 \%$ per mM c-DDP $(p=0.0001)$ and $15 \%$ per mM c-DDP $(p=0.0001)$ were observed in hemolysate and hepatocytes respectively. GSH was also concentration dependently depleted in hemolysate and hepatocytes ( $46 \%$ per mM c-DDP $(p=0.0001)$ and $38 \%$ per $\mathrm{mM} c-\mathrm{DDP}(\mathrm{p}=0.0001)$ respectively). MTX, Ara-C and 5 -FU had no effect on the erythrocyte GST activity and GSH concentrations despite the presence of MAS.

Since the increase in GST by addition of CP did not lead to values above the control value without MAS it is possible that the effects observed are not caused 


\begin{tabular}{lccc}
\hline \multicolumn{3}{c}{ GST Activity $\left(\mathbf{U} \cdot g \mathbf{H b}^{-1}\right)$ in Human Erythrocytes } \\
\hline & \multicolumn{3}{c}{ Drug concentration (mM) } \\
\cline { 2 - 4 } Drug type & 0.0 & 1.0 & 2.0 \\
\hline MTX (MAS) & 3.61 & $3.50(0.28)$ & $3.37(0.25)$ \\
MTX & 4.89 & $4.82(0.25)$ & $4.89(0.32)$ \\
5-FU (MAS) & 3.42 & $3.18(0.09)$ & $3.22(0.07)$ \\
5-FU & 4.92 & $4.62(0.14)$ & $4.62(0.18)$ \\
Ara-C (MAS) & 3.61 & $3.62(0.11)$ & $3.53(0.11)$ \\
Ara-C & 4.89 & $4.89(0.16)$ & $4.89(0.29)$ \\
\hline
\end{tabular}

GSH Concentration $(\mu \mathrm{M})$ in Human Erythrocytes

\begin{tabular}{lccc}
\hline & \multicolumn{3}{c}{ Drug concentration (mM) } \\
\cline { 2 - 4 } Drug type & 0.0 & 1.0 & 2.0 \\
\hline MTX (MAS) & 120.3 & $109.0(8.6)$ & $109.9(7.4)$ \\
MTX & 143.4 & $140.3(5.8)$ & $148.9(1.9)$ \\
5-FU (MAS) & 113.4 & $111.5(0.9)$ & $115.8(3.1)$ \\
5-FU & 128.6 & $136.5(4.9)$ & $138.8(11.0)$ \\
Ara-C (MAS) & 120.3 & $110.9(0.9)$ & $109.2(8.6)$ \\
Ara-C & 143.4 & $138.8(8.1)$ & $132.9(7.9)$ \\
\hline
\end{tabular}

Table 4.4: Effects of MTX, 5-FU and Ara-C on the GST activity and GSH concentration in human erythrocytes after incubation $\left(1 \mathrm{~h}, 37^{\circ} \mathrm{C}\right)$ with and without microsomal activating system (MAS). Values represent the mean followed by the standard error of the mean difference (SEMD) between sample value and its control in brackets.

by real GST activation but rather by a decrease in the GST deactivation originating from MAS. To study this, three different experiments were performed. First, incubations with erythrocytes and higher CP concentrations were carried out. The purpose being to evaluate whether GST values above control values without MAS could be obtained in incubations with MAS and higher CP concentrations. Table 4.5 shows that this was not the case. Next we studied whether the effect of MAS could also be reduced with another substrate for microsomal activation. 3-Hydroxyacetanilide (3-HAA) was used for this purpose. 3-HAA is metabolized by MAS and the metabolites can deplete GSH in added erythrocytes [26]. No significant change in GST activity was found in 3-HAA incubations without MAS. Incubations with 3-HAA and MAS caused a GST activity decrease from $2.35 \mathrm{U} \cdot \mathrm{g}$ 
GST Activity (U.g $\mathrm{Hb}^{-1}$ ) in Human Erythrocytes

\begin{tabular}{|c|c|c|c|c|c|}
\hline \multirow[b]{2}{*}{ Drug type } & \multicolumn{5}{|c|}{ Drug concentration (mM) } \\
\hline & 0.0 & 1.0 & 2.0 & 4.0 & 6.0 \\
\hline $\mathrm{CP}(\mathrm{MAS})^{a}$ & 2.15 & $-b$ & $2.79(0.03)$ & $2.79(0.04)$ & $2.98(0.10)$ \\
\hline $\mathrm{CP}$ & 3.36 & - & $3.17(0.25)$ & $3.07(0.24)$ & $3.14(0.10)$ \\
\hline 3-HAA (MAS) & 2.35 & $1.81(0.23)$ & $1.91(0.10)$ & $1.91(0.14)$ & - \\
\hline 3-HAA & 3.44 & $3.15(0.18)$ & $3.10(0.06)$ & $3.33(0.13)$ & - \\
\hline
\end{tabular}

a. Increase of GST activity in incubations with CP and MAS was significantly related to the CP concentration $(p=0.002)$.

b. Not determined

Table 4.5: Effects of CP and 3-HAA on the GST activity in human erythrocytes after incubation $\left(1 \mathrm{~h}, 37^{\circ} \mathrm{C}\right)$ with and without microsomal activating system (MAS). Values represent the mean followed by the standard error of the mean difference (SEMD) between sample value and its control in brackets.

Lipid Peroxidation and Methemoglobin Formation

\begin{tabular}{llc}
\hline $\begin{array}{c}\text { CP concentration } \\
(\mathrm{mM})\end{array}$ & \multicolumn{1}{c}{$\begin{array}{c}\text { MDA release } \\
(\mu \mathrm{M})\end{array}$} & $\begin{array}{c}\text { Methemoglobin formation } \\
\end{array}$ \\
\cline { 1 - 2 } 0.0 & 0.11 & 0.05 \\
0.5 & $0.11(0.01)$ & $-0.32(0.29)^{c}$ \\
1.0 & $0.11(0.01)$ & $-0.30(0.17)$ \\
2.0 & $0.11(0.01)$ & $-0.37(0.15)$ \\
0.0 (MAS) & 29.56 & 3.48 \\
0.5 (MAS) & $29.08(3.00)$ & $4.36(0.60)$ \\
1.0 (MAS) & $23.93(2.98)$ & $4.74(0.55)$ \\
2.0 (MAS) & $23.53(3.71)$ & $4.52(0.39)$ \\
\hline
\end{tabular}

a. Decrease in MDA release in incubations with MAS was significantly related to the CP concentration $(p=0.01)$.

b. Methemoglobin formation in incubations with MAS was significantly related to the CP concentration $(p=0.03)$.

c. The method used was specifically adapted to determine differences in methemoglobin formation. Absolute values are slightly higher and in all cases above zero.

Table 4.6: Effects of CP on MDA formation and methomoglobine formation in human erythrocytes after incubation $\left(1 \mathrm{~h}, 37^{\circ} \mathrm{C}\right)$ with and without microsomal activating system (MAS). Values represent the mean followed by the standard error of the mean difference (SEMD) between sample value and its control in brackets. 
$\mathrm{Hb}^{-1}$ (SE 0.69) without 3-HAA to $1.81 \mathrm{U}: \mathrm{g} \mathrm{Hb}^{-1}$ (SE 0.46) at a 3-HAA concentration of $1.0 \mathrm{mM}$. No further decrease in human erythrocyte GST activity was seen for 3-HAA concentrations up to $4 \mathrm{mM}$ (table 4.5). Finally, the effect of CP on lipid peroxidation (as indicated by MDA release) and formation of active oxygen species (AOS; as indicated by methemoglobin formation) were studied (table 4.6). MAS addition alone (i.e. without drug addition) clearly gave a large release of lipid peroxidation products ( $30 \mu \mathrm{M}$ SE 5.20$)$ and gave methemoglobin formation ( $3.48 \% \mathrm{SE} 0.81 ; \mathrm{p}=0.03, \mathrm{n}=6$ for both parameters). CP incubations without MAS showed no appreciable effect on MDA formation and methemoglobin formation. CP with MAS caused a minor concentration dependent decrease in MDA formation of $3.35 \mu \mathrm{M}$ per mM CP and a minor concentration dependent increase in methemoglobin formation of $0.45 \%$ per $\mathrm{mM} \mathrm{CP}$.

\section{Discussion}

Glutathione S-transferases and the non-protein thiol glutathione prevent the cell from damage through conjugation of electrophiles and removal of lipid peroxides. Various reactive chemicals influence the activity of the GSH/GST system, either by depletion of GSH or by modulation of GST activity $[18,15,16,17]$. Should such effects occur after in vivo drug treatment, this could lead to changes in the bioavailability of reactive compounds and by that to changes in drug efficacy. Furthermore, such changes in GSH content or GST activity could possibly be of use in biological effect monitoring.

The in vitro effects of the antineoplastic agents CP, c-DDP, MTX, 5-FU and Ara-C on the GSH/GST detoxification system were tested in rat liver fractions and in human erythrocytes. This in vitro test system allows to discriminate whether compounds or the metabolites formed are able to enter the erythrocyte [26]. Of the five antineoplastic agents used in this in vitro study, $\mathrm{CP}$ and c-DDP are known to act as alkylating compounds, while 5-FU, Ara-C and MTX are known to act as antimetabolites. Therefore, effects of CP and c-DDP on the GSH/GST system were more likely a priori than effects by $5-F U$, Ara-C and MTX.

Addition of RS alone (i.e. without drug addition) led to an increase in liver microsomal GST activity. In contrast, addition of MAS alone led to a decrease in liver cytosolic and in erythrocyte GST activity and GSH concentrations. This effect in the control values is probably a result of AOS formed by the microsomes in the presence of RS [34]. Supportive evidence for increased AOS availability in erythrocytes was given by methemoglobin formation and lipid peroxidation in erythrocyte incubations with MAS (table 4.6). It is known that microsomal GST activity and the soluble class $\mu$ GST can be activated by AOS $[35,36,37,38]$. GSTs from the $\alpha$ and $\pi$ class can be inactivated by AOS $[38,39,40,41]$. Erythrocytes only contain the $\pi$ class GST, while the $\alpha$ class GSTs are the most abundant 
in rat liver cytosol, especially when rats are pretreated with phenobarbital [2]. From this one can conclude that AOS generated by MAS probably caused the initial increases in microsomal GST activity and the initial decreases in rat liver cytosolic GST $(\alpha)$ activity and in human erythrocyte GST $(\pi)$ activity. The initial GST decreases in incubations with non-diluted cytosol were much smaller than in incubations with diluted cytosol. This suggests that GSH prevent GST activity changes by AOS. Depletion of GSH by AOS in the control incubations with MAS may be due to direct oxidation, and to consumption in protective reactions catalyzed by GST and glutathione peroxidase $[12,13]$. Furthermore, the liver and erythrocytes export oxidized glutathione and GSH S-conjugates $[12,13]$ and oxidation of GSH leads to mixed disulfide formation with proteins [42].

5-FU did not affect the GST activity and GSH concentrations in the different incubations. For Ara-C with MAS a slight increase in cytosolic GST activity was found. As other incubations with Ara-C expressed no clear effect, and since it is known that Ara-C requires no microsomal metabolism, it is likely that Ara-C does not affect GSH or GST levels and that the single divergent result was found by chance. The microsomal GST enzyme is different from soluble GST enzymes with regard to occurrence, substrate specificity, kinetic parameters [43] and in fact belongs to a different gene family [44]. Our results (table 4.1) indicate that MTX at millimolar concentrations is only able to inhibit about $20 \%$ of the microsomal GST activity. As expected in advance no serious effects were found for the three antimetabolites.

In vivo reduction of GST activity in liver and kidney was previously described for c-DDP [45]. Next to this, c-DDP reacts with sulfhydryl groups of enzymes and sulfur containing anino acids, peptides and proteins such as cysteine, GSH and metallothionein $[29,46,47,48]$. This is consistent with our findings where c-DDP causes a concentration dependent GST inactivation and GSH depletion in cytosolic liver incubations. However, in erythrocyte incubations there was no significant effect of c-DDP on GSH or GST levels. This implicates that c-DDP is not able to enter the erythrocyte under the conditions used. This was not due to the use of PBS in stead of sodium/phosphate buffer, as incubations with erythrocytes and this buffer also gave negative results. In fact PBS was used because the two chloride ligands are stable at the chloride concentration of the extracellular matrix. After diffusion into a cell, the lower chloride concentration permits loss of chloride from the drug. The drug becomes then an aquated, charged electrophile which reacts with nucleophilic sites on cellular macromolecules [29]. Moreover, c-DI)P caused a decrease of GSH and GST levels in hemolysate and in hepatorytes. A possible explanation for the phenomenon that c-DDP does hardly pass the erythrocyte membrane is the fact that c-DDP binds avidly to red cell membranes $[49,50]$.

CP is metabolized mainly by hepatic microsomal enzymes to 4-hydroxycyclophosphamide, producing equimolar amounts of phosphoramide mustard and acrolein [5l]. CP metabolites, especially acrolein, have long been known to cause 
GSH depletion $[52,53]$. As expected GST activities were not affected in any of the CP incubations without MAS. However, CP incubations without MAS induced a slight GSH depletion in rat liver cytosol and in human erythrocytes. This indicates that erythrocytes and liver cytosol itself may be able to activate a small amount of CP. GSH was almost completely depleted and GST activity was increased in all incubations with CP in the presence of MAS. This confirms that CP has to be metabolized to give an effect and proves that the CP metabolites can enter the erythrocyte. Activation of microsomal GST was already at a maximum at a CP concentration of $0.5 \mathrm{mM}$. It is known that acrolein activates microsomal GST if there is no GSH available [54], and since acrolein is a major CP metabolite $[22,51]$, the microsomal GST activation seen here was probably caused by acrolein. No increase in GST activity was seen after CP treatment with MAS in the liver cytosolic incubations. After dilution of the cytosol, a clear GST increase was found, suggesting that GSH prevent GST activity changes by CP metabolites. Moreover, when GSH was added to incubations with diluted cytosol the GST activation was lowered (data not shown). The increase in GST activity seen in diluted liver cytosol and erythrocyte incubations after CP treatment with MAS did not exceed the control value without MAS. Therefore, it could not be excluded that this increase was actually a reduction of the inhibition caused by MAS addition. So, perhaps CP serving as a substrate for the microsomes, caused a reduction in AOS formation leading to a reduction in GST inactivation. To detect whether the GST activity changes were caused by reactive CP metabolites or by a reduction in AOS, three additional experiments were performed. As a first approach, higher concentrations CP were used (up to $6 \mathrm{mM}$ ). However, even under these conditions no GST activities above the control value were found. 3HAA, another substrate for the microsomes, showed no concentration dependent increase in GST activity. In other words there was no significant reduction in the formation of AOS responsible for GST inactivation. Therefore, reduction in AOS formation by microsomal substrates does not seem to be a general phenomenon. Finally, methemoglobin formation and lipid peroxidation were evaluated. The rational being that $\mathrm{CP}$ induced reduction in AOS formation should lead to concomitant changes in these parameters. A CP concentration dependent decrease in MDA release was found in the incubations with MAS. However, the relative change in MDA release is much smaller than the relative change in GST activity. Contrary to what might be expected if CP caused a reduction in AOS formation, CP caused a concentration dependent increase in methemoglobin formation. Based on the latter three findings it is not likely that a reduction in AOS formation is responsible for the activation of GST but rather that the CP metabolites are responsible for the GST activation.

The GST activity and the GSH concentrations in tumor cells are thought to be very important for the resistance against chemotherapy $[5,6,7,8,9]$ and radiation therapy $[13,14]$. GSH and GST detoxify some alkylating antineoplastic agents and detoxify organic hydroperoxides formed as a result of radical for- 
mation during treatment with some antineoplastic agents and during radiation therapy $[1,4]$. Therefore, changes in GST and GSH levels may result in different cytotoxicity patterns and may influence drug efficacy. The results presented here indicate that apart from changes in GST expression, direct modulation of the available enzyme may be important. Since modulation will be isoenzyme specific and the GST isoenzyme content in tumor cells is known to differ from normal tissue [8], this modulation, particularly seen here in erythrocytes, is likely to play a role in relative sensitivity of tumor tissue. In addition, tumors could be sensitized to alkylating antineoplastic agents and radiation therapy by GSH depletion. In fact, GSH depletion with L-buthionine sulfoximine and diethylmaleate has been suggested for this purpose $[55,56]$. So, GSH depletion in tumors by alkylating antineoplastic agents in combination with radiation therapy will be a useful strategy for tumor sensitization. This would especially be the case if targetting of GSH depleting and/or GST inactivating antineoplastic agents could result in selective sensitization of tumor tissue. The two alkylating antineoplastic agents used in this study both resulted in significantly lowered GSH levels and c-DDP also caused GST activity decrease. CP on the other hand increased the GST activity but this increase is negligible in comparison with the GSH depletion. Therefore, changes in GST activity and in GSH levels induced by CP and c-DDP may result in increased tumor sensitivity to subsequent radiation therapy.

Acknowledgements The authors wish to thank Vivian Geelen and Raphael Janssen for their technical support, Dr A. Kester for his advice in statistical analyses, the Red Cross Blood Bank "Zuid Limburg" for the collection of blood samples and Multipharma B.V. (Weesp, NL) for their generous gifts (cis-diamminedichloroplatinum(II) and methotrexate). 


\section{References}

[1] Ketterer B, Detoxification reactions of glutathione and glutathione transferases. Xenobiotica 16: 957-973, 1986.

[2] Mannervik B, The isoenzymes of glutathione transferases. Adv Enzymol Relat Areas Mol Biol 57: 357-417, 1985.

[3] Mannervik B and Danielson UH, Glutathione Transferases - structure and catalytic activity. Crit Rev Biochem 23: 283-337, 1988.

[4] Tan KH, Meyer DJ, Gillies N and Ketterer B, Detoxification of DNA hydroperoxide by glutathione transferase and the purification and characterization of glutathione transferase of the rat liver nucleus. Biochem $J$ 254: 841-845, 1988.

[5] Morrow CS and Cowan KH, Glutathione S-transferases and drug resistance. Cancer Cells 2: 15-22, 1990.

[6] Black SM and Wolf CR, The role of glutathione-dependent enzymes in drug resistance. Pharmacol Ther 51: 139-154, 1991.

[7] Cazenave LA, Moscow JA, Myers CE and Cowan KH, Glutathione S-transferase and drug resistance. Cancer Treat Res 48: 171-187, 1989.

[8] Tsuchida S and Sato K, Glutathione transferases and cancer. Crit Rev Biochem Mol Biol 27: 337-384, 1992.

[9] Waxman DJ, Glutathione S-transferases: Role in alkylating agent resistance and possible target for modulation chemotherapy - A review. Cancer Res 50: 6449$6454,1990$.

[10] Sato K, Glutathione transferases as markers of preneoplasia and neoplasia. Adv Cancer Res 52: 205-255, 1989.

[11] Seidegard J, Vorachek WR, Pero RW and Pearson WR, Hereditary difference in the expression of the human glutathione transferase active on trans-stilbene oxide are due to a gene deletion. Proc Natl Acad Sci USA 85: 7293-7297, 1989.

[12] Meister A and Anderson ME, Glutathione. Annu Rev Biochem 52: 711-760, 1983.

[13] Shan X, Aw TY and Jones DP, Glutathione-dependent protection against oxidative injury. Pharmacol Ther 47: 61-71, 1990.

[14] Bump EA and Brown JM, Role of glutathione in the radiation response of mammalian cells in vitro and in vivo. Pharmacol Ther 47: 117-136, 1990.

[15] Evelo CTA and Henderson PTh, Biological effect monitoring. Arch Toxicol suppl 15: 268-277, 1992.

[16] Ansari GAS, Singh SV, Gan JC and Awasthi YC, Human erythrocyte glutathione S-transferase: a possible marker of chemical exposure. Toxicol Lett 37: 57-62, 1987.

[17] Kilpikari I and Savolainen H, Decreased erythrocyte glutathione S-transferase activity in rubber workers. Int Arch Occup Eaviron Health 53: 299-302, 1984.

[18] Brouwer EJ, Evelo CTA, Verplanke AJW, Welie van RTH and Wolff FA, Biological effect monitoring of exposure to 1,3-dichloropropene: effects on liver and renal function and on glutathione conjugation. Br J Ind Med 48: 167-172, 1991.

[19] Evelo CTA, Palmen NGM, Artur Y and Janssen GME, Changes in blood glutathione concentrations, and in erythrocyte glutathione reductase and glutathione S-transferase activity after running training and after participation to contests. Eur J Appl Physiol 64: 354-358, 1992. 
[20] Evelo CTA, Bos RP and Borm PJA, Decreased glutathione content and glutathione S-transferase activity in red blood cells of coal miners with early stages of coal miners pneumoconiosis. Br J Ind Med 50: 633-636, 1993.

[21] Guengerich FP and Liebler DC, Enzymatic activation of chemicals to toxic metabolites. Crit Rev Toxicol 14: 259-307, 1985.

[22] Torkelson AR, LaBudde JA and Weikel JH, The metabolic fate of cyclophosphamide. Drug Metab Rev 3: 131-165, 1974.

[23] Sladek NE, Therapeutic efficacy of cyclophosphamide as a function of its metabolism. Cancer Res 32: 535-542, 1972.

[24] Palmen NGM, Evelo CTA, Borm PJA and Henderson PTh, Toxicokinetics of dimethylacetamide (DMAc) in rat isolated perfused liver. Hum Exp Toxicol 12 : 127-133, 1993.

[25] Prieur DJ, Albino animals: their use and misuse in biomedical research. Comp Pathol Bull 14: 1-4, 1982.

[26] Palmen NGM and Evelo CTA, Glutathione depletion in human erythrocytes as an indicator for microsomal activation of cyclophosphamide and 3-hydroxyacetanilide. Toxicology 84: 157-170, 1993.

[27] Lowry OH, Rosebrough NJ, Farr AL and Randall RJ, Protein measurement with the folin phenol reagent. $J$ Biol Chem 193: 265-270, 1951.

[28] Kampen van EJ and Zijlstra WG, Determination of hemoglobin and its derivatives. Adv Clin Chem 8: 141-187, 1965.

[29] Chu G, Cellular responses to cisplatin. The roles of DNA-binding proteins and DNA repair. J Biol Chem 269: 787-790, 1994.

[30] Habig WH and Jakoby WB, Assays for the differentiation of glutathione Stransferases. Methods Enzymol 77: 398-405, 1981.

[31] Anderson $\mathrm{ME}$, Determination of glutathione and glutathione disulfide in biological samples. Methods Enzymol 113: 548-555, 1985.

[32] Tietz NW, Textbook of Clinical Chemistry. WB Saunders, Philadelphia, 1986.

[33] Stocks $\mathbf{J}$ and Dormandy TL, The autoxidation of human red cell lipids induced by hydrogen peroxide. Br $J$ Haematol 20: 95-111, 1971.

[34] Wills ED, Lipid peroxide formation in microsomes; General considerations. Biochem J 113: 315-324, 1969.

[35] Aniya $\mathrm{Y}$ and Anders MW, Activation of rat liver microsomal glutathione Stransferase by reduced oxygen species. J Biol Chem 264: 1998-2002, 1989.

[36] Aniya $Y$ and Naito A, Oxidative stress-induced activation of microsomal glutathione S-transferase in isolated rat liver. Biochem Pharmacol 45: 37-42, 1993.

[37] Lundqvist $G$ and Morgenstern $R$, Mechanism of activation of rat liver microsomal glutathione transferase by noradrenaline and xanthine oxidase. Biochem Pharmacol 43: 1725-1728, 1992.

[38] Murata T, Hatayama I, Satoh K, Tsuchida S and Sato K, Activation of rat glutathione transferases in class mu by active oxygen species. Biochem Biophys Res Commun 171: 845-851, 1990.

[39] Tamai K, Satoh K, Tsuchida S, Hatayama I, Maki T and Sato K, Specific inactivation of glutathione S-transferases in class pi by SH-modifiers. Biochem Biophys Res Commun 167: 331-338, 1990. 
[40] Shen H, Tamai K, Satoh K, Hatayama I, Tsuchida S and Sato K, Modulation of class pi glutathione transferase activity by sulfhydryl group modification. Arch Biochem Biophys 286: 178-182, 1991.

[41] Shen H, Tsuchida S, Tamai K and Sato K, Identification of cysteine residues involved in disulfide formation in the inactivation of glutathione transferase $\mathrm{P}$ form by hydrogen peroxide. Arch Biochem Biophys 300: 137-141, 1993.

[42] Reed DJ, Glutathione: Toxicological implications. Annu Rev Pharmacol Toxicol 30: 603-631, 1990.

[43] Morgenstern R, Meyer J, DePierre JW and Ernster L, Characterization of rat liver microsomal glutathione S-transferase activity. Eur J Biochem 104: 167-174, 1980.

[44] DeJong JL, Morgenstern R, Jörnvall H, DePierre JW and Tu CD, Gene expression of rat and human microsomal glutathione S-transferases. J Biol Chem 263: 8430$8436,1988$.

[45] Bompart G, Cisplatin-induced changes on cytochrome P-450, lipid peroxidation and some P-450 related specific catalytic activities in rat liver. $J$ Toxicol Clin Exp 10: 375-383, 1990.

[46] Aull JL, Allen RL, Bapat AR, Daron HH, Friedman ME and Wilson JF, The effects of platinum complexes on seven enzymes. Biochim Biophys Acta 571: 352$358,1979$.

[47] Odenheimer B and Wolf $W$, Reactions of cisplatin with sulfur-containing amino acids and peptides I. Cysteine and glutathione. Inorg Chim Acta 66: L41-L43, 1982.

[48] Suzuki CAM and Cherian MG, The interactions of cis-diamminedichloroplatinum with metallothionein and glutathione in rat liver and kidney. Toxicology 64: 113127, 1990.

[49] Manaka RC and Wolf W, Radiopharmacokinetic studies with Pt-195m labelled cisplatin. J Nucl Med 19: 732, 1978 (abstract).

[50] Dawson M, Brown EA and Barr RD, The effects of cisplatin on normal human erythrocytes in vitro. Scand J Haematol 31: 283-286, 1983.

[51] Honjo I, Suou T and Hirayama C, Hepatotoxicity of cyclophosphamide in man: pharmacokinetic analysis. Res Commun Chem Pathol Pharmacol 61: 149-165, 1988.

[52] Alarcon RA, Studies on the in vivo formation of acrolein: 3-hydroxypropylmercapturic acid as an index of cyclophosphamide (NSC-26271) activation. Cancer Theat Rep 60: 327-335, 1976.

[53] Gurtoo HL, Hipkens JH and Sharma SD, Role of glutathione in the metabolismdependent toxicity and chemotherapy of cyclophosphamide. Cancer Res 41: 3584$3591,1981$.

[54] Haenen GRMM, Vermeulen NPE, Tai Tin Tsoi JNL, Ragetli HMN, Timmerman H and Bast A, Activation of the microsomal glutathione S-transferase and reduction of the glutathione dependent protection against lipid peroxidation by acrolein. Biochem Pharmacol 37: 1933-1938, 1988.

[55] Griffith OW, L-Buthionine-SR-sulfoximine: mechanism of action, resolution of diastereomers and use as a chemotherapeutic agent. In: Glutathione Centennial; 
Molecular Perspectives and Clinical Implications (Eds. Taniguchi N, Higshi T, Sakamoto Y and Meister A), pp. 285-299. Academic Press, San Diego, 1989.

[56] Bump EA, Yu NY, Taylor YC, Brown JM, Travis EL and Boyd MR, Radiosensitization and chemosensitization by diethylmaleate. In: Radioprotectors and Anticarcinogens (Eds. Nygaard OF and Simic MG), pp. 297-324. Academic Press, New York, 1983. 
Chapter 5

Two Mechanisms for Toxic Effects of Hydroxylamines in Human Erythrocytes: Involvement of Free Radicals and Risk of Potentiation

Chris T.A. Evelo, Rob A.G. Bisschops, Leo G.M. Baars, Anita A.M.G. Spooren and John M. Neis'.

Department of Pharmacology (Toxicology section), University of Limburg, P.O. Box 616, 6200 MD Maastricht, The Netherlands.

1: Corporate Department for Safety and Environment; DSM, Heerlen, The Netherlands.

Submitted for publication. 
Summary. The toxic potency of three industrially used hydroxylamines was studied in human blood cells in vitro. The parent compound hydroxylamine $(H Y A M)$ and the O-ethyl derivative $(O E H)$ gave very similar results. Both compounds induced a high degree of methemoglobin $\left(\mathrm{Hb}^{+}\right)$ formation and glutathione depletion. Cytotoxicity was visible as Heinz body formation and hemolysis. High levels of lipid peroxidation $(L P)$ occurred, in this respect $\mathrm{OEH}$ was more active than HYAM. In contrast $\mathrm{H}_{2} \mathrm{O}_{2}$ induced LP was lowered after OEH or HYAM treatment, this is explained by the ferrohemoglobin dependence of $\mathrm{H}_{2} \mathrm{O}_{2}$ induced radical species formation. Glutathione S-transferase (GST) and NADPH methemoglobin reductase ( $N A D P H-H b R)$ activities were also impaired, probably as a result of the radical stress occurring. The riboflavin availability was decreased. Other enzyme activities (glutathione reductase $(G R)$, glucose 6-phosphate dehydrogenase $(G 6 P D H)$, glucose phosphate isomerase and $\mathrm{NADH}$ methemoglobin reductase) were not or only slightly impaired by HYAM or $\mathrm{OEH}$ treatment.

A strikingly different scheme of reactivity was found for $\mathrm{N}, \mathrm{O}$-dimethyl hydroxylamine (NODMH). This compound gave much less $\mathrm{Hb}^{+}$formation and no hemolysis or Heinz body formation at concentrations up to and including $7 \mathrm{mM}$. LP induction was not detectable, but could be induced by subsequent $\mathrm{H}_{2} \mathrm{O}_{2}$ treatment. GST and NADPH-HbR activities and riboflavin availability were not decreased. On the other hand GR and G6PDH activities were inhibited. These results combined with literature data indicate the existence of two different routes of hematotoxicity induced by hydroxylamines. HYAM as well as O-alkylated derivatives primarily induce $\mathrm{Hb}^{+}$, a process involving radical formation. The radical stress occurring is probably responsible for most other effects. $\mathrm{N}$-alkylated species like NODMH primarily lead to inhibition of the protective enzymes G6PDH and GR. Since these enzymes play a key role in the protection of erythrocytes against oxidative stress a risk of potentiation during mixed exposure does exist.

\section{Introduction}

Hydroxylamines are derivatives of the parent compound hydroxylamine ( $H Y A M$, chemical formula $\mathrm{H}_{2} \mathrm{NOH}$ ). Hydroxylamine itself is used in the synthesis of Caprolactam, which is used for the production of Nylon $6^{T M}$. It is also used as a reducing agent in photography, as an antioxidant for soaps and fatty acids, as a tanning agent and as an intermediate in the production of pesticides and pharmaceuticals $[8,30]$. Derivatives of HYAM often serve as intermediates in chemical synthesis. The main toxic effect of HYAM is of hematological nature $[8,30]$. Methernoglobin $\left(\mathrm{Hb}^{+}\right)$formation was found in vitro $[7,11,18,63]$. In in vivo animal studies anemia with increased $\mathrm{Hb}^{+}$levels and sometimes with sulfhemoglobinemia was consistently found $[3,8,20,30,39,44,54,59,60,71,72]$. In some studies this was 
found to be accompanied by remarkable splenomegaly $[20,54,72]$. In a more recent subchronic (ninety days) study - performed according to guidelines of the Organisation for Economic Co-Operation and Development (OECD) - rats were exposed to HYAM-sulfate [5]. In the $250 \mathrm{ppm}$ exposed groups (male and female) hematological effects and increased spleen weight were found among other effects. In the $50 \mathrm{ppm}$ treated groups small increases in reticulocyte numbers and some other marginal effects were found. The "no effect level" in this study was between 10 and $50 \mathrm{ppm}$ for both sexes. In his review Gross [30] quotes a single incidence of human hydroxylamine poisoning described in Russian literature [45]. A woman who had drunk about "two swallows" of HYAM solution in water developed rapidly progressing hemolytic anemia which required five weeks for recovery.

Martin et al. [46] described the development of serious anemia in five laboratory workers working with methylated hydroxylamines (O-methyl, N,O-dimethyl $(N O D M H)$ and trimethyl hydroxylamine). In the most acute patient lowered hemoglobin and increased serum iron levels were found, indicating hemolytic anemia. All patients had shown jaundice symptoms and had increased numbers of bone marrow erythroblasts. Reticulocyte numbers were increased in two patients. Heinz bodies were not found and $\mathrm{Hb}^{+}$could not be detected spectrophotometrically. These findings prompted the authors to further in vitro studies.

Interestingly trimethyl hydroxylamine in these studies gave by far the highest hemolytic activity, while it did not lead to increased methemoglobin levels. In contrast the far less hemolytic O-methyl hydroxylamine and the N,O-dimethyl compound did strongly induce methemoglobin formation. The higher hemolytic potency of trimethyl, and to a much lesser extent N,O-dimethyl hydroxylamine, was found to be accompanied with strong glucose 6-phosphate dehydrogenase $(G 6 P D H)$ inhibition and loss of reduced glutathione (GSH).

This suggests that two separate mechanisms for the hematotoxicity of hydroxylamines may exist. For the first one methemoglobin formation is a major effect, for the other G6PDH inhibition is predominant. Both routes seem to be able to give rise to hemolytic anemia. The purpose of the present study was to further elucidate these two mechanisms. Three industrially used hydroxylamines were tested: HYAM, O-ethyl hydroxylamine $(O E H)$ and NODMH. Next to the effects described above we were especially interested in the fact that the $\mathrm{Hb}^{+}$ formation by HYAM does involve a radical mechanism [63], and therefore might give rise to free radical induced lipid peroxidation.

\section{Materials and Methods}

\section{Chemicals and Enzymes}

The following chemicals were used: N,O-dimethyl hydroxylamine (NODMH, methoxymethylamine, CAS-nr 1117-97-1, purity 99.5\%) and O-ethyl hydroxylamine $(\mathrm{OEH}$, ethoxyamine, CAS-nr $624-86-2,55 \%(\mathrm{w} / \mathrm{v})$ solution in water), 
were a gift from DSM Special Products (Geleen, NL). Brilliant cresyl blue was from BDH (Poole, UK), malonaldehyde bis(diethylacetal) (used as precursor for malondialdehyde reference) was from Janssen Chimica (Beerse, Belgium), 2-thiobarbituric-acid ( $T B A$ ) was from Merck (Darmstadt, FRG), 1-chloro2,4-dinitrobenzene, 5,5'-dithio-bis(2-nitrobenzoic acid), 4,4'-dithiodipyridine (4$P D S)$, dithiothreitol, flavin adenine dinucleotide $(F A D)$, fructose 6-phosphate, glucose 6-phosphate, glucose 6-phosphate dehydrogenase (grade XI from Torula yeast) $(G 6 P D H)$, reduced $(G S H)$ and oxidized $(G S S G)$ glutathione, glutathione reductase (type III) (GR), hydroxylamine $\mathrm{HCl}$ (HYAM, CAS-nr: 5470-11-1 (free base CAS-nr: 7803-49-8) (ACS reagent, purity 99.1\%), methylene blue, reduced $\beta$-nicotinamide adenine dinucleotide $(N A D H), \beta$-nicotinamide adenine dinucleotide phosphate $(N A D P)$, reduced $\beta$-nicotinamide adenine dinucleotide phosphate $(N A D P H)$, and 6-phosphogluconic dehydrogenase were from Sigma (St. Louis, Mo, USA). All other chemicals were of analytical quality. Only microfiltrated deionized water was used.

\section{Blood samples.}

Human blood samples were collected in vacuum tubes containing $K_{3}$ EDTA as an anticoagulant. For the determinations of Heinz body formation, lipid peroxidation, peroxidation resistance and glutathione S-transferase and glutathione reductase activities fresh samples from individual persons were used. For all other experiments pooled blood samples from three to five persons with blood group $\mathrm{O}+$ wore used. The latter samples were checked for viral infections and stored at $4^{\circ} \mathrm{C}$ until the next day.

\section{Incubations}

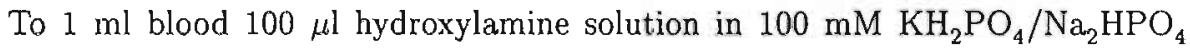
of $\mathrm{pH} 7.4$ were added, and the samples were incubated in a shaking waterbath (80 revolutions per minute) for 1 hour at $37^{\circ} \mathrm{C}$. All experiments were performed three times on separate days and with different blood samples, each day all incubations were performed in duplicate. Except for the determinations of Heinz bodies, hemolysis and lipid peroxidation, erythrocytes were washed three times with five volumes of cold phosphate buffered saline ( $15 \mathrm{mM} \mathrm{KH}_{2} \mathrm{PO}_{4} / \mathrm{Na}_{2} \mathrm{HPO}_{4}$ $+130 \mathrm{mM} \mathrm{NaCl} ; \mathrm{pH}=7.4$ ). Where applicable the erythrocytes were lysed by addition of three to five volumes of cold water, after 15 minutes storage on ice cellular debris was removed by centrifugation at $13000 \times g$ for $10 \mathrm{~min}$.

\section{Analyses}

Heinz body formation. To $1 \mathrm{ml}$ blood $0.5 \mathrm{ml} 1 \%(\mathrm{w} / \mathrm{v}$ ) brilliant cresyl blue in saline was added. Heinz bodies are colored during subsequent incubation. More severe cellular damage leads to detectable numbers of Heinz bodies after shorter incubation times and at lower temperatures. For this reason, of two identical 
samples one was incubated at $20^{\circ} \mathrm{C}$ and the other at $37^{\circ} \mathrm{C}$. After 20,40 and 60 minutes of incubation samples were dried and evaluated by light microscopy (1000x) under oil immersion [33].

Hemolysis. After incubation the $\mathrm{Hb}$ content of the plasma was used to determine the degree of hemolysis.

Methemoglobin $\left(\mathrm{Hb}^{+}\right)$. The percentage $\mathrm{Hb}^{+}$present in hemolysates was calculated from the absorbance change after addition of $\mathrm{KCN}$ compared to the same change in a sample fully converted to the $\mathrm{Hb}^{+}$form by the addition of $\mathrm{K}_{3} \mathrm{Fe}(\mathrm{CN})_{6}$ [65].

Total glutathione (GT). GT was determined after precipitation of protein (200 $\mu \mathrm{l}$ packed cells plus $200 \mu \mathrm{l} 8 \%$ (w/v) trichloroacetic acid) using the cyclic oxidation-reduction method essentially as described by Anderson [2]. Especially for the determination of GT, it was of interest whether the Torula yeast GR enzyme used was itself inhibited by any of the hydroxylamines studied. This was tested separately with hydroxylamine concentrations of $0,2.5$ and $7 \mathrm{mM}$, no significant inhibition of Torula yeast GR was found under the assay conditions used.

Reduced glutathione (GSH). GSH was determined as non-protein sulfhydryl after trichloroacetic acid precipitation of erythrocytes by measurement of the reactivity towards 5,5'-dithio-bis(2-nitrobenzoic acid) as previously described [23].

Release of thiobarbituric-acid reactive substances (TBARS). The accumulation of lipid peroxidation $(L P)$ products in the extracellular medium was assessed by determination of the amount of TBARS released and was expressed as malondialdehyde equivalents [62]. After incubation of $1.5 \mathrm{ml}$ fresh blood with hydroxylamines, the plasma was collected after centrifugation (1500 $\times \mathrm{g}$ for $10 \mathrm{~min}$ ). The protein was precipitated by addition of an equal volume of $15 \%(w / v)$ trichloroacetic acid and subsequent centrifugation. $1.5 \mathrm{ml}$ of the supernatant was added to $1 \mathrm{ml} \mathrm{TBA}$ solution (1\% (w/v) in $50 \mathrm{mM} \mathrm{NaOH})$ and heated in a boiling waterbath for $15 \mathrm{~min}$. After forced cooling, $1.25 \mathrm{ml}$ butanol was added, and the two phases were thoroughly mixed. The absorbance of the butanol phase at $535 \mathrm{~nm}$ was determined and corrected for the background absorbance at $590 \mathrm{~nm}$.

Resistance to $\mathrm{H}_{2} \mathrm{O}_{2}$ forced lipid peroxidation. The remaining resistance to $\mathrm{H}_{2} \mathrm{O}_{2}$ induced LP of erythrocytes pretreated with hydroxylamines was assessed. After incubation of fresh blood samples with hydroxylamines the plasma was removed by centrifugation. The erythrocytes were washed three times to remove remaining hydroxylamines and were diluted in phosphate buffered saline to a cell concentration of $5 \%(\mathrm{v} / \mathrm{v})$. To $2.5 \mathrm{ml}$ erythrocyte suspension an equal volume of $20 \mathrm{mM}$ 
$\mathrm{H}_{2} \mathrm{O}_{2}$ plus $1 . \mathrm{mM} \mathrm{NaN}_{3}$ was added. TBARS release was determined after reincubation at $37^{\circ} \mathrm{C}$ for $0,15,30,45$ and 60 min [22].

Free hemoglobin sulfhydryl ( $\mathrm{HbSH}$ ). Free hemoglobin sulfhydryl groups were determined in hemolysates from the reactivity towards 4-PDS [29] as previously described [23].

NADH methemoglobin reductase (NADH-HbR). NADH-HbR activity in hemolysates was determined using DEAE-cellulose puritied hemoglobin converted to the methemoglobin-ferrocyanide complex as substrate with the method described by Hegesh et al. [35] and some small modifications according to Bauer [6].

NADPH mothemoglobin reductase (NADPH-HbR). NADPH-HbR activity in hemolysates was determined from the reduction of methylene blue by NADPH $[9,38]$. Disappearance of NADPH was followed spectrophotometrically at $340 \mathrm{~nm}$. Corrections were made for spontaneous methylene blue reduction.

Glutathione S-transferase (GST). GST (EC 2.5.1.18) activity with 1-chloro2,4-dinitrobenzene as substrate was determined in hemolysates prepared from incubates of fresh blood samples by the addition of three volumes $1.4 \mathrm{mM}$ neutralized dithiothreitol, using the method of Habig and Jakoby [32] with previously described modifications [10].

Glutathione reductase (GR). GR (EC 1.6.4.2) activity in hemolysates was determined by a modification of the method described by Carlberg and Mannervik [12]. $100 \mu \mathrm{l}$ Hemolysate were added to $2 \mathrm{ml} 100 \mathrm{mM}$ potassium phosphate buffer, $50 \mu \mathrm{l}$ $80 \mathrm{mM}$ EDTA, $100 \mu \mathrm{l} 2 \mathrm{mM}$ NADPH and $100 \mu \mathrm{l} 0.3 \mathrm{mM}$ FAD. After 2 min preincubation $\left(37^{\circ} \mathrm{C}\right)$, the reaction was started by addition of $100 \mu 17.5 \mathrm{mM}$ GSSG. After $15 \mathrm{sec}$ the reaction was followed spectrophotometrically at $340 \mathrm{~nm}$ for $2 \mathrm{~min}$. The FAD was added in order to convert all enzyme to its holo form.

Glutathione reductase riboflavin activity coefficient $\left(G R_{\text {coeff }}\right)$. The coefficient of erythrocyte GR activity with and without addition of FAD to the assay was used as an indicator of the riboflavin content. The determinations were carried out exactly as described for GR above except that FAD was left out from one of the 2 samples[65].

Glucose 6-phosphate dehydrogenase (G6PDH). G6PDH (EC 1.1.1.49) activity in hemolysates was determined spectrophotometrically; the reduction of $\mathrm{NADP}^{+}$ was followed at $340 \mathrm{~nm}[65]$. 
Glucose-phosphate isomerase. Glucose-phosphate isomerase (EC 5.3.1.9) activity in hemolysates was determined using fructose 6-phosphate as substrate in the presence of $\mathrm{NADP}^{+}, \mathrm{G6PDH}$ and 6-phosphogluconic dehydrogenase. Under these circumstances each molecule of fructose 6-phosphate converted will give rise to reduction of two molecules $\mathrm{NADP}^{+}$, which was followed spectrophotometrically at $340 \mathrm{~nm}[6]$.

Hemoglobin $(\mathrm{Hb})$. The $\mathrm{Hb}$ concentrations were determined with the hemoglobin cyanide procedure [41].

\section{Statistical Evaluation}

Significance of concentration dependent changes was evaluated using linear regression analysis with a model including day of experiment and hydroxylamine concentration as explanatory variables. Using this model, we tested whether slopes of parameter changes versus concentration were significant correcting for the day of experiment. In each experiment incubations were performed with $0,1,2.5,5$ and $7 \mathrm{mM}$ hydroxylamine concentrations. All experiments were performed three times. Duplicate values obtained during a single experiment were averaged before statistical analysis since these values are not independent. This leads to a total of 3 (experiments) $\times 5$ (concentrations) $=15$ data points for each regression analysis. The regression model used, will correct for interexperiment variations in control values. For this reason the standard errors shown in the figures are given as the standard error of the mean difference between sample value and its control (i.e. the corresponding value at concentration 0 ).

\section{Results}

\section{Oxidative effects}

A concentration dependent $\mathrm{Hb}^{+}$formation was found for all three hydroxylamines (Figure 5.1 on the following page). The effects of HYAM and OEH (about $8 \%$ $\mathrm{Hb}^{+}$formation for each $\mathrm{mM}$ addition) were much stronger than the effect caused by NODMH. GT decreased for all three hydroxylamines (Figure 5.3A on page 85). GT depletion caused by OEH (45 (SE 2.5) $\mu \mathrm{M}$ GT decrease/mM OEH) was much more pronounced than the effect caused by the other two hydroxylamines (24 (SE 3) and 19 (SE 3) $\mu \mathrm{M}$ GT decrease/mM for HYAM and NODMH respectively). The decreases in reduced GSH also were strongest for OEH (Figure 5.3B). The regression coefficient of this GSH decrease amounted to 36 (SE 3) $\mu \mathrm{M} / \mathrm{mM} \mathrm{OEH}$ and to 18 (SE 3) $\mu \mathrm{M} / \mathrm{mM}$ HYAM. For NODMH the depletion was only about 8 (SE 4) $\mu \mathrm{M} / \mathrm{mM}$, and the significance of this depletion was doubtful ( $p=0.0726)$. Plasma GT was found to increase for all three hydroxylamines (figure 5.3C). Contrary to what might be expected from erythrocyte depletions, the increase 


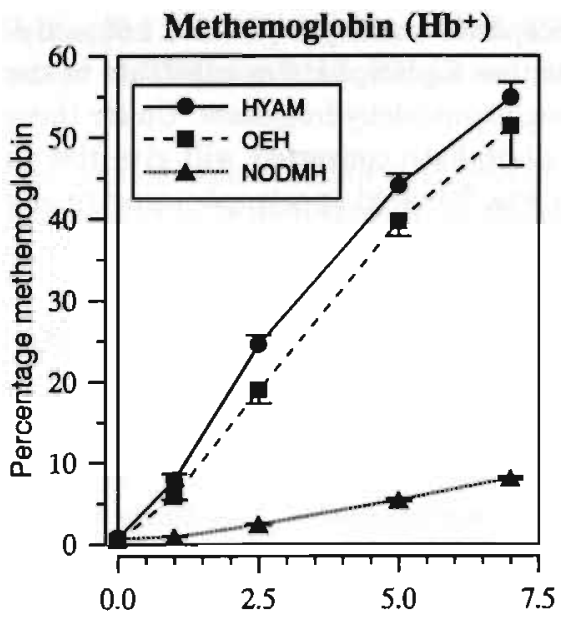

Hydroxylamine concentration [mM]

Figure 5.1: Formation of methemoglobin in human erythrocytes after incubation with hydroxylamines ( 1 hour, $37^{\circ} \mathrm{C}$ ). Regression analyses showed significant $(p<$ 0.0001 ) increases in methemoglobin formation with increasing concentration for all three hydroxylamines.

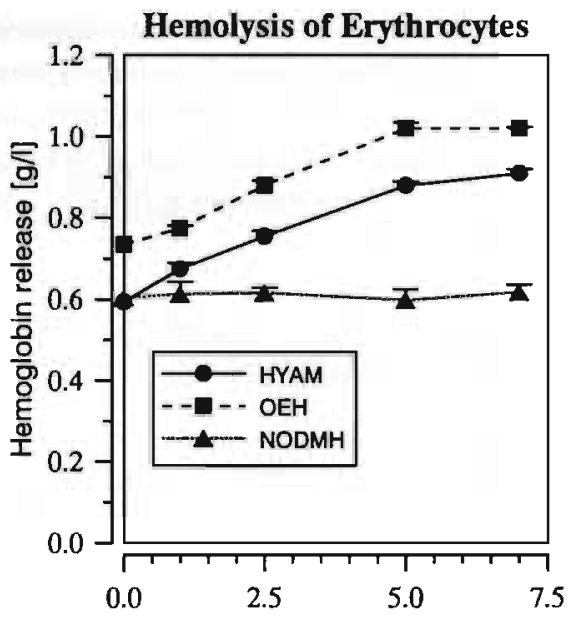

Hydroxylamine concentration [mM]

Figure 5.2: Occurrence of hemolysis of human erythrocytes after incubation with hydroxylamines ( 1 hour, $37^{\circ} \mathrm{C}$ ). Regression analyses showed significant $(p<$ $0.0001)$ increases in hemolysis with increasing HYAM and OEH concentrations.

was strongest for NODMH (about $5.4 \mu \mathrm{M}$ increase/mM NODMH). For OEH and HYAM increases were not more than half that amount. Loss of hemoglobin sulfhydryl group availability was not found for any of the chemicals studied.

\section{Cell damage}

Increased hemolysis occurred for HYAM and OEH (Figure 5.2). Both compounds liberated about $45 \mathrm{mg} \mathrm{Hb} / \mathrm{l}$ from the erythrocytes for each $\mathrm{mM}$ added. For NODMH no increased hemolysis was detectable. Heinz bodies were visible in all blood samples treated with $2.5 \mathrm{mM} \mathrm{HYAM}$ or OEH (Table 5.1 on the next page). In the $2.5 \mathrm{mM}$ HYAM treated samples cell blue spots, normally indicating Heinz bodies, were also visible extracellularly. The same indications for cell breakdown were also present in the $2.5 \mathrm{mM} \mathrm{OEH}$ treated samples, but only when they were incubated at $37^{\circ} \mathrm{C}$. Minor Heinz body formation was present in the $1 \mathrm{mM}$ HYAM treated samples incubated at $37^{\circ} \mathrm{C}$ or incubated for $60 \mathrm{~min}$ or more at $21^{\circ} \mathrm{C}$ as well as in the $1 \mathrm{mM} \mathrm{OEH}$ treated samples incubated at $37^{\circ} \mathrm{C}$ for $60 \mathrm{~min}$ or more. The occurrence of Heinz bodies at a lower temperature and after shorter incubation times for HYAM compared to $\mathrm{OEH}$, indicates that the effect is strongest for HYAM. In NODMH treated blood samples no Heinz body formation could be detected even at concentrations up to $10 \mathrm{mM}$. 


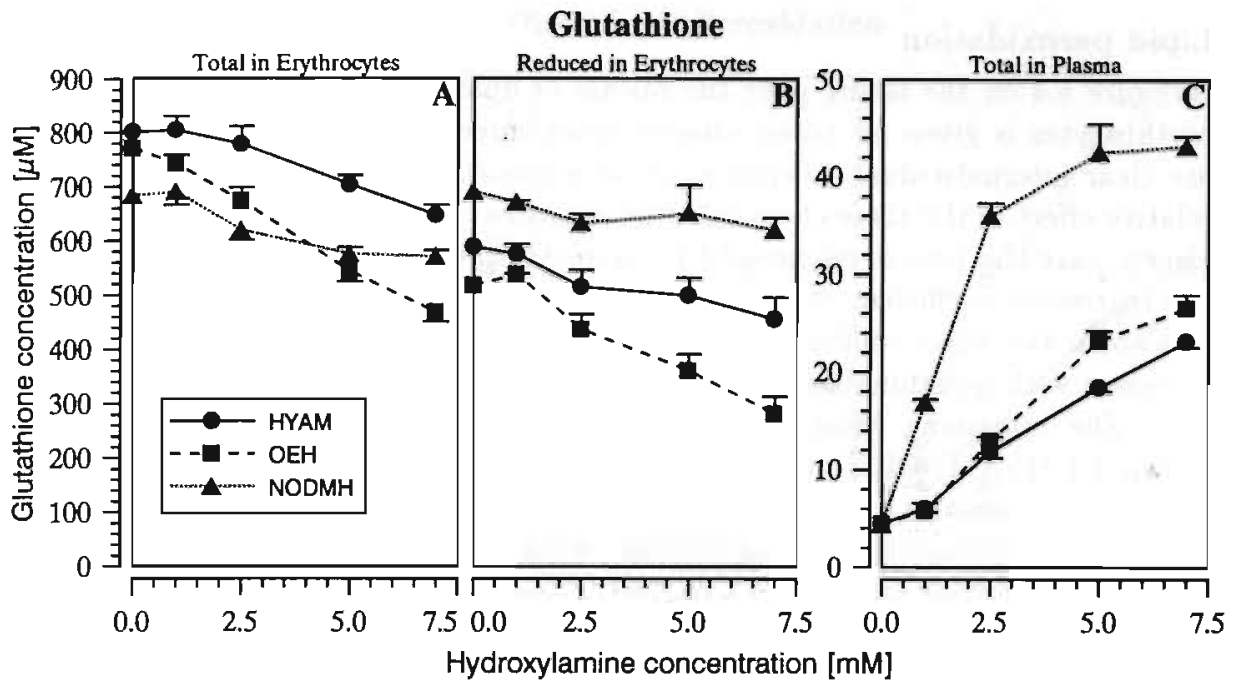

Figure 5.3: Availability of A: total glutathione (reduced plus oxidized) in human erythrocytes; B: reduced glutathione in human erythrocytes and C: total glutathione in human plasma, after incubation with hydroxylamines ( 1 hour, $37^{\circ} \mathrm{C}$ ). Separate experiments were performed to obtain the data for panel A, B and C. Regression analyses showed that all concentration dependent changes were significant with $p<0.0001$, with the exception of the decrease in reduced glutathione with increasing NODMH (panel B) where $p=0.073$.

\begin{tabular}{|l|c|c|c||c|c|c|}
\hline \multirow{2}{*}{ Sample } & \multicolumn{3}{|c||}{$21^{\circ} \mathrm{C}$} & \multicolumn{3}{c|}{$37^{\circ} \mathrm{C}$} \\
\cline { 2 - 7 } & $20 \min$ & $60 \mathrm{~min}$ & $120 \mathrm{~min}$ & $20 \mathrm{~min}$ & $60 \mathrm{~min}$ & $120 \mathrm{~min}$ \\
\hline Blank & - & - & - & - & - & - \\
\hline NODMH 10 mM & - & - & - & - & - & - \\
\hline HYAM 1 mM & - & \pm & \pm & \pm & \pm & + \\
\hline HYAM 2.5 mM & $+^{I}$ & $+^{I}$ & $+^{I}$ & $+^{I}$ & $+^{I}$ & $+^{I}$ \\
\hline OEH 1 mM & - & - & - & - & \pm & \pm \\
\hline OEH 2.5 mM & + & + & + & $+^{I}$ & $+^{I}$ & $+^{I}$ \\
\hline
\end{tabular}

${ }^{1}$ Blue spots were also seen extracellularly.

Table 5.1: Presence of Heinz bodies in human erythrocytes after incubation with hydroxylamines ( 1 hour, $37^{\circ} \mathrm{C}$ ). After addition of brilliant cresyl blue the erythrocytes were incubated at $21^{\circ} \mathrm{C}$ or $37^{\circ} \mathrm{C}$ for a specified amount of time. Visibility of Heinz bodies is indicated as positive $(+)$, negative $(-)$ or visible but minor $( \pm)$. 


\section{Lipid peroxidation}

In figure 5.4 on the facing page the release of lipid peroxidation products from erythrocytes is given for blood samples from three individuals. Although there are clear interindividual differences in both susceptibility and background, the relative effect of the three chemicals was consistent in all three individuals. OEH clearly gave the largest release of LP products. For the three persons combined the regression coefficient was 117 (SE 13) nM/mM OEH. The effect of HYAM was about two times smaller, but still very significant. NODMH gave only minor increases with questionable statistical significance $(p=0.093)$.

The remaining resistance of erythrocytes towards $\mathrm{H}_{2} \mathrm{O}_{2}$ induced LP is shown for HYAM, OEH and NODMH in figures 5.5, 5.6 and 5.7 respectively. Fresh blood samples from three individuals were used, and the individual data are presented separately. As can be seen clearly from the figures the main effect of hydroxylamine treatment is a changed speed of TBARS liberation (i.e. the slopes of the TBARS release versus time curves change). The patterns seen for HYAM (figure 5.5) and OEH (figure 5.6) are very similar. For both substances and in the samples from all three individuals pretreatment with one of these two hydroxylamines leads to a hydroxylamine-concentration dependent decrease in the $\mathrm{H}_{2} \mathrm{O}_{2}$ induced LP. For NODMH the effect occurring is more complex. The amounts of LP products released from erythrocytes from person A were not markedly influenced by NODMH pretreatment. Blood samples from this individual did generally have the lowest induced LP both after direct treatment with hydroxylamines (figure 5.4) and after subsequent $\mathrm{H}_{2} \mathrm{O}_{2}$ treatment (figures 5.5 and 5.6). The erythrocytes from the other two individuals showed a hydroxylamineconcentration dependent increase in $\mathrm{H}_{2} \mathrm{O}_{2}$ induced LP after 1 and $2.5 \mathrm{mM}$ pretreatment. In samples from person $B$ however, the response to $\mathrm{H}_{2} \mathrm{O}_{2}$ was lower in the 5 and $7 \mathrm{mM}$ pretreated samples than the (very high) response in the $2.5 \mathrm{mM}$ pretreated samples.

\section{Enzyme inhibitions}

GST activity was strongly decreased in both HYAM and OEH treated samples (figure 5.8 on page 89 ). For HYAM and OEH the GST activity decreased with about $0.35 \mathrm{U} \cdot \mathrm{g} \mathrm{Hb}^{-1} / \mathrm{mM}$ addition. As a consequence about two-thirds of the initial GST activity was lost at the highest $(=7 \mathrm{mM})$ HYAM and OEH concentrations used. For NODMH no significant changes in the GST activity were found. In contrast the GR activity was only decreased for NODMH, for this substance GR activities in $7 \mathrm{mM}$ incubations were about $20 \%$ lower than the $6.7 \mathrm{U} \cdot \mathrm{g}$ $\mathrm{Hb}^{-1}$ found in control incubations (figure $5.10 \mathrm{~A}$ on page 90 ). The $\mathrm{GR}_{\text {coeff }}$ was slightly decreased in both HYAM $(p=0.025)$ and OEH $(p=0.01)$ treated samples (figure 5.10B). This indicates a decrease in riboflavin availability in these samples [65].

The G6PDH activity was strongly impaired by NODMH (0.76 (SE 0.04) U.g 


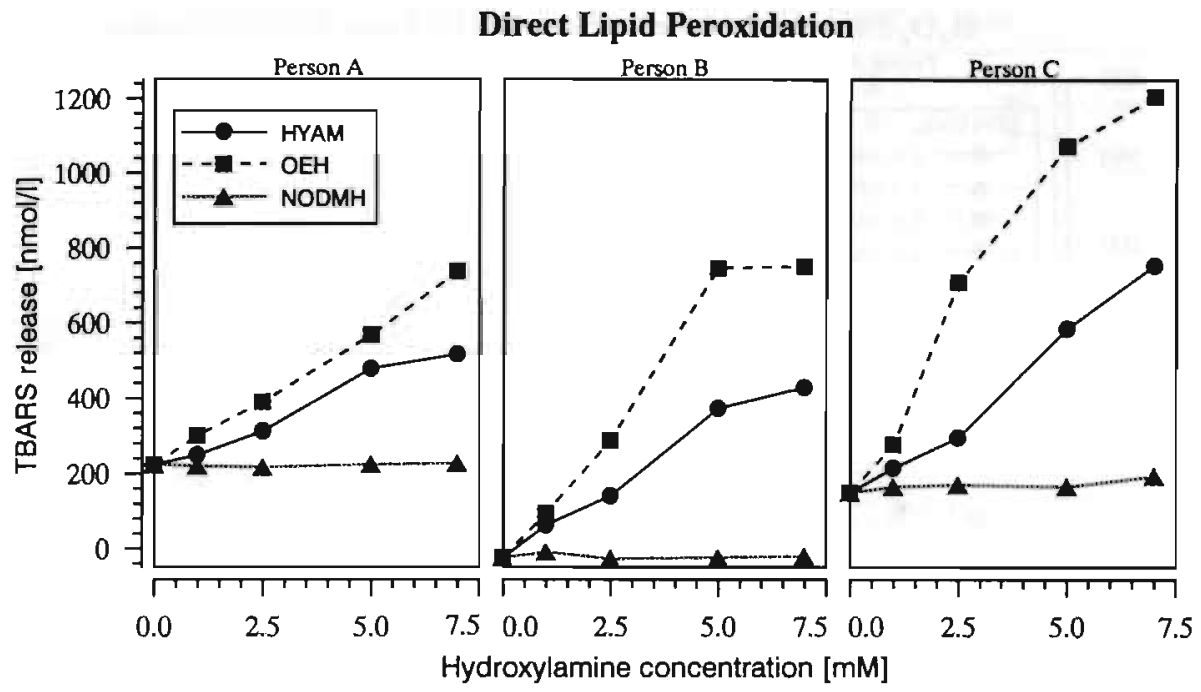

Figure 5.4: Lipid peroxidation, expressed as malondialdehyde equivalents in reactivity towards TBA, in blood samples of three individuals after incubation with hydroxylamines ( 1 hour, $37^{\circ} \mathrm{C}$ ). Regression analyses on the combined data showed significant increases in TBARS release with increasing OEH and HYAM concentrations $(p<0.0001)$.

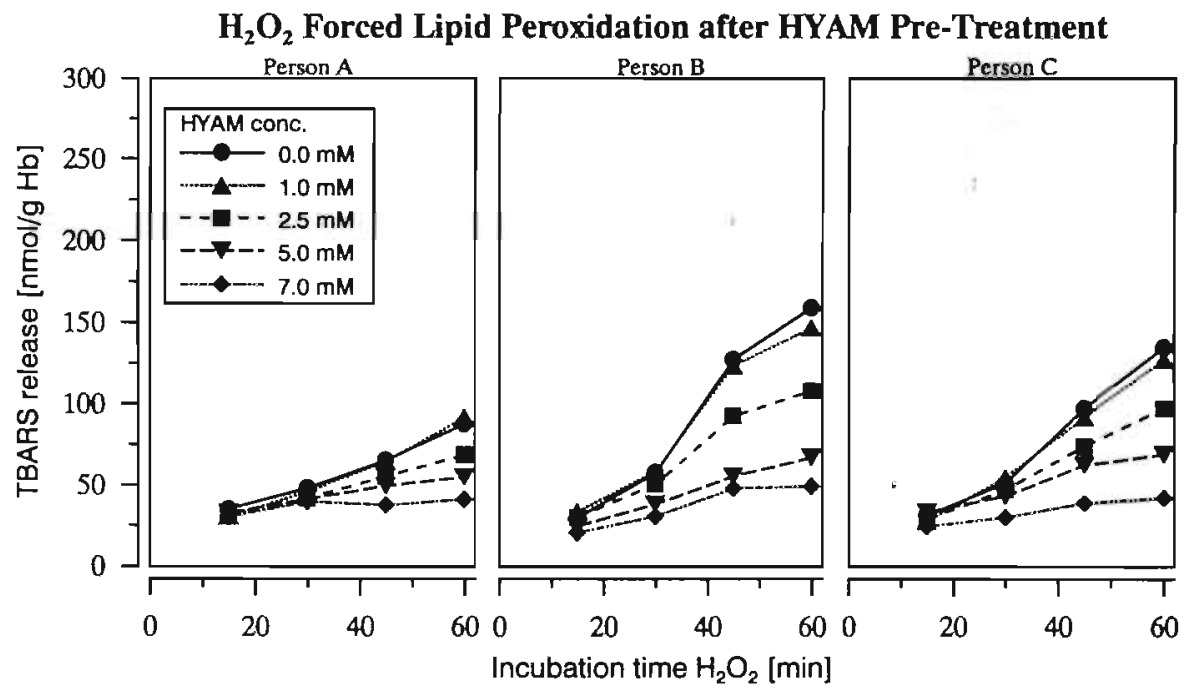

Figure 5.5: Hydrogen peroxide $(10 \mathrm{mM})$ forced lipid peroxidation, expressed as malondialdehyde equivalents in reactivity towards TBA, in erythrocytes of three individuals after pre-incubation of blood with various concentrations of HYAM (1 hour, $\left.37^{\circ} \mathrm{C}\right)$. 


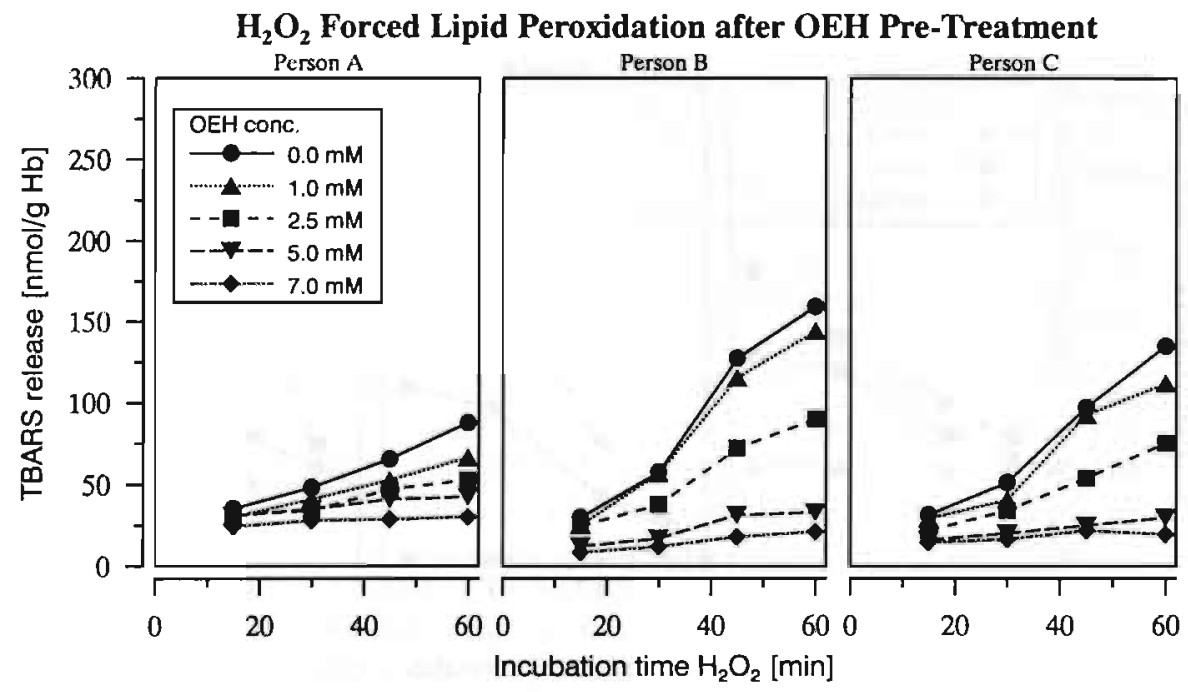

Figure 5.6: Hydrogen peroxide (10 mM) forced lipid peroxidation, expressed as malondialdehyde equivalents in reactivity towards TBA, in erythrocytes of three individuals after pre-incubation of blood with various concentrations of $\mathrm{OEH}$ (1 hour, $37^{\circ} \mathrm{C}$ ).

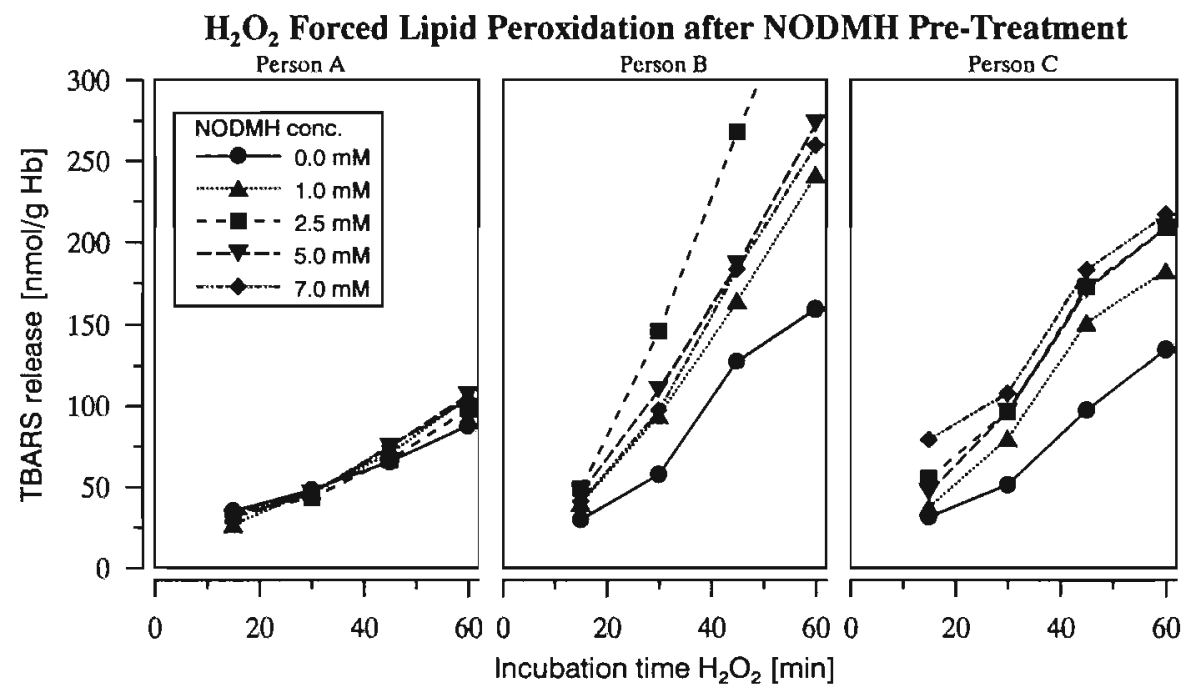

Figure 5.7: Hydrogen peroxide (10 mM) forced lipid peroxidation, expressed as malondialdehyde equivalents in reactivity towards TBA, in erythrocytes of three individuals after pre-incubation of blood with various concentrations of NODMH (1 hour, $37^{\circ} \mathrm{C}$ ). 


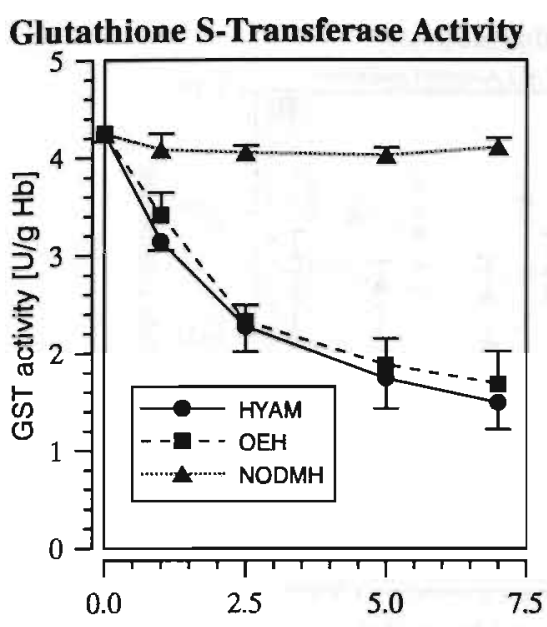

Hydroxylamine concentration [mM]

Figure 5.8: Activity of glutathione Stransferase in human erythrocytes after incubation with hydroxylamines (1 hour, $37^{\circ} \mathrm{C}$ ). Regression analyses showed significant decreases in GST activity with increasing HYAM and OEH concentrations $(p<0.0001)$.

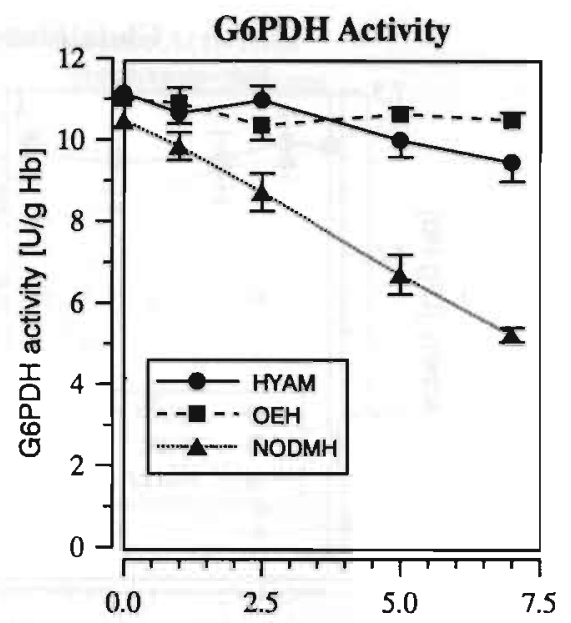

Hydroxylamine concentration [mM]

Figure 5.9: Activity of glucose 6-phosphate dehydrogenase in human erythrocytes after incubation with hydroxylamines $\left(1\right.$ hour, $\left.37^{\circ} \mathrm{C}\right)$. Regression analyses showed significant decreases in activity of G6PDH with increasing concentrations of OEH and NODMH $(p<0.0001)$.

$\mathrm{Hb}^{-1}$ lost $/ \mathrm{mM}$ NODMH), leading to about $50 \%$ reduction at the highest $(=7 \mathrm{mM})$ NODMH concentration tested (figure 5.9). For OEH a much smaller decrease was found $(0.23$ (SE 0.04$) \mathrm{U} \cdot \mathrm{g} \mathrm{Hb} \mathrm{Hb}^{-1} / \mathrm{mM} \mathrm{OEH}$ ). For HYAM only a small tendency towards impairment of G6PDH activity was found, which was not statistically significant $(p=0.14)$. The activity of another pentose-phosphate shunt enzyme tested, glucose-phosphate isomerase, was not significantly influenced by any of the three hydroxylamines. NADH-HbR activity was only impaired by HYAM. The control activity of $1.9 \mathrm{U} \cdot \mathrm{g} \mathrm{Hb} \mathrm{Hb}^{-1}$ fell to about $1.5 \mathrm{U} \cdot \mathrm{g} \mathrm{Hb}^{-1}$ in $7 \mathrm{mM}$ HYAM incubations (figure $5.11 \mathrm{~A}$ on page 91 ). NADPH-HbR activity was strongly decreased in incubations with both HYAM and OEH. For both substances the decrease amounted to about $0.17 \mathrm{U} \cdot \mathrm{g} \mathrm{Hb} \mathrm{Hb}^{-1}$ for each $\mathrm{mM}$ addition, and a result less than $20 \%$ of the control activity was found in the $7 \mathrm{mM}$ incubations (figure $5.11 \mathrm{~B}$ on page 91).

\section{Discussion}

On the whole the effects caused by HYAM and OEH were very much alike, while the effects of NODMH differed markedly. A schematic representation of the mechanisms involved is given in figure 5.12 on page 92. For HYAM and OEH massive 


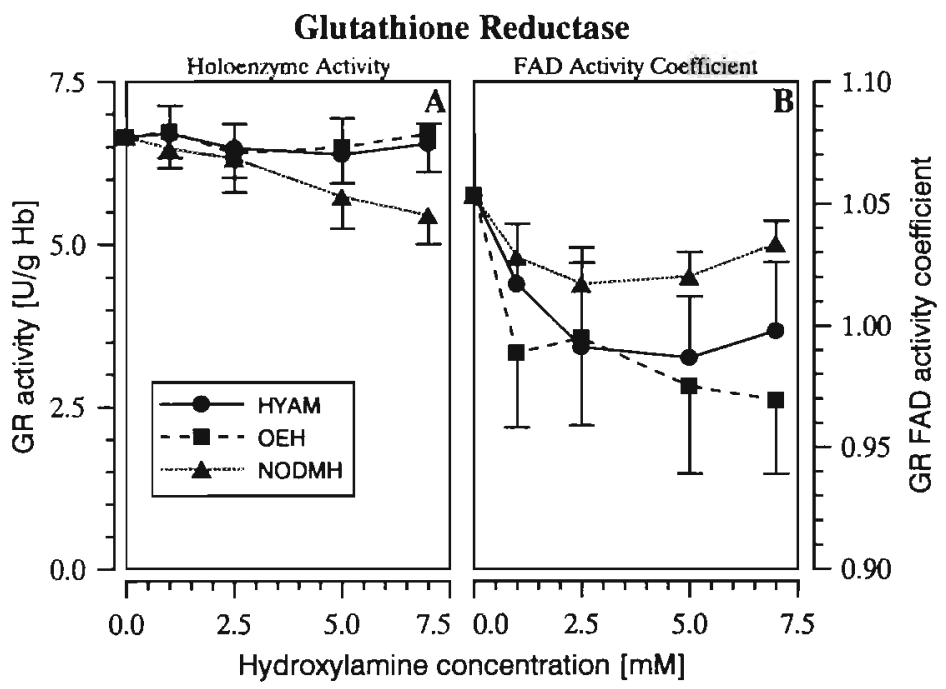

Figure 5.10: A: Activity of glutathione reductase (holoenzyme) and B: FAD activity coefficient of glutathione reductase in human erythrocytes after incubation with hydroxylamines $\left(1\right.$ hour, $\left.37^{\circ} \mathrm{C}\right)$. The coefficients were calculated by division of the activity in the presence of FAD $(11.75 \mu \mathrm{M})$ by the activities determined in a parallel assay without FAD addition. Regression analyses showed a significant decrease in GR activity with increasing NODMH concentration $(p=0.0002)$ as well as significant decreases in FAD activity coefficients with increasing HYAM $(p=0.025)$ and $\mathrm{OEH}(p=0.010)$ concentrations.

methemoglobin formation was found, for NODMH this was much lower. HYAM forms complexes with hemoproteins, for instance leading to inactivation of catalase $[1,16,42]$. Methemoglobin formation in vitro was previously described for HYAM $[7,11,16,18,63,66]$ and NODMH [11]. The mechanism of methemoglobin furmation by HYAM is known to differ from that induced by nitrite [18]. Reaction of HYAM with hemoglobin involves $\mathrm{Hb} / \mathrm{Hb}^{+}$cycle reactions $[7,16]$, and leads to decomposition of HYAM. The methemoglobin forming reaction, which produces $\mathrm{NH}_{3}$ from HYAM, was found to be very fast, explaining the high methemoglobin concentrations found. During the other step of the cycle $\mathrm{N}_{2}$ is formed. Stolze and Nohl [6:3] proved with electron spin resonance spectroscopy techniques that free hydronitroxide radicals $\left(\mathrm{NH}_{2} \mathrm{O} \cdot\right)$ are formed as intermediates in the methemoglobin formation induced by HYAM. Stoichiometric considerations lead them to the expectation that $\mathrm{H}_{2} \mathrm{O}_{2}$ and active oxygen species might also be formed. This radical formation can be one of the causes for LP.

The reduced availability of GSH will also facilitate LP. GSH consumption ("in he the result of direct oxidation, of reversed GR activity as resulting from the need fior extra NADP reduction, and of use in the protective reactions catalysed 


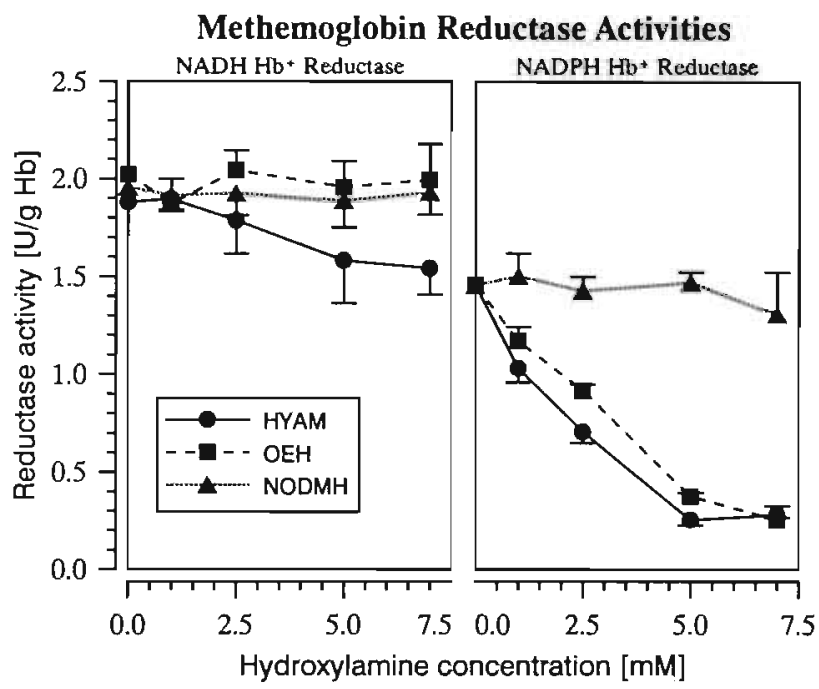

Figure 5.11: Activity of A: NADH methemoglobin reductase and B: NADPH methemoglobin reductase in human erythrocytes after incubation with hydroxylamines ( 1 hour, $37^{\circ} \mathrm{C}$ ). Regression analyses showed a significant decrease in $\mathrm{NADH}$ methemoglobin reductase with increasing HYAM concentrations ( $p=$ 0.002 ) and significant decreases in NADPH methemoglobin concentrations with increasing HYAM and OEH concentrations $(p<0.0001)$.

by GST and glutathione peroxidase $[15,56]$. In this respect LP formation may not only be facilitated by GSH depletion [17] but may also provoke it [56]. This agrees with our finding that $\mathrm{OEH}$ as the substance with the highest LP activity also gives the highest GT depletion. Loss of 4-PDS-reactive HbSH groups was not found. After treatment with electrophilic agents such a loss can be clearly demonstrated [23]. However, oxidative loss of HbSH groups for instance by formation of mixed disulfides with GSH, will probably not be picked up by this assay, as dithiodipyridines are able to break GSH sulfhydryl bindings [13]. Such a formation of mixed disulfides may well have occurred in our experiments, since the increases in extracellular GT (mainly present as oxidized glutathione) did not make up for the loss of GT from the erythrocytes. Formation of mixed disulfides from proteins and GSH are a general result of glutathione oxidation [53]. Grossman et al. [31] found that mixed disulfide formation in erythrocytes was one of the most important effects of the hydroxylamine metabolite of dapsone. The finding by Kotsifopoulos [43] that HYAM is able to change the electrophoretic behavior of erythrocyte membrane proteins, also indicates the occurrence of mixed disulfides.

$\mathrm{Hb}^{+}$formation, GT depletion and membrane damage - as indicated by LP - are all strongly associated with cellular damages like Heinz body formation 


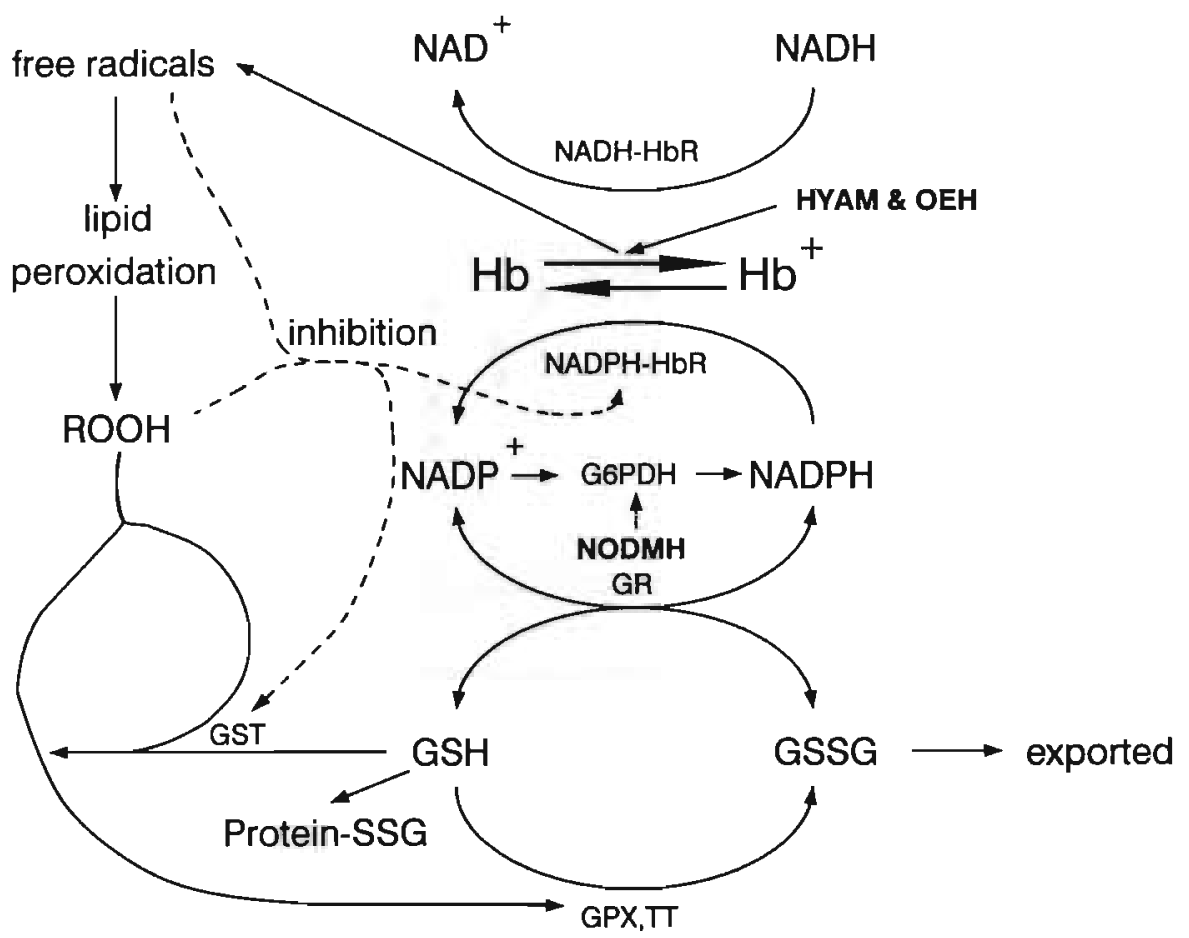

Figure 5.12: Schematic representation of the proposed mechanisms for hydroxylamine erythrotoxicity. Hydroxylamine (HYAM) and the O-ethyl derivative $(\mathrm{OEH})$ induce formation of methemoglobin. During this process free radicals are formed that induce lipid peroxidation. The free radicals plus the lipid peroxides (ROOH) formed lead to inhibition of glutathione S-transferase (GST) and NADPH methemoglobin reductase (NADPH-HbR). The oxidative stress occurring leads to depletion of glutathione (GSH) by various routes. N-substituted hydroxylamines like $\mathrm{N}, \mathrm{O}$-dimethyl hydroxylamine (NODMH) inhibit glucose 6phosphate dehydrogenase ( $\mathrm{G} 6 \mathrm{PDH})$, and to a lesser extend glutathione reductase (GR). The resulting inability to reduce $\mathrm{NADP}^{+}$and glutathione renders the erythrocyte more vulnerable to oxidative stress, including that caused by HYAM and OEH. Other abbreviations used: GPX = glutathione peroxidase, ProteinSSG $=$ protein-glutathione mixed disulfides, $\mathrm{TT}=$ thiol transferase.

and hemolysis. Induction of this kind of damage by the two substances with high potencies for $\mathrm{Hb}^{+}$formation, GT depletion and LP is therefore in accordance with expectations. For HYAM Heinz body formation in mice [69] and in pigs [59] were previously reported.

It is well known that LP products can give rise to inhibition of several enzymes $[48,61,701$, and to protein damage in general [21]. Purified rat GST-P 
(7-7), which is equivalent to human GST $\pi$ - the form of GST predominating in human erythrocytes [28]- is very vulnerable to oxidative stress $[47,57,58,68]$. The human enzyme itself is also inhibited by $\mathrm{H}_{2} \mathrm{O}_{2}$ [57]. This was confirmed in control experiments where erythrocytes were treated directly with $\mathrm{H}_{2} \mathrm{O}_{2}$ (data not shown). Previously we showed that GST activity in human erythrocytes is impaired by occupational exposure to coal tar products [24] and to the pesticide dichloropropene [10], in miners with early forms of pneumoconiosis [26] and after long-distance running [25]. At least in the latter two cases oxidative stress is the most likely cause for GST activity loss. Therefore, activity loss of GST under conditions causing LP was expected beforehand. In fact these experiments were included in order to examine the possible use of GST activity loss as a biomarker for hydroxylamine exposure. As expected, GST inactivation was only found for the strong LP causing substances HYAM and OEH and not for NODMH. NADPH-HbR was also strongly inhibited by HYAM and OEH and not by NODMH. Inhibition of NADPH-HbR by HYAM was previously shown by Layne and Smith [44], and does explain the lowered effectiveness of methylene blue treatment in case of HYAM poisoning in mice [60]. The absence of inhibition by NODMH indicates a possible relation between radical stress and inhibition of this reductase. The loss of riboflavin, as indicated by the decreases in $\mathrm{GR}_{\text {coeff }}$ after HYAM and OEH treatment, might also be caused by consumption during radical scavenging.

NODMH showed far less activity in most aspects discussed so far. $\mathrm{Hb}^{+}$formation was low, LP, hemolysis and Heinz body formation were not found, GST and NADPH-HbR inhibition were absent, and riboflavin loss was not found. On the other hand NODMH treatment of erythrocytes resulted in a strong decrease of G6PDH activity, consistent with the earlier findings by Martin et al. [46]. GR activity was also decreased by NODMH, but since more than $80 \%$ of GR activity was still present at NODMH concentrations of $7 \mathrm{mM}$, this may be of less importance. Interestingly GT concentrations in erythrocytes were decreased by NODMH while GT in plasma was even more increased than for the two other hydroxylamines. GT depletion by NODMH can be the result of oxidation in glutathione peroxidation and thiol transferase reactions, combined with lower availability of NADPH reduction equivalents for GR activity, due to G6PDH inhibition. Even the G6PDH inactivation alone will render the erythrocyte much more vulnerable to oxidative stress from subsequent exposure to other oxidative compounds. This is confirmed by the fact that NODMH treated erythrocytes did show a higher vulnerability towards subsequent $\mathrm{H}_{2} \mathrm{O}_{2}$ induced LP. The same kind of effect was to be expected if a glucose-phosphate isomerase inhibition had occurred [55], but such an inhibition was not found for any of the hydroxylamines tested. Contrary to what might have been expected HYAM and OEH pretreatment did not lead to an increased vulnerability to $\mathrm{H}_{2} \mathrm{O}_{2}$. This is however easily explained. For $\mathrm{H}_{2} \mathrm{O}_{2}$ induced LP in erythrocytes ferrous-hemoglobin is a prerequisite [14]. After HYAM and OEH treatment a large fraction of hemoglobin is 
converted to the ferric form, necessarily leading to a decrease in LP. It should be noted that changes in $\mathrm{H}_{2} \mathrm{O}_{2}$ resistance cannot be the result of catalase inhibition by the hydroxylamines, since $\mathrm{NaN}_{3}$ was added to the assays in order to obtain a full inhibition of catalase. HYAM is known to inhibit catalase both in vitro $[1,16]$ and in vivo in mouse liver $[42]$, and this inhibition will in itself increase the vulnerability of erythrocytes to oxidative stress.

To our knowledge induction of LP by aliphatic hydroxylamines has not been described previously. The occurrence of this phenomenon in erythrocytes exposed to HYAM and OEH indicates the availability of free radicals, possibly including active oxygen species. The presence of active oxygen species and of the resulting peroxides in vivo is associated with increased cancer risks and accelerated aging $[4,19,27,40,64,67]$. It should be noted however that radical production in this case seems to be strongly linked to the presence of hemoglobin. In pilot experiments with HYAM we did not see any LP in washed erythrocyte membranes or in isolated rat hepatocytes. Since erythrocytes do not contain a nucleus, direct DNA damage is excluded. On the other hand reactive products formed in erythrocytis might of course reach other cells and provoke damage there, and sortlike radical mechanisms might be induced by hydroxylamines at hemoproteins elsewhere. In the carcinogenicity studies performed so far $[34,49,50,72]$, no clear carcinngrnic efferts were found. However, the quality of these studies is insufficient 10 decide whether HYAM is an animal carcinogen [8]. HYAM showed some anti-carcinogenic activity with respect to virus induced mammary tumors in mice when treatment was started at an early age [49]. Some other carcinostatic effects of hydroxylamine have also been described [30]. Diethyl hydroxylamine has relatively strong antitumorogenic properties $[36,37]$, it is probably able to terminate free radical processes by sequestration of secondary free radical intermediates [52].

Considering the above, the most serious threat resulting from possible exposure of humans to hydroxylamines seems to come from the direct erythrotoxic effects. $\mathrm{Hb}^{+}$formation, LP, GT depletion and inhibition of protective enzymes can lead to faster senescence of erythrocytes and increased sequestration in the spleen. Next to clinical parameters for anemia and increases in reticulocytes, determination of GST and NADPH-HbR and assessment of LP in vivo [51] may be useful biomarkers to monitor human exposure to hydroxylamines with direct oxidative activity, like HYAM and OEH. Two special aspects should be noted: 1) due to the inhibition of NADPH-HbR by hydroxylamines like HYAM and OEH and due to the inhibition of G6PDH by compounds like NODMH and trimethyl hydroxylamine, treatment of accidental methemoglobinemia with methylene blue may fail, 2) exposure to compounds like NODMH and trimethyl hydroxylamine will inhibit G6PDH and thereby will render the erythrocytes more vulnerable to a subsequent exposure to direct oxidative compounds. Because of the latter, determination of G6PDH activitins may also serve as a valuable biomarker when exposure to this group of hydroxylamines can occur. 
Acknowledgment. The authors are grateful to Dr. L. Volovics and Dr. A. Kester of the department for Methodology and Statistics for valuable advices on statistical procedures, to Astrid Feijts for assistance with the analyses of glucose-phosphate isomerase and NADPH-HbR; to Mrs. M. Catsberg from the "Maasland Hospital" (Sittard, NL) for her assistance with the Heinz body determinations and to the "Red Cross Bloodbank, South-Limburg" for the blood samples used. Financial support was given by DSM Special Products b.v. (Geleen, NL). 


\section{References}

[1] Adams D.H. and Roe F.J. (1953). The action of some chemical substances on mouse liver catalase activity in vivo. $\mathrm{Br} J$ Cancer 7: 509-518.

[2] Anderson M.E. (1985). Determination of glutathione and glutathione disulfide in biological samples. Meth Enzymol 113: 548-555.

[3] Arnoldova K.A. and Speransky N.N. (1963). Some aspects of the effect produced by muriatic hydroxylamine on the animal body. Gig Tr Prof Zabol 7: 38-42.

[4] Bandy B. and Davison A.J. (1990). Mitochondrial mutations may increase oxidative stress: implications for carcinogenesis and aging? Free Rad Biol Med 8: 523-539.

[5] BASF AG, Department of Toxicology (1989). Bericht Prüfung der oralen Toxicität von Hydroxylaminsulfat an Ratten, Verabreichung im Trinkwasser über 3 monate. Projekt-Nr.32C0389/8474, (cited in: [8]).

[6] Bauer J.D. (1980). Laboratory investigation of hemoglobin. In: Gradwohl's clinical laboratory methods and diagnosis Volume 1 (8th ed), (Sonnenwirth A.C. and Jarett L. Eds.), C.V. Mosby Company, St. Louis, pp. 809-902.

[7] Bazylinsky D.A., Arkowitz R.A. and Hollocher T.C. (1987). Decomposition of hydroxylamine by hemoglobin. Arch Biochem Biophys 259: 520-526.

[8] Berufsgenossenschaft der chemischen Industrie (1991). Hydroxylamin und seine Salzr. Toxicologische Bewertung nr. 62. Heidelberg.

[9] Beutler E. (1975). Red cell metabolism. (A manual of biochemical methods) $2^{\text {nd }}$ Edition. Grune \& Stratton, New York

[10] Brouwer E.J., Evelo C.T.A., Verplanke A.J.W., van Welie R.T.H. and de Wolff F.A. (1991). Biological effect monitoring of exposure to 1,3-dichloropropene: effects on liver and renal function and on glutathione conjugation. $B r J$ Ind Med 48: $167-172$.

[11] Calabrese E.J., Tilli F., Horton H.M. and Stoddard A. (1988). The effects of ethanol on the hematotoxicity of twelve pharmaceutical and environmental agents. $J$ Environ Sci Health A23: 359-367.

[12] Carlberg I. and Mannervik B. (1985). Glutathione reductase. Meth Enzymol 113: 484-490.

[13] Carlsson J., Svenson A. and Rydén L. (1977). Isolation of cysteine peptides from proteins by solid-phase techniques based on thiol-disulfide exchange. In: Solid phase methods in protein sequence analysis. INSERM symp. no. 5. (Previero A. and Coletti-Previero M.-A., Eds). Elsevier, Amsterdam, pp. 29-37.

[14] Clemens M.R., Einsele H., Remmer H. and Waller H.D. (1985). An essential requirement for ferrous-haemoglobin in the hydrogen peroxide stimulated oxidation of red blood cell membrane lipids. Biochem Pharmacol 34: 1339-1341.

[15] Coles B. and Ketterer B. (1990). The role of glutathione and glutathione transferases in chemical carcinogenesis. Crit Rev Biochem Mol Biol 25: 47-70.

[16] Colter J.S. and Quastel J.H. (1950). Catalytic decomposition of hydroxylamine by hemoglobin. Arch Biochem 27: 368-389.

[17] Comporti M. (1989). Three models of free radical-induced cell injury. Chem Biol Interact 72: $1-56$. 
[18] Cranston R.D. and Smith R.P. (1971). Some aspects of the reaction between hydroxylamine and hemoglobin derivatives. J Pharmacol Exp Ther 177: 440-446.

[19] Cutler R.G. (1991). Antioxidants in aging. Am J Clin Nutr 53: 373S-379.

[20] Derelanko M.J., Gad S.C., Gavigan F.A., Babich P.C. and Rinehart W.E. (1987). Toxicity of hydroxylamine sulfate following dermal exposure: variability with exposure method and species. Fund Appl Toxicol 8: 583-594.

[21] Desai I.D. and Tappel A.L. (1963). Damage to proteins by peroxidized lipids. $J$ Lipid Res 4: 204-207.

[22] Engelen J.J.M., Borm P.J.A., van Sprundel M. and Leenaerts L. (1990). Blood anti-oxidant parameters at different stages of pneumoconiosis in coal workers. Env Health Perspect 84: 165-172.

[23] Evelo C.T.A. and Henderson P.Th. (1988). Influence of glutathione on the formation of cysteine alkylation products in human hemoglobin. Toxicology 52: 177186.

[24] Evelo C.T.A. and Henderson P.Th. (1992). Biological Effect Monitoring. Arch Toxicol suppl. 15: 268-277.

[25] Evelo C.T.A., Palmen N.G.M., Artur Y. and Janssen G.M.E. (1992). Changes in blood glutathione concentrations, and in erythrocyte glutathione reductase and glutathione S-transferase activity after running training and after participation to contests. Eur J Appl Physiol 64: 354-358.

[26] Evelo C.T.A., Bos R.P. and Borm P.J.A. (1993). Decreased glutathione content and glutathione S-transferase activity in red blood cells of coal miners with early stages of coal miners pneumoconiosis. Br J Ind Med 50: 633-636.

[27] Farber J.L., Kyle M.E. and Coleman J.B. (1990). Biology of disease. Mechanisms of cell injury by activated oxygen species. Lab Invest 62: 670-679.

[28] Fazi A., Accorsi A., Piatti E. and Magnani M. (1991). Cell age dependent decay of human erythrocytes glutathione S-transferase. Mech Ageing Dev 58: 255-266.

[29] Grassetti D.R. and Murray J.F. Jr. (1967). Determination of sulfhydryl groups with 2,2'- or 4,4'-dithiopyridine. Arch Biochem Biophys 119: 41-49.

[30] Gross P. (1985). Biologic activity of hydroxylamine: a review. Crit Rev Toxicol 14: 87-99.

[31] Grossman S.J., Simson J. and Jollow D.J. (1992). Dapsone-induced hemolytic anemia: effect of $\mathrm{N}$-hydroxy dapsone on the sulfhydryl status of membrane proteins of rat erythrocytes. Toxicol Appl Pharmacol 117: 208-217.

[32] Habig W.H. and Jakoby W.B. (1981). Assays for the differentiation of glutathione S-transferases. Meth Enzymol 77: 398-405.

[33] Hak Hyun B., Gulati G.L. and Ashton J.K. (1986). Color atlas of clinical chemistry. Igaku-Shoin, New York-Tokyo. pp. 66-67 and pp. 140-141.

[34] Harman D. (1961). Prolongation of the normal lifespan and inhibition of spontaneous cancer by antioxidants. $J$ Gerontol 16: 247-254.

[35] Hegesh E., Calmanovici N. and Avron M. (1968). New method for determining ferrihemoglobin reductase (NADH methemoglobin reductase) in erythrocytes. $J$ Lab Clin Med 72: 339-344.

[36] Heicklen J., Meagher J.F., Weaver J, Kelly N., Partymiller K., Latt R., Ferguson F., Putman C., Sapanski W. and Billups L. (1981). Toxicological testing of rats 
subjected to inhalation of diethylbydroxylamine, nitroethane and diethylamine hydrogen sulfite. Environ Res 26: 258-273.

[37] Heicklen J., Lundgard R., Partymiller K., Ferguson F., Putman C., Sapanski W., Tankard J. and Billups L. (1982). Chronic inhalation study of mice subjected to diethylhydroxylamine, nitroethane and diethylamine hydrogen sulfite. Eaviron Res 27: 277 -289.

[38] Huennekens F.M., Caffrey R.W., Basford R.E., Gabrio B.W. (1957). Erythrocyte metabolism IV. Isolation and properties of methemoglobin reductase. $J$ Biol Chem 227: 261-272.

[39] Jacobsen E, Plum C.M. and Milwertz I. (1939). Experimental anemias with hydroxylamine and their relation to human pernicious anemia. Nord Med 3: 28512858.

[40] Janssen Y.M.W., Van Houten B., Borm P.J.A. and Mossman B.T. (1993). Biology of disease. Cell and tissue responses to oxidative damage. Lab Invest 69: 261-274.

[41] Kampen van E.J. and Zijlstra W.G. (1965) Determination of hemoglobin and its derivatives. Adv Clin Chem 8: 141-187.

[42] Keilin D. and Hartree E.F. (1936). On some properties of catalase haematin. Proc Roy Soc (London) B121: 173-191.

[43] Kotsifopoulos P.N. (1975). In vitro effect of oxidizing and analgesic agents on the erythrocyte membrane protein electrophoretic pattern. Nouv Rev Fr Hematol 15: 141-146.

[44] Layne W.R. and Smith R.P. (1969), Methylene blue uptake and the reversal of chemically induced methemoglobinemias in human erythrocytes. Pharmacol Exp Ther 165: 36-44.

[45] Makotchenko V.M. and Rutshtein L.P. (1974). Poisoning with hydroxylamine hydrochloride. Vrach Delo 7: 125-127.

[46] Martin H., Wörner W. and Rittmeister B. (1964). Hämolytische Anämie durch Inhalation von Hydroxylamine. Zugleich ein Beitrag zur Frage der Heinz-KörperBildung. Klin Wochenschr 15: 725-731.

[47] Murata T., Hatayama I., Satoh K., Tsuchida S. and Sato K. (1990). Activation of rat glutathione transferases in class mu by active oxygen species. Biochem Biophys Res Comm 171: 845 .851.

[48] O'Malley B.W., Mengel C.E., Meriwether W.D. and Zirkle L.G., Jr. (1966). Inhibition of erythrocyte acetylcholinesterase by peroxides. Biochemistry 5: 40-45.

[49] Poukka Evarts R. and Brown C.A. (1977). Morphology of mammary gland, ovaries, and pituitary gland of hydroxylamine-fed C3H/HeN mice. Lab Invest 37: 53-63.

[50] Poukka Evarts R., Brown C.A. and Atta G.J. (1979). The effect of hydroxylamine on the morphology of the rat mammary gland and on the induction of mammary tumors by 7,12-dimethylbenz(a)anthracene. Exp Mol Pathol 30: 337-348.

[51] Pryor W.A. and Godber S.S. (1991). Noninvasive measures of oxidative stress status in humans. Free Rad Biol Med 10: 175-176.

[52] Reddy C.C, Scholz R.W., Chih-Ying H., Burgess J.R., Massaro E.J. and Heicklen J. (1985). Effects of diethylhydroxylamine on hepatic microsomal lipid peroxidation and glutathione S-transferases. $J$ Toxicol Env Health 15: 467-475. 
[53] Reed D.J. (1990). Glutathione: toxicological implications. Annu Rev Pharmacol Toxicol 30: 603-631.

[54] Riemann H. (1950). On the toxicity of hydroxylamine. Acta Pharmacol Toxicol 6: $285-290$.

[55] Schröter W., Koch H.H., Wonneberger B., Kalinkowsky W., Arnold A., Blume K.G. and Hüther W. (1974). Glucose phosphate isomerase deficiency with congenital nonspherocytic hemolytic anemia: a new variant. Pediatr Res 8: 18-25.

[56] Shan X., Aw T.Y. and Jones D.P. (1990). Glutathione-dependent protection against oxidative injury. Pharmacol Ther 47: 61-71.

[57] Shen H., Tamai K., Satoh K., Hatayama I., Tsuchida S., and Sato K. (1991). Modulation of class $\mathrm{Pi}$ glutathione transferase activity by sulfhydryl group modification. Arch Biochem Biophys 286: 178-182.

[58] Shen H., Tsuchida S., Tamai K., and Sato K. (1993). Identification of cysteine residues involved in disulfide formation in the inactivation glutathione transferase P-form by hydrogen peroxide. Arch Biochem Biophys 300: 137-141.

[59] Sinha D. and Sleight S.D. (1968). Experimental production of Heinz bodies in the pig. Toxicol Appl Pharmacol 12: 435-439.

[60] Smith R.P. and Layne W.R. (1969). A comparison of the lethal effects of nitrite and hydroxylamine in the mouse. J Pharmacol Exp Ther 165: 30-35.

[61] Stadtman E.R. (1986). Oxidation of proteins by mixed-function oxidation systems: implication in protein turnover, ageing and neutrophil function. Trends in Biochemical Sciences (TIBS) 11: 11-12.

[62] Stocks J. and Dormandy T.L. (1971). The autoxidation of human red cell lipids induced by hydrogen peroxide. Br $J$ Haematol 20: 95-111.

[63] Stolze K. and Nohl H. (1989). Detection of free radicals as intermediates in the methemoglobin formation from oxyhemoglobin induced by hydroxylamine. Biochem Pharmacol 38: 3055-3059.

[64] Sun Y. (1990). Free radicals, antioxidant enzymes, and carcinogenesis. Free Rad Biol Med 8: 583-599.

[65] Tietz N.W. (Ed.) (1986). Textbook of clinical chemistry. W.B Saunders, Philadelphia.

[66] Tomoda A., Matsukawa S., Tatkeshita M. and Yoneyama Y. (1977). Opposite effects of organic phosphates on hemoglobin oxidation by hydroxylamine under aerobic and anaerobic conditions. J Biol Chem 252: 6105-6107.

[67] Trush M.A. and Kensler T.W. (1991). An overview of the relationship between oxidative stress and chemical carcinogenesis. Free Rad Biol Med 10: 201-209.

[68] Tsuchida S. and Sato K. (1992). Glutathione transferases and cancer. Crit Rev Biochem Mol Biol 27: 337-384.

[69] Webster S.H., Liljegren E.J., and Zimmer D.J. (1949). Heinz body formation by certain chemical agents. J Pharmacol Exp Ther 95: 201-211.

[70] Wills E.D. (1961). Effect of unsaturated fatty acids and their peroxides on enzymes. Biochem Pharmacol 61: 7-16.

[71] Winter A.J. and Hokanson J.F. (1964). Effects of long-term feeding of nitrate, nitrite, or hydroxylamine on pregnant dairy heifers. Am J Vet Res 25: 353-361. 
[72] Yamamoto R.S., Weisburger E.K. and Korziz J. (1967). Chronic administration of bydroxylamine and derivatives in mice. Proc Soc Exp Biol Med 124: 1217-1220. 


\section{Chapter 6}

\section{Biological Effect Monitoring}

C.T.A. Evelo ${ }^{1}$ and P.Th. Henderson ${ }^{2}$

Department of Occupational \& Environmental Health and Toricology,

University of Limburg, Maastricht, The Netherlands.

1: Present address:

Department of Pharmacology (Toxicology section)

University of Limburg, P.O. Box 616, 6200 MD Maastricht, The Netherlands.

2: Present address:

$M B L-T N O$

P.O. Box 5815, 2280 AA Rijswijk, The Netherlands.

Published in: Arch Toxicol suppl. 15, 1992, 268-277. 


\section{Introduction}

Monitoring activities have an important role in occupational and environmental practice. Techniques to detect and to control chemical exposure in order to protect people from environmental and occupational illness are rapidly expanding. Most obvious are the methods related to the evaluation of the presence of xenobiotic chemical agents either in the contaminated environment or in the exposed organism. In the first case the procedures are indicated as environmental monitoring (EM). In inhalatory exposure, estimations can be made of the 'intake' or 'external load' on the basis of known concentrations in the ambient air. The actual 'uptake' or 'internal load', however, can only be approximated by means of EM methods. On the other hand, measurement of the chemical agents and/or their metabolites in tissues, secreta or excreta of the exposed organism provides an estimate of the total uptake. The latter approach has been defined biological monitoring (BM) (Berlin 1984). In addition to these methods many other preventive activities have

Table 6.1: Overview of monitoring methods in occupational and environmental toxicology.

\begin{tabular}{|c|c|c|}
\hline & Monitoring type: & Assessment of: \\
\hline EM & Environmental Monitoring & external exposure \\
\hline $\mathrm{BM}$ & Biological Monitoring & internal load \\
\hline BEM & Biological Effect Monitoring & $\begin{array}{l}\text { biological effects } \\
\text { (not necessarily health related) }\end{array}$ \\
\hline HS & Health Surveillance & health state \\
\hline
\end{tabular}

been developed, including periodic medico physiological examinations of the exposed people. This approach is more directly related to the detection of early health effects, and is defined as health surveillance (HS). Changes in physiological functions of the organism can be indicative of changes in the state of health as a consequence of a certain chemical exposure. Such information on the state of health or early impairment of health is very useful in the prevention of overt intoxications due to continuation of overexposures. Well-known examples in this area are the increased levels of serum transaminases providing information on hepatotoxic effects, e.g. after exposure to certain halogenated alkanes. Most of the HS parameters a priori have to be regarded as adverse effects, which means that their significance in terms of prevention is limited. 'Early' adverse effect should also be prevented. Generally, an impaired state of health of the organism can be considered as an endpoint of a sequence of several events at lower levels of homeostasis. Such a 'causality chain' can be depicted as shown in figure 6.1. 


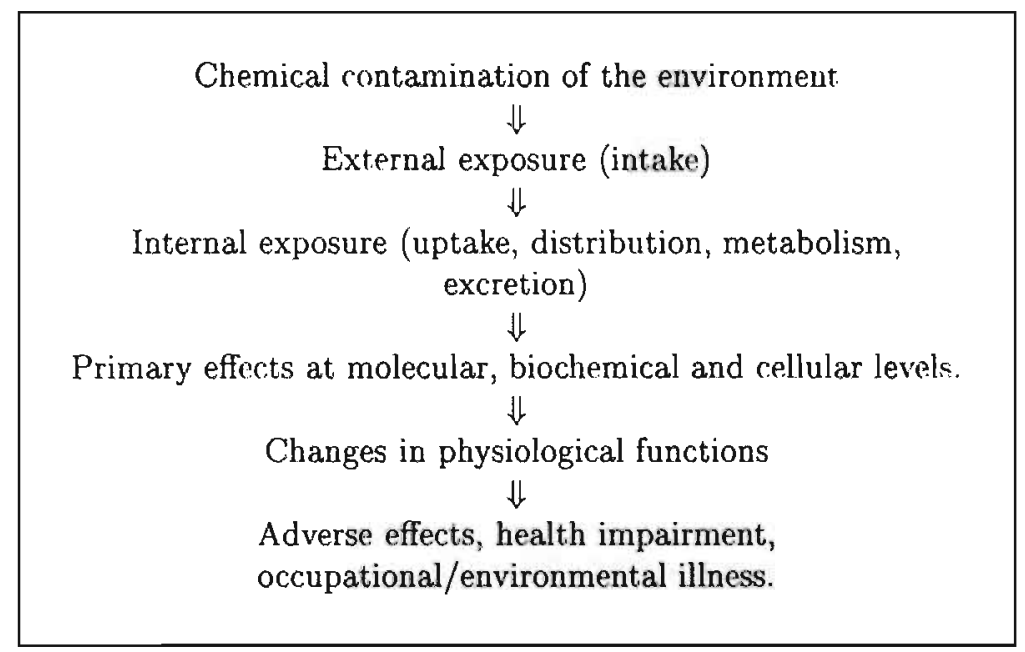

Figure 6.1: Causality chain leading to health effects.

In recent years the arsenal of monitoring techniques has been extended with test methods directed to the assessment of early, possibly reversible, biological effects (Biological effect monitoring: BEM). Mostly it is unknown a priori whether primary biological effects have to be regarded as adverse or nonadverse. In this respect the health significance of biological effect parameters has still to be established. In order to avoid confusion among the various monitoring programmes, Zielhuis and Henderson (1986) proposed the following definition:

Biological effect monitoring (BEM) is "the measurement and assessment of early biological effects, of which the relationship to health impairment has not yet been established, in exposed workers to evaluate exposure and/or health risk compared to an appropriate reference".

Most of the tests for EM and BM are agent specific or specified for certain groups of related chemical, e.g. thioethers, mutagens. The ultimate objective of EM and $\mathrm{BM}$ is to estimate the target dose. Because this dose or concentration in the critical organ is determined by toxicokinetic processes, (distribution, biotransformation, elimination), BM is based on 'the impact of organism on agent'. On the other hand, effect parameters (BEM, HS) refer to toxicodynamic processes and reflect the impact of the target dose on the state of health. Biological effects may be due to many causes: chemical, nonchemical as well as multifactorial causes may be involved. Therefore, BEM and HS are generally agent nonspecific. 


\section{Example: Effects on the Glutathione Dependent Detoxification System in Erythrocytes}

Some aspects of the BEM approach can be exemplified by methods that are based on changes in the glutathione system in erythrocytes after exposure to electrophilic agents.

\section{Glutathione Depletion}

Depletion of liver glutathione (GSH) during exposure to chemically reactive compounds is a well-known phenomenon both in vitro and in vivo. GSH is also involved in the netabolism of many substances that pose an occupational health hazard. This leads to the urinary excretion of thioethers (van Doorn et al., 1981; Henderson et al., 1984), which itself is used for biological monitoring. In principle, exposure to such compounds might lead to a decrease in GSH concentrations not only in the liver but also in more easily accessible material like blood cells. In vitro GSH in erythrocytes can be depleted with thiol reactive substances like iodoacetamide, N-ethylmaleimide and diethylmaleate (Evelo and Henderson, 1988) and also by metabolites of 3-acetamidophenol and cyclophosphamide (Palmen and Evelo, 1993). The reactivity of GSH is so high that it results in an effective protection of cellular macromolecules. Figure 6.2 shows that during in vitro treatment of erythrocytes with iodoacetamide and $\mathrm{N}$-ethylmaleimide the hemoglobin cysteine is not significantly alkylated as long as the intracellular GSH is not fully depleted. This kind of observations prompted us to study GSH levels in some situations where people are potentially exposed to electrophilic agents.

\section{Glutathione S-Transferase Inactivation}

The activity of erythrocyte glutathione S-transferase (GST $\rho$ ) is another interesting, and biochemically related, parameter. The activity of GST in general is known to be susceptible to many chemicals (Mannervik and Danielson, 1988). The in vitro susceptibility of GST activity from human erythrocytes to industrially important electrophiles like acrolein, propylene-oxide, styrene oxide, ethylene dibromide and ethylene dichloride has been described by Ansari et al. (1987). Kilpikari and Savolainen (1984) reported decreased values of erythrocyte GST activity in workers exposed to hot rubber fumes. Normal GST activity is known to vary largely between individuals (Strange et al., 1982). In this respect the comparison of individual pre- and post exposure values is expected to be more sensitive than the comparison with a control group.

\section{Creosote Workers}

In a pilot study we determined GST activities in erythrocytes and GSH in blood of two workers creosoting wood. The samples for this study were collected as part of a biomonitoring study carried out by Jongeneelen and co-workers. Blood and 


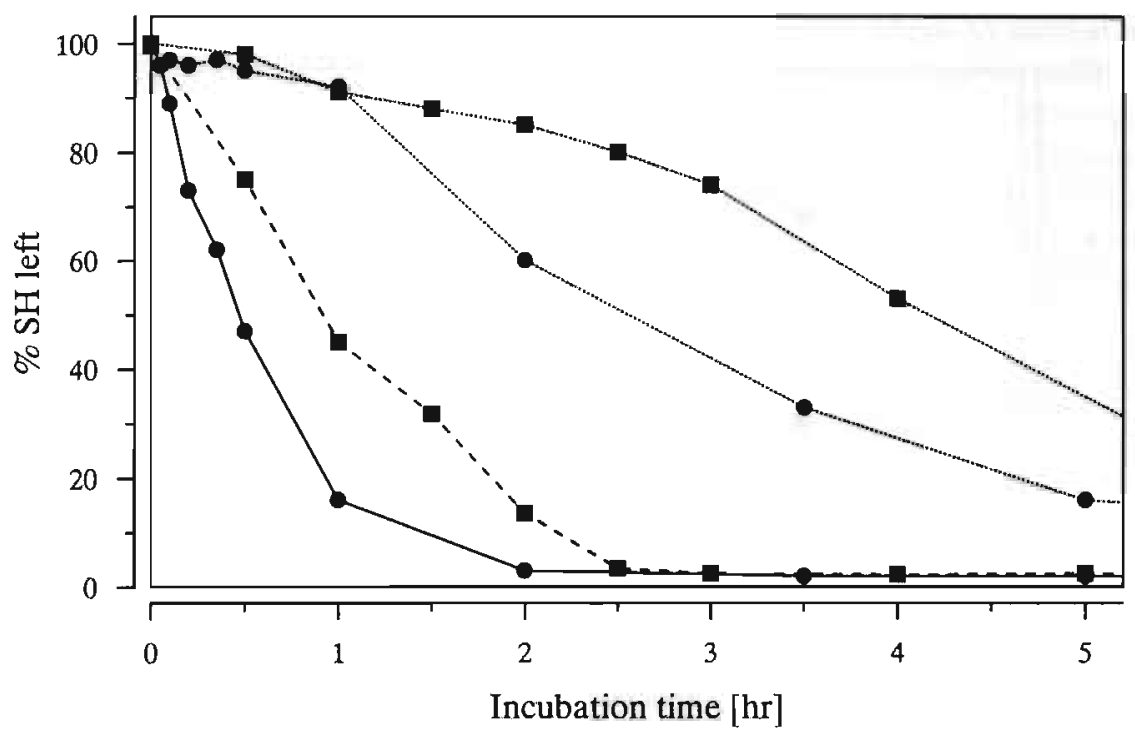

Figure 6.2: Free sulfhydryl groups of hemoglobin $(\mathrm{Hb}, \cdots)$ and glutathione ( $\mathrm{GSH},-$ ) after incubation of human blood with the depletors iodoacetamide (IACA, $\bullet, 1$ hour) and $\mathrm{N}$-ethylmaleimide (NEM, $\mathrm{N}, 15 \mathrm{~min}$.) at $37^{\circ} \mathrm{C}$. Data are the mean of duplicate determinations. $100 \% \mathrm{HbSH}$ values were 2.15 and 2.18 moles/mole and $100 \%$ GSH values were 0.86 and $0.72 \mathrm{mM}$ respectively. Determined by titration with 4,4'-dithiodipyridine (HbSH) and 5,5'-dithiobis 2nitrobenzoic acid (GSH).

urine samples of two exposed workers and four control persons, all nonsmokers, were collected: at the beginning of a work week - which was after an exposure free period of several weeks - at the end of that week and after the weekend. Total (i.e. reduced plus oxidized) glutathione was determined with the cyclic oxidation reduction method (Anderson, 1985). GST activity towards 1-chloro2,4-dinitrobenzene (CDNB) was determined essentially as described by Habig and Jakoby (1981). Both methods were slightly modified as described previously (Brouwer et al., 1991). Figure 6.3 shows the separate GSH and GST values for the two workers. In order to exclude errors caused by day to day analytical variations, values were expressed as the ratio of the individual value and the mean value of the four control persons determined the same day. In both workers GST and GSH values were decreased at the end of the week, and returned to values close to the initial values after the weekend. These data, which in themselves have a rather limited value, become more interesting when related to some other parameters determined in the same workers, as described below.

Environmental monitoring of pyrene and biological monitoring of urinary 1hydroxypyrene, as markers for the exposure to polycyclic aromatic hydrocarbons, 

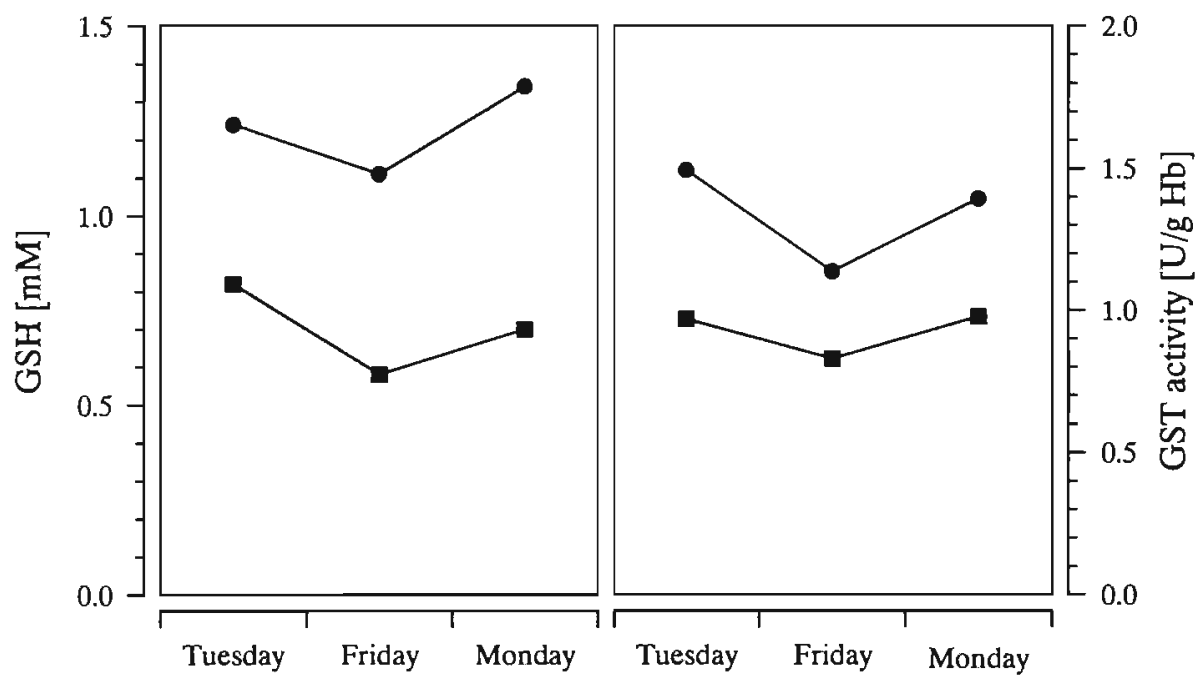

Figure 6.3: Glutathione concentrations in blood and Glutathione S-Transferase activities in erythrocytes of two workers ( and $\square$ ) creosoting wood. Samples were collected before and after the work period and after the weekend. All values are the result of determinations in duplicate, and were expressed as relative values compared to samples from four nonexposed persons collected and determined on the same day.

were done by Jongeneelen and coworkers (Dr. F. Jongeneelen, personal communication). Environmental monitoring revealed that dermal and inhaled exposition for person 1 were generally at least two times higher than for person 2 . Hydroxypyrene in urine was determined twice each day with previously described methods (Jongeneelen et al., 1987). The individual excretion values for hydroxypyrene on the morning of the sampling days for the blood samples are shown in table 6.2 . For both workers the urinary hydroxypyrene values were clearly above the normal range (normal 95 percentile value is $0.66 \mu \mathrm{mol} / \mathrm{mol}$ creatinine) at the end of the week. The interindividual differences in excretion were in accordance with the BM data.

Even more interesting were the findings by Steenwinkel and Baan (Dr. R. Baan personal communication) who determined DNA adducts of polycyclic aromatic hydrocarbons in white blood cells with the ${ }^{32} \mathrm{P}$-postlabeling method developed by Randerath and co-workers (Gupta et al., 1982, Randerath et al., 1981; Watson, 1987) in the same blood samples used for the GSH and GST determinations. The results are listed in table 6.2. All values are the means of two, in some cases three, determinations. The analytical variation between experiments was about $20 \%$. The end of week values are clearly elevated compared to the 
pre-exposure values. For the DNA adducts a tendency for return to normal values is visible too, but this effect is small compared to the analytical variability. A slowness in recovery for DNA alkylation need not only be the result of slow repair processes, but can also be caused by continued availability of reactive compounds from internal storage in for instance fat tissue. Faster recovery of GSH and GST would, on the other hand, not only indicate the relatively fast reversibility of their impairment, but would also indicate that this impairment is caused by substances whose residency is relatively short.

Table 6.2: DNA adduct values in creosote workers.

\begin{tabular}{|c|c|c|c|c|}
\hline Sampling day & $\begin{array}{l}\text { DNA ad } \\
\text { [attomol } \\
\text { person } 1\end{array}$ & $\begin{array}{l}\text { ucts } \\
/ \mu \mathrm{g} \text { DNA] } \\
\text { person } 2\end{array}$ & $\begin{array}{l}\text { Hydroxyp } \\
{[\mu \text { moles } /} \\
\text { person } 1\end{array}$ & $\begin{array}{c}\text { yrene exc. } \\
\text { hol creat.] } \\
\text { person } 2\end{array}$ \\
\hline Tuesday & 6 & n.d. ${ }^{a}$ & 0.35 & 0.70 \\
\hline Friday & 15 & 19 & 2.8 & 1.15 \\
\hline Monday & 13 & 18 & 0.55 & 0.5 \\
\hline
\end{tabular}

a. n.d. is not detcctable, detcction limit was 4 attomoles/ $\mu \mathrm{g}$ DNA

\section{Dichloropropene Workers}

Further indications for the usefulness of the determination of GSH and GST came from a prospective study which was performed in the Dutch flower bulb culture, in collaboration with Brouwer and de Wolff, to investigate the possible effects of the soil fumigant 1,3-dichloropropene (DCP) (Brouwer et al., 1991). At the start of the season in July, and after the season in October, blood and urine samples of workers applying DCP were collected. The activity of erythrocyte GST was significantly ( $p<0.002$; Wilcoxon matched pair analysis) decreased from 4.7 before to $3.3 \mathrm{U} / \mathrm{g} \mathrm{Hb}$ after the season. The GSH values in blood were also significantly $(p<0.02)$ decreased from 0.93 to $0.82 \mathrm{mM}$. With a single exception for an unusual low GSH value in the pre-season samples, all individual values were found to be decreased at the end of the season (Fig. 6.4).

The study was combined with environmental and biological monitoring of 1,3-dichloropropene (van Welie et al., 1991). In the biological monitoring study excretion of two mercapturic acid metabolites of DCP was determined. Since these mercapturic acids are the result of GSH conjugation, their excretion indicates that GSH is actually used in the metabolism of DCP. Changes in health effect parameters for liver and kidney function in these workers were determined by Verplanke. Decrease of total serum bilirubin together with an increase in serum $\gamma$-glutamyltranspeptidase activity indicated moderate hepatic enzyme induction. And a possible subclinical nephrotoxic effect was indicated by significant increases 


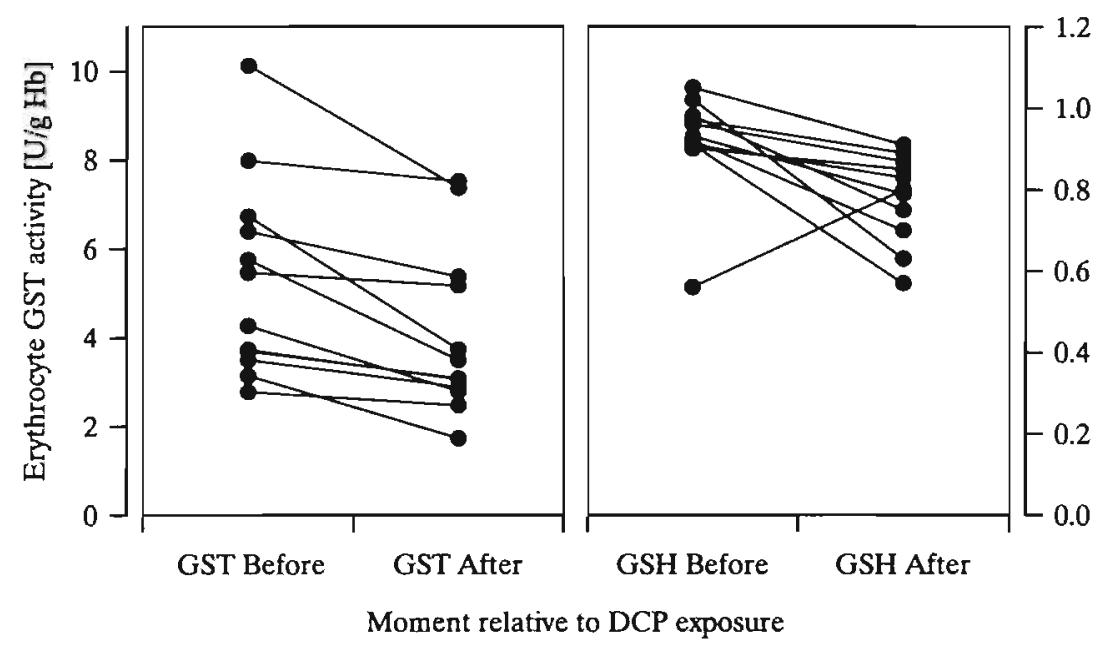

Figure 6.4: Glutathione S-transferase activity in erythrocytes and glutathione in blood of workers exposed to 1,3-dichloropropene.

in urinary excretion of albumin and retinol binding protein. The direction of the change in the determined health effect parameters for the liver - enzyme induction, not liver impairment- and the size of the changes for the kidney functions - within the normal clinical range- lead to the conclusion that there were no significant health effects on the individual level. Nevertheless, significant biological effects were found, which lead to the identification of internal exposure, and possibly increased risk.

\section{Smokers}

Since smokers are continuously exposed to electrophilic compounds originating from cigarette smoke, some effects on the glutathione system could be anticipated. Table 6.3 shows the concentration of total GSH in blood, erythrocyte GST activity and the amount of GST present in the erythrocytes. The latter amount was determined by a competitive ELISA assay with antibodies towards human GST $\pi$ class enzymes (Medlabs, Dublin Ireland).

The thioether excretion in smokers was significantly increased. Such an increase is usually found in smokers (Henderson et al., 1984), and it is included in the table only because it indicates exposure. Total blood GSH did not differ between smokers and nonsmokers. The decrease in erythrocyte GST activity towards CDNB was not statistically significant. The amount of GST $\pi$ class protein however, was strongly increased in the smokers. This means that the specific activity of the GST $\pi$ protein present in the erythrocytes of smokers towards the common substrate CDNB is lower than normal. This may indicate that GST 
Table 6.3: GST and GSH in blood and urinary thioether excretion of smokers and nonsmokers. Median values and ranges are shown. Symbols indicate significant differences from the values for nonsmokers by Wilcoxon 2-sample test; $*: p<0.10$; $\ddagger: p<0.02$.

nonsmokers

\begin{tabular}{lcc}
\hline $\begin{array}{l}33 \pm 7 \\
(\text { mean } \pm \text { s.d.) }\end{array}$ & $\begin{array}{c}37 \pm 10 \\
\mathrm{n}=11\end{array}$ & $\mathrm{n}=10$ \\
\hline $\mathrm{GSH}$ & 1.06 & 1.12 \\
{$[\mathrm{mM}]$} & $0.88-1.32$ & $0.77-1.17$ \\
\hline
\end{tabular}

GST $\rho$ act. (CDNB)

$[\mathrm{U} / \mathrm{ml}$ blood]

0.71

0.52

$0.42-1.13$

0.6

$4.2^{\ddagger}$

GST $\pi$ conc. (ELISA)

$0.3-4.5$

$1.6-5.0$
$\equiv[\mathrm{U} / \mathrm{ml}$ blood $]$

Thioether excr.

$[\mathrm{mmol} / \mathrm{mol}$ creat.]
3.3

$4.7^{*}$

$0.5-9.9$
$3.0-14.0$

synthesis during erythrocyte formation is induced in smokers, to compensate for inactivation that takes place during the erythrocyte life cycle. The induction of a GST not active towards CDNB would be another explanation.

\section{Physical Activity}

Since part of the GST activity loss may be caused by reactive oxygen species "we decided to study the influence high oxygen consumption due to physical activity (Evelo et al., 1992). Previously sedentary men $(n=23)$ and women $(n=18)$ were trained to run a $1 / 2$ marathon contest after 40 weeks. After 20 weeks of training total blood GSH and erythrocyte glutathione reductase (GR) activity were increased. After 40 weeks total blood GSH values were returned to normal, while GR remained elevated. Erythrocyte GST activity was strongly increased after 40 weeks, this may be indicative of the occurrence of lipid peroxidation in this training phase.

The participants ran a $15-\mathrm{km}$ race after the first 20 weeks of training and a $1 / 2$ marathon after 40 weeks. After the $15-\mathrm{km}$ race total blood GSH and erythrocyte GST activity were decreased, while GR activity was increased. GSH and GR values were returned to before race conditions 5 days after the $15-\mathrm{km}$ race. After the $1 / 2$ marathon total blood GSH and erythrocyte GR activity were increased, while CST activity was decreased. 5 Days after the $1 / 2$ marathon all values were 
returned to before race conditions. The difference in GSH sensibility after both races may be caused by differences in before race conditions. GSH was elevated before the 15- $\mathrm{km}$ race. The increases in GR activities after the races could at least partially be explained by concurrent increases in riboflavin concentrations.

\section{Concluding Remarks}

More and more methods in occupational and environmental toxicology, allow the determination of biological effects of which either no clear relationship to health impairment has been established, or at levels where no known clinical significance exists. The primary value of the use of such methods lays in the relation between the determined effects and the internal dose. If the relation between internal dose and the ultimate risk is known, like it is suggested for hemoglobin and DNA adducts (Henderson et al., 1989), the assessment of biological effects can be used for risk estimations. However, even if such a clear relationship is not established the determination of biological effects may be indicative of exposure to reactive compounds, and may be used for the control of exposure situations. Much opposition against the use and development of BEM methods is based on a bad understanding of their results. Problems arise when health significance is attributed to results which do not allow such conclusions. It has often been overseen that methods leading to such results can still be very valuable for the management of risk. A clear distinction between BEM and HS is needed to improve this situation.

The development of new BEM methods depends largely on knowledge of toxicodynamics. The development of the methods for the glutathione system for instance, was stimulated by the understanding of the biochemical processes leading to thioether excretion and by insight in reactive oxygen toxicity. To put it in another way, knowledge of toxicodynamics can, and in our view should, be used for the development of new methods for biological effect monitoring.

Acknowledgements. The authors wish to thank Dr. Jongeneelen from the university of Nijmegen and Dr. Baan from the Medical Biological Laboratory of TNO for the opportunity to reference unpublished data on hydroxypyrene excretion and DNA adducts in the creosote workers. 


\section{References}

[1] Anderson M.E. (1985). Determination of glutathione and glutathione disulfide in biological samples. Meth Enzymol 113: 548-555.

[2] Ansari G.A.S.. S.V. Singh, J.C. Gan and Y.C. Awasthi (1987). Human erythrocyte glutathione S-transferase: a possible marker of chemical exposure. Toxicol Lett 37 : $57-62$.

[3] Berlin A.. V. Riihimäki and H. Vainio (eds) (1984). Assessment of toxic agents at the work place. Roles of ambient and biological monitoring. Nijhof, Boston, The Hague, Dordrecht, Lancaster.

[4] Brouwer E.J., C.T.A. Evelo, A.J.W. Verplanke, R.T.H. van Welie and F.A. de Wolff (1991). Biological effect monitoring of occupational exposure to 1,3-dichloropropene: effects on liver and renal function and on glutathione conjugation. Br J Ind Med 48: 167-172.

[5] Doorn R. van, Ch.-M. Leijdekkers, R.P. Bos, R.M.E. Brouns and P.Th. Henderson (1981). Detection of human exposure to electrophilic compounds by assay of thioether detoxication products in urine. Ann Occup Hyg 24: 77-92.

[6] Evelo C.T.A. and P.Th. Henderson (1988). Influence of glutathione on the formation of cysteine alkylation products in human hemoglobin. Toxicology 52: 177186.

[7] Evelo C.T.A., N.G.M. Palmen, Y. Artur and G.M.E. Janssen (1992). Changes in blood glutathione concentrations, and in erythrocyte glutathione reductase and glutathione S-transferase activity after running training and after participation to contests. Eur J Appl Physiol 64: 354-358.

[8] Gupta R.C.. M.V. Reddy and K. Randerath (1982). ${ }^{32}$ P-Postlabeling analysis of non-radioactive aromatic carcinogen-DNA adducts. Carcinogenesis 3: 1081-1092.

[9] Habig W.H. and W.B. Jakoby (1981). Assays for the differentiation of glutathione S-transferases. Meth Enzymol 77: 398-405.

[10] Henderson P.Th., R. van Doorn, Ch.-M Leijdekkers and R.P. Bos (1984). Excretion of thioethers in urine after exposure to electrophilic chemicals. In: Berlin A. et al. (eds.) Monitoring human exposure to carcinogenic and mutagenic agents. IARC scientific publ. 59, Lyon, pp. 173-188.

[11] Henderson R.F., W.E. Bechtold, J.A. Bond and J.D. Sun (1989). The use of bic logical markers in toxicology. Crit Rev Toxicology 20: 65-82.

[12] Jongeneelen F.J., R.B.M. Anzion and P.Th. Henderson (1987). Determination of hydroxylated metabolites of polycyclic aromatic hydrocarbons in urine. $J$ Chromatogr 413: 227-232.

[13] Kilpikari I. and H. Savolainen (1984). Decreased erythrocyte glutathione S-transferase activity in rubber workers. Int Arch Occup Environ Health 53: 299-302.

[14] Mannervik B. and U.H. Danielson (1988). Glutathione Transferases - structure and catalytic activity. Crit Rev Biochem 23: 283-337.

[15] Palmen N.G.M. and C.T.A. Evelo (1993). Glutathione depletion in human erythrocytes as indicator for microsomal activation of cyclophosphamide and 3 hydroxyacetanilide. Toxicology 84: 157-170.

[16] Randerath K., Reddy M.V. and Gupta R.C. (1981). ${ }^{32}$ P-Labeling test for DNA damage. Proc Natl Acad Sci USA 78: 6126-6129. 
[17] Watson W.P. (1987). Post-radiolabeling for detecting DNA damage. Mutagenesis 2: 319-331.

[18] Welie R.T.H. van, P. van Duyn, D.H. Brouwer, J.J. van Hemmen, E.J. Brouwer and N.P.E. Vermeulen (1991). Inhalation exposure to 1,3-dichloropropene in the Dutch flower bulb culture. Part II. Biological monitoring by measurement of urinary excretion of two mercapturic acid metabolites. Arch Environ Contam Toxicol 20: 6-12.

[19] Zielhuis R.L. and P.Th. Henderson (1986). Definitions of monitoring activities and their relevance for the practice of occupational health. Int Arch Occup Environ Health 57: 249-257. 


\section{Biological Effect Monitoring of Occupational Exposure to 1,3-Dichloropropene: Effects on Liver and Renal Function and on Glutathione Conjugation}

E.J. Brouwer ${ }^{1,2}$, C.T.A. Evelo ${ }^{3}$, A.J.W. Verplanke ${ }^{4}$, R.T.H. van Welie $^{5}$ and F.A. de Wolff ${ }^{1}$

1: Toxicology Laboratory, University Hospital, P.O. Box 9600, 2300 RC Leiden, The Netherlands

2: Present address:

Stichting Kwaliteitsbevordering Bedrijfsgezondheidszorg Amsterdam, The Netherlands

3: Department of Toxicology, Faculty of Medicine, University of Nijmegen, Nijmegen, The Netherlands

Present address:

Department of Pharmacology (Toxicology Section), University of Limburg, P.O. Box 616, 6200 MD Maastricht

4: Coronel Laboratory for Occupational and Environmental Health, University of Amsterdam, Amsterdam, The Netherlands

5: Department of Pharmacochemistry, Division of Molecular Toxicology, Free University, Amsterdam, The Netherlands.

Published in: $\operatorname{Br} J$ Ind Med 48, 1991, 167-172*.

*. A reaction to the original paper by N.J. van Sittert, G.E. Veenstra, E.P. Dumas and W.F. Tordoir from Shell International and a reply by the authors was published in: Br J Lnd Med 48, 1991, 646-648 
Summary. A prospective study was performed in the Dutch flower bulb culture to investigate the possible effects of subchronic exposure to the soil fumigant 1,3-dichloropropene (DCP) on liver and kidney function and on glutathione conjugation capacity in blood. Urine spot samples and venous blood samples from 14 workers applying DCP (applicators) were taken at the start of the season in July, and after the season in October. The parameters of liver function measured were: alanine aminotransferase, aspartate aminotransferase, alkaline phosphatase, lactate dehydrogenase, gamma-glutamyl transpeptidase, and total bilirubin (conjugated and unconjugated). Total bilirubin was significantly decreased from 9.5 before to $7.0 \mu \mathrm{M}$ after the season. In combination with an increase in serum gamma-glutamyl transpeptidase activity from 12.5 to $19.5 \mathrm{U} \cdot \mathrm{l}^{-1}$, this indicates moderate hepatic enzyme induction. To study renal function, creatinine and $\beta_{2}$-microglobulin in serum, and $\beta_{2}$-microglobulin, albumin, alanine aminopeptidase, $\gamma$-galactosidase, and retinol binding protein in urine were measured. The glomerular function parameters albumin in urine and creatinine in serum changed significantly during the season: albumin concentration increased from 5.2 to $7.6 \mathrm{mg} \cdot \mathrm{l}^{-1}$, whereas creatinine excretion decreased from 93.0 to $87.5 \mu \mathrm{M}$. The tubular function parameter retinol binding protein also increased in concentration from 20.0 to $26.9 \mu \mathrm{g} \cdot \mathrm{l}^{-1}$. Therefore, a subclinical nephrotoxic effect of subchronic exposure to DCP cannot be excluded. Effects on glutathione conjugation capacity were studied by measuring erythrocyte glutathione S-transferase activity and blood glutathione concentrations. The activity of glutathione S-transferase in erythrocytes was significantly decreased from 4.7 before to $3.3 \mathrm{U} \cdot \mathrm{g} \mathrm{Hb}^{-1}$ after the season. The same was true for the blood glutathione concentrations, which decreased from 0.93 to $0.82 \mathrm{mM}$. Both parameters seem to be affected by exposure to DCP.

\section{Introduction}

A mixture of Z- and $\mathrm{E}-1,3$-dichloropropene $(D C P)$ is used extensively in the Dutch flower bulb culture for soil fumigation. This is mainly performed by commercial applicators. Products containing DCP, such as Telone II and Shell-DD 95, are injected into the soil, without previous dilution, in the period between June and November. During field application of soil fumigants containing DCP, applicators may be exposed to DCP, mainly by inhalation.

The primary target organs of DCP toxicity in experimental animals are the liver and the kidney. Exposure of rats and guinea pigs to $50 \mathrm{ppm}\left(220 \mathrm{mg} \cdot \mathrm{m}^{-3}\right)$ DCP vapor by inhalation for seven hours a day), five days a week during one month induced liver and kidney injury. Exposure to $3 \mathrm{ppm}\left(13.6 \mathrm{mg} \cdot \mathrm{m}^{-3}\right)$ for six months induced cloudy swelling of the renal tubular epithelium in male rats. This was found to be reversible after stopping exposure [22]. Based on evidence of no effects in rats, mice, guinea pigs, and dogs exposed seven hours a day to $1 \mathrm{ppm}$ 
$\left(4.5 \mathrm{mg} \cdot \mathrm{m}^{-3}\right)$ for 6 months, and of the reversible injury in male rats exposed to $3 \mathrm{ppm}$, a time weighted averaged threshold limit value $(T L V)$ of $1 \mathrm{ppm}$ has been recommended for dichloropropene [1]. This is also the present. Dutch occupational exposure limit $(O E L)[16]$.

Apart from a recent study about short-term exposure to DCP and renal effects [18], no studies of exposure to DCP on health effects in man have been published.

In combination with an environmental and biological monitoring study of DCP in the Dutch flower bulb culture $[6,26]$, the present prospective exploratory study was carried out to investigate the early effects of subchronic exposure to DCP on liver and renal function of commercial applicators.

Exposure to electrophilic compounds such as DCP or its metabolites might lead to a loss of biologically active thiol groups and assessment of this loss could be useful as a biological marker of exposure [10]. In this study two parameters of change in thiol groups - namely, erythrocyte glutathione S-transferase activity and blood glutathione concentration - were also evaluated.

\section{Methods}

\section{Population and study design}

The study was restricted to the "Bollenstreek", the area between Leiden and Haarlem (The Netherlands) where the flower bulb culture is mainly concentrated. All 14 commercial applicators using DCP in soil fumigation in this region participated in the study, which was approved by the medical ethics committee of the University Hospital of Leiden.

By means of a questionnaire, completed in July on the first sampling day, information was obtained from each subject on age, snoking and drinking habits, medication, and current and past diseases. The mean age was 42 years (median 40 , range 33-60). Five workers smoked, with an average rate of 15-20 cigarettes a day (range 1-5 to $>20$ ). The average alcohol intake was 5-10 glasses a week (range $<1$ to $>60$ ). One applicator did not drink alcoholic beverages. Two applicators used an oral anticoagulant (phenprocoumon). None of the workers was known to have liver or kidney disease.

For 12 applicators blood and urine samples were collected between 12.00 a.m. and 2.00 p.m. both before and after the season; for two, samples were collected between 6.00 and 7.00 p.m. before and after the season.

Possible effects of exposure to DCP on the liver were studied by measuring alanine aminotransferase $(A L A T)$, aspartate aminotransferase $(A S A T)$, lactate dehydrogenase $(S L D H), \gamma$-glutamyl transpeptidase $(\gamma G T)$, and alkaline phosphatase $(A L P)$ activities, and total bilirubin concentrations (Bil-tot) in serum. To study effects on renal function, parameters were chosen to discriminate between effects on glomerular and tubular function. Glomerular function was measured 
by assessing concentrations of $\beta_{2}$-microglobulin in serum $\left(\beta_{2}-M-S\right)$, creatinine in serum (Creat-S), and albumin in urine $(A l b-U)$. Proximal tubular function was reflected by the excretion of $\beta_{2}$-microglobulin $\left(\left(\beta_{2}-\mathrm{M}-\mathrm{U}\right)\right.$, retinol binding protein $(R B P), \beta$-galactosidase $(\beta$-gal $)$, and alanine aminopeptidase $(A A P)$ in urine. $\mathrm{Ef}$ fects on glutathione conjugation capacity in blood were evaluated by measuring blood glutathione $(G S H)$ concentrations and the activity of erythrocyte glutathione S-transferase (GST: EC 2.5.1.18).

\section{Analytical methods}

Blood samples for measurement of liver and renal function parameters were collected by vein puncture using $10 \mathrm{ml}$ Vacutainer tubes. Blood was allowed to clot and transported within two hours in a cool box to the laboratories for Clinical Chemistry and Toxicology, University Hospital of Leiden. For the determination on GST activities and GSH concentrations, blood samples were collected in $10 \mathrm{ml}$ Vacutainer tubes containing ethylenediaminetetra-acetic acid (EDTA). The samples for the determination of ALAT, ASAT, SLDH, $\gamma \mathrm{GT}$, and ALP activities and Bil-tot and Creat-S concentrations in serum were analyzed within 24 hours with a SMAC multichannel analyzer (Technicon Instruments Corporation, Tarrytown, NY, USA), according to the manufacturer's instructions. Concentrations of the protein $\beta_{2}-\mathrm{M}$ in urine and serum were measured with a commercial radioimmunoassay kit (Pharmacia Diagnostics AB, Uppsala, Sweden). For the determination of Alb-U and RBP concentrations and $\beta$-Gal and AAP activities, the urine samples were collected and transported on ice to the Coronel Laboratory, University of Amsterdam, prepared the same day, and analyzed within one week. Concentrations of Alb-U and RBP were analyzed with a latex immunoassay according to Bernard and Lauwerys [5]. For the determination of $\beta$-Gal activity, a colorimetric assay according to Maruhn [15] was used. Alanine aminopeptidase activity was assayed by the method of Jung and Scholz [11]. In earlier studies reported from the Coronel Laboratory coefficients of variation were: Alb-U $3 \%$, RBP $10 \%$, and $\beta$-Gal $5 \%$ [23]. Assuming that the ratio between the renal function parameters and the urinary density was the same before and after the season, the data were adjusted for urinary density [23].

Blood samples used for GST and GSH determinations were transported in a cool box to the Department of Toxicology, University of Nijmegen, and prepared (GST) or analyzed (GSH) the same day. Concentration of GSH was determined essentially as described by Anderson [3]. For the determination of GST activity in erythrocytes, red cells were washed three times with phosphate buffered saline $(P B S ; \mathrm{pH} 7.0)$ and lysed by addition of three volumes of water containing $1.4 \mathrm{mM}$ neutral dithiothreitol $(D T T)$ to prevent oxidation of thiol groups. After the ionic strength had been restored by adding one volume twofold concentrated PBS containing $1.4 \mathrm{mM}$ DTT, cell fragments were removed by centrifugation at $15,000 \mathrm{~g}$ for 10 minutes. Only the clear upper part of the supernatant was used for the determinations. The activity towards 1-chloro-2,4-dinitrobenzene $(C D N B)$ was 
determined as described by Habig and Jakoby [9] with a Cary 119 spectrophotometer in auto-slit mode with the gain adjusted to 2.5 .

The concentration of hemoglobin $(H b)$ in the hemolysates was determined with the hemoglobin cyanide procedure [12].

\section{Exposure}

After the season, all applicators were asked to estimate the number of hours and days worked in soil fumigation.

\section{Statistical Analyses}

To test for significance of differences between values for liver and renal function parameters and blood GST and GSH values measured before and after the season, matched pair analysis was performed with the Wilcoxon non-parametric signed rank test. For $\beta$-Gal at $\mathrm{pH}>7.0$ (5 samples) and for $\beta_{2}-\mathrm{M}-\mathrm{U}$ at $\mathrm{pH}<5.5(8$ samples), data were excluded from the analysis because of instability above or below these $\mathrm{pH}$ values [23]. Data were analyzed both with and without adjustment for urinary density.

The Friedman test was used to test for equality between values before and after the season for the liver parameters, and the glomerular and tubular function parameters simultaneously. All statistical analyses were performed with the statistical package of the social sciences SPSS(-X) [17].

\section{Results}

\section{Exposure}

All 14 applicators took part in soil fumigation with DCP during the season. The total number of working hours for each subject during this period varied from 26 to 300 with a median of 142 hours, divided over 4 to 37 days with a median of 20 days.

The number of hours during which the applicators fumigate soil only indicates the duration and not the level of exposure. These exposure data are not used, therefore, to calculate a dose response relation.

In the environmental monitoring study [6], exposure to DCP for each applicator was measured on one or two days for biological monitoring [26]. These data cannot be considered representative of the average exposure of the different applicators during the season and are, therefore, not suitable for an estimation of subchronic exposure to DCP of the 14 workers in this study.

From the environmental monitoring study it appeared that exposure was comparatively high. The TWA concentration of DCP ranged from 1.9 to 18.9 $\mathrm{mg} \cdot \mathrm{m}^{-3}$. On $30 \%$ of the observed working days the Dutch occupational exposure limit of $5 \mathrm{mg} \cdot \mathrm{m}^{-3}(1 \mathrm{ppm})$ was exceeded. 


\section{Liver function}

With the exception of Bil-tot, no significant differences were found for the parameters of liver function between samples obtained before and after the seasons (table 7.1). Concentration of Bil-tot was significantly decreased after the season from 9.5 to $7.0 \mu \mathrm{M}$ (median values; $p=0.025$ ). Activity of $\gamma \mathrm{GT}$ was appreciably increased from 12.5 before to $19.5 \mathrm{U} \cdot 1^{-1}$ after the season but the difference was only of borderline significance (median values; $p=0.099$ ).

Table 7.1: Liver function parameters before and after the season: values corrected for specific density $(n=14)$

\begin{tabular}{llll}
\hline & $\begin{array}{l}\text { Before season } \\
(\text { median (range) }\end{array}$ & $\begin{array}{l}\text { After season } \\
(\text { median (range) }\end{array}$ & $p$ Value \\
\hline Bil-tot $(\mu \mathrm{mol} / \mathrm{l})$ & $9.5(6.0-15.0)$ & $7.0(1.0-14.0)$ & $0.025^{*}$ \\
ALP (U/1) & $38.5(26.0-69.0)$ & $39.5(26.0-68.0)$ & 0.576 \\
ASAT (U/1) & $8.5(6.0-11.0)$ & $8.0(5.0-18.0)$ & 0.155 \\
ALAT (U/1) & $10.5(5.0-20.0)$ & $12.0(6.0-36.0)$ & 0.235 \\
SLDH (U/1) & $145.5(117.0-189.0)$ & $149.0(119.0-194.0)$ & 0.972 \\
$\gamma$ GT (U/l) & $12.5(5.0-31.0)$ & $19.5(9.0-34.0)$ & 0.099 \\
\hline
\end{tabular}

*. Statistically significant $(p<0.05)$

\section{Renal function}

For 2 out of 3 glomerular function parameters, Creat-S and Alb-U, significant differences between the concentrations before and after the season were found. Concentration of Creat-S decreased from 93.0 to $87.5 \mu \mathrm{M}$ (median values; $p=$ 0.013 )(table 7.2). In one subject, however, Creat-S was very low, especially at the end of the season. This person had been treated with ampicillin one month before the study. Concentration of Alb-U increased from 5.2 to $7.6 \mathrm{mg} \cdot \mathrm{l}^{-1}$ (median values; $p=0.044$ )(table 7.2). The excretion of albumin in urine is normally less than $8 \mathrm{mg} \cdot \mathrm{l}^{-1}[20]$. One applicator had values 3 times higher than this value, before as well as after the season. This person was advised to consult his general practitioner.

The only tubular function parameter that was significantly increased after the season was RBP, from 20.0 to $26.9 \mu \mathrm{g} \cdot l^{-1}$ (median values; $p=0.036$ ). No significant differences were found for $\beta_{2}-\mathrm{M}$ concentrations in urine or in serum, and for AAP and $\beta$-Gal activities in urine (table 7.2).

The concentration of $\beta_{2}-\mathrm{M}$ in urine is normally $200 \mu \mathrm{g} \cdot \mathrm{I}^{-1}$ [20]. Three workers had values above this value but below $300 \mu \mathrm{g} \cdot \mathrm{l}^{-1}$, which is the normal upper limit according to the manufacturer of the assay kit. A significant difference was 
Table 7.2: Renal function parameters before and after the season. Values corrected for specific density ( $n=14$ unless stated otherwise)

\begin{tabular}{|c|c|c|c|}
\hline & $\begin{array}{l}\text { Before season } \\
\text { (median (range)) }\end{array}$ & $\begin{array}{l}\text { After season } \\
\text { (median (range)) }\end{array}$ & $p$ Value \\
\hline Creat-S $(\mu \mathrm{mol} / \mathrm{l})$ & $93.0(74.0-109.0)$ & $87.0(42.0-100.0)$ & $0.045^{*}$ \\
\hline$\beta_{2}-\mathrm{M}-\mathrm{S}(\mathrm{mg} / \mathrm{l})$ & $1.3(0.8-1.8)$ & $1.4(1.1-1.8)$ & 0.563 \\
\hline$\beta_{2}-\mathrm{M}-\mathrm{U}(\mu \mathrm{g} / 1)$ & $\begin{array}{l}76.4(45.0-174.3) \\
(\mathrm{n}=8)\end{array}$ & $\begin{array}{l}109.9(65.3-350.9) \\
(n=12)\end{array}$ & 0.208 \\
\hline $\mathrm{AAP}(\mathrm{U} / \mathrm{l})$ & $\begin{array}{l}9.7(6.5-13.9) \\
(\mathrm{n}=12)\end{array}$ & $\begin{array}{l}8.3(5.0-18.0) \\
(n=13)\end{array}$ & 0.754 \\
\hline$\beta-\mathrm{Gal}(\mathrm{U} / \mathrm{l})$ & $\begin{array}{l}1.9(1.1-7.2) \\
(\mathrm{n}=11)\end{array}$ & $\begin{array}{l}2.4(1.7-5.6) \\
(\mathrm{n}=12)\end{array}$ & 0.308 \\
\hline Alb-U (mg/l) & $5.2(1.6-31.8)$ & $7.6(2.7-37.0)$ & $0.013^{*}$ \\
\hline $\operatorname{RBP}(\mu \mathrm{g} / \mathrm{l})$ & $20.0(8.4-36.1)$ & $26.9(16.5-72.7)$ & $0.036^{*}$ \\
\hline
\end{tabular}

*. Statistically significant $(p<0.05)$

Table 7.3: Glutathione S-transferase activity (CDNB) in erythrocytes and glutathione concentrations in blood before and after the season $(n=12)$

\begin{tabular}{llll}
\hline & $\begin{array}{l}\text { Before season } \\
\text { (median (quartile 1-3)) }\end{array}$ & $\begin{array}{l}\text { After season } \\
\text { (median (quartile 1-3)) }\end{array}$ & $p$ Value \\
\hline GST (U/g Hb) & $4.7(3.6-6.6)$ & $3.3(2.8-5.3)$ & $0.002^{*}$ \\
GSH (mM) & $0.93(0.90-0.97)$ & $0.82(0.73-0.86)$ & $0.02^{*}$ \\
\hline
\end{tabular}

*. Statistically significant $(p<0.05)$

found by testing the differences between values before and after the season for all three glomerular function parameters together (median values: $p=0.011$; Friedman test). Statistical analyses of the data not adjusted for urinary tensity did not show significant differences in any renal function parameters under study.

\section{Blood GST and GSH}

The concentration of GSH in blood decreased significantly from 0.93 before to $0.82 \mathrm{mM}$ after the season (table 7.3; median values; $p=0.023$ ). The median GST activity decreased from 4.7 to $3.3 \mathrm{U} \cdot \mathrm{g} \mathrm{Hb} \mathrm{Hb}^{-1}$ (median values; $p=0.002$ ). The GSH concentrations were lowered after the season in all but one person, whereas GST activity was decreased in all persons (figures 7.1 and 7.2).

Lymphocytes from the same blood samples were tested for the presence of 
GST [24] The GST activity in erythrocytes and GSH concentrations in blood were not significantly different for the $\mu$ positive and $\mu$ negative groups.

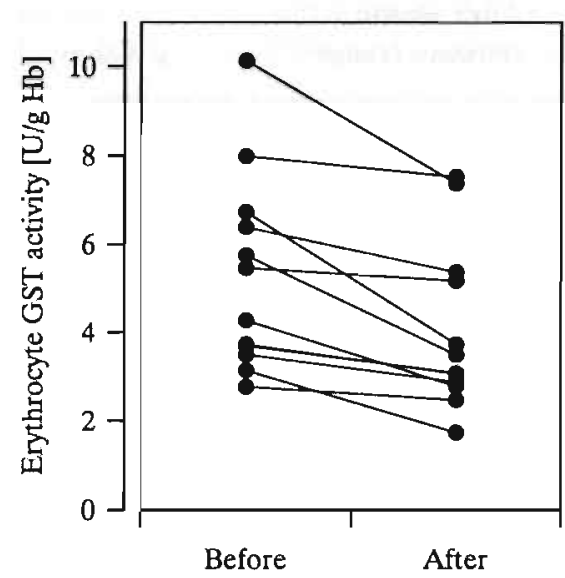

Moment relative to DCP exposure

Figure 7.1: Glutathione S-transferase activity in erythrocytes measured before and after the season.

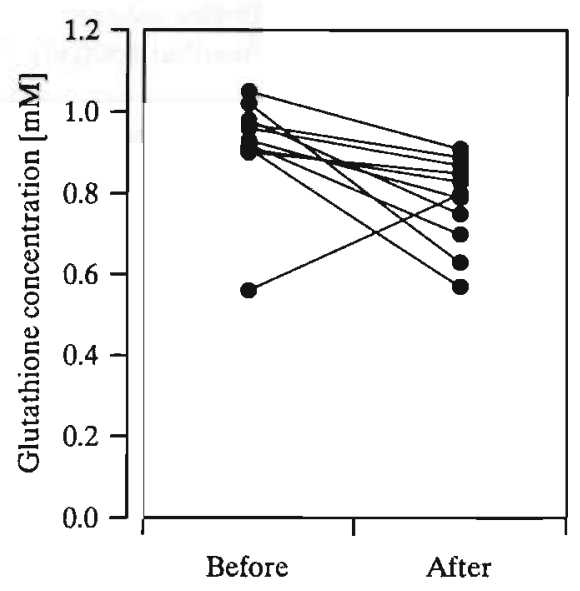

Moment relative to DCP exposure

Figure 7.2: Glutathione concentrations in blood measured before and after the season.

\section{Discussion}

Monitoring in occupational toxicology is directed towards the assessment of exposure, which may lead to minimization of hazards or towards determination of early health effects, which may serve the added purpose of better risk evaluations $[10,27]$. The liver and kidney function tests used in this study give information on the functional state of the organs concerned. Changes in GSH and GST may indicate primary biological effects. These cannot be interpreted, as yet, in terms of health effects, but only in terms of endogenous exposure to electrophilic agents. The renal function tests used in this study are considered to be sensitive enough to detect early effects of nephrotoxins and are feasible as indicators of early changes in renal function [14]. Low molecular weight proteins, such as $\beta_{2}-\mathrm{M}-U$ and RBP, are freely filtered from the plasma by the renal glomerulus and reabsorbed by the proximal tubular cells. The reabsorption of these proteins by the kidney is almost complete, which explains why their presence in urine is a sensitive indicator of impaired proximal tubular function [14]. In this study a significant increase of $\mathrm{Alb}-\mathrm{U}$ and RBP in urine was found after the season. If the increase in Alb- $U$ excretion can be attributed to reduction in tubular reabsorption, a much larger increase in RBP excretion would be expected [14]. Both 
for Alb-U and RBP the excretion in urine was, however, low compared to other studies.

No significant increase in $\beta_{2}-\mathrm{M}-\mathrm{U}$ was found, by contrast with what might be expected from another study in which a high correlation between RBP and $\beta_{2}$-M-U was shown [5]. This may be explained by the small amount of data on $\beta_{2}$ $\mathrm{M}-\mathrm{U}$ that could be used in our calculations. Data from 8 out of 28 urine samples had to be excluded from the analysis because of a pH less than $5.5 ; \beta_{2}-\mathrm{M}-\mathrm{U}$ in acid urine is very unstable and the protein degrades quickly.

Increased excretion of high molecular weight proteins such as albumin and ferritin may also result from a reduced tubular reabsorption of the filtered load [14]. An increased excretion of both a high (Alb-U) and a low (RBP) molecular weight protein may indicate a reduced tubular reabsorption capacity in these workers. Effects on the proximal tubules can also be detected by measuring the activity of several enzymes in the urine [14]. Neither of the two urinary enzymes measured in this study, AAP and $\beta$-Gal, had significantly increased activities after exposure to DCP during the season. After the present study was completed Osterloh et al. [18] described a subclinical effect on renal function expressed in an increased urinary excretion of $\mathrm{N}$-acetyl-glucosamidase after short-term exposure to DCP through soil fumigation. The concentrations exposed to ranged from 0.26 to $9.36 \mathrm{mg} \cdot \mathrm{m}^{-3}$.

The exposure concentrations measured in our corresponding environmental monitoring study ranged from 1.9 to $18.9 \mathrm{mg} \cdot \mathrm{m}^{-3}$, and are comparable with those used in the animal studies in which a cloudy swelling of the renal tubular epithelium of male rats was found at $3 \mathrm{ppm}\left(13.6 \mathrm{mg} \cdot \mathrm{m}^{-3}\right)$ after 6 months of exposure [22]. With regard to liver function, a significant decrease in concentration of Bil-tot in serum within the normal range was found after the season. Together with the remarkable increase in $\gamma$ GT this may indicate that: DCP has enzymeinducing properties. Induction of the $\beta$-glucuronidase activity may result in an increased contribution of conjugated Bil-tot, and hence in an increased elimination. In animal studies, an effect on the liver was also found at a comparable exposure level; in female rats exposed for 6 months to $3 \mathrm{ppm}\left(13.6 \mathrm{mg} \cdot \mathrm{m}^{-3}\right)$, a higher liver to body weight ratio was found. No histopathological changes in the liver were seen, however, and the increase was considered not to be an adverse effect, although it may be related to exposure [22]. Because the data from the present study were not compared to a control group, the results might be influenced by seasonal variation. When the results were compared, however, with those of a study by Gidlow et al. [8] about seasonal fluctuations of some biochemical parameters monitored in industrial workers in the United Kingdom exposed to a variety of potentially toxic chemicals, it appeared that our results (a decrease in creat-S and an increase in $\gamma \mathrm{GT}$ ) were opposite to those expected from seasonal fluctuations.

Because of the electrophilic nature of DCP attack on sulfhydryl groups can be expected. Glutathione provides the largest pool of biologically available thiol 
gremps. Normal GS'H concentrations in blood do not differ much between people of the same' age group [2].

The in vitro susceptibility of erythrocyte GST activity to industrially importaut electrophilic agents has been described [4]. The authors expected to find induction of GST synthesis, which in that case could occur during the proliferation of erythrocytes. In a separate study we found that such an induction does take place in smokers as GST concentrations determined by ELISA increased, whereas the activity towards CDNB was not increased [7]. In the current exposire situation a decrease in activity due to inactivation of GSt is expected to prevail over induction because the duration of the exposure period was short compared to the life span of an erythrocyte. Normal GST activity shows appreciable variation between subjects [21]. In this respect, the comparison of individual preand post-exposure values is expected to be more sensitive than comparison with a control group. Until now, no genetic inhomogeneity has been found to explain the interindividual variations in erythrocyte GST activity towards CDNB (mainly GST activity). Such genetic differences are known to exist for GST $\mu$ [25] and are expected for the minor erythrocyte GST [19]. Therefore, the absence of a relation between erythrocyte GST and the presence of absence of GST $\mu$ in lymphocytes was not surprising. The distinct decrease of both GSH and GST values found in this study indicates that exposure to DCP has affected glutathione conjugating capacity in erythrocytes.

Acknowledgments. We wish to thank A.J. Moolenaar, J.H.M. Souverijn, M.A. Verschoor, A.M. van Schijndel, H. de Jour and G.J. Reijmer for their analytical support, and D.H. Brouwer, J.J. van Hemmen, R.P. Bos, P.Th. Henderson, and R.L. Zielhuis for their valuable comments on the manuscript. This study was financially supported by the Food and Allied Workers Union. 


\section{References}

[1] Albrecht N.A. (1987). Toxicology and hazard assessment of 1,3-dichloropropene (Telone II). Arch Environ Health 42: 292-296.

[2] Al-Turk W.A., Stohs S.J., El-Rashidy F.H. and Othman S. (1987). Changes in glutathione and its metabolizing enzymes in human erythrocytes and lymphocytes with age. J Pharm Pharmacol 39: 13-16.

[3] Anderson M.E. (1985). Determination of glutathione and glutathione disulfide in biological samples. Meth Enzymol 113: 548-555.

[4] Ansari G.A.S., Singh S.V., Gan J.C., Awasthi Y.C. (1987). Human erythrocyte glutathione S-transferase: a possible marker of chemical exposure. Toxicol Lett 37: $57-62$.

[5] Bernard A.M. and Lauwerys R.R. (1983). Latex immunoassay of urinary albumin. $J$ Clin Chem Clin Biochem 21: 25-30.

[6] Brouwer E.J., Brouwer D.H., Vreede de J.A.F., Welie van R.T.H. and Wolff de F.A. (1991). Inhalation exposure to 1,3-dichloropropene in the Dutch flower-bulb culture. Part I. Environmental monitoring. Arch Environ Contam Toxicol 20: 1-5.

[7] Evelo C.T.A. and Henderson P.Th. (1992). Biological Effect Monitoring. Arch Toxicol suppl. 15: 268-277.

[8] Gidlow D.A., Church J.F. and Clayton B.E. (1983). Haematological and biochemical parameters in an industrial workforce. Ann Clin Biochem 20: 341-348.

[9] Habig W.H. and Jakoby W.B. (1981). Assays for the differentiation of glutathione S-transferases. Meth Enzymol 77: 398-405.

[10] Henderson R.F., Bechtold W.E, Bond J.A. and Sun J.D. (1989). The use of biological markers in toxicology Crit Rev Toxicol 20: 65-82.

[11] Jung K. and Scholz D. (1980). An optimized assay of alanine aminopepticlase activity in urine. Clin Chem 26: 1251-1254.

[12] Kampen van E.J. and Zijlstra W.G. (1965). Determination of hemoglobin and its derivatives. Adv in Clin Chem 8: 141-187.

[13] Kilpikari I. and Savolainen H. (1984). Decreased erythrocyte glutathione S-transferase activity in rubber workers. Int Arch Occup Environ Health 53: 299-302.

[14] Lauwerys R.R. and Bernard A. (1987). Early detection of nephrotoxic effects of industrial chemicals: state of the art and future prospects. Am J Ind Med 11: $275-285$.

[15] Maruhn D. (1976). Rapid colorimetric assay of $\beta$-galactosidase and N-acetyl- $\beta$ glucosaminidase in human urine. Clin Chim Acta 73: 453-461.

[16] Ministry of Social Affairs and Workforce, Directorate General of Labour. Nationale MAC-list (in Dutch). Voorburg, 1989.

[17] Norusis M.J. SPSS Lect. Chicago, III, SPSS Inc. 1986.

[18] Osterloh J.D, Wang R., Schneider S. and Maddy K. (1989). Biological monitoring of dichloropropene: air concentrations, urinary metabolite, and renal enzyme excretion. Arch Environ Health 44: 207-213.

[19] Peter H., Deutschman S., Reichel C. and Hallier E. (1989). Metabolism of methyl chloride by human erythrocytes. Arch Toxicol 63: 351-355.

[20] Roels H. and Lauwcrys R. (1984). Early detection of nephrotoxic effects of industrial chemicals. Umwelthygiene suppl I: 217-244. 
[21] Strange R.C., Johnson P.H., Lawton A., Moult J.A.. Tector M.J., Tyminski R.J. and Cotton $W$. (1982). Studies on the variability of glutathione S-transferase from human erythrocytes. Clin Chim Acta 120: 251 260.

[22] Torkelson T.R. and Oyen F. (1977). The toxicity of 1,3-dichloropropene as determined by repeated exposure of laboratory animals. Am Ind $H_{y g}$ Assoc $J$ 38: $217 \cdot 223$.

[23] Verschoor M.A. Occupational exposure to metals and renal function. Rodopi, Amsterdam, 1987 (PhD-thesis).

[24] Vos R.M.E., Welie van R.T.H., Peters W.H.M., Evelo C.T.A., Boogaards J.J.P., Vermeulen N.P.E. and Bladeren van P.J. (1991). Genetic deficiency of human class wu isuenzymes in relation to mercapturic acid excretion. Arch Toxicol 65: 95-99.

[25] Warholm M., Guthenberg C. and Mannervik B. (1983). Molecular and catalytic properties of glutathione transferase $\mu$ from human liver: an enzyme efficiently conjugating epoxides. Biochemistry 22: 3610-3627.

[26] Welie van R.T.H., Duyn van P., Brouwer D.H., Hemmen van J.J., Brouwer E.J. and Vermeulen N.P.E. (1991). Inhalation exposure to 1,3-dichloropropene in the Dutch flower bulb culture. Part II. Biological monitoring by measurement of urinary excretion of two mercapturic acid metabolites. Arch Environ Contam Taxicol 20: $6-12$.

[27] Zielhuis R.L. and Henderson P.Th. (1986). Definitions of monitoring activities and their relevance for the practice of occupational health. Int Arch Occup Environ Health 57: 249-257. 
Chapter 8

\section{Changes in Blood Glutathione Concentrations, and in Erythrocyte Glutathione Reductase and Glutathione S-Transferase Activity After Running Training and After Participation in Contests}

C.T.A. Evelo ${ }^{1}$, N.G.M. Palmen ${ }^{1}$, Y. Artur ${ }^{3}$ and G.M.E. Janssen'

1: Department of Pharmacology (Toxicology section)

University of Limburg, P.O. Box 616, 6200 MD Maastricht, The Netherlands.

2: Department of Human Biology, University of Limburg, P.O. Box 616, 6200 MD Maastricht, The Netherlands.

3: Centre de Médecine Préventive, 2 Avenue du Doyen J. Parisot, F-54500 Vandoeuvre-Les-Nancy, France.

Published in: Eur J Appl Physiol 64, 1992, 354-358. 
Summary. Previously sedentary men $(n=23)$ and women $(n=18)$ were trained to run a half marathon contest after 40 weeks. Total blood glutathione had increased by 20 weeks of training and had returned to normal after 40 weeks. Erythrocyte glutathione reductase activity had increased by 20 weeks and remained elevated after 40 weeks. This effect was accompanied by decreases in glutathione reductase coefficients, which indicated that increases in the presence of ribollavin may have been responsible for the changes in reductase activity. Erythrocyte glutathione S-transferase activity had increased slightly after 20 weeks of training and a much more marked increase was found after 40 weeks. This may have been indicative of the occurrence of lipid peroxidation in this phase of training. The participants ran a $15-\mathrm{km}$ race after the first 20 weeks of training and a half marathon after 40 weeks. Blood glutathione tended to decrease after the 15-km race and increased after the half marathon. In both cases it had returned to normal values 5 days after the race. Erythrocyte glutathione reductase was elevated 1 day after the races, and had returned to normal after 5 days. This could also have been explained from concurrent changes in the riboflavin content of the erythrocytes. Erythrocyte glutathione Stransferase activity decreased after both races, but was restored 5 days after the half marathon while such a restoration was not the case after the 15-km race.

\section{Introduction}

Endurance training has been shown to have positive effects with respect to endurance capacity, metabolic stress tolerance and a number of haematological parameters [8]. Increased physical activity leads to increased oxygen consumption. Since $1 \%-2 \%$ of the oxygen consumed gives rise to reactive oxygen species, this also has led to an increased challenge to the antioxidant system[9]. Part of this change in the antioxidant system may also result from the partial ischaemia in active tissues that may have occurred during heavy exercise[2], or from the release of heat shock proteins in these tissues[6]. Lipid peroxidation initiated by free radical reactions has occurred in muscle after heavy exercise, and gave rise to increased thiobarbituric acid reactive substances which were accompanied by increased activities of creatine kinase, lactate dehydrogenase and aspartate aminotransferase in serum[14,15]. Especially in untrained rats increased levels of tissue lipid peroxidation have been accompanied by elevated hepatic catalase and cytosolic superoxide dismutase activities [10]. Increased oxygen turnover could also lead to an increased formation of reactive oxygen species in erythrocytes. Increased methaemoglobin formation alone would already provide a challenge for glutathione-dependent reducing systems. Ohno et al. [16] have reported increases in erythrocyte glutathione reductase (GR) activity and in GR coefficients in seven males after 10 weeks of training. Indications of radical stress in blood have also 
been found by Pincemail et al. [17], who showed that, after exercise on a cycle ergometer increased concentrations of the radical scavenging vitamin tocopherol were found not only in plasma but also in the erythrocyte.

To gain a better insight of the exact nature of the effects of exercise on the glutathione dependent defense system in the erythrocyte, we studied the effects of running training on total blood glutathione (GSH), on GR and glutathione Stransferase (GST) activities in erythrocytes and on the riboflavin content of the erythrocytes. Blood samples were collected before the start of the experiment, after 20 weeks of training and after 40 weeks of training. The 20 - and 40 week samples were collected before the subjects studied participated in a $15-\mathrm{km}$ and a half marathon contest, respectively. The effects of the contest itself were studied in samples taken before and after the races.

\section{Methods}

\section{Study design}

The participants (23 men and 18 women) were selected from a population of 370 who replied to a bulletin issued through the local media. Prior to the study they had not participated in any running sport and were not active in any other sport for more than $1 \mathrm{~h}$ a week. The selection was made to produce a comparable group of both sexes in respect of age (28-41 years) and body mass index $\left(19.4-26.4 \mathrm{~kg} \cdot \mathrm{m}^{-2}\right)$. The subjects were examined medically and gave their written informed consent before the start of the study.

The training programme has been described before [8]. In brief, it consisted of three to four prescribed training sessions weekly, one of which was supervised by one of the authors (GJ). The time spent running was gradually increased from 10 to $30 \mathrm{~min}$ during the first 8 weeks, to 20 to $60 \mathrm{~min}$ in weeks 9 to 20 and to 30 to $90 \mathrm{~min}$ in the last part of the study.

Two participants of each sex did not continue the training until the first 20 weeks, and were removed from the study. Due to personal circumstances no samples were collected from 4 women and 1 men before and after the 15 -km race. One woman and 3 men abandoned the study during the second period of training and, therefore, did not participate in the half marathon contest.

To study the effect of training, blood samples were collected before the start of the experiment, after 20 weeks of training, and after 40 weeks of training. To evaluate the effects of participation in contests blood samples were taken 5 days before (day -5 ), immediately after (day 1) and 5 days after (day 5 ) a 15-km contest ran after 20 weeks and a half marathon run after 40 weeks.

The GSH concentrations in blood, GR [Enzyme Commission no. (EC) 1.6.4.2)] and GST (EC 2.5.1.18) activities in erythrocytes and the glutathione reductase coefficient ( $\mathrm{GR}_{\text {coeffic. }}$ an indicator of the riboflavin content) of the erythrocytes were determined in all samples. 


\section{Analytical methods}

Chemicals.

The following chemicals were used: 5,5'-dithiobis-(2-nitrobenzoic acid) (DTNB; E. Merck, Darmstadt, FRG). Oxidized (GSSG) and reduced (GSH) glutathione (Boehringer Mannheim, Mannheim, FRG), 1-chloro-2,4-dinitrobenzene (CDNB), flavin adenine dinucleotide $(F A D)$, nicotinamide adenine dinucleotide phosphate, reduced (NADPH) and GR (Sigma; St. Louis, MO, USA). All other chemicals were of analytical quality. Only microfiltrated deionized water was used.

\section{Determination of blood GSH.}

Blood samples for determination of total GSH were collected in 5-ml vacutainers containing $7.5 \mathrm{mg} \mathrm{Na}{ }_{2}$ EDTA (ethylenediaminetetraacetic acid). To 1-ml blood an equal volume of $14 \%(\mathrm{v} / \mathrm{v}) \mathrm{HCLO}_{4}$ was added. After centrifugation at $3000 \mathrm{~g}$ for $10 \mathrm{~min}$ the supernatant was neutralized with a mixture of $0.3 \mathrm{~mol} \cdot \mathrm{l}^{-1} \mathrm{~N}-2$ hydroxyethylpiperazine- $\mathrm{N}^{2}$-2-ethanesulfonic acid (buffer) (HEPES) and $2 \mathrm{~mol} \cdot \mathrm{I}^{-1}$ $\mathrm{KOH}$. The samples were stored below $-70^{\circ} \mathrm{C}$ until determination. Total GSH was determined with the cyclic oxidation-reduction method essentially as described by Anderson [1].

\section{Determination of enzyme activities.}

Erythrocytes isolated from $10-\mathrm{ml}$ blood samples collected in vacutainers containing heparin, were washed three times with saline and stored below $-70^{\circ} \mathrm{C}$ until further use. To the frozen erythrocyte samples 1-ml water was added, and the samples were thawed on ice. Thereafter, the samples were diluted twenty fold with $100 \mathrm{mmol} \cdot \mathrm{l}^{-1}$ potassium phosphate buffer $(\mathrm{pH}=6.5)$ containing $6.3 \mathrm{mM} \mathrm{Na}_{2}$ EDTA and centrifuged at $10.000 \mathrm{~g}$ for $10 \mathrm{~min}$. The GST activity towards CDNB was determined in $200 \mu \mathrm{l}$ of this sample as described by Habig and Jakoby [7] with a Philips PU 8740 spectrophotometer (Philips; Eindhoven; NL) with the slit adjusted to $2 \mathrm{~nm}$. A quantity of $200 \mu \mathrm{l}$ of the same sample was used for determination of GR activity according to the method described by Carlberg and Mannervik [4]. The haemoglobin concentrations in the erythrocytes were determined with the haemoglobin cyanide procedure described by Van Kampen and Zijlstra [12].

\section{Determination of riboflavin content.}

The coefficient of erythrocyte GR activity with and without addition of FAD to the assay was used as an indicator of the riboflavin content. The determinations were carried out essentially as described for GR above, except that $0.01 \mathrm{mM}$ FAD was added to one of the two samples[18]. 


\section{Statistical analyses.}

Sex related differences were evaluated with the Mann-Whitney $U$-test. Differences between values on different days were analysed with Wilcoxon's matched pair analysis with matches for values from the same individual.

\section{Results}

\section{Sex differences.}

Sex related differences were evaluated for data combined for all days. The GSH values were found to be higher in men than in women [1.14 (SD 0.34) $\mathrm{mM}$ and 1.06 (SD 0.35) $\mathrm{mM}$, respectively; $p<0.029$. This difference resulted directly from the difference in packed cell volume between men and women, and disappeared when GSH concentrations were expressed as mmol.g Hb${ }^{-1}$. The GR activity was higher $(p<0.005)$ and the $\mathrm{GR}_{\text {coeffic. }}$ were lower $(p<0.046)$ in women. The values were 3.29 (SD 0.56) U.g Hb ${ }^{-1}$ with a ratio of 1.05 (SD 0.09) for men and 3.5 (SD 1.2) U.g Hb-1 with a ratio of 1.03 (SD 0.10) for women. Since the statistical procedures were carried out as matched pair analyses, and since there were no qualitative differences between sexes in the changes found, all reported changes were calculated for men and women taken together. There was one exception, and that was that the glutathione concentration increase after the $1 / 2$ marathon (see below) did only occur in females, while in males an opposite (not statistically significant) tendency existed.

\section{Values after training.}

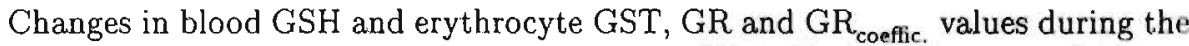
training period are given in Table 8.1. Total GSH in blood was increased almost $50 \%$ after the first 20 weeks of training. After the prolonged (heavy) training in the second part of the study, the values returned to the initial levels and were in fact even slightly lower. The GR activity had also increased [from 3.13 (SD 0.76) $\mathrm{U} \cdot \mathrm{g} \mathrm{Hb}^{-1}$ to 3.36 (SD 0.85$) \mathrm{U} \cdot \mathrm{g} \mathrm{Hb} \mathrm{Hb}^{-1}$ ] after the first 20 weeks and was still at a high level $\left[3.42\right.$ (SD 1.01) U.g Hb-1 $\mathrm{Hb}^{-1}$ after 40 weeks. Accompanying this change in GR activity, we found a decrease in the $\mathrm{GR}_{\text {coeffic. }}$ values [from 1.08 (SD 0.09) to 1.04 (SD 0.03)] in the first 20 weeks. Like the GR values these values showed no further changes during the second training period. The GST activity increased only slightly during the first period $[1.08$ (SD 0.41) U.g Hb $0.43) \mathrm{U} \cdot \mathrm{g} \mathrm{Hb}^{-1}$ after 20 weeks] but increased markedly during the second part of the study [to $1.86(\mathrm{SD} 0.75) \mathrm{U} \cdot \mathrm{g} \mathrm{Hb} \mathrm{Hb}^{-1}$.

\section{Participation in contest.}

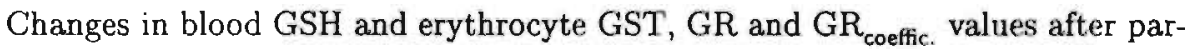
ticipation in the $15-\mathrm{km}$ race and in the half marathon and the values for all four 
Table 8.1: Effects of training on glutathione concentrations (GSH) in blood, glutathione S-transferase (GST) and glutathione reductase (GR) activity and the glutathione reductase activity coefficient $\left(\mathrm{GR}_{\text {coeffic. }}\right)$ in erythrocytes. The training schedule lasted 40 weeks and for the values after 20 weeks and 40 weeks levels of significance for differences with the earlier samples (Wilcoxon matched pair test) are given. $p$ Values $>0.1$ are given as NS (not significant).

\begin{tabular}{|c|c|c|c|c|}
\hline & & & \multicolumn{2}{|c|}{$\begin{array}{l}\text { level of significance for } \\
\text { difference from: }\end{array}$} \\
\hline & & & 0 weeks & 20 weeks \\
\hline GSH & $\begin{array}{l}0 \text { weeks } \\
20 \text { weeks } \\
40 \text { weeks }\end{array}$ & $\begin{array}{l}\text { 6.54 (SD 2.26) mmol.g } \mathrm{Hb}^{-1} \\
9.73 \text { (SD 2.09) mmol.g } \mathrm{Hb}^{-1} \\
5.94 \text { (SD 1.61) mmol.g } \mathrm{Hb}^{-1}\end{array}$ & $\begin{array}{l}p<0.0001 \\
\text { NS }\end{array}$ & $p<0.0001$ \\
\hline GR & $\begin{array}{l}0 \text { weeks } \\
20 \text { weeks } \\
40 \text { weeks }\end{array}$ & 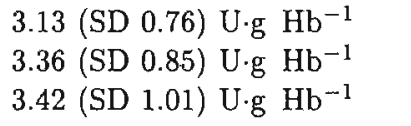 & $\begin{array}{l}p<0.0037 \\
p<0.0003\end{array}$ & NS \\
\hline $\mathrm{GR}_{\text {coeffic. }}$ & $\begin{array}{l}0 \text { weeks } \\
20 \text { weeks } \\
40 \text { weeks }\end{array}$ & $\begin{array}{l}1.08(\mathrm{SD} 0.09) \\
1.04(\mathrm{SD} 0.03) \\
1.03(\mathrm{SD} 0.10)\end{array}$ & $\begin{array}{l}p<0.015 \\
p<0.016\end{array}$ & NS \\
\hline GST & $\begin{array}{l}0 \text { weeks } \\
20 \text { weeks } \\
40 \text { weeks }\end{array}$ & $\begin{array}{l}1.08\left(\mathrm{SD} \mathrm{0.41)} \mathrm{U} \cdot \mathrm{g} \mathrm{Hb}^{-1}\right. \\
1.15\left(\mathrm{SD} \mathrm{0.43)} \mathrm{U} \cdot \mathrm{g} \mathrm{Hb} \mathrm{Hb}^{-1}\right. \\
1.86(\mathrm{SD} 0.75) \mathrm{U} \cdot \mathrm{H} \mathrm{H}^{-1}\end{array}$ & $\begin{array}{l}p<0.018 \\
p<0.0001\end{array}$ & $p<0.0001$ \\
\hline
\end{tabular}

parameters determined 5 days after each race are given in table 8.2. For both races the GSH values in the samples taken 5 days after the race were not statistically different from the precontest values. The GSH concentrations tended to be lower after the $15-\mathrm{km}$ race. While the decrease from pre- to postrunning samples did not attain statistical significance, the $p$ value for the subsequent increase (equal to a return to normal values) was 0.066 . Since the precontest values were in fact increased in comparison with the samples taken at the start of the project, the decrease went towards normal values. After the half marathon we found an increase in GSH values. As the precontest values for the half marathon were lowered in comparison with the pretraining values, here too the shift was in the direction of the pretraining values.

The GR activities were increased significantly $(p<0.03)$ in the day 1 samples taken after both contests and had returned to prerunning values on day 5 . Here too, the change was accompanied by a change in $\mathrm{GR}_{\text {coeffic. }}$ values. There was a slight decrease in these values after both contests (not significant after the half marathon) and a return to normal at day 5 (the increase between 
Table 8.2: Effects of participation in a $15-\mathrm{km}$ and a half marathon contest on glutathione concentrations (GSH) in blood, glutathione S-transferase (GST) and glutathione reductase (GR) activity and the glutathione reductase activity coefficient $\left(G R_{\text {coeffic. }}\right.$ ) in erythrocytes. Values are given for the participants 5 days before $(-5), 1$ day after $(+1)$ and 5 days $(+5)$ after the contests. For the values at days 1 and 5 levels of significance for differences with the earlier samples (Wilcoxon matched pair test) are given. $p$ Values $>0.1$ are given as NS (not significant).

\begin{tabular}{|c|c|c|c|c|}
\hline & & & $\begin{array}{l}\text { level of signifi } \\
\text { difference fron } \\
5 \text { days before } \\
\text { race }(-5)\end{array}$ & $\begin{array}{l}\text { cance for } \\
\text { values at: } \\
1 \text { day after } \\
\text { race }(+1)\end{array}$ \\
\hline GSH & $\begin{array}{l}15 \mathrm{~km}-5 \\
15 \mathrm{~km}+1 \\
15 \mathrm{~km}+5 \\
\frac{1}{2} \operatorname{mar}-5 \\
\frac{1}{2} \operatorname{mar}+1 \\
\frac{1}{2} \operatorname{mar}+5\end{array}$ & 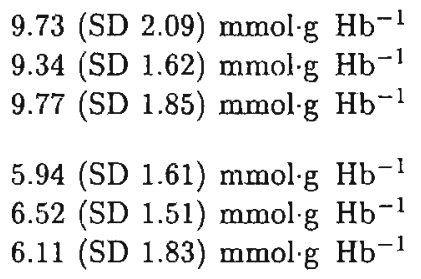 & $\begin{array}{l}p<0.057 \\
\text { NS }\end{array}$ & $p<0.066$ \\
\hline GR & $\begin{array}{l}15 \mathrm{~km}-5 \\
15 \mathrm{~km}+1 \\
15 \mathrm{~km}+5 \\
\frac{1}{2} \operatorname{mar}-5 \\
\frac{1}{2} \operatorname{mar}+1 \\
\frac{1}{2} \operatorname{mar}+5\end{array}$ & 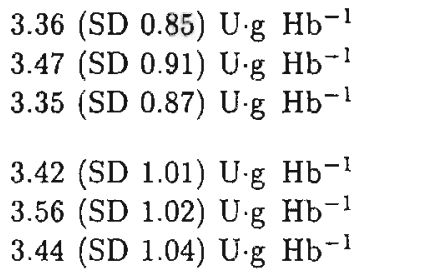 & $\begin{array}{l}p<0.021 \\
\text { NS }\end{array}$ & $p<0.0067$ \\
\hline GR reeffic & $\begin{array}{l}15 \mathrm{~km}-5 \\
15 \mathrm{~km}+1 \\
15 \mathrm{~km}+5 \\
\frac{1}{2} \operatorname{mar}-5 \\
\frac{1}{2} \operatorname{mar}+1 \\
\frac{1}{2} \operatorname{mar}+5\end{array}$ & $\begin{array}{l}1.04(\text { SD 0.09) } \\
1.02(\text { SD } 0.09) \\
1.03(\text { SD } 0.09) \\
1.03(\text { SD } 0.10) \\
1.02(\text { SD } 0.11) \\
1.04(\text { SD } 0.11)\end{array}$ & $\begin{array}{l}p<0.010 \\
\text { NS }\end{array}$ & $p<0.022$ \\
\hline GST & $\begin{array}{l}15 \mathrm{~km}-5 \\
15 \mathrm{~km}+1 \\
15 \mathrm{~km}+5 \\
\frac{1}{2} \operatorname{mar}-5 \\
\frac{1}{9} \operatorname{mar}+1 \\
\frac{1}{2} \operatorname{mar}+5\end{array}$ & 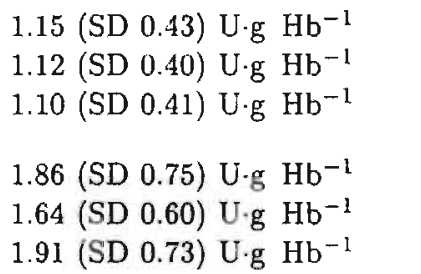 & $\begin{array}{l}p<0.077 \\
p<0.018\end{array}$ & $p<0.081$ \\
\hline
\end{tabular}


day 1 and day 5 was significant for the half marathon).

The GST activities had decreased after both the $15 \mathrm{~km}$ contest and the half marathon. This change was much more pronounced for the balf marathon samples but it should be noted that the precontest values for this race were increased compared with the pretraining values. In the day 5 samples taken after the $15-\mathrm{km}$ contest the GST activity values were even further decreased, whereas the values at day 5 after the half marathon had returned to precontest values.

\section{Discussion}

We found increases of the order of $50 \%$ for GSH after 20 weeks of training. An increase in blood GSH during a period of training can be explained by the high amounts of reduced GSH that are needed for the reduction of methaemoglobin formation and for protection against reactive oxygen species. The same argument applies to the (less pronounced) increase in GR activity. During the second part of the study the GSH values returned to normal. This phenomenon could be explained by a shortage in glutathione synthesis or by the disappearance of the need for elevated glutathione concentrations. Increases in GR activity could be a possible cause for such a diminution in the need for GSH availability, as higher GR activity levels could have resulted in a shift of the ratio of GSH and GSSG. The continuously high levels of GR activity found in the second part of the training period, indicated that a decrease in the need for GSH was not likely. The increase in GR activity was, at least in part a result of increases in riboflavin availability, which was indicated by decreased $\mathrm{GR}_{\text {coeffic. }}$ values in the samples collected after the training periods. The findings of Ohno et al.[16] would suggest that this was not the only cause. While they have also reported increases in GR activity after training they have found increased $G_{\text {coeffic. }}$ The differences in the procedures used in these two studies may have accounted for this difference in the effects on $\mathrm{GR}_{\text {coefic. }}$ (only 7 subjects and only 10 weeks of training were used by Ohno et al. 1988). Training would seem to increase the need of erythrocytes for reduced GSH. While this need was initially countered by increased GSH synthesis, later on only increases in GR activity were found. The presence of relatively large amounts of younger cells in the 20 week samples may also have contributed to the explanation of the increased GSH concentrations. This was indicated by the lower $(p<0.0001)$ mean cell volumes $(\mathrm{MCV})$ in these samples [MCV values were 93.2 (SD 4.1) $\mathrm{fl}$ in the pretraining period; 91.5 (SD 4.1) $\mathrm{fl}$ in the 20-week and 92.6 (SD 3.8 ) in the 40 -week samples]. This decrease in MCV in the early training phase was in accordance with what has been found in a previous study [11]. While there was only a small increase in the level of GST activity during the first 20 weeks of training, a marked increase occurred during the second period. Since GST is vulnerable in the presence of reactive species (see below), which could be seen in the decrease of GST activity after the races, this increase may have been a result 
of a kind of overshoot adaptation to such repeated inactivations. On the other hand, GST apart from its functions as a transferase and an intracellular transport protein, has an important function as an organic peroxidase [13]. Exercise can lead to increased lipid peroxidation in muscles $[14,15]$ : our findings indicated that lipid peroxidation after exercise may also have occurred in erythrocytes.

In previous studies [3] a decrease in GST activities in erythrocytes after exposure to the soil fumigant dichloropropene has been reported. The decrease found after heavy physical activity may also have been indicative of the formation of reactive substances. The return to normal values 5 days after the half marathon (but not after the earlier 15-km race) indicated that GST inactivation was reversible and suggested that the reactive species were either formed less or removed faster in longer trained persons. The increase of GR activity directly after the races could hardly have been a result of de novo synthesis of GR, since erythrocytes lack active protein synthesis, and since red-cell proliferation is slow. The concurrent changes in GR activity coefficients indicated that the changes in GR activity were most likely to have been caused by modulations in activity as a result of changes in erythrocyte riboflavin concentrations. The changes in GSH after the races were minor. Duthie et al. [5] have reported significant ( $\pm 15 \%)$ decreases of reduced GSH in samples taken $24 \mathrm{~h}$ after a half marathon. Both the direction and the magnitude of this change are not in agreement with the values reported here.

In general it can be concluded that both endurance training and competitive physical exercise had important effects on the glutathione dependent defense. system in erythrocytes. Most effects appeared to be reversible adaptations. The pronounced increase in GST activity during the second phase of the training programme may, however, indicate a response to cell damaging reactions.

Acknowledgment. We thank A.J.P. van Bommel for his technical assistance. 


\section{References}

[1] Anderson ME (1985). Determination of glutathione and glutathione disulfide in biological samples. Meth Enzymol 113: 548-555.

[2] Banister EW, Rajendra W, Mutch BJC (1985). Ammonia as an indicator of exercise stress - Implications of recent findings to sports medicine. Sports Med 2 : 34-46.

[3] Brouwer EJ, Evelo CTA, Verplanke AJW, van Welie RTH and de Wolff FA (1991). Biological effect monitoring of exposure to 1,3-dichloropropene: effects on liver and renal function and on glutathione conjugation. $\mathrm{Br} J$ Ind Med 48: 167-172.

[4] Carlberg I and Mannervik B (1985). Glutathione reductase. Meth Enzymol 113: 484-490.

[5] Duthie GG, Robertson JD, Maugham RJ, Morrice PC (1990). Blood antioxidant status and erythrocyte lipid peroxidation following distance running. Arch Biochem Biophys 282: 78-80.

[6] Freeman ML, Spitz DR and Meredith MJ (1990). Does heat shock enhance oxidative stress? Studies with ferrous and ferric iron. Radiat Res 124: 288-293.

[7] Habig WH and Jakoby WB (1981). Assays for the differentiation of glutathione S-transferases. Meth Enzymol 77: 398-405.

[8] Janssen GME and Hoor ten F (1989). Marathon running: functional changes in male and female subjects during training and contests. Int J Sports Med 10: suppl. 3.

[9] Jenkins RR (1988). Free radical chemistry. Relationship to exercise. Sports Med 5: $156-170$.

[10] Ji LL, Stratman FW and Lardy HA (1988). Antioxidant enzyme systems in rat liver and skeletal muscle. Influences of selenium deficiency, chronic training and acute exercise. Arch Biochom Biophys 263: 150-160.

[11] Kaiser V, Janssen GME, van Wersch JWJ (1989). Effect of training on red blood cell parameters an plasma ferritin: a transverse and a longitudinal approach. Int $J$ Sports Med 10: suppl. 3, 169-175.

[12] Kampen van EJ and Zijlstra WG (1965). Determination of hemoglobin and its derivatives. Adv Clin Chem 8: 141-187.

[13] Mannervik B and Danielson UH (1988). Glutathione Transferases - structure and catalytic activity. Crit Rev Biochem 23: 283-337.

[14] Maugham RJ, Donnelly AE, Gleeson M, Whiting PH, Walker KA and Clough PJ (1989). Delayed onset muscle damage and lipid peroxidation in man after a downhill run. Muscle Nerv 12: 332-336.

[15] Nilsson S and Marklund L (1988). Effect of venous stasis and physical exercise on plasma extracellular-superoxide dismutase. Scand J Clin Lab Invest 48: 441-444.

[16] Ohno H, Yahata T, Sato Y, Yamamura $K$ and Taniguchi $N$ (1988). Physical training and fasting erythrocyte activities of free radical scavenging enzyme systems in sedentary men. Eur J Appl Physiol 57: 173-176.

[17] Pincemail J, Deby C, C'umus G, Pirnay F, Bouchez R, Massaux L and Goutier R (1988). Tocopherol mobilization during intensive exercise. Eur J Appl Physiol 57: 189-191. 
[18] Tietz NW (Ed.) (1986). Textbook of clinical chemistry. Saunders Philadelphia. pp. 946-949. 



\section{Chapter 9}

\section{Decreased Glutathione Content and}

\section{Glutathione S-Transferase Activity in Red}

Blood Cells of Coal Miners with Early Stages of

\section{Pneumoconiosis}

Chris T.A. Evelo ${ }^{1}$, Robert P. Bos ${ }^{2}$ and Paul J.A. Borm ${ }^{3}$

1: Department of Pharmacology (Toxicology section), University of Limburg, P.O. Box 616, 6200 MD Maastricht, The Netherlands.

2: Department of Toxicology, University of Nijmegen, P.O. Box 9101, $6500 \mathrm{HB}$ Nijmegen, The Netherlands.

3: Department of Health Risk Analysis and Toxicoloyy, Unincrsity of Limburg, P.O. Box 616, 6200 MD Maustricht, The Nethrrlands.

Published in: Br J Ind Med 50, 1993, 633-636. 
Summary. Blood samples of miners heavily exposed to coal dust were examined for changes in glutathione S-transferase (GST). Decreased GST activity was found in red blood cells of subjects at early stages of coal workers' pneumoconiosis (International Labour Office classification 0/1-1/2) when compared to control miners. At further progression of coal workers' pneumoconiosis $(\geq 2 / 1)$, the activity of GST was not different from controls. In the same group with moderate coal workers' pneumoconiosis a decrease in GSH in red blood cells occurred. Decreases in GST activity in early stages of coal workers' pneumoconiosis, as well as the decreases in glutathion peroxidase ( $G P X)$ activity and in GSH reported earlier [9], may originate from damage caused by reactive oxygen species. These changes might imply an impairment of the detoxification capacity for electrophilic and oxidative compounds during this stage of the disease.

\section{Introduction}

Lung fibrosis related to the inhalation of dusts containing toxic particles such as silica, or asbestos is a serious occupational hazard. It is well known that during the immune defense against dust particles, reactive oxidant species are secreted by various types of inflammatory cells with the alveolar macrophage playing a key rolc in this process $[5,21]$. The lung tissue possesses an elaborate defense mechanism to detoxify reactive oxygen species, constituted by a set of antioxidant enzymirs $(A O E)$ such as superoxide dismutase and glutathione-peroxidase (GPX) and low-inolecular compounds such as glutathione (GSH) acting as a substrate for GPX and glutathione S-transferase (GST) or as direct radical scavengers. Also, antioxidants localised in erythrocytes are involved in the antioxidant protection of the lung $[2,22]$, acting as circulating antioxidant carriers.

Previously, we showed $[9,3,4]$ that AOE and GSH in erythrocytes are affected at different stages of pneumoconiosis in coal workers or silicotic patients and in lung tissue of rats exposed to silica[13]; GSH concentration and GST activity were also found to be affected after occupational exposure to reactive compounds $[6,10]$ and in situations involving reactive oxygen species stress like smoking [10] and heavy exercise [11]. This paper presents the results of GSH determinations and GST-analyses with an activity assay and enzyme linked immunosorbent assay (ELISA) in red blood cells of a cohort of coal miners previously investigated by our research group [9].

\section{Materials and Methods}

\section{Subjects}

Ninety one coal miners, all heavily exposed to coal dust underground at the coal face for at least twelve years, were selected from the Belgian coal mining industry 
pits (Kempense Steenkolenmijnen). Blood samples were taken and treated as described previously [9]. Control miners $(n=58)$ and miners with coal workers pneumoconiosis $(C W P)(n=33)$ were matched for exposure and age at which they started work. In this study persons with the classification $0 / 1,1 / 0,1 / 1$ and $1 / 2[17]$ were gathered in group $2(n=19)$; persons with classification $2 / 1$ and higher in group $3(n=14)$; control miners constituted group 1 .

\section{Analytical methods}

\section{Chemicals.}

The chemicals used were: rabbit polyclonal antibodies against GST $\pi$ (Medlabs; Dublin, Ireland), swine anti-rabbit IgG antibodies conjugated to horse-radish peroxidase $(H R P)$ and orthophenylenediamine $(O P D)$ (Dakopatts; Kopenhagen, Denmark), 5,5'-dithio-bis(2-nitrobenzoic acid) (DTNB); E. Merck; Darmstadt, FRG). Reduced glutathione (GSH) (Boehringer Mannheim; Mannheim, FRG), 1-chloro-2,4-dinitrobenzene (CDNB), dithiothreitol (DTT), GST $\pi$ from human placenta and tween-20 (Sigma; St. Louis, MO, USA). All other chemicals were of analytical quality. Only microfiltrated deionized water was used.

\section{Determination of blood GSH.}

Total GSH was determined with the cyclic oxidation-reduction method essentially as described by Anderson [1].

\section{Assays for GST.}

GST (EC 2.5.1.18) activity was determined by a modification of the method described by Habig and Jakoby [12] as previously described [11] lysing the RBC by addition of three volumes of water containing $1.4 \mathrm{mM}$ neutral DTT, centrifugation and measuring the activity towards CDNB. A Cary 118 spectrophotometer was used in auto slit mode with the gain adjusted to 2.5 .

For the competitive ELISA, Costar ${ }^{T M}$ flat bottom 96-well EIA plates (Data Packaging Corporation; Broadway, MA, USA) were coated overnight at $4^{\circ} \mathrm{C}$ with $200 \mu \mathrm{l}$ phosphate buffered ( $10 \mathrm{mM}$ ) saline of $\mathrm{pH} 7.2$ containing $11 \mu \mathrm{U}$ GST $\pi$ from human placenta per well. Each well was washed three times with $200 \mu$ l ELISA buffer $(10 \mathrm{mM}$ sodiumphosphate $+0.5 \mathrm{M}$ sodiumchloride $+0.1 \%(\mathrm{v} / \mathrm{v})$ Tween20) of $\mathrm{pH}$ 7.2. This and all further steps were performed at room temperature. To each well $50 \mu \mathrm{l}$ of the antigen solution (hemolysate) and $150 \mu \mathrm{l}$ antibodies against GST $\pi$ diluted 2250 fold with ELISA buffer were added. After 2 hours incubation the wells were washed three times with ELISA buffer and incubated for 1 hour with $200 \mu \mathrm{l}$ HRP labeled anti-IgG diluted 1500 fold with ELISA buffer. After another three washes with ELISA buffer $100 \mu \mathrm{l}$ of a $100 \mathrm{mM}$ citrate-phosphate buffer of $\mathrm{pH} 5.0$ containing $0.67 \mathrm{mg} / \mathrm{ml}$ OPD and $0.0125 \%(\mathrm{w} / \mathrm{v}) \mathrm{H}_{2} \mathrm{O}_{2}$ were added to each well. After exactly 15 minutes the enzymatic reaction was stopped 
by addition of $150 \mu \mathrm{l} 1 M$ sulfuric acid. The extinctions at $492 \mathrm{~nm}$ were read with a multiscan interfaced to a MINC computer.

Reference data for the quantitation of the ELISA results were obtained with GST $\pi$ from human placenta. Known quantities of this enzyme - expressed in activity units - were tested in the competitive ELISA assay. The results were fitted to the general logistic function [7]:

$$
Y=\frac{a-d}{1+\left(\frac{C}{E C_{50}}\right)^{s}}+d
$$

where $Y$ is the response; $C$ the concentration of the antigen; $a$ the response when $C=0 ; d$ the response for "infinite" concentrations of antigen; $E C_{50}$ the antigen concentration resulting in a response halfway between $a$ and $d$; and $s$ is a slope factor which corresponds to the slope of the logit-log plot, when $C$ is plotted in terms of natural logarithms. For curve fitting the NLIN procedure from the SAS ${ }^{T M}$ package was used with the DUD [20] method for nonlinear regression. The response was expressed as fraction of the maximum extinction, found without addition of antigen, $E=\frac{Y}{a}$.

The haemoglobin concentrations in the erythrocytes were determined with the haemoglobin cyanide procedure [14].

\section{Statistical Evaluation}

Analytical results were coupled to previous data on this cohort in a database. Correlations between variables were studied using STATGRAPH 3.01 statistical package. Differences between variables in separate groups were evaluated with the Wilcoxon 2 sample test.

\section{Results}

Table 9.1 shows the mean values and standard deviations (SDs) of GSH concentrations, GST activity towards CDNB and GST content as determined by competitive ELISA in the blood of the control miners and the two groups of miners with coal workers' pneumoconiosis. No effect of smoking was seen on any parameter mentioned. GSH values were determined previously [9]. Repeated analyses in the frozen samples used for the GST determinations did not show significant differences from the original values. Therefore, the original data rearranged for the current purpose are listed in table 9.1. Both GSH concentration and GST activity values were decreased in group 2, the workers with moderate forms of coal workers" pneumoconiosis. In group 3 such a decrease was not found. The GST protein content showed a tendency to follow the GST activities, although the decrease in group 2 did not attain statistical significance. 
Table 9.1: Glutathione (GSH) concentrations, glutathione S-transferase (GST) activity towards CDNB and glutathione S-transferase protein content as determined by ELISA in red blood cells of coal workers. Levels of significance for decrease compared to the control group (Wilcoxon 2 sample test) are given for $p$ values smaller than 0.1 .

\begin{tabular}{|c|c|c|c|}
\hline & $\begin{array}{l}\text { Control } \\
\text { miners }(0 / 0)\end{array}$ & $\begin{array}{l}\text { Group } 2 \\
\text { CWP }(0 / 1-1 / 2)\end{array}$ & $\begin{array}{l}\text { Group } 3 \\
\text { CWP }(\geq 2 / 1)\end{array}$ \\
\hline $\begin{array}{l}\text { GSH } \\
\left(\mathrm{mmol} \cdot \mathrm{g} \mathrm{Hb} \mathrm{Hb}^{-1}\right)\end{array}$ & $\begin{array}{l}3.97(\text { SD } 0.08) \\
(n=58)\end{array}$ & $\begin{array}{l}3.62(\mathrm{SD} 0.14) \\
(n=19 ; p=0.016)\end{array}$ & $\begin{array}{l}3.98(\mathrm{SD} 0.46) \\
(n=14)\end{array}$ \\
\hline $\begin{array}{l}\text { GST (CDNB) } \\
\left(\mathrm{U} \cdot \mathrm{g} \mathrm{Hb}^{-1}\right)\end{array}$ & $\begin{array}{l}2.99(\mathrm{SD} 1.36) \\
(n=45)\end{array}$ & $\begin{array}{l}2.31(\text { SD 1.09) } \\
(n=9 ; p=0.061)\end{array}$ & $\begin{array}{l}3.37 \text { (SD 1.14) } \\
(n=10)\end{array}$ \\
\hline $\begin{array}{l}\text { GST (ELISA) } \\
\left(\equiv \mathrm{U} \cdot \mathrm{g} \mathrm{Hb}^{-1}\right)\end{array}$ & $\begin{array}{l}2.46(\mathrm{SD} 1.93) \\
(n=34)\end{array}$ & $\begin{array}{l}1.92(\operatorname{SD} 0.90) \\
(n=6)\end{array}$ & $\begin{array}{l}2.54(\text { SD } 1.39) \\
(n=7)\end{array}$ \\
\hline
\end{tabular}

\section{Discussion}

Our data show that. as well as GSH, erythrocyte GST activity is decreased in subjects with early stages of pulmonary fibrosis $(0 / 1-1 / 2)$ when compared with control miners. At further progression of coal workers' pneumoconiosis $(2 / 1+)$ however, erythrocyte activity was not different from controls. In the same group with moderate coal workers' pneumoconiosis, a decrease in GSH in erythrocytes occurs. Previously, we reported an increase in total GPX activity in the same workers at early stages of the disease [9] and in rat lung homogenates after in: vivo exposure to silica or asbestos [13]. We think that the decrease in GSH and GST activity is caused by excessive release of reactive oxygen species by alveolar macrophages and neutrophils in the lung tissue. A decrease in GST activity cannot be the result of decreased GSH concentrations during determinations, since saturating concentrations of GSH $(1 \mathrm{mM})$ are added in the assay. Moreover, there is no (negative) correlation between GSH content and GST activity of the blood samples. Combined with our data obtained with the ELISA on GST in erythrocytes (which tended to decreased in the same group) we conclude that a fraction of GST is damaged, possibly by oxidation of SH-sites. The decrease. in available GST activity plus the fact that GST activity is GSH dependent, might imply that in vivo functioning of the enzyme is affected rendering these individuals more susceptible to damage resulting from lipid peroxidation or from co-exposure to electrophilic compounds. Various mineral fibers were reported [19] to inhibit GST activity in cytosol of rat lung homogenates after in vitro and in vivo exposure, while phase 1 reactions were increased at advanced stages of the 
disease. An induction of phase I enzymes in advanced stages of fibrosis might further aggrevate the accumulation of activated metabolites in the lung.

Previously, we argued that the restoration of erythrocyte GSH content in miners with coal workers' pneumoconiosis beyond $2 / 1$ to control values, is caused by a hepatic efflux of GSH [9]. We found comparable phenomena for GST in sporters. After moderate running training (up to 60 min after 20 weeks) [11] GST activity and GSH concentrations in RBC were both increased. After heavy training (up to 90 min after 40 weeks) GSH values were returned to normal and GST was strongly increased. Increases in GST protein content in RBC can be the result of increased protein synthesis during RBC proliferation, or, less likely, of increased longevity of the protein itself. Increases in GST content were also found in smokers [10]. Here lower specific activities and equal total activities were found. This too might be a result of compensatory GST synthesis. Thus, GST activity in coal miners with coal workers' pneumoconiosis $(>2 / 1)$ could remain at normal values due to compensation of inactivation by extra protein synthesis during $\mathrm{RBC}$ proliferation. This extra synthesis could be triggered by inflammatory processes generating cytokine release in coal workers' pneumoconiosis[15] or very heavy exercise. Possibly the formation of lipid peroxides, documented in exercise [8] and rats exposed to mineral fibers[18], could be an important factor in this respect. Lipid peroxides are known to detoxified by GST, which shows selenium independent GPX activity [16].

In conclusion, red blood cell GST activity is affected in early phases of coal workers' pneumoconiosis, possibly as a result of oxidative damage. Combined with our earlier findings (a decrease in GSH, and increase of GPX) this might mean that detoxification of electrophilic compounds in this stages is impaired.

Acknowledgement. The authors wish to thank drs. K. Herberichs and J.G.P. Peters of the Department of toxicology from the University of Nijmegen for their assistance with the analyses. 


\section{References}

[1] Anderson ME (1985). Determination of glutathione and glutathione disulfide in biological samples. Methods Enzymol, 113: 548-555.

[2] Asbeck BS van, Hoidal J, Vercelotti GM, Schwartz BA, Moldow CF and Jacobs HS (1984). Protection against lethal hyperoxia by tracheal insufflation of erythrocytes: role of red cell glutathione. Science 277: 756-758.

[3] Borm PJA, Bast A, Wouters EFM, Slangen JJM, Swaen GMH and de Boorder $\mathrm{Tj}$ (1986). Red blood cell anti-oxidant parameters in silicosis. Int Arch Occup Env HIth 58: 235-244.

[4] Borm PJA, Engelen JJM, Palmen N and Buurman WA (1991). Red blood cell anti-oxidants and monocyte tumor necrosis factor (TNF) in the pathogenesis of coal workers' pneumoconiosis. In: Mechanisms in Occupational Lung Diseases (Sebastien P, (Ed)), Colloque INSERM, 203: pp. 161-167.

[5] Bowden DH (1987). Macrophages, dust and pulmonary diseases. Exp Lung Res, 12: 89-107.

[6] Brouwer EJ, Evelo CTA, Verplanke AJW, van Welie RTH and de Wolff FA (1991). Biological effect monitoring of exposure to 1,3-dichloropropene: effects on liver and renal function and on glutathione conjugation. Br J Ind Med 48: 167-172.

[7] De Lean A, Munson PJ and Rodbard D (1978). Simultaneous analysis of families of sigmoidal curves: application to bioassay, radioligand assay and physiological dose-response curves. Am J Physiol 235: E97-E102.

[8] Duthie GG, Robertson JD, Maugham RJ and Morrice PC (1990). Blood antioxidant status and exythrocyte lipid peroxidation following distance running. Arch Biochem Biophys 282: 78-80

[9] Engelen JJM, Borm PJA, van Sprundel M, Lenaerts L (1990). Blood anti-oxidant. parameters at different stages of pneumoconiosis in coal workers. Environ Health Perspect 84: $165-172$.

[10] Evelo CTA and Henderson PTh (1992). Biological Effect Monitoring. Arch Toxicol suppl. 15: 268-277.

[11] Evelo CTA, Palmen NGM, Artur Y and Janssen GME (1992). Changes in blood glutathione concentrations, and in erythrocyte glutathione reductase and glutar thione S-transferase activity after running training and after participation to contests. Eur J Appl Physiol 64: 354-358.

[12] Habig WH and Jakoby WB (1981). Assays for the differentiation of glutathione S-transferases. Methods Enzymol 77: 398-405.

[13] Janssen YMW, Marsh JP, Absher MP, Hemenway D, Vacek PM, Leslie KO, Borm PJA and Mossman BT (1992). Expression of antioxidant enzymes in rat lungs after inhalation of asbestos or silica. $J$ Biol Chem 267: 10625-10630.

[14] Kampen van EJ and Zijlstra WG (1965). Determination of hemoglobin and its derivatives. Adv Clin Chem 8: 141-187.

[15] Kelley J (1990). Cytokines of the lung. Am Rev Respir Dis 141: 765-788.

[16] Mannervik B and Danielson UH (1988). Glutathione Transferases - structure and catalytic activity. Critical Reviews in Biochemistry 23: 283-337. 
[17] Parmeggiani L (1983) International classification of pneumoconiosis. In: Parmeggiani L. (Ed.) Encyclopedia of occupational health and safety. 3rd ed. Vol. II. Geneva: International Labour Organisation, 1733-1741.

[18] Petruska JM, Leslie KO and Mossman BT (1991). Enhanced lipid peroxidation in bronchoalveolar lavage of rats after inhalation of crocidolite asbestos. Free Radic Biol Med 11: 425-432.

[19] Rahman Q, Khan SG and Ali S (1990). Effect of crysotile asbestos on cytochrome P-450-dependent monooxygenase and glutathione-S-transferase activities in rat lung. Chem Biol Interact 75: 305-313.

[20] Ralston ML and Jennrich RI (1978). DUD, a derivative-free algorithm for nonlinear least squares. Technometrics 20: 7-14.

[21] Sibille Y and Reynolds HY (1990). Macrophages and polymorphonuclear neutrophils in lung and injury. Am Rev Respir Dis 141: 471-501.

[22] Toth KM, Clifford DP, Berger EM, White CW, Repine JE (1984). Intact human erythrocytes prevent hydrogen peroxide-mediated damage to isolated perfused rat lungs and cultured bovine pulmonary artery endothelial cells. $J$ Clin Invest $\mathbf{7 4}$ : 292-295. 


\section{Chapter 10}

\section{General Discussion}

The presence of reactive chemicals within the human body may lead to a disruption of the integrity of various biological macromolecules including nucleic acids. Toxicological stress factors that produce such effects can roughly be divided in two types: electrophilic compounds and oxidative stress. Exposure to a broad variety of chemicals can give rise to increased electrophilic stress, either because of the direct reactivity of these xenobiotics or because of the formation of reactive metabolites. When reactive electrophilic compounds reach nucleophilic centers in biological macromolecules like DNA or protein, they can react directly, often leading to the formation of covalent bindings. The exact consequences of such reactions depend on the identity of the biological target and the nature and stability of the adduct. At low exposures to electrophiles, such as may occur during occupational exposure to chemicals used at the workplace or for instance as a result of cigarette smoking, the occurrence of mutations in the nucleic acid sequence is the most important risk factor. Oxidative stress can originate from a broad gamut of conditions ranging from endogenous formation of active oxygen species during normal metabolism and inflammatory activity [26] to radical formation upon exposure to oxidative compounds. As a result of oxidative stress, free radical reactions may occur which can cause damage to nucleic acid and protein structures. The most prominent target for such radical reactions however, are the lipid structures in biological membranes. Especially polyunsaturated lipids tend to propagate radical chain reactions. During this lipid peroxidation process reactive products like aldehydes and lipid peroxides are formed, which can cause secondary damage to other biological structures.

The glutathione - glutathione S-transferase systern described in this thesis is involved both in the protection against electrophiles and in the reduction of oxidative stress. The glutathione S-transferase (GST) catalysed phase II conjugation of electrophilic compounds with reduced glutathione (GSH) is the important first step in the formation of mercapturic acid excretion products [32]. Usually this results in detoxification. GSH itself is consumed in the transferase reactions, and since the thioethers formed are removed from the cell [2] this may lead to a depletion of GSH. Furthermore, GST may also become a target for electro- 
philic compounds. This suicidal reaction leads to loss in GST activity $[8,20,39]$. This phenomenon also occurs when human red blood cells are exposed in vitro to important industrially used compounds like acrolein, propylene oxide, styrene oxide, ethylene dibromide and ethylene dichloride [1].

The involvement of GSH in protection against oxidative stress is of a more complex nature $[5,29]$. GSH can be used to detoxify hydroperoxides generated as a result of oxidative stress (equation $2.1 ;$ p. 18). Selenium dependent glutathione peroxidases catalyse this reaction for both hydrogenperoxide and lipidperoxides. Scavenging of hydrogenperoxide is of particular interest since it can react with superoxide $\left(\mathrm{O}_{2}^{-} \cdot\right)$ radicals, thereby generating the potent hydroxyl (HO.) radical. Removal of lipidperoxides is of importance since these reactive compounds can damage other biological structures and because they are potentially involved in amplification of radical reactions [eqs. 2.18 and 2.19 ; p. 26]. For lipidperoxides the peroxidase reaction is also catalysed by the nonselenium GST. GSH might also protect by direct free radical scavenging, but the importance of this mechanism is not clear. The effectiveness of such direct scavenging is further limited by the presence of GSH in the aqueous phase, which makes it impossible to terminate lipid radical propagation. GSH may however have another important contribution to free radical scavenging. The main lipid soluble antioxidant is $\alpha-$ tocopherol (vitamin E). GSH is expected to be able to reduce the tocopheroxyl radical formed from radical scavenging by $\alpha$-tocopherol $[18,24]$. Apart from this, ascorbate (vitamin $\mathrm{C}$ ) is well known for the same kind of tocopherol restoring activity $[4,24]$. Therefore, GSH might also aid in the restoration of $\alpha$-tocopherol indirectly by reducing dehydroascorbate. A glutathione dehydroascorbate oxidoreductase is present in plant tissues. It was shown recently that dehydroascorbate reduction by GSH is catalysed by thioltransferases from procine liver, human placenta and bovine thymus as well as by bovine protein disulfide isomerase [41]. This lead Wells et al. to the suggestion that the same activity might be present in erythrocytes [42]. They did not actually demonstrate the activity in human erythrocytes however. The findings by Stahl and coworkers, who took a closer look at the glutathione dehydroascorbate reductase activity in human leucocytes and only found evidence for nonenzymatic activity [33], show how important such an actual demonstration is. GSH also functions as a general buffer for redox equivalents. This is possible because of the high concentration of GSH in red blood cells (about $2 \mathrm{mM}$ ) and because of the normally very high redox potential of the GSH/GGSG couple. Oxidation of GSH will result in an activation of glutathion reductase and in a GSSG and glutatione reductase mediated activation of glucose 6-phosphate dehydrogenase [19]. As long as glucose supply is sufficient this will result in a rapid recovery of homeostatic GSH/GSSG ratios. Another important function of GSH is the protection of protein thiol groups. GSH can reduce disulfides and sulfoxides formed as a result of oxidative reactions thus restoring damaged and thereby often inactivated proteins $[9,21,22]$. Following oxidative stress conditions mixed protein-glutathion disulfides are of- 
ten detectable. Since oxidized glutathione GSSG is toxic to erythrocytes, storage of oxidized glutathione as mixed disulfides might be more beneficial. In fact the quantitative importance of this mixed disulfide formation is larger than GSSG excretion, at least under some in vitro conditions studied (Chapter 5 and [12]). Since all protective effects described will lead either to the excretion of GSSG from the erythrocyte or to the fixation of free glutathione as mixed disulfides, the net result of oxidative stress will also be a decrease in erythrocyte GSH. The analogy between the effects of the two stress factors goes even further. The main glutathione S-transferase isoenzyme present in human erythrocytes belongs to the $\pi$ class [11]. In studies published during the last few years evidence was presented that this class of GST is vulnerable to oxidative stress $[30,31,37]$. Our own in vitro experiments (not shown in this thesis) confirmed that human erythrocyte GST activity can also be strongly impaired by hydrogenperoxide treatment.

From the above it can be concluded that it is conceivable that exposure to electrophilic or oxidative compounds, or to any other kind of oxidative stress, would lead to decreases in glutathione content or glutathione S-transferase activity in erythrocytes. The studies described in this thesis were focussed on the practical usefulness of this idea for experimental toxicological research and for biological effect monitoring purposes. The first part (chapter 3-5) consists of in vitro studies using human blood. In the second part (chapter 6-9) a number of in vivo biological effect monitoring studies are described.

Directly reactive electrophiles like iodoacetamide, diethyl maleate and $\mathrm{N}$ ethylmaleimide have a high reactivity towards glutathione. All these compounds gave strong GSH depletions both in hemolysates and in intact erythrocytes (Chapter 3). As a result of this, GSH is able to protect other molecules present in the erythrocytes. The formation of hemoglobin adducts showed a strong increase when reagent concentrations above that leading to full GSH depletion were used. Modulation of the GSH related protection in vivo will also have consequences for the formation of hemoglobin adducts. This may be of practical importance since measurement of hemoglobin adducts is itself used as a biological effect monitoring parameter for exposure to electrophilic genotoxic chemicals $[10,23,38]$. Especially the development of nonlinear models for hemoglobin adduct formation [6] will benefit from increased understanding of this kind of protection mechanisms.

The cytostatic drug cisplatin is known to covalently bind towards DNA and proteins [7]. It also caused depletion of total (=-reduced + oxidized) glutathione (GT) in isolated cytosol of human red blood cells and in rat hepatocytes or rat liver cytosol (chapter 4). In intact human red blood cells no GT depletion was found, probably because the erythrocyte membrane effectively prohibits uptake of cisplatin. Cisplatin also caused decreases of GST activity. In rat liver fractions both microsomal and cytosolic GSTs were inhibited. As was expected from the glutathione determinations, GST was also inhibited in intact rat hepatocytes and in hemolysates made from human erythrocytes and not in intact human eryth- 
rocytes. The finding that both human erythrocyte GST ( $\pi$ class) and rat liver cytosolic (mainly $\alpha$ class) and rat liver microsomal GST are inhibited, indicates that the inhibition is rather nonspecific [20] and therefore probably caused by the high direct alkylating activity of cisplatin.

Cyclophosphamide, another well-known alkylating cystostatic drug, was also tested. The alkylating activity of cyclophosphamide is attributed to mustard compounds and acrolein formed as a result of metabolic transformations [13]. In agreement with this need for metabolic activation, cyclophosphamide itself caused only small decreases in the GT content of human red blood cells. This small but significant decrease is interesting because it proves that red blood cells are able to metabolize cyclophosphamide. When rat liver microsomes plus an NADPH regenerating system were added to the red blood cells a strong depletion of intracellular GT was found. This glutathione depletion is accompanied by increased activity of GST in the red blood cells. As expected, cyclophosphamide in the presence of rat liver microsomes and an NADPH regenerating system also caused GT depletion in rat liver cytosol. In this svstem however, glutathione effectively prevents an effect on GST activity. When diluted cytosol (with lower GSH concentrations) was used an increase in GST activity was found. Activity increases were also found for microsomal GST in the presence of an NADPH regenerating system. This is in good agreement with the findings for the effects on cytosolic GST since no detectable amounts of GT were present in the incubations with microsomes, and GSH protection was therefore excluded. The interpretation of the GST activity increases in human red blood cells and in rat liver cytosol is difficult because of the formation of free radicals by the microsomal system [43,44]. Addition of a microsomal activating system alone does lead to a decrease in red blood cell and rat liver cytosolic GST activity. Because of this, a possibility exists that the cyclophosphamide dependent activation is really decreased inactivation. Additional experiments showed however that cyclophosphamide addition did not result in lower lipid peroxidation as detected with thiobarbituric acid and did not result in lower methemoglobin formation, and therefore probably does not lead to decreases in free radical release from the microsomes.

Next to cisplatin and cyclophosphamide three other cytostatic drugs were tested. They all belonged to the group of antimetabolites and do not have alkylating activity. Of these 5-fluorouracil and cytosine arabinoside did not affect GT or GST activity in all test systems, while methotrexate only caused an inbibition of microsomal GST. This confirms that the GT depleting activities of cisplatin and of cyclophosphamide metabolites are not a general effect of cytostatic drugs, but can be attributed to the alkylating nature of these substances. The results also suggest that for this class of electrophilic substances the relative effect on GT is larger and more consistent than the effects on GST. The more so because glutathione seems to protect the transferase against low levels of reactive metabolites.

In a third in vitro study effects of three industrially used hydroxylamines on 
human red blood cells were studied (chapter 5). The parent compound hydroxylamine is known for its hematotoxic potency, with a strong ability to induce methemoglobin [3]. Strong methemoglobin formation was also found for O-ethyl hydroxylamine. Both compounds also induced lipid peroxidation as detectable from the release of thiobarbituric acid reactive compounds. This is probably a result of the formation of free radicals during the oxidation of hemoglobin [34]. As expected the oxidative processes were accompanied by GT depletion in the red blood cells. The relative magnitude of this effect was however much smaller than methemoglobin formation or release of thiobarbituric acid reactive substances. Only a small fraction of the GT that disappeared from the red blood cells could be recovered as oxidized glutathione in the plasma. This indicates that a large fraction of the oxidized glutathione is immobilized within the red blood cells as a result of mixed disulfide formation. This was also found to occur for the hydroxylamine metabolite of the antileprotic drug dapsone [12]. In vivo these mixed disulfides will probably be reduced by thioltransferase activity [21] whenever oxidative stress conditions become more favorable. In this way mixed disulfide formation can act as a kind of storage for oxidized glutathione, enabling the cell to retain a nontoxic GSH/GSSG ratio without to much loss of glutathione. While this will be beneficial for the cell it will limit the usability of GT depletion measurements for biological effect monitoring purposes in case of oxidative stress. In parallel with methemoglobin formation and lipid peroxidation, strong decreases in GST activity in red blood cells were found. The same was true for the activity of another protective enzyme, NADPH methemoglobin reductase. Based on these results the use of GST and NADPH methemoglobin reductase measurements for biological effect monitoring of exposure to oxidative agents seems promising.

The third compound used in this in vitro study was $\mathrm{N}, \mathrm{O}$-dimethyl hydroxylamine. This compound was found to have much less oxidative potency. The methemoglobin formation was much lower than for hydroxylamine or O-ethyl hydroxylamine, there was hardly any lipid peroxidation detectable and we found no GST or NADPH methemoglobin reductase inhibition. On the other hand $\mathrm{N}, \mathrm{O}$-dimethyl hydroxylamine addition did result in some GT depletion in the red blood cells, and the increase in plasma GSSG was even somewhat higher than for the other two hydroxylamines. N,O-dimethyl hydroxylamine pretreated red blood cells also had a decreased resistance to hydrogenperoxide induced lipid peroxidation. A likely explanation of this phenomenon was found, when it appeared that $\mathrm{N}, \mathrm{O}$-dimethyl hydroxylamine treatment results in a strong inhibition of glucose 6-phosphate dehydrogenase. In the erythrocyte this enzyme is crucial for the production of NADPH. NADPH is needed for many reductive reactions, including glutathione reductase and NADPH methemoglobin reductase activity. Glutathione reductase itself was also, but to a lesser extend, inhibited by $\mathrm{N}, \mathrm{O}-$ dimethyl hydroxylamine. The reduced availability of NADPH will render the erythrocytes more vulnerable to a subsequent oxidative stress, as was found in the experiments with hydrogenperoxide. This may have practical consequences in 
situations where combined exposure to $\mathrm{N}$-substituted hydroxylamines - like $\mathrm{N}, \mathrm{O}$ dimethyl hydroxylamine - and compounds with higher direct oxidative potency - like hydroxylamine and O-ethyl hydroxylamine - may occur. Potentiation of the oxidative toxicity by the in itself nonoxidative compounds could be the result of such situations.

Contrary to the conclusions given for electrophilic stress, the hydroxylamine studies indicate that in vivo determination of GST (and possibly NADPH methemoglobin reductase) activity in red blood cells may be a more sensitive parameter for oxidative stress than determination of GT depletion. The expected reversibility of mixed disulfide formation in vivo will make this even more true.

The first chapter of the second part (chapter 6) gives an overview of a number of biological effect monitoring studies. In a pilot study with smokers and nonsmokers no significant changes in GT concentration or GST activity were found. It became clear from immunochemical determinations however, that the total amount of GST protein was nevertheless increased. Extra synthesis of GST protein must have occurred in smokers without an accompanying increase in GST activity. A possible explanation is that the GST activity is initially decreased as a result of the electrophilic and oxidative stress occurring in smokers. Because of this chronic stress, extra synthesis of GST during erythropoesis may be induced. This suggests that GST activity in older erythrocytes should be lower than in younger cells. Initially this was contradicted by studies reported in the literature [35], but more recent studies confirm that GST activity is decreased during red cell senescence [11]. This study by Fazi and coworkers is also of interest from another point of view. They proved that erythrocyte GST $\rho$ is converted in another form during red cell senescence. While the $\mathrm{K}_{\mathrm{m}}$ value of this secondary form is not changed, it is possible that $\mathrm{V}_{\max }$ is lowered. The activity loss of GST described in this thesis might involve the same kind of conversion, which according to Shen et al $[30,31]$ would be a cysteine modification. This would explain why GST activity seems to stabilize at higher concentrations of oxidative compounds used, as was seen for hydroxylamine and O-ethyl hydroxylamine and, in studies not described here, also for hydrogenperoxide and doxorubicine.

In another study blood and urine samples were collected of two workers preserving wood with coal tar containing creosote oil. Erythrocyte GT concentrations and GST activities in these workers were decreased at the end of the week. After the free weekend, normal values were restored. Despits the very small group size these findings are of interest because of the good correlation with biological monitoring values for coal tar exposure (determined as 1-hydroxypyrene in urine) and genotoxic effects (determined as DNA adducts in white blood cells).

The study described in chapter 7 concerns soil fumigators working in the flower bulb culture in the Dutch "Bollenstreek". This study was carricd out in close cooperation with several other institutes. Samples were collected before and after the season during which they applied dichloropropene. At the end of 
the season erythrocyte GT concentrations and GST activities had decreased. In clinical chemical studies performed at the universities of Leiden and Amsterdam low levels of liver enzyme induction and subclinical nefrotoxic effects were found in the same group of soil fumigators. The effects on GT and GST were however remarkably less ambiguous than these results from clinical chemical studies. Dichloropropene is a broad working pesticide used for soil fumigation between cultures, and has very high chemical reactivity. As well as the related dichloropropane [14], it is known to be metabolized by glutathione conjugation. In a biological monitoring study, performed at the Free University of Amsterdam, the mercapturic acid derivatives of dichloropropene were detected in urine [40]. The consumption of glutathione by this metabolic activity, is the most likely cause of the decreased erythrocyte GT levels. The decrease in GST activity - which was actually more surprising considering the in vitro results described abovemust probably be attributed to reactive metabolites and/or reactive breakdown products of cellular constituents.

The biological effect monitoring study described in chapter 8 was directed to what at first sight might be considered a rather special population, which consisted of of 23 male and 18 female runners. Previously sedentary, they received intensive running training during a period of 40 weeks. They participated to a competitive run of $15 \mathrm{~km}$ length after 20 weeks and ran a half marathon at the end of the study. Blood samples were collected at the start of the study, before and after each run and five days later. After the first 20-week training period GT concentrations and glutathione reductase activity in the erythrocytes were found to have increased. Training consists of periodically high activity with accompanying elevated oxygen turnover. This increased oxygen turnover will result in increased free radical stress $[15,17]$. The increases in GT and glutathione reductase are probably part of the physiological reaction that counteracts this increased stress. Increases in plasma GSH after prolonged training has also been described in runners [16] and trained beagle dogs [17]. Increased glutathione reductase activities after running training were also reported by Ohno et al [25]. The explanation that increased GT values are compensatory for GT loss during acute exercise is consistent with the finding of decreased GT values directly after the $15-\mathrm{km}$ race. After the half marathon the GT values were increased, a phenomenon that is currently hard to explain. Glutathione reductase activities in erythrocytes were increased after both competitive runs. At least a part of these increases was caused by increased availability of the glutathione reductase cofactor riboflavin. Erythrocyte GST activities were lowered after both runs. This is consistent with our expectations, since erythrocyte GST is vulnerable to oxidative stress as it will appear during intensive exercise. As might be expected, the glutathione reductase activities remained elevated after the second training period. In contrast normal GT values were found after 40 weeks. It is not clear whether this is a result of normalized demand for glutathione due to other compensatory mechanisms --like the increased glutathione reductase activity - or whether a lack of synthetical 
potential prohibits the preservation of the high GT levels. An indication for the latter explanation was found in the increased GST activities after the second training period. This is probably a reaction to the on going oxidative stress and the associated lipid peroxidation. This suggests that, considering the resulting oxidative effects, the second more intensive training period is less beneficial than the first.

In the final chapter of the experimental part (chapter 9) differences between groups of former Belgian coalminers are described. Both former miners with various stages of coal workers pneumoconiosis $(n=33)$ and former miners without $(n=58)$ this disease were included. It appeared that both erythrocyte GT concentrations and erythrocyte GST activities are decreased during early stages of the inflammatory disease. A causal relationship is likely because in these patients the disease is in an active phase. During continuous inflammatory activity large portions of active oxygen species are generated by the alveolar macrophages [28]. These active oxygen species are expected to be responsible for the effects on GT and GST found. Also in the sporting population a more diffusive form of inflammatory activity may have contributed to the oxidative effects seen.

It can be concluded that the two most important parameters described in this thesis - the glutathione concentration and the glutathione S-transferase activity in red blood cells-are interesting tools for mechanistic toxicological research and for biological effect monitoring. In in vitro experiments glutathione seems to give the most interesting results in situations where electrophilic exposure is at stake. In vivo effects were also seen after heavy exercise and in miners, and were reported in the literature as a result of lipid peroxidation for workers exposed to lead [36]. Glutathione S-transferase activity is of most interest in situations where oxidative stress occurs. It may be used as an interesting addition to, and an alternative for, the problematic determination [27] of in vivo lipid peroxidation. 


\section{References}

[1] Ansari G.A.S., S.V. Singh, J.C. Gan and Y.C. Awasthi (1987). Human erythrocyte glutathione S-transferase: a possible marker of chemical exposure. Toxicol Lett 37 : $57-62$.

[2] A wasthi Y.C., Singh S.V., Ahmad H., Wronski L.W., Srivastava S.K. and LaBelle E.F. (1989). ATP dependent primary active transport of xenobiotic-glutathione conjugates by human erythrocyte membrane. Mol Cell Biochem 91: 131-136.

[3] BG Chemie (Ed). Toxicological eveluations 6. Potential health hazards of existing chemicals. Springer, Heidelberg, 1993.

[4] Berg J.J.M. van den, Kuypers F.A., Roelofsen B. and Op den Kamp J.A.F. (1990). The cooperative action of vitamins $\mathrm{E}$ and $\mathrm{C}$ in the protection against peroxidation in human erythrocyte membranes. Chem Phys Lipids 53: 309-320.

[5] Bump E.A. and Brown J.M. (1990). Role of glutathione in the radiation response of mammalian cells in vitro and in vivo. Pharmac Ther 47: 11;-136.

[6] Calleman C.J., Stern L.G., Bergmark E. and Costa L.G. (1992). Linear versus nonlinear models for hemoglobin adduct formation by acrylamide and its metabolite glycidamide: implications for risk estimation. Cancer Epidemiol Biomarkers Prev 1: 361-368.

[7] Chu G. (1994) Cellular responses to cisplatin. The roles of DNA-binding proteins and DNA repair. $J$ Biol Chem 269: 787-790.

[8] Coles B. and Ketterer B. (1990). The role of glutathione and glutathione transferases in chemical carcinogenesis. Crit Rev Biochem Mol Biol 25: 47-70.

[9] Cotgreave I.A., Weis M., Atzori L. and Moldéus P. Glutathione and protein function. In: Glutathione: metabolism and physiological functions. Vina J. (Ed.), CRC Press, Boca Raton (1990) pp. 155-175.

[10] Ehrenberg L., and Tornqvist M. (1991). Human health risk assessment and biological reactive intermediates: hemoglobin binding. Adv Exp Med Biol 283: 641-647

[11] Fazi A., Accorsi A., Piatti E. and Magnani M. (1991). Cell age dependent decay of human erythrocytes glutathione S-transferase. Mech Ageing Dev 58: 255-266.

[12] Grossman S.J., Simson J. and Jollow D.J. (1992). Dapsone-induced hemolytic anemia: effect of $\mathrm{N}$-hydroxy dapsone on the sulfhydryl status of membrane proteins of rat erythrocytcs. Toxicol Appl Pharmacol 117: 208217.

[13] Honjo I., Suou T. and Hirayama C. (1988). Hepatotoxicity of cyclophosphamide in man: pharmacokinetic analysis. Res Cormmun Chem Pathol Pharmacol 61: 149-165.

[14] Imberti R., Mapelli A., Colombo P., Richelmi P., Berté F. and Bellomo G. (1990). 1,2-Dichloropropane (DCP) toxicity is correlated with DCP-induced glutathione (GSH) depletion and is modulated by factors affecting intracellular GSH. Arch Toxicol 64: 459-465.

[15] Jenkins R.R. (1988). Free radical chemistry. Relationship to exercise. Sports Med 5: $156-170$.

[16] Kretzschmar M., Müller D., Hübscher J., Marin E. and Klinger W. (1993). Influence of aging, training and acute physical exercise on plasma glutathione and lipid peroxides in man. Int $J$ Sports Med 12: 218-222. 
[17] Kretzschmar M. and Müller D. (1993). Aging, training and exercise. A review of effects on plasma glutathione and lipid peroxides. Sports Med 15: 196-209.

[18] Livesey J.C. and Reed D.J. (1987). Chemical protection against ionizing radiation, Adv Radiat Biol 13: 285-353.

[19] López-Barea J., Bárcena J.A., Bocanegrá J.A., Florido J., García-Alfonso C., López-Ruiz A., Martínez-Galisteo E. and Peinado J. Structure, mechanism, functions, and regulatory properties of glutathione reductase. In: Glutathione: metabolism and physiological functions. Viña J. (Ed.), CRC Press, Boca Raton (1990) pp. 105-116.

[20] Mannervik B. and Danielson U.H. (1988). Glutathione transferases - structure and catalytic activity. Crit Rev Biochem 23: 283-337.

[21] Mieyal J.J., Starke D.W., Gravina S.A., Dothey C. and Chung J.S. (1991). Thioltransferase in human red blood cells: purification and properties. Biochemistry 30: 6088-6097.

[22] Mieyal J.J., Starke D.W., Gravina S.A. and Hocevar B.A. (1991). Thioltransferase in human red blood cells: kinetics and equilibrium. Biochemistry 30: 8883-8891.

[23] Neumann H.G., Birner G., Kowallik P., Schutze D. and Zwirner-Baier I. (1993). Hemoglobin adducts of $\mathrm{N}$-substituted aryl compounds in exposure control and risk assessment. Environ Health Perspect 99: 65-69.

[24] Niki E. (1987). Lipid antioxidants: how they may act in biological systems. $B_{\Gamma} J$ Cancer 55 (Suppl. VIII): 153-157.

[25] Ohno H., Yahata T., Sato Y., Yamamura K. and Taniguchi N. (1988). Physical training and fasting erythrocyte activities of free radical scavenging enzyme systems in sedentary men. Eur J Appl Physiol 57: 173-176.

[26] Oliver C.N. (1987). Inactivation of enzymes and oxidative modification of proteins by stimulated neutrophils. Arch Biochem Biophys 253: 62-72.

[27] Pryor W.A. and Godber S.S. (1991). Noninvasive methods of oxidative stress status in man. Free Rad Biol Med 10: 177-184.

[28)] Sedgwick J.B., Geiger K.M. and Busse W.W. (1990). Superoxide generation by hypodense eosinophils from patients with asthma. Am Rev Respir Dis 142: 120125.

[29] Shan X., Aw T.Y. and Jones D.P. (1990). Glutathione-dependent protection against oxidative injury. Pharmac Ther 47: 61-71.

[30] Shen H., Tamai K, Satoh K., Hatayama I., Tsuchida S., and Sato K. (1991). Modulation of class $\mathrm{Pi}$ glutathione transferase activity by sulfhydryl group modification. Arch Biochem Biophys 286: 178-182.

[31] Shen H., Tsuchida S., Tamai K, and Sato K. (1993). Identification of cysteine residues involved in disulfide formation in the inactivation glutathione transferase P-form by hydrogen peroxide. Arch Biochem Biophys 300: 137-141.

[32] Sies H. and Ketterer B. (Eds.), Glutathione conjugation. Academic Press, London (1988).

[33] Stahl R.L., Liebes L.F. and Silber R. (1985). A reappraisal of leukocyte dehydroascorbate reducase. Biochim Biophys Acta 839: 119-121. 
[34] Stolze K. and Nohl H. (1989). Detection of free radicals as intermediates in the methemoglobin formation from oxybemoglobin induced by hydroxylamine. Biochem Pharmacol 38: 3055-3059.

[35] Strange R.C., Johnson P.H., Lawton A., Moult J.A., Tector M.J., Tyminski R.J. and Cotton W. (1982). Studies on the variability of glutathione S-transferase from human erythrocytes. Clin Chim Acta 120: 251-260.

[36] Sugawara E., Nakamura K, Miyake T., Fukumura A. and Seki Y. (1991). Lipid peroxidation and concentration of glutathione in erythrocytes from workers exposed to lead. Br J Ind Med 48: 239-242.

[37] Tamai K., Satoh K., Tsuchida S., Hatayama I., Maki T. and Sato K. (1990). Specific inactivation of glutathione S-transferases in class pi by SH-modifiers. Biochem Biophys Res Comm 167: 331-338.

[38] Vineis P. (1992). The use of biomarkers in epidemiology: the example of bladder cancer. Toxicol Lett 64-65 Spec No: 463-467.

[39] Vos R. and van Bladeren P. (1990). Glutathione S-transferases in relation to their role in the biotransformation of xenobiotics Chem Biol Interact 75: 241-265.

[40] Welie van R.T.H., Duyn van P., Brouwer D.H., Hemmen van J.J., Brouwer E.J. and Vermeulen N.P.E. (1991). Inhalation exposure to 1,3-dichloropropene in the Dutch flower bulb culture. Part II. Biological monitoring by measurement of urinary excretion of two mercapturic acid metabolites. Arch Environ Contam Toxicol 20: 6-12.

[41] Wells W.W., Xu D.P., Yang Y. and Rocque P.A. (1990). Mammalian thioltransferase (glutaredoxin) and protein disulfide isomerase have dehydroascorbate reductase activity. J Biol Chem 265: 15351-15364.

[42] Wells W.W., Yang Y. and Deits T.L. (1993). Thioltransferases. Adv Enzymol Rel Areas Mol Biol 60: 149-201.

[43] Wills E.D. (1969a). Lipid peroxide formation in microsomes; General considerations. Biochem J 113: 315-324.

[44] Wills E.D. (1969b). Lipid peroxide formation in microsomes; The role of non-haem iron. Biochem $J$ 113: 325-332. 



\section{Hoofdstuk 11}

\section{Samenvatting en Discussie}

Chemische factoren die een risicobron vormen voor beschadigingen van belangrijke biologische macromoleculen, waaronder het genetisch materiaal, laten zich ruwweg in twee groepen verdelen. Enerzijds zijn er de electrofiele verbindingen, en stoffen die tot dergelijke verbindingen kunnen worden gemetaboliseerd. Deze stoffen zijn direct in staat biologische macromoleculen te beschadigen. Daarbij treedt dan veelal adductvorming op. Anderzijds zijn er omstandigheden die leiden tot de vorming van vrije radicalen. Dergelijke vrije radicalen kunnen eveneens tot beschadiging van biologische materialen leiden, zij kunnen echter ook aanleiding geven tot aantasting van de lipide structuur van membranen via lipide-peroxidatie. Bij deze lipide-peroxidatie ontstaan opnieuw reactieve verbindingen, die op hun beurt weer elders schade kunnen aanrichten. Het in dit proefschrift besproken glutathion - glutathion S-transferase systeem vormt een bijzondere factor doordat het zowel een bijdrage levert aan de bescherming tegen electrofiele als aan het verminderen van oxidatieve stress.

Bescherming tegen electrofiele verbindingen komt tot stand door koppeling van de nucleofiele thiolgroep van het glutathion aan het electrofiele reagens. In veel gevallen verloopt deze reactie spontaan, zij kan echter ook door het glutathion S-transferase worden gekatalyseerd. De zo gevormde thioether-produkten worden in het algemeen uit de cel afgevoerd, en verder gemetaboliseerd. In principe kan dit leiden tot een vermindering van het in de cel aanwezige glutathion. Bovendien is reeds langere tijd bekend dat in sommige gevallen reactieve verbindingen niet alleen via de S-transferase reactie worden gekoppeld, maar ook via een soort zelfmoordreactie aanleiding geven tot een beschadiging van het glutathion-S-transferase zelf.

De bescherming tegen oxidatieve stress is complexer van aard. Glutathion kan bijdragen aan de enzymatische reductie van vitamine $\mathrm{E}$, zowel direct als indirect via de reductie van vitamine $\mathrm{C}$. Het goed vetoplosbare, gereduceerde vitamine $\mathrm{E}$ beschermt effectief tegen lipide-peroxidatie processen. Als gevolg van oxidatieve stress treedt ook oxidatie van eiwit-sulfhydrylgroepen op. Dit kan leiden tot crosslinking van eiwitten. Hierdoor kunnen enerzijds enzymactiviteiten verloren gaan, en kunnen anderzijds, door crosslinking van structuureiwitten, 
vormveranderingen van cellen zonder cytoskelet optreden. Van rode bloedcellen, die voor hun mobiliteit door perifere weefsels in sterke mate afhankelijk zijn van de vervormbaarheid van hun celmembraan, is bekend dat zij vatbaar zijn voor dit soort oxidatie processen. Glutathion kan via thioltransferase activiteit. gebruikt worden om geoxideerde sulfhydrylgroepen te reduceren. Ook kan als gevolg van de oxidatieve stress crosslinking van de glutathion-sulfhydrylgroep met eiwit-sulfhydrylgroepen optreden. Met name in rode bloedcellen is gereduceerd glutathion ook een algemene buffer voor reducerend vermogen. In deze cellen zijn namelijk geen mitochondriën aanwezig, die in andere celtypes voor de snelle levering van grotere hoeveelheden energie en reductie-equivalenten kunnen zorgen. Homeostase van de glutathion redox status wordt, bij voldoende aanlevering van glucose, gegarandeerd via regulatie van de glutathion reductase en de glucose 6-fosfaat dehydrogenase activiteit.

Bovendien is glutathion van belang in de glutathion-peroxidase reactie. Gekatalyseerd door het selenium afhankelijke enzym glutathion-peroxidase ontgift het zowel waterstofperoxide als de bij lipide-peroxillatie gevormde organische peroxiden. De ontgifting van de laatste categorie peroxiden kan ook worden gekatalyseerd door glutathion S-transferases. Deze activiteit van glutathion S-transferase wordt ook wel aangeduid met selenium onafhankelijke glutathionperoxidase activiteit. De genoemde beschermende reacties leiden in alle gevallen tot de oxidatie van glutathion. In principe kan dit geoxideerde glutathion vervolgens door glutathion-reductase weer worden gereduceerd. Geoxideerd glutathion is echter toxisch voor rode bloedcellen, en wordt hieruit actief verwijderd. De oxidatieve vorming van glutathion-eiwitbruggen, ook wel aangeduid met mixed disulfides, leidt bovendien direct tot een verlies van beschikbaar glutathion. Dit betekent dat, net als bij electrofiele stress, ook als gevolg van oxidatieve stress een afname van de beschikbare hoeveelheid glutathion kan optreden. De analogie in effecten van beide stress-factoren gaat echter nog verder. Het is bekend dat het glutathion S-transferase iso-enzym dat aanwezig is in de rode bloedcel, en dat behoort tot de de zogenaamde $\pi$ klasse, zelf gedeeltelijk geïnactiveerd kan worden als gevolg van oxidatieve stress.

Het bovenstaande, grotendeels gebaseerd op in de literatuar beschreven in vitro experimenten, geeft aan dat het a priori denkbaar was dat als gevolg van een belasting met electrofiele of oxidatieve xenobiotica of als gevolg van een op andere wijze tot stand gekomen oxidatieve stress, veranderingen in het glutathion-gehalte of in de glutathion S-transferase activiteit van rode bloedcellen zouden optreden. De studies beschreven in dit proefschrift waren er op gericht de praktische bruikbaarheid van dit idee voor experimenteel toxicologisch onderzoek en voor biologisch effect monitoring te onderzoeken. Het eerste deel (hoofdstuk 3-5) bevat in vitro studies met humaan bloed. In het tweede deel (hoofdstuk 6-9) wordt een aantal in vivo biologisch effect monitoring studies beschreven.

Direct reactieve electrofiele verbindingen zoals iodoaceetamide, diethylma- 
leaat en $\mathrm{N}$-ethylmaleimide zullen, ongeacht de aanwezigheid van al dan niet intacte bloedcellen, in sterke mate met glutathion reageren. De aanwezigheid van glutathion in de rode bloedcel werkt daardoor in feite beschermend t.o.v. andere biologische effecten. Uit hoofdstuk 3 blijkt dat voor deze zeer reactieve verbindingen de vorming van hemoglobine-adducten sterk toeneemat nadat het glutathion volledig is verbruikt. Beïnvloeding van de effectiviteit van de glutathion bescherming in vivo zal ook consequenties hebben voor de mate van hemoglobine-adduct vorming. Dit is mogelijk van belang omdat hemoglobine-adduct nivo's zelf soms gehanteerd worden als biologisch effect parameter voor expositie aan electrofiele genotoxische agentia.

Uit hoofdstuk 4 blijkt dat ook het direct alkylerende cytostaticum cisplatina in vitro depletie van glutathion veroorzaakt in geisoleerd cytosol van humane rode bloedcellen en in al dan niet intacte rattelever-cellen. In intacte rode bloedcellen vertoont cisplatina dit effect niet, waarschijnlijk doordat het celmembraan van dit type cellen opname effectief voorkomt. Cisplatina veroorzaakte naast glutathion-depletie ook een inhibitie van glutathion S-transferase. Deze inhibitie werd na belasting van rattelever-fracties zowel gevonden voor de enzymactiviteit in microsomen als voor die in cytosol. In overeenstemming met wat werd gevonden voor de glutathion-gehaltes veroorzaakte cisplatina in intacte humane rode bloedcellen geen effect op glutathion S-transferase en werd wel een inhibitie gevonden wanneer cisplatina aan hemolysaten of aan al dan niet intacte hepatocyten werd toegevoegd. De inhibitie van glutathion S-transferase door cisplatina blijkt dus niet iso-enzym specifiek te zijn, en is waarschijnlijk een direct gevolg van de hoge alkylerende activiteit van dit cytostaticum.

Een tweede alkylerend cytostaticum, cyclophosphamide, werd eveneens getest. Van cyclophosphamide is bekend dat het moet worden gemetaboliseerd alvorens het zijn biologische activiteit kan uitoefenen. In overeenstemming hiermee bleek cyclophoshamide zelf slechts geringe effecten te hebben op het glutathiongehalte van rode bloedcellen. Dit geringe, maar significante effect zelf is interessant omdat het aangeeft dat cyclophosphamide metabolisme ook kan optreden in de rode bloedcel. In aanwezigheid van metabole systemen op basis van rattelevermicrosomen geeft cyclophoshamide een sterke depletie van het glutathion in rode bloedcellen. Deze depletie gaat gepaard met een activatie van het glutathion S-transferase in deze cellen. In aanwezigheid van een metabool systeem op basis van rattelever-microsomen veroorzaakt cyclophoshamide, zoals verwacht, ook een depletie van het glutathion in rattelever-cytosol. Hier voorkomt glutathion echter effectief een effect op het glutathion S-transferase: slechts bij gebruik van verdund cytosol werd een verhoging van deze enzym activiteit gevonden. De activiteit van het microsomale glutathion S-transferase werd, mits een NADPH regenererend systeern aanwezig was, wel verhoogd door cyclophosphamide. In dit testsysteem waren echter geen aantoonbare hoeveelheden glutathion aanwezig, zodat een bescherming door glutathion was uitgesloten. De interpretatie van de glutathion S-transferase activeringen in rode bloedcellen en rattelever-cytosol 
wordt bemoeilijkt doordat het microsomale systeem zelf, doordat vrije radicalen gevormd worden, een inactiverend effect op de glutathion S-transferase activiteit heeft. Het is mogelijk dat er feitelijk geen activatie, maar een verminderde inactivatie plaats vindt. Aanvullende experimenten gaven daarbij echter wel aan dat dit dan niet gepaard gaat met een verminderde radicaal vorming zoals die valt te detecteren in de vorm van verbindingen die reactief zijn t.o.v. thiobarbituurzuur of die aanleiding geven tot methemoglobine vorming.

Drie andere cytostatica, allen zogenaamde anti-metabolieten, werden eveneens getest. 5-Fluoruracil en cytosine-arabinoside hadden geen enkel effect op de glutathion-gehaltes en de glutathion S-transferase activiteiten in de diverse geteste systemen. Methotrexate veroorzaakte uitsluitend een inhibitie van het microsomale glutathion S-transferase. Dit bevestigt dat de voor cisplatina en cyclophosphamide metabolieten gevonden glutathion depleterende eigenschappen niet een algemeen effect van cytostatica zijn, maar eerder een gevolg zijn van het alkylerend karakter van deze verbindingen. Ook suggereren de resultaten van de experimenten met cyclophosphamide en cisplatina dat voor electrofiele verbindingen het relatieve effect op glutathion groter, en meer eenduidig is dan dat op glutathion S-transferase. Dit te meer omdat glutathion zelf ook het transferase lijkt te beschermen tegen lage concentraties aan electrofielen zoals die bijvoorbeeld via de metabole activatie van cyclophosphamide ontstaan.

In een derde in vitro studie werden de effecten van een drietal industriële chemicaliën die behoren tot de zogenaamde hydroxylamines (HO-N-derivaten) bestudeerd. Van de moederverbinding, hydroxylamine, was reeds bekend dat zij hematotoxisch is en ondermeer methemoglobine veroorzaakt. Sterke methemoglobine-vormende eigenschappen werden ook gevonden voor het O-ethylhydroxylamine. Beide verbindingen gaven, waarschijnlijk als gevolg van de vrije radicalen die ontstaan bij de methemoglobine-vorming, bovendien lipide-peroxidatie. Zoals verwacht werd onder deze oxidatieve omstandigheden ook een vermindering van het beschikbare glutathion in de rode bloedcellen gevonden. Dit effect was echter beduidend minder sterk dan de methemoglobine-vorming en de lipideperoxidatie zelf. Opvallend was dat het verdwenen glutathion slecht voor een klein deel in geoxideerde vorm in het plasma werd teruggevonden. Kennelijk is veel glutathion gebonden aan eiwitten. In vivo kunnen dergelijke mixed disulfides na vermindering van de oxidatieve stress weer gereduceerd worden, hetgeen de bruikbaarheid van glutathion-depletie voor biologisch effect monitoring zou kunnen beperken. Parallel aan de methemoglobine-vorming en lipide-peroxidatie werd een sterke vermindering van de glutathion S-transferase activiteit in de rode bloedcellen gevonden. Hetzelfde gold overigens voor de acitiviteit van een ander enzym, het NADPH-methemoglobine-reductase. Op basis van deze bevindingen lijkt het interessant deze beide parameters te testen in biologisch effect monitoring studies met oxidatieve verbindingen. Een derde hydroxylamine verbinding, het $\mathrm{N}, \mathrm{O}$-dimethylhydroxylamine, bleek aanzienlijk minder oxidatieve capaciteit te hebben. Er werd aanzienlijk minder methemoglobine-vorming, nau- 
welijks lipide-peroxidatie, en in het geheel geen glutathion S-transferase remming gevonden. Wel bleek ook deze verbinding aanleiding te geven tot milde glutathion-depletie in rode bloedcellen, waarbij zelfs een wat sterkere toename van de hoeveelheid glutathion in plasma werd gevonden. Bovendien bleken N,Odimethylhydroxylamine behandelde bloedcellen een duidelijk verminderde weerstand tegen door waterstofperoxide geïnduceerde lipide-peroxidatie te hebben. Een waarschijnlijke verklaring voor deze fenomenen werd gevonden in de inhibitie van glucose-6-fosfaat-dehydrogenase door N,O-dimethylhydroxylamine. Verlies van deze enzymactiviteit maakt dat de cel niet meer kan beschikken over NADPH dat nodig is voor reducerende reacties. Daardoor zou ondermeer het glutathion reductase niet meer kunnen functioneren. Het glutathion reductase werd daarnaast ook zelf geremd door N,O-dimethylhydroxylamine. Maar deze inhibitie was minder sterk. De verminderde weerstand tegen oxidatieve stress, zoals veroorzaakt door het zelf minder sterk oxidatieve N,O-dimethylhydroxylamine, zou van praktische betekenis kunnen zijn omdat bij gecombineerde blootstelling aan N,O-dimethylhydroxylamine en bijvoorbeeld O-ethylhydroxylamine potentiering van de toxiciteit van die laatste het gevolg zou kunnen zijn.

In tegenstellling tot de hierboven beschreven conclusies voor electrofiele verbindingen geven de hydroxylamine-studies aan dat bij oxidatieve belasting de activiteit van glutathion S-transferase (en mogelijk ook die van het NADPH-methemoglobine-reductase) een gevoeliger parameter is dan de glutathion-depletie. Dit is extra interessant omdat glutathion-depletie via oxidatie voor een belangrijk deel blijkt te bestaan uit de vorming van eiwit-glutathion disulficlen. Dezi: gemengde disulfiden zullen bij voldoende beschikbaarheid van NADPH-reducticequivalenten opnieuw gereduceerd worden via een gecombinecrde activitcit van thioltransferase en glutathion-reductase. Het valt te verwachten dat een dergelijk compensatoir mechanisme de relatieve betekenis van glutathion oxidatie in vivo nog zal verminderen.

In het eerste hoofdstuk van het tweede deel (hoofdstuk 6) wordt een overzicht gegeven van een aantal biologisch effect monitoring studies. In een pilot studie met rokers en niet-rokers werd geen aantoonbaar effect van roken op de glutathion S-transferase activiteit gevonden. Uit immunochemische bepalingen kwam echter naar voren dat de totale hoeveel glutathion S-transferase eiwit wel was verhoogd. Kennelijk is er bij de rokers extra glutathion S-transferase gesynthetiseerd, zonder dat de enzymactiviteit is toegenomen. Een mogelijke verklaring is dat als een gevolg van de zowel oxidatieve als electrofiele stress die door het roken wordt veroorzaakt in eerste instantie de enzymactiviteit afneemt, waarbij vanwege de chronische belasting ter compensatie tijdens de erythropoiese extra glutathion S-transferase wordt aangemaakt. Een tweede studie had betrekking op een tweetal werknemers betrokken bij de houtconservering m.b.v. koolteer houdende creosoot-olie. Bij deze werknemers werden aan het eind van de werkweek verlaagde glutathion-gehaltes en verlaagde glutathion S-transferases activiteiten 
in rode bloedcellen aangetoond. $\mathrm{Na}$ het weekend waren deze waarden weer hersteld. Ondanks de zeer kleine groepsomvang is deze bevinding interessant omdat gevonden effecten op de beide hier bestudeerde parameters goed bleken te correleren met biologische monitoring waarden voor koolteerbelasting (gemeten als hydroxypyreen in urine) en met genotoxische effecten (vastgesteld via bepaling van DNA-adducten in witte bloedcellen).

Hoofdstuk 7 beschrijft een studie bij een veertiental grondontsmetters afkomstig uit de Bollenstreek, die tijdens de onderzoeksperiode werkten met dichloorpropeen. Deze studie werd gezamenlijk met diverse andere instituten uitgevoerd. $\mathrm{Na}$ afloop van het seizoen bleek zowel de glutathion als de glutathion S-transferase waarde bij de twaalf op deze parameters onderzochte grondontsmetters duidelijk verlaagd te zijn. In aan de universiteiten van Leiden en Amsterdam uitgevoerde klinisch chemische studies werden indicaties gevonden voor een geringe leverenzym-inductie en voor een subklinisch toxisch effect op de nier. Opvallend was dat de effecten op glutathion en glutathion S-transferase aanzienlijk eenduidiger waren dan de resultaten van deze klinisch chemische studies. Dichloorpropeen is een zogenaamde allesdoder met een zeer hoge reactiviteit. Van deze stof bekend is dat zij gedeeltelijk via de mercaptuurzuur-route wordt gemetaboliseerd. In aan de Vrije Universiteit uitgevoerde biologische monitoring studies bij deze zelfde werknemers, werden in urine ook inderdaad verhoogde gehaltes aan mercaptuurzuur-metabolieten van dichloorpropeen aangetoond. Het glutathionverbruik tijdens dit metabolisme is waarschijnlijk primair verantwoordelijk voor de optredende glutathion-depletie. De afname van de glutathion S-transferase activiteit valt waarschijnlijk toe te schrijven aan de gevormde reactieve metabolieten en/of cel-afbraakprodukten.

In hoofdstuk 8 wordt een biologisch effect monitoring studie bij een op het eerste gezicht wat bijzondere populatie beschreven. Het betreft hier geen beroepsmatig blootgestelden, maar 23 mannelijke en 18 vrouwelijke sporters. Ongetrainde individuen werden gedurende een langere periode intensief getraind. $\mathrm{Na} 20$ weken namen zij deel aan een $15 \mathrm{~km}$ hardloop wedstrijd, en na 40 weken aan een halve marathon. Aan het begin van de studie, voor en na de beide wedstrijden, en ook enkele dagen daarna werden bloedmonsters afgenomen. Tijdens de eerste 20 weken trainingsperiode nam zowel het glutathion-gehalte als de glutathion-reductase activiteit in de rode bloedcellen toe. Mogelijk zijn deze beide toenames het gevolg van een behoefte aan extra bescherming tegen de hogere zuurstof-turnover en daarmee gepaard gaande oxidatieve stress. In overeenstemming hiermee werd direct na de $15 \mathrm{~km}$ wedstrijd een tendens richting lagere glutathion-waarden waargenomen. Na de halve marathon was het glutathion-gehalte overigens, om niet geheel duidelijke redenen, verhoogd. Het glutathion-reductase was direct na de beide wedstrijden actiever dan daarvoor, iets wat op zijn minst gedeeltelijk werd veroorzaakt door de beschikbaarheid van extra riboflavine. Glutathion S-transferase was na beide wedstrijden in activiteit verlaagd. Dit is in overeenstemming met de verwachting. Immers het transferase is gevoelig voor de extra oxidaticve stress, 
zoals die tijdens inspanning zal optreden. Na de tweede trainingsperiode was het glutathion-reductase volgens verwachting nog altijd verhoogd. Dit gold echter niet voor het glutathion. Het is daarbij op zichzelf niet duidelijk of dit een gevolg is van verminderde behoefte als gevolg van andere aanpassingen (zoals de toegenonien reductase activiteit) of van gebrek aan synthese capaciteit. Een indicatie in deze laatste richting wordt wel gegeven door de bevinding dat de glutathion S-transferase activiteit na deze tweede trainingsperiode was gestegen. Waarschijnlijk is dit een reactie op de voortdurende oxidatieve stress, en de daarmee waarschijnlijk gepaard gaande lipide-peroxidatie. Dit wijst er op dat vanuit het oogpunt van oxidatieve belasting de tweede, intensievere trainingsfase minder positief is dan de eerste.

In hoofdstuk 9 tenslotte worden verschillen beschreven tussen diverse groepen Belgische ex-mijnwerkers met $(n=33)$ en zonder $(n=58)$ mijnwerkers pneumoconiose. Het blijkt dat tijdens de vroege stadia van de inflammatoiro rickte zowel het glutathion als het glutathion S-transferase verlaagd zijn. Een oorzakelijk verband is waarschijnlijk omdat het hier gaat om mensen met artieve stadia van deze ziekte. Tijdens de voortdurende inflammatoire activiteit worden door de alveolaire macrofagen grote hoeveelheden reactieve zuurstofspecies gevormd. Hot is waarschijnlijk dat die uiteindelijk verantwoordelijk zijn voor de beschreven effecten. Ook bij de sporters kan een als gevolg van spierbeschadigingen optredende meer diffuse vorm van inflammatie een rol hebben gespeeld.

Geconcludeerd kan worden dat de beide belangrijkste beschreven parameters, het glutathion en de glutathion $S$-transferase activiteit in rode bloedcellen, interessante gereedschappen vormen voor mechanistisch onderzoek en voor biologisch effect monitoring. Glutathion lijkt daarbij het meest relevant in die gevallen waarin het gaat om electrofiele belastingen. Glutathion S-transferase daarentegen is vooral van betekenis wanneer het gaat om oxidatieve belastingen. Het kan daarbij een bruikbare aanvulling vormen op de, op zichzelf nog altijd problematische, detectie van in vivo lipide-peroxidatie. 



\section{Curriculum Vitae}

Ik werd op 7 april 1957 geboren te Gouda. Een stadje waar ik me vooral van herinner dat de grond er altijd langzaam onder vandaan leek te zakken. Omdat de eerste jaren vaders wil nu eenmaal wet was, bezocht ik de lagere school in diverse kleine West-Duitse dorpjes. In 1969 begon ik mijn middelbare school loopbaan op het internaat van het Gabriel College in Mook. Twee jaar later bleek dit een onhoudbare situatie en werd het internaat opgeheven. Het diploma Atheneum B behaalde ik in 1975 dan ook aan Christelijk Lyceum - met een harde G - te Alphen aan den Rijn. Ik studeerde vervolgens Moleculaire Wetenschappen aan de Landbouw Hogeschool te Wageningen, waar de Wageningse Lente toevallig tijdens mijn aanwezigheid bleek te ontluiken. Na wat bestuurlijke activiteiten en een jaar als werkstudent projektonderwijs studeerde ik in 1983 af. In die tijd was het nog mogelijk een vakken pakket te kiezen. Het werden hoofdvakken Biochemie (bij Dr. H. Haaker) en Toxicologie (bij Dr. B. Blaauboer in Utrecht), en een praktijkperiode bij de Vereniging Milieudefensie. De activiteiten daar hadden, anders dan de titel "Spuiten kan niet meer" doet vermoeden, geen betrekking op hard drugs maar op pesticiden gebruik in openbaar groen. In het bijvak wetenschapsfilosofie tenslotte vond ik de ruimte ook in studietijd over de zin en onzin van dat alles na te denken.

$\mathrm{Na}$ te zijn afgestudeerd $\mathrm{kwam}$ ik in dienst bij wat later de vakgroep Toxicologie van de Katholieke Universiteit Nijmegen zou worden, eerst als wetenschappelijk assistent en later als universitair docent. Het daar uitgevoerde onderzoek had betrekking op de vorming van hemoglobine adducten na beroepsmatige blootstelling aan genotoxische verbindingen. Het was er op gericht eenvoudige ook in de bedrijfsgezondheidszorg bruikbare methodieken te ontwikkelen. Hoewel er natuurlijk nog ongekende mogelijkheden moeten liggen in het gebruik van een stethoscoop, bleek dit uitgangspunt helaas een misvatting. Gelukkig kon, door het bestuderen van de invloed die glutathion heeft op de hemoglobine adduct vorming, in die tijd ook al een aanzet worden gegeven voor het in dit proefschrift beschreven onderzoek. In $1989 \mathrm{kwam}$ ik in dienst bij de vakgroep Arbeidsgeneeskunde, Milieugezondheidkunde en Toxicologie van de Rijksuniversiteit Limburg. In een ten gevolge van reorganisaties roerige periode, als uitvloeisel waarvan de vakgroep uiteindelijk hetzelfde lot was beschoren als het Gabriel College, werden ondermeer de veldstudies met marathon lopers en mijnwerkers zoals beschreven in dit proefschrift afgerond. Vanaf eind $1991 \mathrm{kwam}$ ik als leider van de Toxicologie sectie bij de vakgroep Farmacologie in een wat rustiger vaarwater. Hier werd nog een deel van de beschreven in vitro studies uitgevoerd, en vond uiteindelijk de afronding van dit proefschrift plaats.

Chris Evelo. 


\section{List of Publications}

\section{Articles}

1. Evelo C.T.A., J.F.M. Versteegh and B.J. Blaauboer (1984). Kinetics of the formation and secretion of the aniline metabolite 4-aminophenol and its conjugates by isolated rat hepatocytes. Xenobiotica 14: 409-416.

2. Evelo C.T.A., R.P. Bos, J.G.P. Peters and P.Th. Henderson (1986). Urinary cyclophosphamide assay as a method for biological monitoring of occupational exposure to cyclophosphamide. Int Arch Occup Environ Health 58: 151-155.

3. Evelo C.T.A., H.-M. Niessen, H.M.J. Roelofs and P.Th. Henderson (1987). Cysteine adducts of human hemoglobin measured by isoelectric focusing in polyacrylamide gels with a non-lineair $\mathrm{pH}$ gradient. J Chromatogr 420: 35-42.

4. Evelo C.T.A., T.C. Kon, P.H.S. Fijneman and P.Th. Henderson (1988). Separation of human hemoglobin alkylated at $\beta 93$ cysteine from its native form by fast protein liquid chromatography. J Chromatogr 427: 335-340.

5. Evelo C.T.A. and P.Th. Henderson (1988). Influence of glutathione on the formation of cysteine alkylation products in human hemoglobin. Toxicology 52: $177-186$.

6. Evelo C.T.A., J. Atema, J.H.J. Copius-Peereboom, P.H.S. Fijneman, J.-M. Pertijs and R.P. Bos (1989). Liver damage after coal tar treatment does not prevent induction of glutathione S-transferases in rat liver. Arch Toxicol suppl. 13: 112116.

7. Vos R.M.E., R.T.H. van Welie, W.H.M. Peters, C.T.A. Evelo, J.J.P. Boogaards, N.P.E. Vermeulen and P.J. van Bladeren (1991). Genetic deficiency of human class mu isoenzymes in relation to mercapturic acid excretion. Arch Toxicol 65: 95-99.

8. Brouwer E.J., C.T.A. Evelo, A.J.W. Verplanke, R.T.H. van Welie and F.A. de Wolff (1991). Biological effect monitoring of occupational exposure to 1,3dichloropropene: effects on liver and renal function and on glutathione conjugation. Br J Ind Med 48: 167-172.

9. Brouwer E.J., C.T.A. Evelo, A.J.W. Verplanke, R.T.H. van Welie and F.A. de Wolff (1991). Authors reply to letter of the editor by: van Sittert et al Br J Ind Med 48: 646-648.

10. Evelo C.T.A. and P.Th. Henderson (1992). Biological Effect Monitoring. Arch Toxicol suppl. 15: 268-277.

11. Evelo C.T.A., N.G.M. Palmen, Y. Artur and G.M.E. Janssen (1992). Changes in blood glutathione concentrations, and in erythrocyte glutathione reductase and glutathione S-transferase activity after running training and after participation to contests. Eur J Appl Physiol 64: 354-358.

12. Palmen N.G.M., C.T.A. Evelo, P.J.A. Borm and P.Th. Henderson (1992). Influence of oxygen supply on liver condition and elimination of dimethylacetamide in the isolated perfused rat liver. Toxicol in vitro 6: $357-365$.

13. Palmen N.G.M., C.T.A. Evelo, P.J.A. Borm and P.Th. Henderson (1993). Toxicokinetics of dimethylacetamide (DMAC) in rat isolated perfused liver. Hum 
Exp Toxicol 12: 127-133.

14. Evelo C.T.A and P.E.E.M. van Daele (1993). Development of a software package for computer simulations: the use of a sorted event list for reduction of calculation times. Comp Biol Med 23: 273-281.

15. Evelo C.T.A., R.P. Bos and P.J.A. Borm (1993). Decreased glutathione content and glutathione S-transferase activity in red blood cells of coal miners at early stages of coal miners pneumoconiosis. Br J Ind Med 50: 633-636.

16. Palmen N.G.M. and C.T.A. Evelo (1993). Glutathione depletion in human erythrocytes as indicator for microsomal activation of cyclophosphamide and 3-hydroxyacetanilide. Toxicology 84: 157-170.

17. Evelo C.T.A., J.G.M. Oostendorp, W.F. Ten Berge and P.J.A. Borm (1993). Physiologically based toxicokinetic modelling of 1,3-butadiene: lung metabolism becomes more important at low doses. Env Health Persp 101: 496-502.

18. Evelo C.T.A., R.A.G. Bisschops, L.G.M. Baars, A.A.M.G. Spooren and J.M. Neis. Two Mechanisms for Toxic Effects of Hydroxylamines in Human Erythrocytes: Involvement of Free Radicals and Risk of Potentiation. (submitted for publication).

19. Palmen N.G.M. and C.T.A. Evelo. Glutathione depletion in human erythrocytes and rat liver: a study on the interplay between bio-activation and inactivation functions of liver and blood. (submitted for publication).

20. Spooren A.A.M.G. and C.T.A. Evelo. Modulation of glutathione and glutathione S-transferase levels by five antineoplastic agents. (submitted for publication)

21. Palmen N.G.M. and C.T.A. Evelo. Oxidative effects of some oximes and hydroxylamine in human erythrocytes. (submitted for publication).

22. Evelo C.T.A. Physiological, chemical and biochemical determinants required for computer simulation and reference values. (submitted for publication).

\section{Abstracts}

1. Evelo C.T.A., J.M. Neis, J.G.P. Peters, M.A.M. ten Broeke, C.A.J.M. Vulders and P.Th. Henderson (1984). Monitoring of cystcine alkylation in Human Hemoglobin Beta-chains. Pharmaceutisch Weekblad Sri Ed 6: 169.

2. Evelo C.T.A., R.P. Bos, J.G.P. Peters and P.Th. Henderson (1986). Biological Monitoring of Occupational Exposure to Cyclophosphamide. Human Toxicol 5 : 129.

3. Evelo C.T.A., R.P. Bos, J.G.P. Peters, J.L.G. Theuws and P.Th. Henderson (1987). Biological monitoring of occupational exposure to cytostatic Drugs. $M u-$ tation Research 181: 311-353 (nr. 41).

4. Evelo C.T.A., R.P. Bos, J.G.P. Peters, J.L.G. Theuws and P.Th. Henderson. (1986). Biological monitoring of occupational exposure to cytostatic drugs. symposium arbeidstoxicologie, Jaarvergadering NvT, 24 januari 1986.

5. Evelo C.T.A., A.J. van Zeist, J.G.P. Peters and P.Th. Henderson (1986) Measurement of methylated histidine after in vitro methylation of human hemoglobin. Development of a method for biological monitoring. Symposium arbeidstoxicologie, Jaarvergadering NvT, 24 januari 1986 
6. Evelo C.'T.A., H.-M. Niessen, H.M.J. Roelofs and P.Th. Henderson (1987). Biological effect monitoring of exposure to alkylating agents; isoelectric focusing of hemoglobin adducts. Jaarvergadering NvT, 14 januari 1987.

7. Evelo C.T.A., H.-M. Niessen, H.M.J. Roelofs and P.Th. Henderson (1987). Isoelectric focusing of hemoglobin adducts formed by in vitro alkylation; development of a method for biological effect monitoring. 28e jaarvergadering FEDERA, 22 en 23 april 1987.

8. Evelo C.T.A., P.H.S. Fijneman and P.Th. Henderson (1987). Purification of human hemoglobin alkylated at $\beta 93$ cysteine by fast protein liquid chromatography. Pharmaceutisch Weekblad Sci Ed 9: 352.

9. Evelo C.T.A. and P.Th. Henderson (1987). Glutathione protects human hemoglobin against in vitro alkylation by iodoaceetamide. Pharmaceutisch Weekblad Sci Ed 9: 352.

10. Evelo C.T.A. (1988). Het gebruik van eiwitalkylering in bloed als biologisch effect parameter bij expositie aan alkylerende genotoxische verbindingen. Nederlandse Vereniging voor Toxicologie. Symposium t.g.v. het 10-jarig bestaan van de Sectie Genetische Toxicologie, 9 juni 1988.

11. Evelo C.T.A., J. Atema, P.H.S. Fijneman and R.P. Bos (1988). Coal tar treatment lowers the activity of glutathione S-transferase (GST) in blood while it induces the GST activity in the liver. European Society of Toxicology (Eurotox), München, September 4-7 1988, p. 89.

12. Evelo C.T.A. (1988). Glutathione dependant detoxification in erythrocytes; consequences for biological effect monitoring. F.G.W.O. Kontaktgroep "Experimentele Toxicologie", Brussels, March 181988.

13. Evelo C.T.A., P.H.S. Fijneman, A.J.G. Pötgens and R.P. Bos (1989). Intraindividual differences in blood glutathione and in erythrocyte glutathione S-transferase in persons without known exposure do not explain differences in urinary thioether excretion. Pharmaceutisch Weekblad Sci Ed 11: suppl. B B6.

14. Evelo C.T.A., P.H.S. Fijneman and T.C. Kon (1989). Separation of Human Hemoglobin Alkylated at $\beta 93$ Cysteine with Iodoacetamide from Native Hemoglobin by Fast Protein Liquid Chromatography. Abstract derde FPLC symposium (Pharmacia-LKB), Maarssen NL, 14 maart 1989.

15. Evelo C.T.A. (1989). Beïnvloeding van enzymactiviteiten in erythrocyten t.g.v. blootstelling aan electrofiele verbindingen. TCDD 12: (4) p. 53.

16. Evelo C.T.A., N.G.M. Palmen, O.H.H. Bell, Y. Kant and P.J.A. Borm (1990). Physiological simulation model for study of metabolic interactions: choice of simulation package. Pharmaceutisch Weekblad Sci Ed 12: suppl. B B6.

17. Evelo C.T.A., N.G.M. Palmen, O.H.H. Bell, Y. Kant and P.J.A. Borm (1990). Physiologically simulation model performance and usability when integrated in different simulation packages. International workshop on pharmacokinetic modelling in occupational health. Leysin Switserland, March 4-8 1990, p. 73.

18. Palmen N.G.M., P.J.A. Borm, A.L.A. Sesink, C.T.A. Evelo and P.Th. Henderson (1990). Liver perfusion and physiological simulation to study the effect of combined exposure. Beltox second annual meeting. Leuven, March 31 1990, p. 7.

19. Evelo C.T.A. and P.Th. Henderson (1990). Influence of environmental factors 
on glutathione S-transferase and glutathione in human erythrocytes. Twelfth european workshop on drug metabolism. Basel, September 16-21 1990.

20. Janssen G.M.E., C.T.A. Evelo and A.J.P. van Bormmel (1991). Adaptation of glutathione defense system due to endurance exercise. Int. congress and exposition on sports medicine and human performance. Vancouver, April 16-20 1991, p. 59.

21. Palmen N.G.M., C.T.A. Evelo, P.Th. Henderson (1991) Depletion of erythrocyte glutathione by extracellularly activated metabolites. Third international ISSX meeting, Amsterdam, June 24-28 1991. Abstract no. 5A24.

22. Evelo C.T.A., N.G.M. Palmen, W.F. ten Berge and P.J.A. Borm (1991). Physiologically based pharmacokinetic modelling of 1,3 butadiene: increased importance of lung metabolism at low doses. Third international ISSX meeting, Amsterdam. June 24-28 1991. Abstract no. 9A10.

23. Palmen N.G.M., C.T.A. Evelo, P.J.A. Borm, P.Th. Henderson (1991). Saturation of DMAC metabolism in isolated perfused rat liver. The 1991 Eurotox congress, Maastricht. September 1-4 1991. Abstract no. 153.

24. Palmen N.G.M., C.T.A. Evelo and P.Th. Henderson (1991). Depletion of erythrocyte glutathione by metabolites formed by fortified liver microsomes. The 1991 Eurotox congress, Maastricht. September 1-4 1991. Abstract no. 154.

25. Evelo C.T.A., N.G.M. Palmen, R. Pisters and P.J.A. Borm (1991). Development of a new software package for physiologically based pharmacokinetic modelling. The 1991 Eurotox congress, Maastricht. September 1-4 1991. Abstract no. 243.

26. Evelo C.T.A., N.G.M. Palmen, W.F. ten Berge and P.J.A. Borm (1991). Physiologically based kinetic modelling of 1,3 butadiene: importance of lung metabolism increased at low exposures. The 1991 Eurotox congress, Maastricht. September 1-4 1991. Abstract no. 244.

27. Evelo C.T.A., A.J.P. van Bommel and G.M.E. Janssen (1991). Reductase and glutathione S-transferase activity after running training. The 1991 Eurotox congress, Maastricht. September 1-4 1991. Abstract no. 280.

28. Evelo C.T.A., A.J.P. van Bommel and G.M.E. Janssen (1991). Changes in erythrocyte glutathione reductase and glutathione S-transferase activity after running races. The 1991 Eurotox congress, Maastricht. September 1-4 1991. Abstract no. 281.

29. Evelo C.T.A. (1993). Application of toxicokinetic simulation models. Hum Exp Toxicol 12: 54.

30. Evelo C.T.A., P.E.E.M van Daele, T.H. Hellekamp and R. Pisters (1993). Software for toxicokinetic modelling: the use of a sorted event list for the reduction of calculation times. Hum Exp Toxicol 12; 62.

31. Palmen N.G.M., C.T.A. Evelo and P.Th. Henderson (1993). Glutathione depletion as an indication for reactive metabolite formation in microsomes. Hum Exp Toxicol 12; 71-72.

32. Spooren A.A.G.M., N.G.M. Palmen and C.T.A. Evelo (1993). Influences of cyclophosphamide on the glutathione S-transferase activity and glutathione concentration in rat liver fractions and human erythrocytes. Hum Exp Toxicol 12: $78-79$. 
33. Palmen N.G.M., C.T.A. Evelo, P.J.A. Borm and P.Th. Henderson. Saturation of dimethylacetamide metabolism in rat isolated perfused liver. Jaarvergadering NvT; Utrecht 14 januari 1993.

34. Evelo C.T.A., R.P. Bos and P.J.A. Borm (1993). Red blood cells of coal miners with early stages of pneumoconiosis show decreased glutathione content and glutathione S-transferase activity. Hum Exp Toxicol 12: 347.

35. Spooren A.A.G.M., V.E.A.P. Geelen and C.T.A. Evelo (1993). Is (re)activation of soluble glutathione S-transferase by cyclophosphamide in incubations with microsomes caused by a reduction of reactive oxygen species. Hum Exp Toxicol 12: 351 .

36. Bisschops R.A.G, A.A.M.G. Spooren, L.G.M. Baars, J.M. Neis and C.T.A. Evelo (1993). Structure activity relations in hematotoxic effects of hydroxylamines. Hum Exp Toxicol 12: 344.

37. Baars L.G.M., R.H.M. Langenveld and C.T.A. Evelo. (1994). Inhibition of aldehyde dehydrogenase in human erythrocytes by some oximes. Hum Exp Toxicol 13: 725 .

38. Palmen N.G.M. and C.T.A. Evelo (1994). Hydroxylamine and some Oximes cause Oxidative Effects in Human Erythrocytes. Hum Exp Toxicol 13: 729.

39. Evelo C.T.A., R.A.G. Bisschops, A.A.M.G. Spooren and J.M. Neis (1994). Toxic effects of some hydroxylamines in human erythrocytes. European ISSX workshop 1994. Toxicology of Industrial Compounds. Sluchsee: June 12-15.

\section{Publications in Dutch}

1. Evelo C.T.A., H. van Gelderen en F. Loos (1983). Spuiten kan niet meer. Vereniging Milieudefensie, Amsterdam.

2. Fransman L.G., M.Th. van der Put, J.L.A. van Rijckevorsel, R.P. Bos en C.T.A. Evelo (1986). Verslag van het onderzoek naar de blootstelling aan parenterale (genotoxische) cytostatica bij werknemers in de gezondheidszorg. R.B.B. Augustus 1986.

3. Evelo C.T.A., N.G.M. Palmen, P.J.A. Borm, P.F.R. Schins, R. Zondag, R. Pisters en M. Leummens (1991). Fysiologisch gebaseerd farmacokinetiek model (PB-PK model) voor 1,3-butadieen. Rapport opgesteld in opdracht van DSM-Limburg bv, kunststoffendivisie (KDS), Geleen.

4. Bisschops R.A.G., L.G.M. Baars en C.T.A. Evelo (1992). Diagnostiek voor de hemolyserende werking van hydroxylamines. Rapport opgesteld in opdracht van DSM special products.

5. Evelo C.T.A. en J.G.M. Oostendorp (1992). Literatuur overzicht butadieen. Aanvulling op rapportage voor DSM-Limburg bv.

6. Bisschops R.A.G., L.G.M. Baars, A.A.M.G. Spooren en C.T.A. Evelo (1993). In vitro hematotoxische effecten van hydroxylamines. Rapport opgesteld in opdracht. van DSM special products. 



\section{Nawoord}

Een heleboel mensen zijn op de een of andere manier betrokken geweest bij het tot stand komen van dit proefschrift. Een aantal daarvan wil ik hier expliciet bedanken, gewoon omdat ik dat belangrijk vindt. Ongetwijfeld zal ik er ook een paar vergeten, niet omdat zij niet belangrijk zijn geweest, maar omdat ik er nu even niet aan denk. Ik hoop dat zij me dat vergeven.

Mijn promotor prof. Henderson, die mij toch maar aan twee verschillende universiteiten een aanstelling bezorgde, voor het vertrouwen, en voor de vele gesprekken, juist omdat die lang niet allemaal over wetenschap gingen.

Alle collega's van de vakgroep Toxicologie in Nijmegen - met name ook die van wat voor mij het eerste uur was - voor de prettige sfeer. Hennie Roelofs, Janny Peters en Peter Fijneman zijn daarbij van onschatbaar belang geweest door het vele praktische werk. Rob Bos, Frans Jongeneelen, en John Neis lieten mij drie heel verschillende manieren van onderzoek doen zien, ik heb daar veel van geleerd. Frans was bovendien de eerste die filosofeerde over de mogelijkheid om biomonitoring van thioethers te combineren met onderzoek naar effecten op het systeem waarin die thioethers worden gevormd. Mogelijk een cruciale stap op weg naar het hier beschreven onderzoek.

De moeilijke tijd die ik meemaakte bij de voormalige vakgroep Arbeidsgeneeskunde, Milieugezondheidkunde en Toxicologie had nooit zo gezellig kunnen zijn zonder het relativerend vermogen van mijn collega's, bedankt daarvoor. Wat overigens te denken van de opmerking: "och, voordat jij kwam was het eigenlijk allemaal nog niet zo erg ...".

De vakgroep farmacologie, dat zijn er meteen een heleboel, maar het is wel gewoon een goeie club. En je moet het toch maar willen, zo'n stelletje dakloze toxicologen opnemen. Daarvoor ben ik met name prof. Struijker Boudier, mijn huidige vakgroep voorzitter, bijzonder dankbaar. De helderheid waarmee afspraken worden gemaakt vind ik nog steeds een verademing. Vakgroepen, zo groot als farmacologie zitten niet zomaar gevangen in het web van de universitaire structuur, zij spinnen ook zelf behoorlijk mee. Dat was voor mij een nieuwe ervaring, en een hele leerzame.

De mensen van de sectie Toxicologie, Nicole Palmen, Leo Baars, Anita Spooren en alle studenten die daar de afgelopen paar jaar een poosje bij wilden horen, kortom mijn eigen groep. Jullie waren in die periode eigenlijk het allerbelangrijkst. Door jullie was het fijne tijd. Jullie zullen ook wel het blijst zijn dat dit proefschrift er nu is, en er weer andere dingen centraal komen te staan.

Heel veel studenten hebben stukjes onderzoek uitgevoerd die voor mij op dat momeut een deel van de legpuzzel vormden. Lianne de Wijs, Geert-Jan Reimer, Toon van Bommel, Karel Herberichs, Anita Spooren en Rob Bisschops zullen hun eigen puzzelstukjes in dit proefschrift hebben terug gezien. Een heleboel andere stukjes pasten uiteindelijk niet zo goed. Hele onderzoekslijnen, bijvoorbeeld 
op de gebieden hemoglobine adducten, biomonitoring van cytostatica en physiologische simulatie modellen, zijn zelfs buiten beeld gebleven.

The discussions with Dr. Niemeyer and Dr. Zechel from Asta about the special aspects of cyclophosphamide proved to be of importance, not only for the biomonitoring studies described elsewhere, but also for the effect studies described in this thesis. Marjo Catsberg van het Maasland Ziekenhuis deed de Heinz Body analyse in de hydroxylamine studie, een erg ondankbare taak. John Neis en Jan Bakker van DSM waren niet alleen als opdrachtgever betrokken bij deze studie. Hun kritische houding, praktijk gerichtheid en de behoefte om echt mee te denken maakten de samenwerking tot een genoegen. Van Wilbert Peters, Ria Vos en prof. van Bladeren heb ik in de korte tijd dat we een soort regionaal GST overleg hadden een heleboel zinnige tips gekregen; toch jammer dat Maastricht niet zo in die regio ligt.

Vooral bij de monitoringsstudies beschreven in het tweede deel van dit proefschrift zijn een heleboel mensen betrokken geweest. Veel van het organisatorische werk in de pilot studie met creosoteerders was in handen van Frans Jongeneelen. Rob Baan deed de bijbehorende DNA-adduct metingen. De organisatie van de dichloorpropeen studie was in handen van Ellie Brouwer, die samen met Ton Verplanke bovendien de lever- en nierfunctie analyses uitvoercle. Ronald van Welie deed de specifieke mercaptuurzuur analyses. De professoren de Wolff en Vermeulen hadden bovendien een belangrijke inhoudelijke inbreng in deze studies. Beiden zijn zij ook op diverse andere momenten door hun grote interesse en creativiteit een belangrijke stimulans geweest. Gène Janssen zorgde op zijn eigen unieke wijze voor de organisatie van de marathon studie. Zonder hem zou deze studie niet uitvoerbaar zijn geweest. Dr. Artur of the Center for Preventive Medicine in Nancy was involved in the study of the oxidative aspects of physical activity. I hope to continue this collaboration in the near future with respect to the antioxidant enzymes. Voor de mijnwerkers studie was al het organisatorische werk al verzorgd door Paul Borm. In diverse gesprekken over allerlei aspecten van het onderzoek bleek Paul telkens weer verrassende ideeën te hebben. Dat hielp zeker om er ook zelf steeds weer vanuit een andere hoek tegenaan te kijken.

Zonder de medewerking van de staf en medewerkers van de Rode Kruis bloedbanken in Nijmegen en Maastricht was dit proefschrift waarschijnlijk ten onder gegaan aan bloedarmoede.

Tenslotte wil ik de medewerkers van de UB in Maastricht bedanken voor hun extreem goede service. Boeken uit het magazijn zijn er altijd sneller dan beloofd (dat kan natuurlijk ook een slimmigheidje zijn), en soms slagen ze er in publicaties te vinden die ik op basis van mijn zelf ingevulde informatie nooit boven tafel zou hebben gekregen.

( 'hantal, Jannemiek en Sjoerd herinnerden mij er, ieder op een eigen manier, telkens weer aan dat er nog zoveel meer is. 


$$
\text { . }
$$



TABLE II. Results of the LRT method in computer simulations of markers attached to a moving left ventricle.

\begin{tabular}{cccccccccc}
\hline$\sigma^{1)}$ & $\begin{array}{c}d^{2}{ }^{2} \\
\text { pixel }\end{array}$ & \multicolumn{2}{c}{$M=25^{3)}$} & \multicolumn{2}{c}{$M=50$} & \multicolumn{2}{c}{$M=75$} & \multicolumn{2}{c}{$M=100$} \\
pixel & $f_{D E}^{4}$ & $f_{C L}{ }^{5)}$ & $f_{D E}$ & $f_{C L}$ & $f_{D E}$ & $f_{C L}$ & $f_{D E}$ & $f_{C L}$ \\
\hline 0.5 & 4 & 4 & 99 & 7 & 95 & 9 & 91 & 14 & 88 \\
0.5 & 8 & 10 & 97 & 25 & 90 & 38 & 84 & 52 & 79 \\
1.0 & 4 & 3 & 92 & 7 & 84 & 9 & 78 & 15 & 71 \\
1.0 & 8 & 10 & 90 & 25 & 80 & 40 & 69 & - & - \\
\hline
\end{tabular}

1) RMS noise level of the marker image position measurement

2) Minimum distance allowed between marker image positions

3) Number of markers used in the simulations

4) The percentage of the $M \times 60$ in 60 frames generated marker image positions, which was deleted because positions were mutually closer than $d_{m}$

s) The percentage of the retained marker image positions which belonged to correct reconstructed tracks of a duration of at least 50 frames

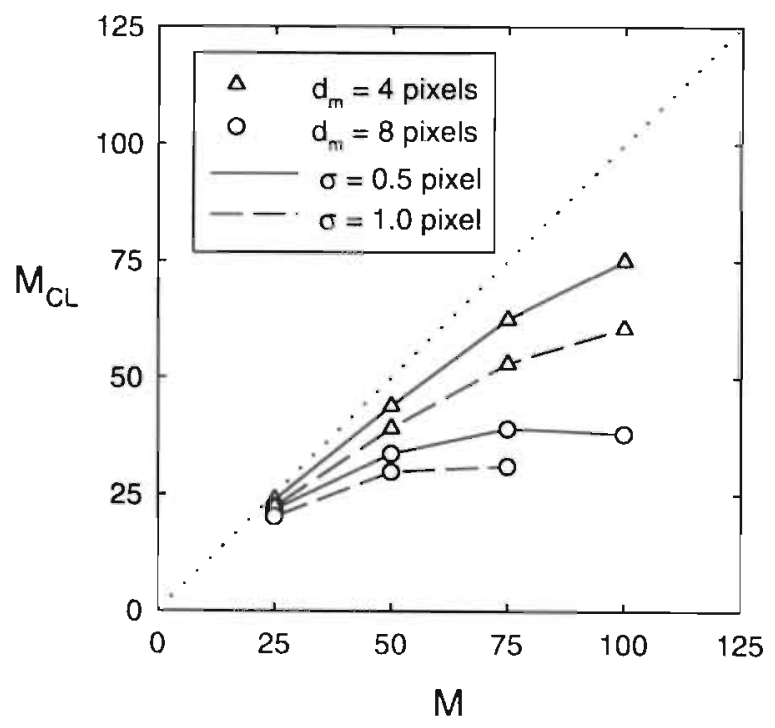

FIGURE 6. The performance index $M_{C}$ is the average number of marker image positions per frame belonging to a correct track with a duration of at least 50 frames. $M_{C Z}$ is shown as a function of the number of markers $M$. The computer simulations were carried out with a minimum distance allowed between marker image positions, $d_{m}$, of 4 (triangle) and 8 pixels (circle), and the RMS noise level $\sigma$ equal to 0.5 (solid line) and 1 pixel (dashed line), respectively. The dotted line $M_{C L}=M$ refers to perfect performance. 